\title{
ANALYSIS AND SYNTHESIS OF HIGHWAY PAVEMENT DESIGN
}

JULY 1968

NO. 13

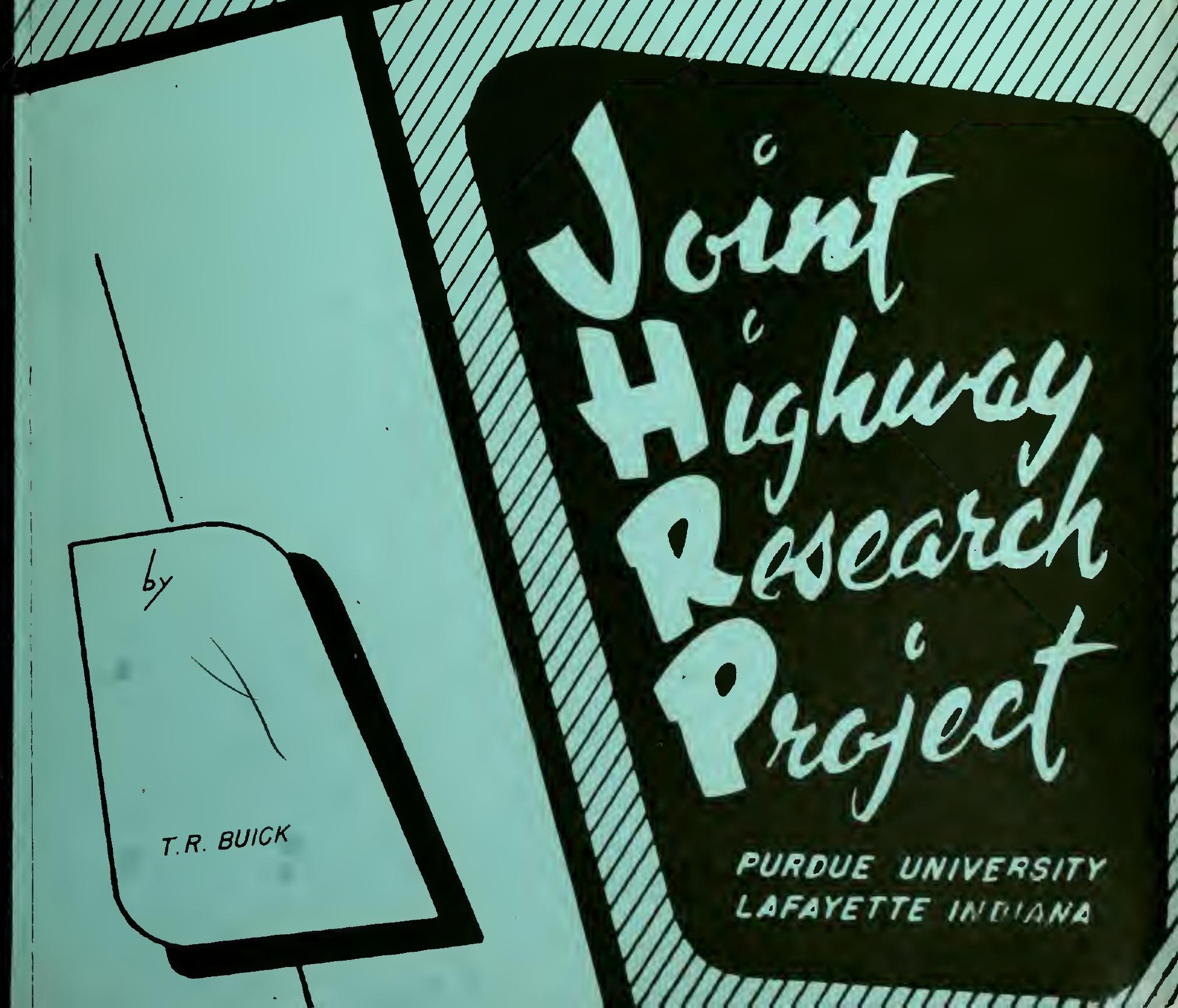



Final Report

ANALYSIS AND SYNTHESIS OF

HIGHWAY PAVEMENT DESIGN

To: J. F. Mclaughlin, Director

Joint Highway Research Project

From: H. L. Michael, Associate Director

Joint Highway Research Project
July 12, 1968

File No.: 6-20-7

Project No.: C-36-52G

Attached is a Final Report on the research project entitled "Sensitivity Analysis of Pavement Design and Performance" which was approved on June 20, 1967. The title of this report is "Analysis and Synthesis of Highway Pavement-Design." It has been authored by Mr. Thomas R. Buick of our staff under the direction of Professor J. C. Oppenlander.

The purposes of this investigation were to determine the relative effects of various design parameters on pavement thickness and to synthesize simplified design methods for flexible and rigid highway pavements. For flexible pavement design, traffic load and subgrade support are the more influencial factors in the determination of pavement thickness. Traffic load and pavement structural properties exert the greater influence on rigid pavement thickness requirements.

This report is presented to the Board for review and comment and for the record.

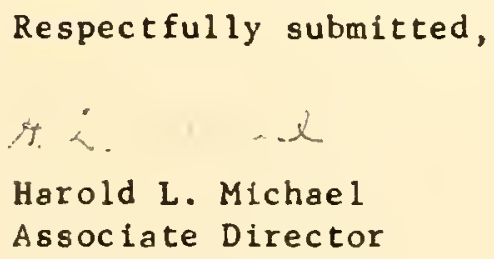

HLM : sb

Attachment

Copy: F. I. Ashbaucher
W. L. Dolch
W. H. Goetz
W. L. Grecco
G. K. Hallock
M. E. Harr
R. H. Harrel1

J. A. Havers

V. E. Harvey

J. F. McLaughlin

F. B. Mendenha11

R. D. Miles

J. C. Oppenlander
C. F. Scholer

M. B. Scott

W. T. Spencer

H. R. J. Walsh

K. B. Woods

E. J. Yoder 
Final Report

ANALYSIS AND SYNTHESIS OF

HIGHWAY PAVEMENT DESIGN

by

Thomas R. Buick

Graduate Assistant in Research

Joint Highwry Research Project

\author{
Project No: C-36-52G \\ File No: $6-20-7$
}

Purdue University

Lafayette, Indiana

July 12,1968 


\section{ACKNOWLEDGMENTS}

The author gratefully acknowledges Dr. Joseph C. Oppenlander, Associate Professor of Civil Engineering, for his direction and encouragement throughout the research project and for his critical review of the manuscript. The assistance of Dr. C. W. Lovell, Jr., Associate Professor of Civil Engineering, in forming this study and in reviewing the manuscript is sincerely appreciated. Thanks is also due Dr. Marcel F. Neuts, Associate Professor of Mathematics, for his help in carrying out this investigation. The author also wishes to express gratitude to E. J. Yoder, Professor of Civil Engineering, whose initial guidance was most beneficial in formulating this study.

Appreciation is extended to the Joint Highway Research Project of Purdue University and the Indiana State Highway Commission for financial support which made this research possible. The writer also thanks Dr. V. I. Anderson and Prof. J. N. Arnold and Messrs. S. R. Yoder, G. M. Jouris, S. S. Hejal and S. T. Roweis who materially contributed to the production of this report.

Special thanks go to the author's wife whose efforts and understanding substantially contributed to the completion of this study. 
Digitized by the Internet Archive in 2011 with funding from

LYRASIS members and Sloan Foundation; Indiana Department of Transportation 
IIST OF TABLES • • • • • • • • • • • • • • • • • V

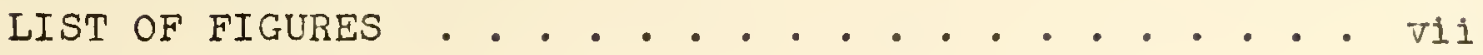

ABSTRACT . . . . . . . . . . . . . . . . . . . xili

INTRODUCTION • . . . . . . . . . . . . . . . . 1

PROCEDURE • . . . . . . . . . . . . . . . . 10

Selection of Pavement Design Methods . . . . . 10

Structuring of the Design-Process Logic . . . . . 11

Modeling of the Design Techniques . . . . . . 14

Sensitivity Analysis . . . . . . . . . . . . 1?

Partial Derivatives as a Theoretical

Neasure of Design Parameter Importance . . . 17

Portions of the Total Differential as a

Measure of the Practical Importance of

Design Parameters . . . . . . . . . . 21

Relative Thickness Changes as Measures of

the Practical Importance of Design

Parameters ............... . 24

Investigation of Tolerable Parameter

Variations ................. . 26

Tolerable Parameter Variations Using a 26

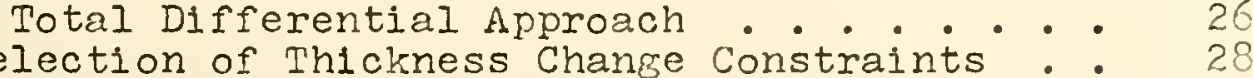

Development of Simplified Pavement Design

Methods : . . . . . . . . . . . 30

REVIEW OF PAVEMENT DESIGN METHODS . . . . . . . . . . 34

Flexible Pavement Design . . . . . . . . . . 34

AASHO Interim Design liethod for Flexible
Pavements . . . . . . . . . . . . 35

Corps of Engineers Flexibie Pavement
Design Hethod for Streets and hoads . . . 40

California Division of Highways Stabilometer
Design Method for Flexible Pavements... . 42

Rigid Pavement Design ............... . . 46

AASHO Interim Design Method for Rigid
Pavements . . . . . . . . . . . . 46

Corps of Engineers Risid Pavement Design
Method for Streets and Roads . . . . . 51 
TABLE OF CONTENTS (continued)

Portland Cement Association Design Method for Rigid Pavements . . . . . . . . .

RESULTS

Flexible Pavement Design.

AASHO Flexible Pavement Design . . . . . . .

Corps Flexible Pavement Design . . . . . .

California Stabilometer Design . . . . . . .

Summary of Flexible Pavement Design

Rigid Pavement Design :. . . . . : . . : . 125

AASHO Rigid Favement Design ........ 130

Corps Rigid Pavement Design ..... . . 154

PCA Rigid Pavement Design ....... . 171

Summary of Rigid Pavement Design Results . . . 191

General Summary of Results . . . . . . . . 196

DEVELOPMENT OF SIMPIFIED DESIGN NETHODS . . . . . 197

Simplified Flexible Design . . . . . . . 2 204

Correlation of Flexible Design Parameters . . 205

Development of a Simplified Flexible

Thickness Equation ......... 20 ?

Applications to Practice......... 2 208

Simplified Rigid Design . . . . . . . . . 211

Correlation of Rigid Design Parameters . . . 211

Development of a Simplified Rigid Thickness

Equation ............. 213

Applications to Practice........ 220

SUMHARY AND CONCLUSIONS . . . . . . . . . 222

RECCMMENDATIONS FOR FURTHER RESEARCH . . . . . . . 225

BIBLIOGRAPHY . . . . . . . . . . . 228

APPENDIX A - AASHO Flexible . . . . . . . . 230

APPENDIX B - Corps Flexible . . . . . . . 237

AFPENDIX C - California Stabilometer . . . . . . 239

APPENDIX D - AASHO Rigid . . . . . . . . . 240

APPENDIX E - Corps Rigid . . . . . . . . 243

APPENDIX F - PCA Rigid . . . . . . . . . 245

APPENDIX G................... 250 

LIST OF TAPLES

Table

Fage

1. Regression Equations for AASHO Flexible ParameterThickness Relationships $(p=2.0)$. . . . . 85

2. Regression Equations for AASHO Flexible ParameterThickness Relationships $(p=2.5) . . .+. . .86$

3. Regression Equations for Corps Flexible ParameterThickness Relationships............ . 108

4. Regression Equations for California Stabilometer Parameter-Thickness Relationships... . . . . 124

5. Parameter Importance for Average Design Conditions . . . . . . . . . . . . . 127

6. Linear Models for Flexible Pavement ParameterThickness Relationships . . . . . . . . . 129

7. Regression Equations for AASHO Rigid parameterThickness Relationships $(p=2.0)$. . . . . . 152

8. Regression Equations for MASHO Rigid ParameterThickness Rejationships $(p=2.5)$. . . . . . 153

9. Regression Equations for Corps Rigid ParameterThickness Relationships . . . . . . . . . . 172

10. Regression Equations for PCA Rigid ParameterThickness Relationships . . . . . . . . . 190

11. Parameter Importance for Average Design Conditions

12. Linear ilodels for Risid Pavement ParameterThiclness Relationships

13. Regression Equations for Corps Flexible, California Stabilometer and AASHO Flexible $(p=2.0)$ Parameter-Thickness Relationships 209

14. Regression Equations for Corps Flexible, California Stabilometer and AASHO Flexible $(p=2.5)$ parameter-Thicinness Relationships... . . . . 210 
.

. 


\section{LIST OF TABLES (cont1mued)}

15. Regression Equations for Corps Rigid, ECA Rigid and AASHO Rigid ( $p-2.0)$ Parameter-Thickness

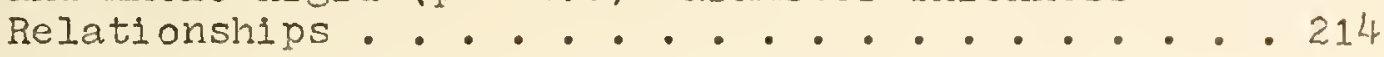

16. Regression Equations for Corps Rigid, PCA Rigid and MASHO Rigid ( $p=2.5)$ Parameter-Thiclkness Relationships . . . . . . . . . . . 216

17. Regression Equations for Corps Rigid and MASHO Rigid $(p=2.0)$ Parameter-Thickness Relationships . 218

18. Regression Equations for Corps Rigid and AASHO Rigid ( $p=2.5)$ Parameter-Thickness Relationships . 219

Appendix Table

A1. First-order Partial Derlvatives of the AASHO

Flexible Structural Number with Respect to Design Farameters ............. . 236

B1. Relationship Among Corps Flexible Design Indices (DI). Traffic Caterories, Poad and Street Classifications, 18,000-Ib Base Load Coverages and Operations ............. 238

C1. First-order Partial Derivatives of the California Stabilometer Thickness with Respect to Design Parameters ............. . 239

D1. First-Order Partial Derivatives of the AASHO Rigid Thickness with Respect to Design Farameters . . . 242

E1. Relationship Amone Corps Rigid Design Indices (DI), Traffic Categories, Road and Street Classifications, 18,000-Ib Base Load. Coverages and Operations per

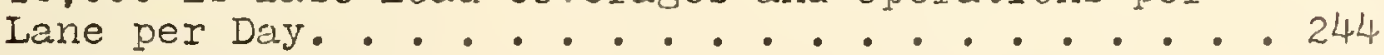

F1. First-order Partial Derivatives of the PCA Rigid Thickness with Respect to Design Parameters. . . 249

G1. Design Parameters and Their Variations . . . 250 

1. The Favement Syster........... 3

2. Sample Hierarchy Chart . . . . . . . . 13

3. Graphically Refined First-order Partial 20

4. Frequency Distribution of Pavement Thiclnesses . . 29

5. Hierarchy Structure of AASHO Flexible DesienProcess Logic................ 59

6. Relative Theoretical Importance of fisho Flexible Design Parameters............ 63

7. Relative Theoretical Importance of AASHO Flexible Design Parameters............ 64

8. Relative Theoretical Importance of AASHO Flexible Design Farameters.......... 65

9. Relative Theoretical Importance of AASHO Flexible Desion Parameters............. 66

10. Underlyins Traffic Conditions Indicated by Ranes of Practical Paraneter Importance . . . . . . . 70

11. Relative Practical Inportance of AASHO Flexible Design Parameters for the Total Differential Approach

12. Relative Practical Importance of AASHO Flexible Design Parameters for, the Total Differential Approach

13. Relative Fractical Importance of AASHO Flexible Design Paraneters for the Total Differential Approach

14. Relative Practical Importance of AASHO Flexible Design Parameters for the Total Differential Approach 
LIST OF FIGURES (continued)

Ficure

Page

15. Relative Practical Importance of AASHO Flexible Design Parameters for the Actual Thickness Change Approach

16. Relative Practical Importance of AASHO Flexible Design Parameters for the Actual Thickness Change Approach . . . . . . . . . . . .

17. Relative Practical Importance of AASHO Flexible Design Parameters for the Actual Thickness Change Approach

18. Relative Practical Importance of MASHO Flexible Design Parameters for the Actual Thickness Change Approach . . . . . . . . . . 79

19. Tolerable Frecision of AASHO Flexible Parameters • 81

20. Tolerable Precision of ASHO Flexible Parameters . 82

21. Hierarchy Structure of Corps Flexible Design-

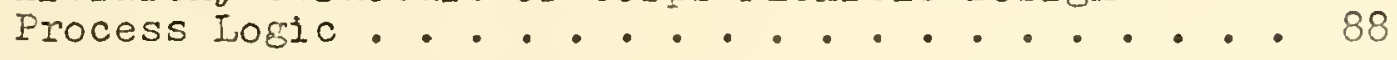

22. Relative Theoretical Importance of Corps Flexible Design Parameters . . . . . . . . . . .

23. Relative Theoretical Importance of Corps Flexible Design Parameters . . . . . . . . . . . . .

24. Relative Theoretical Importance of Corps Flexible Design Parameters... . . . . . . . . . 94

25. Relative Theoretical Importance of Corps Flexible Desion Parameters . . . . . . . . . . .

26. Relative Theoretical Importance of Corps Flexible Design Parameters..............

27. Relative Practical Importance of Corps Flexible Design Parameters............ 98

28. Relative Practical Importance of Corps Flexible Design Parameters............. 99

29. Relative Practical Importance of Corps Flexible Design Parameters............ 100

30. Relative Practical Importance of Corps Flexible Desicn Parameters 


\section{LIST OF FIGURES (continued)}

Fisure

Page

31. Relative Practical Importance of Corps Flexible Design Parameters............. 102

32. Tolerable Precision of Corps Flextble Parameters . 105

33. Tolerable Frecision of Corps Flexible Parameters . 106

34. Hierarchy Structure of Califormia Stabilometer Design-Process Logic . . . . . . . . . 100

35. Relative Theoretical Importance or California Stabilometer Parameters . . . . . . . . 112

36. Relative Theoretical Importance of California Stabllometer larameters............ 114

37. Relative Theoretical Importance of California Stabiloneter Faraneters . . . . . . . . . 115

38. Relative Practical Importance of California Stabilometer Farameters . . . . . . . . 116

39. Relative Fractical Importance of California Stabilometer Farameters . . . . . . . . . 117

40. Relative Practical Importance of California Stabilometer Farameters . . . . . . . . . 118

41. Tolerable Precision or California Stabilometer Fararneters . . . . . . . . . . . . 121

42. Tolerable Precision of California Stabilometer Parameters. . . . . . . . . . . . 122

43. Hierarchy Structure of AASHO Rigid Design-Erocess Logic . . . . . . . . . . . . . . 131

44. Relative Theoretical Importance of AASEO Rigid Design Parameters . . . . . . . . . . 134

45. Relative Theoretical Importance of AASHO Rigid Design Parameters . . . . . . . . . . 135

46. Relative Theoretical Importance of AASHO Rigid Design Parameters . . . . . . . . . . 136

47. Relative Theoretical Importance of AASHO Rigid Design Faraneters . . . . . . . . . 137 


\section{LIST OF FIGURES (continued)}

Figure

Page

48. Relative Practical Importance of AASHO Rigid Design Parameters for the Total Differential Approach

49. Relative Practical Importance of AASHO Rigid Design Parameters for the Total Differential Approach

50. Relative Practical. Importance of NASHO Rigid Design Parameters for the Total Differential Approach ................... . . 142

51. Relative Practical Importance of AASHO Figid Desion Parameters for the Total Differential Approach .................. . . 143

52. Relative Practical Importance of ASHO Rigid Design Parameters for the Actual Thickness Change Approach . . . . . . . . . . . . . . 144

53. Relative Practical Importance of AASHO Rigid Design Parameters for the Actual Thickness Change Approaci 145

54. Relative Practical Importance of AASIO Rigid Design Parameters for the Actual Thiclnness Change Approach ................... . 146

55. Relative Practical Importance of AASHO Rigid Design Parameters for the Actual Thickness Change Approach . . . . . . . . . . . . . . 147

56. Tolerable Precision of AASHO Rigid Paramoters. . 149

57. Tolerable Precision of AASHO Rigid Parameters . . 150

58. Hierarchy Structure of Corps Rigld Design-Process Logic . . . . . . . . . . . . . . . 155

59. Relative Theoretical Importance of Corps Rigid Design Parameters . . . . . . . . . . 157

60. Relative Theoretical Importance of Corps rigid Desisn Parameters... . . . . . . . . . 158

61. Relative Theoretical Importance of Corps Rigid Design Parameters... . . . . . . . . . 159 


\section{LIST OF FIGURES (continued)}

Figure

Page

62. Relative Theoretical Importance of Corps Rigid Design Parameters . . . . . . . . . . 160

63. Relative Practical Importance of Corps Rigid Desion Parameters... . . . . . . . . . 163

64. Relative Practical Importance of Corps Rigid Design Parameters.............. . 164

65. Relative Practical Importance of Corps Rigid Design Parameters . . . . . . . . . . . 165

66. Relative Practical Importance of Corps Risid Design Parameters.......... . 166

67. Tolerable Precision of Corps Rigid Parameters . . 168

68. Tolerable Precision of Corps Rigid Parameters . . 169

69. Hierarchy Structure of FCA Rigid Design-Frocess Logic . . . . . . . . . . . . . . . 174

7o. Relative Theoretical Importance of PCA Rigid Desion Farameters... . . . . . . . . . 177

71. Relative Theoretical Importance of PCA Risid Design Parameters . . . . . . . . . . . 178

72. Relative Theoretical Importance of PCA Risid Design Parameters . . . . . . . . . . . 179

73. Relative Theoretical Importance of PCA Rigid Design Parameters... . . . . . . . . 180

74. Relative Practical Importance of PCA Rieid Design Parameters.............. . 182

75. Relative Practical Importance of PCA Risid Desisn Parameters... . . . . . . . . . 183

76. Relative Practical Importance of PCA Rigid Design Parameters.............. . . 184

77. Relative Practical Importance of PCA Rigid Design Parameters . . . . . . . . . . . 185

78. Tolerable Precision of PCA Rigid Parameters . . . 187

79. Tolerable Precision of PCA Rifid Parameters . . . 188 


\section{LIST OF FIGURE (continued)}

Figure

80. Isometric Plot of AASHO Flexible Design Relationship . . . . . . . . . . . 198

81. Isometric Plot of Corps Flexible Desien Relationship . . . . . . . . . . 199

82. Isometric Plot of California Stabilometer Design Relationship ............ 200

83. Isometric Plot of MASHO Rigid Design Relationship - 201 84. Isometric Plot of Corps Rigid Desion Relationship. 202 85. Isometric Plot of PCA Rigid Design Relationship . . 203 86. Simplified Flexible Favement Design Chart . . . 212 87. Simplified Rigid Pavement Design Chart . . . . 221 Appendix Ficure

A1. MASHO Flexide Design Chart . . . . . . . 234

A2. AASHo Flexible Design Chart.......... 235

31. Corps Flexible Desien Chart . . . . . . . . 237

D1. AASHO Rigid Design Chart . . . . . . . . 240

D2. AsSHO Rigid Design Chart . . . . . . . . 241

E1. Corps Rigid Desicn Chart . . . . . . . . 243

F1. PCA Relationship of Stress Ratio to Allowable Repetitions . . . . . . . . . . 247 


\section{ABSTRACT}

Buick, Thomas Russell. ISCE, Purdue University, June 1968. Analysis and Synthesis of Highway Pavement Design. Major Professor: Joseph C. Oppenlander.

To better understand the art and science of pavement design, an examination of three flexible and three rigid highway design techniques was executed to determine the relative effects of various design parameters on pavement thickness and to synthesize simplified design methods for the two parement types. The analysis phase of this investigation consists of organizing the design-process logic into a hierarchy structure and formulating each technique into a comprehensive mathematical or graphical thickness model. An evaluation of the influences on thickness of the major design factors by a sensitivity analysis with a theoretical and two practical measures of parameter importance, a study of the parameter variations tolerated by selected thickness change constraints and a least squares fitting of appropriate equations to parameter-thickness data preceded the development of simplified flexible and rigid pavement design methods.

The hierarchy structure of design-process logtc and the theoretical measure of parameter importance reveal considerable differences among techniques as to the process of resolving 
design thicknesses and to the relative theoretical influence of various parameters that estimate the same major design factors. However, the practical parameter importance measures, Which account for variations in parameter values as well as the formulated parameter-thickness relationship, demonstrate a greater similarity in the importance of generic factors among design methods. For flexible pavement design, traffic load and subgrade support are the more influencial factors in the determination of pavement thickness. Traffic load and pavement structural properties exert the greater influence on rigid pavement thickness requirements. Design precision is presently not commensurate with design or construction thiclmess tolerances. Of the various model approximations of the parameter-thickness relationships, the linear model is preferable because it best expresses the thickness design relationships and is statistically efficient. The simplified desion methods, which were developed from a synthesis of data generated for the three flexible and for the three rigid techniques, relate thiclness to the two more important independent design variables for each type of pavement. 


\section{INTRODUCTION}

An important highway pavement design objective is the provision of an acceptable riding surface that can withstand the deteriorating effects of traffic and environment for the service life of the facility. This goal is considered an integral part of the total highway transportation program and is constantly sought in quantitative measures. The yearly expenditures of time, money and manpower on pavement research attest to the importance of developing the highway pavement design process to meet more effectively the increasing demands on the highway structure.

In the early $1900^{\prime} \mathrm{s}$, most highway construction was dedicated to improving the movement of farm produce to the urban inarket. High speed-high volume roads were not yet part of the highway image, and there was little need to evaluate extensively the variables of soll, environment, traffic and paving materials as they related to the performance of these early roads. Since that era, travel (in terms of road users, vehicles per person and miles per venicle) has increased and, along with increastine vehicle weights, hos produced greater demands on the expanded network of highway facilities. These increased requirements necessitated an 
1mprovement in the qual1ty of pavement structures. As the h1 ghway transportation system was expanded, a more refined concept of a "good" road evolved, and the need for highways to be planned, designed, constructed and maintained to meet various physical demands (load, repetition of loads, climate, etc.) and to satisfy the subjective desires of the road users fostered an inoreasingly quanti tative science of hi ghway pavement design.

To provide roads of the quality needed today, the factors which are extrinsic to the pavement and which have a significant effect on the required structure must be evaluated. Based on the evaluation of these extrinsic factors, the design thickness and intrinsic properties of the pavement structure must be ascertained so that the highway exhibits a desired level of performance over the life of the structure. Much research has been performed to evaluate these factors which are assumed to be important to the design of the parement thickness. These physical demands are generally categorlzed into the intrinsic structural factors specified by the design product and into the extrinsic factors of supporting solis, traffic loads and various environmental factors. The performance criterla of pavement design is the standard of judgment used to evaluate the ability of the highway "to serve" and is the encompassing design factor which reflects the subjective desires of road users for a "good" pavement. This concept is lilustrated in Figure 1. 


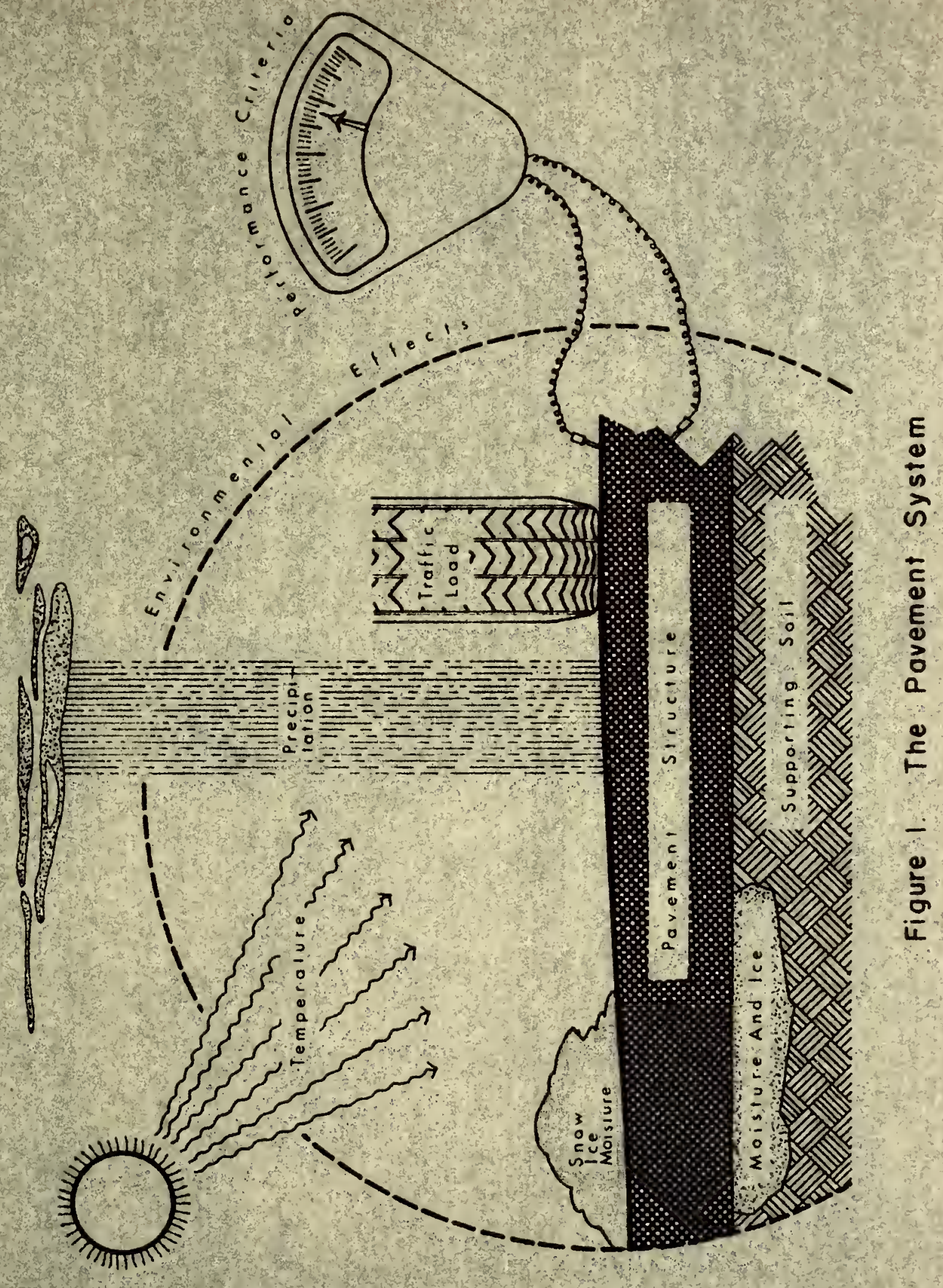


Various measurable parameters are used to quantify physical and subjective demands, and numerous design techniques are available which combine in a logical manner these desien parameters to determine the required pavement thickness. Several supporting soil or subgrade parameters used in pavement desicn are California Bearing Ratio, modulus of subgrade reaction, resistance value, group index and soil support value. Examples of traffic parameters include equivalent wheel load, equivalent 18-kip single-axle load, traffic index, Corps of Engineers design index and Fortland Cement Association's(PCA) controling wheel load. While the environment has a great influence on the behavior of pavements, successful attempts to quantify and explicitly incorporate environmental parameters into design are lacling. Depth of frost penetration, reduced subgrade strength, Kansas saturation coefficient, Wyoming desien factor and American Association of State Highway officials (AASHO) regional factor are introduced into several design procedures to simulate environmental effects. The intrinsic structural factors of paving materials are the more precisely evaluated design parameters and of ten are quantified as modulus of elasticity, flexural strength or modulus of rupture, Poisson's ratio, cohesiometer value. gravel equivalent, California Bearing Ratio and coefficients of relative strength.

Tolerable deflection, allowable stress and degree of cracking are examples of fallure criteria that estimate levels 
of performance provided by the pavement. The subjective destres of road users have recently been measured as another factor in the evaluation of pavement performance. These requirements depend on the riding quality of the pavement and have been quantified in terms of an arbitrary "serviceability" rating. This rating has been correlated with various measures of pavement conditions and defects. Thus, measurements of the subjective and physical factors which logically form the basis of pavement design are approximated by parameter design values, and these measures are combined to deterinine a required pavement thickness which is judged suitable for the conditions anticipated during the design life.

In practice, the design process usually follows the procedure of a particular design method. However, available techniques differ in the design parameters considered, the definition of parameter values and the quantitative manner in which selected desion values are related to thickness. Construction inspection and quality control of pavement thickness, subgrade support and quality of structural components vary so that conformance to or identification of discrepancies from the parameter values used to determine design thicknesses is not consistent within and among road building agencies. Pavements designed for the same traffic load, soll support and environmental conditions, bullt of the same quality of material and workmanship and expected to exhibit similar performance characteristics should be equal 
in thickness regardiess of the agency responsible for the design and construction. Such agreement is not the case because, in addition to the differences of the various design procedures available, much ensineering experience and subjective judgment enter into the decisions required for resolving the design of pavement thicinesses.

Determining a satisfactory design thichness is inherently difficult, and the optimum design can not be ascertained even though the major factors affecting pavement thickmess have been identified. Fart of this problem is due to the uniqueness of the road structure and the conditions under which the facility must serve. A pavement is a thin narrow structure relative to its length and is built at or near the mound surface. 'Thus, a single design, which is seldorn changed over the contracted lensth of the roadray, must satisfy a variety of subgrades and enviromental influences. The heterogeneous nature of pavement building materials and their changing behavior with time and ambient conditions also contribute to the uncertainty of the pavement desion process. While design is Iosically influenced by the performance expected of the pavement, methods of pavemcit evaluation and derinitions of failure conditions have not always been clearly delimited for economical encineering purposes.

The purposes of this research were to identify and examine the relative effects on design thickness of various design parameters which measure the subrrade support, traffic 
Ioad, pavement material properties, environmental factors and performance criteria and to develop a simplified pavement design method. Three flexible and three rigid pavement design methods, which are representative of present design practices, were structured into a hierarchy of design-process logic and were analyzed to derine the important set of pavement design variables considered in each design process. The relative importance of these design factors was determined in a sensitivity analysis which was developed to investigate the impact of changes in parameter values on the pavement system. Pavement thiciness limitations were selected to 1 I Iustrate the variabilities of desicn factors allored before major changes in the final desien are required. Tolerable change, when compared to actual variability encountered in some design factors, resulted in a verification of or sussested changes in present desisn techniques and construction and inspection practices. The feasibility of a simplified design method which contained only the more significant design factors was evident from the results of the sensitivity analysis.

A better understanding of the state of the art and science of pavement design has resulted from this research. Sugrested modifications of current design and construction practices are permitted by indicating deficient phases of the parement desion process and related activities. The following specific benefits were a consequence of this research investigation. 
1. A more advanced basis on which better pavement design decisions can be made and justified was afforded by structuring several design methods into a hierarchy of designprocess lozic, by identifying imprecision, inaccuracy and uncertainty in the design parameters and by examining the resultant effects on design thickness or expected performance.

2. The sensitivity analysis of the physical and subjective factors affecting thiclmess and expected pavement performance permitted the identification of the significant design parameters. The effect of actual deviations associated with these parameter design values demonstrated those phases of the design process requiring closer attention and study and indicated areas where design information is excessively precise.

3. Positive recommendations, based on the analysis of parameter precision required to meet selected thickness change limitations are presented regarding:

a. The degree of quality control needed in paving materials,

b. The extent of soil irivestigations required Ear the route.

c. The precision of traffic prediction needed and

d. The tolerance in thickness allowed in construction. 4. Simplified design methods for rigid and flexible pavements were developed in context with the precision of the data used in ascertaining the selected design parameter values. 
This research further attempted to clarify the relationships among design parameters, design methods and pavement performance to provide a more comprehensive and rational appraisal of pavement systems for the evaluation and justification of pavement thickness design techniques. The design of a riding surface for the anticipated extrinsic and intrinsic physical demands and for the performance desires of the road users over the service life of the proposed pavement has been advanced. Hore realistic decisions to be nade in the pavement design process are now possible, and the ability to attain the objectives of parement design and the goals of highway transportation hopefully has been enhanced by this research. 


\section{PROCEDURE}

The procedure used in the analysis of selected pavement design techniques and in the formation of simplified pavenent design methods is subdivided into six phases:

1. Selection of parement design methods,

2. Structuring of the design-process logic,

3. llodeling of the design techniques.

4. Sensitivity analysis.

5. Investigation of tolerable parameter variations and

6. Development of simplified pavement design methods. A general description of these activities follows, but more detalled elaboration of the procedure is presented in those sections where exceptions varrant additional discussion.

\section{Selection of Favement Design Vethods}

Because numerous techniques exist for the design of highway pavements, selection of several design methods was necessary to carry out this research investigation. Common usage of the technique, a rational approach to resolving the design thickness and the availability of literature pertaining to the design method were the maln criteria used in selecting the six design methods for analysis. The pavement design methods which best satisfy these criteria and which represent 
present design practices are for flexible pavement structures:

1. The AASto Interim Guide for the Design of Flexible Pavement Structures (AAsHo plerible).

2. The Corps of Engineers Flexible Pavement Design for Roads, Streets, Walks and Open Storaere Areas (Corps Flexible) and

3. The California Highway Department Stabilometer Design Method (California Stabilometer).

For rigid parements the following three nethods were chosen for consideration:

1. The AASHO Interim Guide for the Design of Rigid Favement Structures (AABHO Rigid).

2. The Corps of Engineers Design liethod for Rigid Favements for Roads, Streets, Jalks and open Storage Areas (Corps Rigid) and

3. Thiciness Design for Concrete Pavements by the Portland Cement Association (FCA Rigid).

These siz pavement design techniques were the primary sources of information on winich this rescarch investigation was predicated.

\section{Structuring of the Design-Erocess Logic}

Each design method used in this study vas structured into a hierarchy of desien-process logic. This organization of design methods into a ranking of design factors as they are considered in the design process permits a systematic examination of the logic employed in determining the required 
pavement thickness. A sample hierarchy chart, which is shown as Figure 2, 11lustrates the ordering of those items involved in the design rationale. Headed by the final design product which is pavement thickness, the chart depicts the major design parameters and the subordinate factors which influence the selection of the design values.

The hierarchy structure of design-process losic is conceptualized as having an objective and three levels of successive pavement design considerations:

1. While the design objective is a serviceable yet economical structure, this goal is finaliy manifested by a specified pavenent thickness. For rigid pavements the thicleness of the concrete slab is the final desich product, and the layer thiclnesses of surface, base and subbase structural components, which sum to a total flexible pavenent thickness, also conform to the design objective.

2. Najor desien paramoters and pavoment performance criteria constitute the first hierarchy level. These paraneters are explicitly considered in formulating the thickness runction or are actually used to detemine the required thiclness. In addition, they must be the primary factors (traffic load, soll support, paving material quality and environmental effects) which influence the required thiclkness. 


$\begin{array}{clll}\text { Final } & \text { First } & \text { Second } & \text { Third } \\ \text { Product } & \text { Level } & \text { Level } & \text { Level }\end{array}$

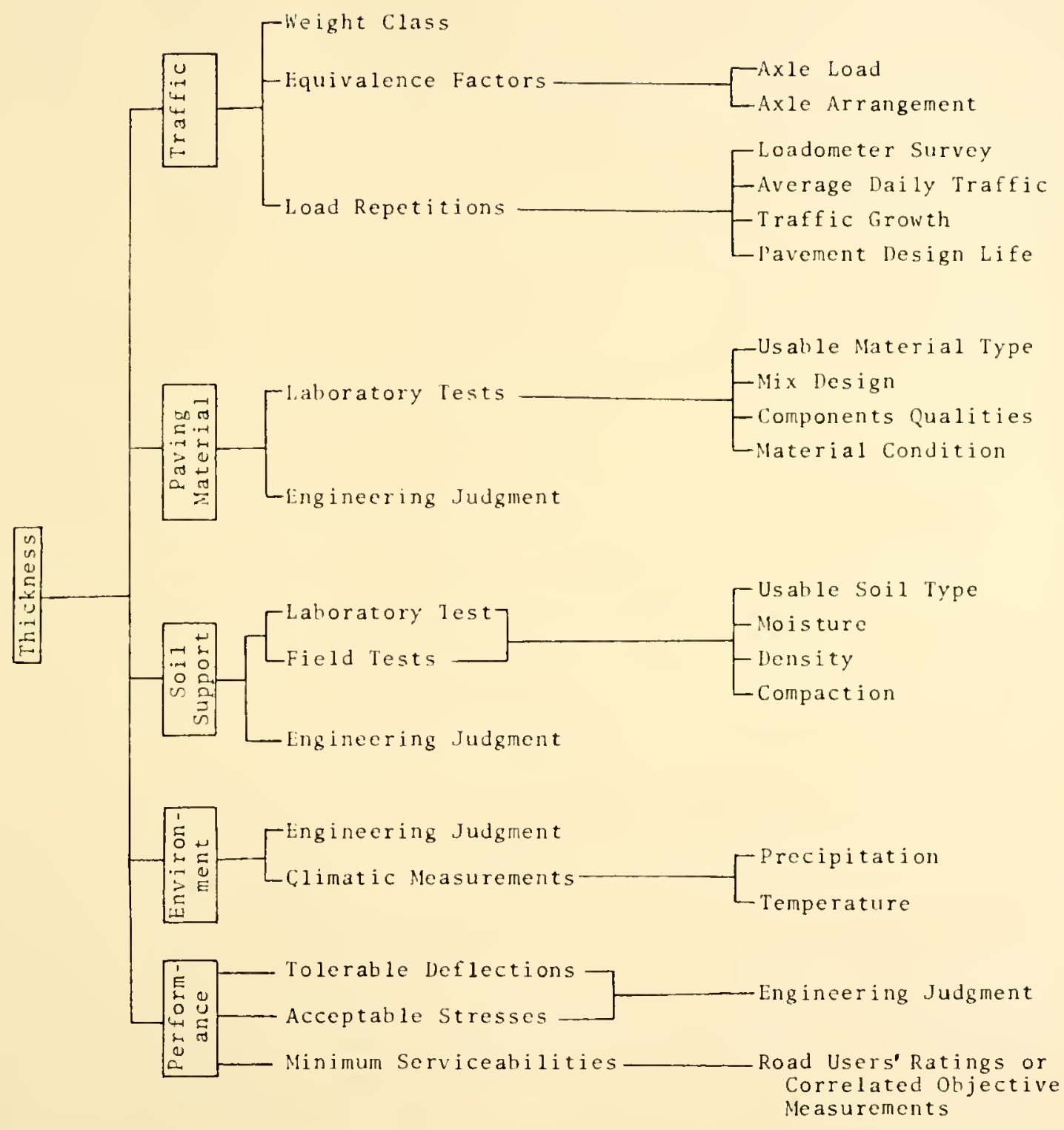

Fiรure 2. Sample Hierarchy Chart 
3. The second level is comprised of those evaluations which are necessary to select definite values for the higher level parameters. Soil tests, loadometer data and factors of safety are examples of design considerations categorized in the second level of the design hierarchy.

4. Items recognized as affecting second level determinations and evaluated as background material for the second level are specified as third hierarchy level considerations. Intrinsic material properties, moisture and density are items typically ranked at this levei.

Until the design objective is reached, decisions in the pavement design process which are made at higher hierarchy levels are based on the evaluation of the preceding level considerations. Unce a thickness required by the various design parameters is determined, it is often re-evaluated on a subjective engineering judgnent basis. However, this aspect of design was not investigated as part of the designprocess logic. The hierarchy structuring of the designprocess logic permitted a qualitative insight into the manner in which the factors considered in design affected the required pavement thickness.

\section{Modeling of the Design Techniques}

After a thorough review of the literature pertaining to the selected pavenent design methods, models of each design method were formulated to mathematically or graphically 
systematize the design-variable relationships for the purpose of executing the sensitivity analysis. Design charts to facilitate the determination of the required pavement thichness and mathematical equations which are basic to the various design processes are available for each of the six methods chosen for this research investigation.

A thickness dosign nodel that is totally expressed by a single mathenatical equation is best for this research; however, only two (CaIifomia. Stabilometer and $\Lambda A S I O$ BI of the six nethods investigated have desigin variable relationships which are expressed adequately enough to stand as acceptable mathematical models for the sensitivity analysis. In adaition to expressing to an acceptable degree the design variable relationships needed to carry out the sensitivity analysis, the Califormia Stabilometer and AASHC Rigid design equations provided sufficient infometion for preparing the respective design charts.

Equations winch are basic to the design methods, but do not completely express the relationships necessary to drai the design charts or which were not adequate models in their siven form, were habilitated from information provided by the design charts and the stated techniques for determining the design thickness. This proceciure was employed in developing the models for the AASHo Flexible and FCA Rigid pavement desion methods. Wile the literature pertaining to the AASHO Flexible design method contained an equational relationship, shom as equation 11 in the Review, and the 
design chart nomographs shown in Appendix $A$, a complete mathematical solution to the design nomographs was not available to relate all design variables in a single expression. Therefore, the desired sensitivity analysis equation was derived from the design nomograph by using the above equation and the explanations of the technique for constructing the nomograph.

The latest Portiand Cement Association design method utilizes equations and corresponding charts which related axle load, modulus of subgrade reaction and concrete strength to parement thickness. These charts and equations, however, were not adequate models for the sensitivity analysis because the total PCA process of determining the thickness required for the variety of traffic loads and repetitions anticipated for the service life of the pavement was not summarized into a lone mathematical expression. This design technique does not employ a single design parameter to estimate traffic effects but does examine the "fatigue resistance" of the pavement "used up" by each repetition of every loading. Eased on the documented (17) "fatigue resistance" concept and the equation basic to the PCA desien method, shown as equation 26 in the Review, a mathenatical model was adequately developed for the sensitivity analysis.

Althoush mathematical expressions were presented with the Corps of Engineers Rigid and Flexible pavement desion methods, the process involved in developing these equations into adequate nodels for the sensitivity analysis produces information which is less precise than if the basic design * Numbers in parantheses refer. to references listed in the Bibliography. 
charts alone are used. Therefore, the Corps of Engineers Rigid and Flexible design charts became the data sources from Which graphical interpretations were made for the sensitivity analysis.

\section{Sensitivity Analys 1s}

The effects on thickness of the factors considered in pavement design were quantitatively evaluated in a sensitivity analysis. Applied to each design technique investigated, the sensitivity analysis basically examined the change in design thickness produced by the various design parameters.

The underlying premise of the sensitivity analysis phase of the procedure is that as the change in required pavement thickness produced by a design parameter becomes larger, the more important is that parameter in the design method. On this basis, the rate of change of thickness with respect to a particular parameter (quantified by the first partial derivative of the thickness with respect to that parameter) defines the theoretical measure of parameter inoortance, and the magnitude of the thickness change produced by comparable parameter variations specilies the practical measure of parameter importance.

Partial Derivatives as a Theoretical Heasure of Design Parameter Importance

The models or thickness functions used in the sensitivity analysis were formulated by graphical or equational relationships of design parameters to design thiclness. In each 
model peculiar to the particular design method, more inportance is attached to some parameters than to other parameters in determining the pavement thickness. The sensitivity analysis investigation evaluated this weighted importance of design parameters by using differential calculus in those methods with mathematical models. Analytical geometry was employed where design equations were not available and could not be derived from the design charts without a significant loss of precision in the sensitivity analysis.

In those design techniques in which mathematical equations modeled the design procedure, first-ordex partial derivatives were used to measure the relative sensitivity of the dependent thiclness variable to each independent design variable. In this study a first-order partial derivative is defined as the limiting value of the ratio of change in thickness to change In the parameter considered as that parameter change approaches zero. Symbolically, this definition is expressed as:

$$
\frac{\partial T}{\partial F_{1}}=\underset{\Delta P_{i} \rightarrow 0}{\operatorname{limit}} \frac{\Delta T_{1}}{\Delta P_{1}}
$$

Where

$$
\begin{aligned}
& \frac{\partial T}{\partial F_{1}}=\frac{\text { rirst-ordes partial derivative of thickness }}{(T) \text { with respect to a parameter }\left(P_{i}\right) \text {, }} \\
& \Delta T=\text { change in thiciness due to } \Delta P_{i} \text { and } \\
& \Delta \mathrm{I}_{i}=\text { change in àcsign parameter. }
\end{aligned}
$$

The first-order partial derivative assesses the exact rate of change of thickness with respect to changes in the parameter considered. Increased rates of pavement thickness changes produced by various parameters correspond to greater 
absolute values of the first-order partial derivatives, and that parameter which produces the greatest rate of change becomes theoretically the most important design factor.

For the Corps of Engineers design methods for rigid and flexible pavements, the thickness functions were graphically formulated, and mathematical procedures were not available to determine the first-order partials. A graphical interpretation of the definition, "limiting value of the ratio of change in thichness to change in the parameter considered as that parameter change approaches zero," was used to gather from these models the data needed to calculate the derivatives. An example application of the first-order partial derivative as graphically defined is illustrated in Figure 3 for the Corps of Engineers Rigid pavement design chart.

Nith the first-order partial derivative determined mathematically or graphically, the relative importance of design parameters due solely to the formulated thickness function was quantified as a percentage of the total changes in thickness for each design rethod. This percentage is specified as the positive ratio of the partial derivative of a thiclness with respect to a particular parameter to the sum of the absolute values of the partial derivative for all parameters. This determination is symbolically written as:

$$
R P P=100 \times\left|\frac{\partial T}{\partial \breve{F}_{i}}\right| \div \sum_{i=1}^{n}\left|\frac{\partial T}{\partial P_{i}}\right|
$$

where

$$
\mathrm{RFF}=\text { relative percentage of a partial. }
$$




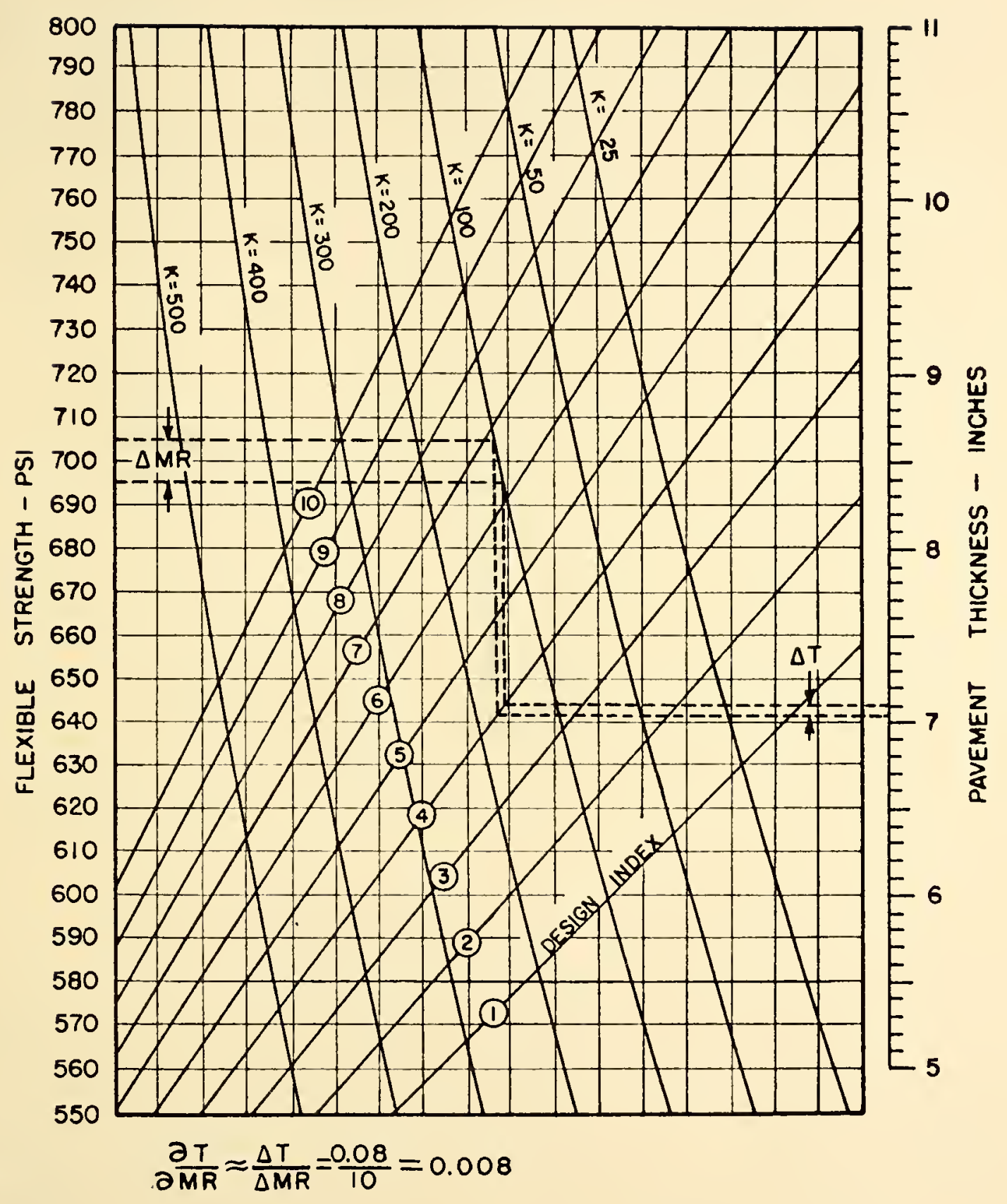

Figure 3. Graphically Defined First-Order Portial Derivative 


$$
\begin{aligned}
& \left|\frac{\partial T}{\partial F_{i}}\right|=\begin{array}{l}
\text { absolute value of the ith partial } \\
\text { derivative and }
\end{array} \\
& \sum_{i=1}^{n}\left|\frac{\partial T}{\partial P_{1}}\right|=\begin{array}{l}
\text { summation of the absolute values of all } \\
\text { partial derivatives considered in the } \\
\text { sensitivity analysis of a design method. }
\end{array}
\end{aligned}
$$

The above relative percentage and the preceding method of analysis adequately determine the importance of each parancter as formulated in the thichness function. Fowever, all parameter variations are implicitly assuned to bo numericalyy "small" and equal in this techique. The sizes of parameter variations encountered in actual paverent design practice differ considerably among parmoters, and these increments of parametcr changes influence the range of design thicknosses required by each pometer. Therefore, failing to account for the actual parameter variations docs not yield an entirely realistic epraisal of the relative importance of eaci design parameter in the actual desion process.

Zortions of the Total Iifrerential as a heasure of the Practical Importance of Design Parameters Although the preceding theoretical neasure of design parameter importance was $a$ suitoble evaluator of design factors as they are included in the thiclness function, the following neasure of paraneter importance evaluates design factors in the contert of the total design process thus providing a realistic measure of importance. is practical evaluation of the importance ô pavement design parametors considers the manner of combining design factors to resolve 
thickness and accounts for the amount of variation or increment of change that occurs in each factor. While the ratio of thichness change to effecting porameter change remains nearly constant regardless of the incremental changes used in calculating the ratio, the magnitude of alterations in thickness is directly proportional to the size of the parameter change. Thereforc, any comparison of the thickness changes brousht about by several design factors is necessarily qua.lified by the selccted size of parameter changes associated with each ractor used in tine analysis.

The schsitivity analysis of this rescarch irvestication examined the combined effects of both the manner in which parameters wore included in the thichness function and the different sized increments of change. These changes were chosen to ropresent actual paraneter variations so that a realistic reasure of the relative importance vas obtained for each design parameter. This combined measure 1 s conveniently Ilustrated by the total differential of calculus and is expressed in terms of thichnoss and design parameters by the following equation:

$$
\begin{aligned}
d T= & \left|\frac{\partial T}{\partial F_{1}} d\right|+\left|\frac{\partial T}{\partial F_{2}} d F_{2}\right|+\ldots+\left|\frac{\partial T}{\partial P_{i}} d I_{1}\right|+\ldots \\
& +\left|\frac{\partial T}{\partial P_{n}} d I_{n}\right|
\end{aligned}
$$

where $d T=$ total change in the required pavement thickness produced by the design factors $\left(F_{i}\right)$ and termed the total differential.

$\frac{\partial T}{\partial P_{i}}=\begin{aligned} & \text { first-order partial derivative of the thickness } \\ & \text { function with respect to the parameter }\left(\bar{F}_{i}\right) \text { and }\end{aligned}$ 


$$
\mathrm{dP}_{1}=\begin{aligned}
& \text { differential or increment size of change of } \\
& \text { the parameter }\left(\mathrm{P}_{i}\right) \text {. }
\end{aligned}
$$

The term $\left(\frac{\partial T}{\partial P_{1}} d P_{1}\right)$, which accounts in total for the contributions of the parameter $\left(\mathrm{P}_{1}\right)$ to the total differential ( $\mathrm{d} T$ ), is conceptually regarded in this study as the combined influence of the manner in which the parameter was incorporated into the thickness function (estimated by the first partial $\left(\frac{\partial T}{\partial F_{i}}\right)$ ) and of the parameter variations $\left(d F_{i}\right)$ wich axe encountered in nomal design situations.

If appropriate $\left(\mathrm{dP}_{1}\right)$ increments are chosen as representative of actual parameter variations, then the absolute value of the term ( $\left.\frac{\partial T}{\partial F_{i}}{ }_{i}\right)$ becomes a realistic measure of the change in thickness caused by a pavement design paroneter. This evaluation is comparable to similarly made measures of other parameter effocts. The portion of the total thiclness change produced by a parameter and calculated as a percentage of the total change provides a relative measure of design parameter irportance to the total design process rather than to the formulated thickness imction alone. This relative percentage measuro of importance is mathenatically shom as follows:

$$
R P T C=100 \times\left|\frac{\partial T}{\partial P_{i}} d P_{i}\right| \div \sum_{i=1}^{n}\left|\frac{\partial T}{\partial T_{i}} d P_{i}\right|
$$

where $\quad$ RPTC = relative percent of the thickness change,

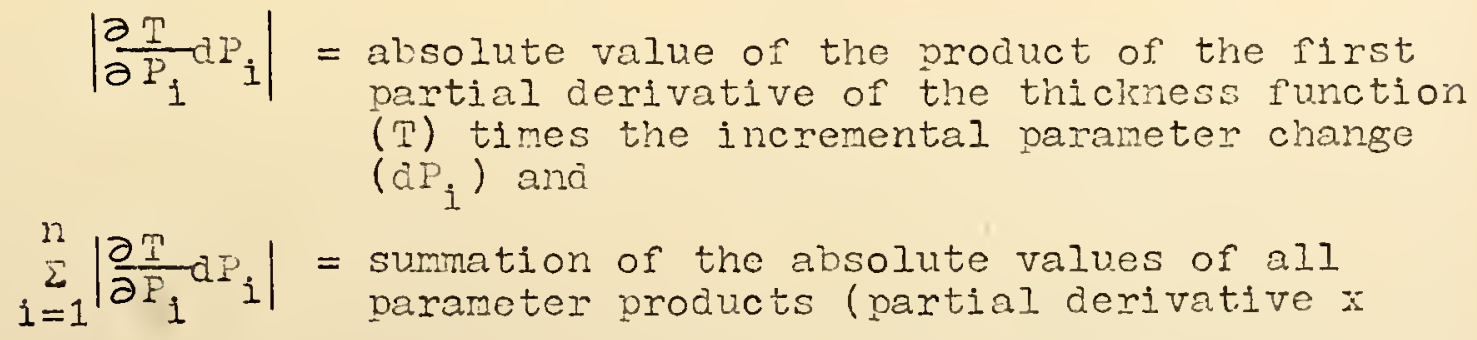


increment) considered in the sensitivity analysis of a design method.

The definition of the first-order partial derivative, as expressed mathematically in equation [1], is not compatible With the use of the total differential in determining the importance of design parameters due to the thickness function and the variation in parameter values. A linear approximation (determined by the first partial) of the thiclness function is adequate for minute changes of the parameter values and is exact as these changes approach zero. Fowever, the validity of the linear approximation is questionable as deviations from the mean parameter values become larger. While the first partial definition designates parameter change to approach zero, the total differential as applied in this sensitivity analysis requires parameter changes to approximate the practical variations evidenced in the actual process of designing pavenents.

Because these discrepancies occur, another approach was devised as a corroborating measure of the practical design parameter importance. This approach accurately defines the relative practical importance of design factors and is predicated on the elementary supposition that a design thickness can be determined for any reasoneble combination of parameter values.

Relative Thicliness Changes as lieasures of the Fractical Importance of Design Parameters

Two different values which are selected for the same parameter yield two thicknesses in the highway pavement 
design process. The difference between these two thiclinesses is interpreted as the actual change in the design thiclmess produced by the parameter and its variation if the two delimiting parameter values are indicative of realistic parameter variations normally encountered. iased on this uncomplicated concept, another relative percentage, which is similar to that calculated by equation 4 , was desired as a substantiating measure of practical design parameter importance. This need was adequately met by the ratio of the thickness change, which resulted from tro delimitins parameter values, to the sum of a.I changes in thiclness similarly calculated ror every design parameter of the particular pavement design technique considered. This relative percentage is symbolized in the following equation:

$$
\text { RPATC }=100 x\left|\Delta T_{I_{i}}\right| \div \sum_{i=1}^{n}\left|\Delta T_{I_{i}}\right|
$$

where RPATC = relative percent of the actual thichiness

$$
\begin{aligned}
\left|\Delta T_{P_{1}}\right|= & \begin{array}{l}
\text { absolute change in thickness due to the } \\
\left(P_{1}\right) \text { parameter and }
\end{array} \\
\sum_{i=1}^{n}\left|\Delta T_{P_{i}}\right|= & \begin{array}{l}
\text { sum of all the absolute thicliness changes } \\
\text { produced by all parameters of the design } \\
\text { method under consiceration. }
\end{array}
\end{aligned}
$$

The findings of this approach were compared with the results from the total differential method of analyzing the sensitivity of pavement thicliness vith respect to the design parameters. Where the results were significantly different the elementary measure of practical parameter importance 
was considered more valid than the results obtained from the total differential approach.

\section{Investigation of Tolerable Parameter Variations}

To ascertain the precision of determining design parameter values which would be commensurate with current design and construction specifications is beyond the scope of this research project. Such a study involves an appraisal of inherent parameter variability, an evaluation of true factors of safety within the design process, an economic analysis of improved data precision and an assessnent of the penalties paid for errors in design and construction. Each factor appears difficult to evoluate within the resource Iimitations of this study. However, estimations of parameter deviations permitted before the designed pavement thickness is chansed by $0.5,1.0$, or 2.0 in. were determined to iliustrate the design factor variabilities allowed before major changes in the final desisn are required.

\section{Tolerable Farameter Variations Using} a Total Differential Approach

The procedure for examining design parameter variations that can be tolerated without exceeding specified thickness changes was again based on the modified concept of the total differential as shown below:

$$
\begin{aligned}
d T= & \left|\frac{\partial T}{\partial P_{1}} d P_{1}\right|+\left|\frac{\partial T}{\partial P_{2}} d P_{2}\right|+\ldots+\left|\frac{\partial T}{\partial P_{i}} d F_{i}\right|+\ldots \\
& +\left|\frac{\partial T}{\partial P_{n}} d P_{n}\right|
\end{aligned}
$$


where $\mathrm{dT}=\mathrm{a}$ selected pavement thickness change limitation. $\frac{\partial T}{\partial P_{i}}=\begin{aligned} & \text { first-order partial derivative of thickness with } \\ & \text { respect to parameter } P_{i} \text { and }\end{aligned}$ $\begin{aligned} a P_{1}= & \text { tolerable chanse in parameter } E_{\text {in }} \text { which in } \\ & \text { combination with other parameter changes } \\ & \text { produces the selected thickness change. }\end{aligned}$

With the first-order partial derivatives a.lready determined in an carlier phase of the sensitivity analysis, finding the linear combinations of parameter variations wich produce the selected thiclmess changes required the substitution of 0.5 . 1.0 or $2.0 \mathrm{in}$. for (dT) and the solution of equation 6 for the various possible values of the (dF's).

Plots of allovible parameter variations were made for the several selected thiclness change constraints to illustrate Eraphically the tolerable variations permitted in the desinn parameters. The allowable parameter variations were expressed as a percentage of the design parameter volues $\left(\frac{d F_{1}}{F_{1}} \times 100\right)$. and these percent deviations are the units of the allowable parameter variation axes of the illustrative plots. Hecause the total differential is a linear equation, plotting was simplified by determining the axis intercepts for the selected thicliness changes.

If aII paraneter chanes but one are equated to zero, thon the selected thichness change limitation (dT) divided by the partial derivative of thicliness with respect to the nonzero parameter $\left(\frac{\partial T}{\partial P}\right)$ yields the maximum permissible variation in that parameter for the selected thichness change constraint. This value of maximum allowable variation is expressed as a 
percent deviation, and is the ecral thichness change Iimitation line intercept of the $\left(\frac{d F_{i}}{F_{i}} \times 100\right)$ axes. Determining the intercept for each parameter of the design method under consideration provides sufficient data to iluustrate the linear combinations of parameter variations allowed within the $0.5-, 1.0-$ or 2.0-in. thichness change constraints.

Selection of Thichness Change Constrairts Selection of $0.5-1.0-$ and 2.0-in. thiclness change Iimitations ror the purpose of demonstrating allowable parametex variations was arbitrary. Fost vavement specifications require that the average thichness be visthin -0.25 in. of the value noted in the construction dirarinos or plens, (8, 12, 14, 15) but significantly larger ioviations in thiciness are produced by the usual design parameter variations. For the purposes of this research analysis, a major change in pavement thichness Is derined as a thichness deviation greatem than the sum of the contract specification tolerance limit plus one standard deviation of actual construction thicknesses rhich are typical of current road building practices. The meanings of thickness variation, standard deviation, contract specirication tolerance, plan thicleness and the major change dorinition as applied to this phase of the sensitivity analysis are illustrated in Fisure 4 .

After a quantitative definition of a major chanse in thickness was determined. the allowable variations in desisn parameteis for tho major thickness change constraint were 
Percent of Meosured Thickness vs.

Povement Thickness

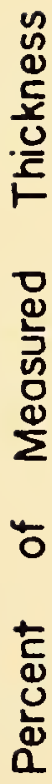

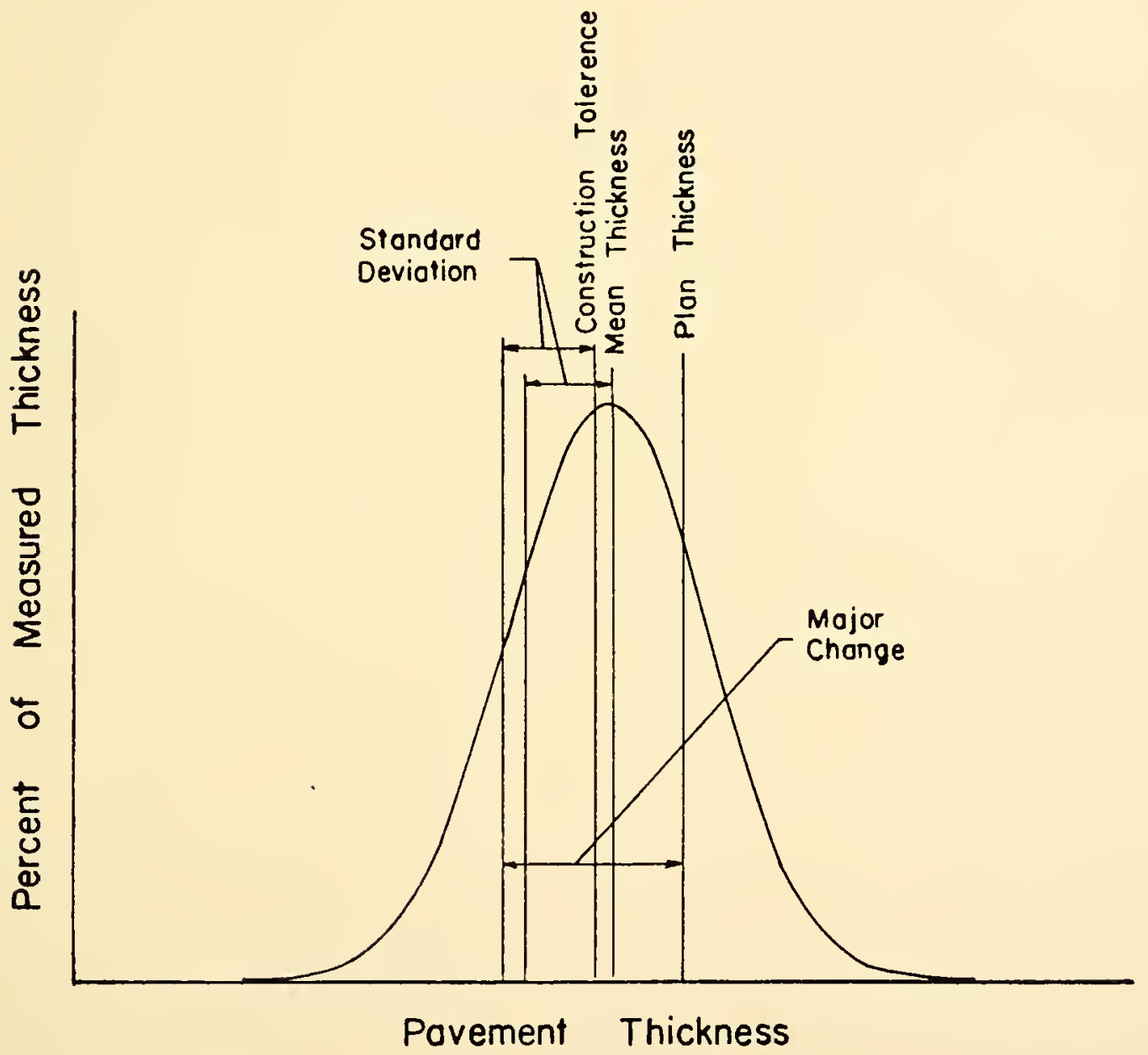

Figure 4: Frequency Distribution of Povement Thickness 
plotted along with the 0.5-, 1.0- and 2.0-in. constraints. These plots were then compared to the thichness chane produced by typical parameters encountered in the actual desion process. This comparison provided additional understandine of the state of the art and science of pavement design and permitted a basis for appraising current design and construction practices.

\section{Develonment of Simplified Favement Desimn liethods}

The final objective of this research investigation was to develop simplified design methods for rigid and flexible pavenents. The requisites on these design methods vere to provide a techrique compatible with present ability to estimate cosign parameters, to encompass the three flexible and the three rigic methods which rere analyzed in this study, to delcte from these destgn processes those relatively unimportant design variables and to simplify the considered design models by minimizing the algebraic operations which, in resolving the desion thickness, propagate errors inherent in design parameter deterninations.

From an examination of the design methods selected for this analysis, pavement thiclness increases with heavier traffic loads, wealser subgrades and pavement structures, more severe clinatic conditions and moro stringent periormance requirements. The sensitivity analysis substantiated these trends and, in addition, evaluated tire relative importance of the various design factors on the resultant changes in 
required thickness. However, only a qualitative comparison of the importance of a selected design factor in a particular design method relative to the importance of the correspondins parameter in another design technique is realized from the sensitivity analysis. While various parameters in the different design techniques are available for estimating the same basic design factor of soil support. traffic, paving material or environment, a common scale was requirch for correlating these various neasures which assess the influence of the same coneric factor. Hth this correlation of ciesin paraneters Which estinate the major factors influcncing pavement thickness. equivalent sets of design parametor values that are appropriate to each design method were selected, and correspondins thiclmesses were detemined accordine to the desicn criteria of each. liy selecting many such cominations of design parameter values, comparable parement thicknesses for each design motinod wore assembled to provide a common basis for evaluating the relative paraneter influences on thickness and for develooing the simplified design technique.

Eased on a priori considerations which vere substantiated by the thichness trends observed throughout the sensitivity analysis of the selected design techniques, linear, quadratic and cublc expressions vere fitted to various combinations of the parameter-thiciness data. These data were generated from the models of the selected clesign methods and were analyzed in siz sroups representing each technique and in two groups 
of data synthesized by comining the information representative of the three flexible and three rigid pavenent design methods. The nodels mich were ritted to these data. and evaluated as approximations of the parameter-thickness relationships are written in eneral notation below.

Linear model:

$$
T=a_{00}+a_{10} F_{1}+a_{01} I_{2}
$$

Quadratic model:

$$
\begin{aligned}
T= & \beta_{00}+\beta_{10}+\beta_{01} F_{2}+\beta_{20}{ }_{1}^{2}+\beta_{11} E_{2} \\
& +\beta_{02} F_{2}^{2}
\end{aligned}
$$

Cuibic model:

$$
\begin{aligned}
T= & \gamma_{00}+\gamma_{10} E_{1}+\gamma_{01} F_{2}+\gamma_{20} E_{1}^{2}+\gamma_{11} I_{1} E_{2} \\
& +\gamma_{02}{ }^{2}+\gamma_{30} E_{1}^{3}+\gamma_{21}{ }_{1}^{2} F_{2}+\gamma_{12} F_{1} P_{2}^{2} \\
& +\gamma_{03} P_{2}^{3}
\end{aligned}
$$

Where $\underline{T}=$ total required pavement tildeliness,

$$
\vec{F}_{1}, P_{2}=\text { selected ciesign factors and }
$$

$\alpha, \beta, \gamma=$ regression coefficients determined from the least squares curve fitting analysis.

The equations which vere obtained from a "least squares curve ritting" of the data were examined to ascertain the conceptual validity as expressed in the nevly formed parareter-thiclness relationships. The coefficients in the conceptually acceptable linear model equations provide a quantitative gauge for comparing the weighted importance of the major factors used in determining pavement thicliness 
Within and anong each of the three rigid and three flexible design teciniques.

To maintain geometric intuition and to conform to the intencied simplicity of the design models, only three variables werc used in the regression analyses of the thickness data. The dependent variable vas pavement thickness, and the two independent variables were those design parameters that were the tro most important in the sensitivity analysis.

The least squares analyses of the combined flexible or rigid thickness data produced a regression equation which was designated as the thiclness function of the flexible or rigid simplified design nethod. While linear, quadratic and cubic models were used in analyzing the combined thickness data, an cmpirical choice was made in regard to that least squares equation which best fulfilled the requisites of the simplified design method. The model finally selected as a simplified design equation for rigid or flexible pavement design was based. on an "optimum" choice between model simplicity and counterbalancing statistical efficiency and on the implied requirement that the relationships expressed are conceptually valid. 
REVIEN OF FAVEMEIT DESIGI VETHODS

Six pavement design methods were selected for analysis in this research investization. While three of the design procedures (AASHO Flexible, Corps Flexible and California Stabilometer) are for flextble pavements and the other three techniques (AAsHo Rigid, Corps Ricid, PCA Rigid) pertain to the design of rigid pavements, a.l methods are characterized as being extensively published, often used and rationa.l in concept. Thus, the selected design methods were sufficiently representative of current pavement desicn practices to permit conclusions that are pertinent not only to the investigated methods but also to the art and science of pavement design in general.

\section{Flexible Favement Design}

Although pavement types do not exhibit distinctly rigid or flexible bchavior, this research recognizes flexible pavements as consisting of "... a relatively thin wearing surface built over a base course and subbase course..." with "... load carrying capacity... brought about by the load-distributing characteristics of the layered system." (19) Asphaltic construction materials are acknowledged as a primary constituent of the pavement structure. A review 
of the design methods selected to represent current design practice for flexible pavements is presented with erphasis on the conceptual development of each technique and on the destgn parameters employed in determining the required parement thickness.

\section{AASHO Interim Design liethod for Flexible Pavements}

Conceptual Develooment of the AASFO Interim Desisin Guide for Flexible pavements. (1,3,4, 10, 11) The AASHO Flexible pavement design method is based on the results of the road Test sponsored by the Arerican Association of State Hi shway Officials and conducted at ottawa. Illinois, from 1956 to 1958. At this road test the functional relationship of serviceability trends to axle load applications was assumed to talse the followine natinematical form:

$$
c_{0}-p=r^{\beta}
$$

where

$$
\begin{aligned}
& c_{0}=\text { initial serviceability index, } \\
& p=\text { terminal serviceability index, } \\
& w=\text { axle load applications } \\
& \beta=\text { positive power dependent on pavement } \\
& \text { thickness and traffic load and } \\
& K=\text { proportionality constant. }
\end{aligned}
$$

Based on substantial data collected at the Road Test, a solution to this general equation was determined to express the fundamental relationship between the number of axle loadings. the pavement thickness and the serviceabilities. This relationship. Which is peculiar to the conditions during the actual 
Road Test, is written below:

$$
\log W=9.36 \log (S \mathrm{SH}+1)-0.20+\frac{\log \frac{c_{0}-p}{c_{0}-1.5}}{0.40+\frac{1094}{(\mathrm{SN}+1)^{5.19}}}
$$

where

$$
\begin{aligned}
W= & \text { total number of equivalent } 18-k i p \text { single- } \\
& \text { axle load applications, } \\
S I= & a_{1} D_{1}+a_{2} D_{2}+a_{3} D_{3}=\text { structural number, } \\
D_{1}= & \text { thickness of surface, base or subbase } \\
& \text { (inches). } \\
a_{1}= & \text { corresponding statistically determined layer } \\
& \text { property coeficients. } \\
c_{0}= & \text { initial serviceability index and } \\
p= & \text { terminal serviceability index. }
\end{aligned}
$$

To extend the results of the Road Test to other situations, the AASio Comittee on Design proposed "soil support value" and "regional factor" measures which permit the Road Test results to be applied to a variety of subgrades and onvironments. The ottawa subrade and environment were assigned a soil support value of 3.0 and a regional factor of 1.0 . respectively. With the basic relationship expressed in equation 11 and with the soil support value and the regional factor concepts for extending the application of the Road Test results for various locales, a graphically determined nomosraph, which is reproduced in Appendix A, was constructed for designing flexible pavement thicknesses.

$$
\text { Farameters of the MSHO Design liethod for Flexible }
$$

Pavements. $(1,3,4,10,11)$ The AASEO Flexible design method includes the factors of soll-support, performance, 
traffic and environment in determining a structural number. The actual thicknesses of surface, base and subbase layers are obtained from the structural number and by the following relationships:

$$
\begin{aligned}
T & =D_{1}+D_{2}+D_{3} \text { and } \\
S N & =a_{1} D_{1}+a_{2} D_{2}+a_{3} D_{3}
\end{aligned}
$$

where $T=$ total thickness of pavement structure. (inches), $D_{1}=$ surface thickness (inches).

$D_{2}=$ base thickness (inches).

$D_{3}=$ subbase thickness (inches).

SN: = structural number.

$a_{1}=$ surface property coefficient.

$a_{2}=$ base property coefficient and

$a_{3}=$ subbase property coefficient.

The property coefficients are statistical correlations and only indirectly relate to the properties of the various materials. Coefficients for pavement materials other than those used at Ottawa are "established by rationalization and a study of comparative cohesion, stability and bearing values obtained in the laboratory." (11)

The soil factor for the AASir Flexible pavement design method was defined in terms of a soil support value. While soil support values have no physical definition of subgrade supporting power, standard soll measures such as CBR, resistance value and Group Index were correlated to the AASHO soil support measures. 
One significant innovation of the AASHO design method was the incorporation of the road users' subjective desires into the determination of the required pavement thickness through serviceability ratiniss. The present serviceability inder estimates the road-user rating of the ridinss quality of a road on a scale from 1 to 5. Lover retings are 1 ind 1 ative of poorer pavements. The index of a new pavement is termed initiel scrviceability, while the subjective ratins of pavenents just deemed unsuitable for travel is designated as terminaI serviceability.

In the AASHO Road Test the destructive effects of traffic were found to depend on the initial and terininal serviceability Indices and on the structural number as well as the axle load and the axle arrangement. Therefore, determination of the equivalent 18-lip single-axle load parameter, which summarizes traffic effects in the AASHO design process, employs relationships which are functions of axle load and arranzement, serviceabilities and structural number. The sum of the products of axle load repetitions and corresponding equivalence factors, which are calculated by the equations below, provides the AMSHO traffic parameter. The axle load equivalence factor is the antilogarithm of equation 14 and 15 for single and tandem axles, respectively:

$$
\begin{aligned}
\log _{18}\left(H_{x}\right)= & 4.79 \log (x+1) / 19+\frac{G}{\beta_{18}}-\frac{G}{\beta_{x}} \\
\operatorname{los}\left(W_{18} / H_{x}\right)= & 4.79 \log (x+2) / 19-4.33 \log 2 \\
& +\frac{G}{\beta_{18}}-\frac{G}{\beta_{x}}
\end{aligned}
$$


where

$$
\begin{aligned}
& W_{18}=\text { rumber of } 18-k 1 p \text { single-axle load applications, } \\
& \begin{aligned}
& W_{x}= \\
& \text { number of } " x "-r i p \text { single or tandem axle load } \\
& \text { applications. }
\end{aligned} \\
& x=\text { axle load in kips for which equivalence } \\
& \text { factors are belne calculated. } \\
& \beta_{18}=0.40+\frac{1004}{(3 t+1)^{5.19}}=\text { beta furction for } 18-k i p \\
& \text { single-arle loads. } \\
& \beta_{x}=0.40+\frac{0.081\left(x+L_{2}\right)^{3.23}}{(5 I+1)^{5.19} L_{2} 3.23}=\text { beta function for } \\
& \text { "x"-kip single or tanciem axle loads. } \\
& \begin{aligned}
\mathrm{L}_{2}= & \text { arle code equal to } 1 \text { for single and } 2 \text { for } \\
& \text { tandem axles and }
\end{aligned} \\
& G=\log \frac{c_{0}-p}{c_{0}-1.5}=\text { scrviceability function. }
\end{aligned}
$$

invironmental conditions are given consideration in the AASHO Flerible desisn method throush a regional factor as a desion parameter. 3y definition, this regional factor is the mean value of seasonal weightins factors that ind cate average pavement deflections for varlous periods in the year. Derived at the hoad Test to improve the correlation of the primary relationships investi gated, this weighted seasonal factor accounted for the inequity of axle load aamage caused during periods of weak pavement conditions relative to that caused when the ground is irozen or dry. However, other circumstances which may be considered in estimating tine regional factor include "... steep grades, high water table, areas of concentrated turning and stopping movements" ... as well as soil conditions. (11) Because of the overwhelmins 

difficulty in appraisine the effects of the above conditions in terms of an unquantified regional factor, a subjective assumption of its value is usually made by a comparison of the design environment with the ottawa. IIlinols, location where the regional factor was arbitrarly assigned as 1.0 .

Corps of Engineers Flextble Favement Design lethod for Streets and Roads

Conceptual Development of the Corps of mine ineers Desion Iiethod for Flexible Pavements. $(7,18,19)$ The California Bearing Ratio design method of the California Division of Highways was the orisinal technique adopted by the Corps of Engineers as an expedient yet rellable design method for flexible airfield pavements. The different Coxps of Engineers versions of the original design method base the required thiclinesses on eqpirically correlated traffic loadings and California Bearing Ratios of supporting materials and subgrade underlyins the asphaltic surface layer. The latest corps Flexible highway design method, which is the concern of this research study, employs design indices that are indicative of traffic loads and CBR measures of the support capabilities of the suberade and paving materials as the primary evaluations needed to determine design thickness.

Hi ghway parement thiclmesses are determined from the design curves of $A$ ppendix $\mathrm{i}$. These curves, which are approximated by equation 16 for CBR-values less than 15.0. Sraphically show the empirical relationship anong design traffic indices. 

CBR-values and thicknesses required above the considered material or subsrade.

$$
T=\sqrt{\frac{P}{8.1 C B R}-\frac{P}{\pi p}}
$$

where $T=$ thickness of pavement required above the material being considered (inches).

$P=$ wheel load (pounds).

$\mathrm{p}=$ tire pressure (pounds per square inch) and

$\mathrm{CBR}=$ California Bearing Fatio of the subgrade or paving material.

The design curves realistically apply only to supporting materials of CER-values less than 50.0 (even thoush several road buldine materials for flexible pavenents have greater values), because minimum thiciness requirements exceed. thiclmosses that correspond to CIBR-values sreater than 50.0 and consequently these minimus control the design.

Parameters of the Corps of Engineers Desizn Pethoi for Flexible Highway Paverent. $(18,19)$ A unique feature of the Corps Flexible design method among the six selected techniques was the quantification of soil support and structural component qualities in the same units. The California Bearing Ratio test porfomed in the laboratory or in the field consists of measuring the force that is required to push a plunger at the rate of $0.05 \mathrm{in}$. per min into the subgrade or paving material sample. Comparison of the specimen resistance to that of a crushed-stone reference naterial permits determination of the CBR parameter. The larger percentage ratio of sample resistance to crushed stone resistance for plunger 
depths of 0.1 and $0.21 \mathrm{n}$. specifies the CBR value which is indicative of the streneth properties of the subgrade, subbase, base or surface material.

The Corps of Englneers desion index paraneter was developed to indicate on a scale from one to ten the ranges of traffic loadings anticipated for the service life of the pavement. For conventional traffic, lower desion indices Indicate less frequent and lishter traffic load applications, and hisher indices denote the opposite traffic influences. Deternination of the appropriate inder to use for design is predicated on classifying the proposed highway by expected traffic volume and on categorizing the traffic stream by vehicular composition. The highway class and traffic category limits which provide the means of establishing the Corps design index traffic parameter are shom in Appendix $B$.

California Division of Himhays Stabilometer Desim letinod for Flexible Fervements

\section{Conceptual Development of the Stabilometer Desicn}

llethod. (9,19) The early California Bearing Ratio design method, which was adopted by the Corps of engineers, was replaced by the California Division of Hlghways in 1948 by the Stabilometer desion method. Dased on the Brighton test track project and on other theoretical and erpirical considerations, $\vec{F}$. F. Hveem and R. $M$. Carnany proposed the following equation as an initial formulation of the relationships of the Stabilometer technique: 


$$
T=K \frac{(P \sqrt{A} 108 r)\left(P_{h} / P_{V}-0.10\right)}{\sqrt[5]{c}}
$$

where

$$
\begin{aligned}
T= & \begin{array}{l}
\text { pavement thickness above the compacted subsrade } \\
\text { inches). }
\end{array} \\
I= & 0.0175=\text { correlation constant, } \\
P= & \text { effective tire pressure (pounds per square } \\
& \text { inch). } \\
A= & \text { effective tire area (square inches). } \\
r= & \text { number of traffic load repetitions, } \\
c= & \text { coheslometer value (pounds per square inch), } \\
P_{V}= & \text { vertical pressure of } 160 \text { psi applied in the } \\
& \text { stabilometer (pounds per square inch) and } \\
P_{h}= & \text { transmitted horizontel pressure measured in the } \\
& \text { stabilometer (pounds per square inch). }
\end{aligned}
$$

A Jess complicated thlclness function resulted when the traffic efrects were summarlzed into a traffic inder parameter and when the stabilometer measurements of the supporting soil were condensed into a slngle resistance value.

Aditional field performance data permitted a modification of earlier thicknoss expressions until the present California Stabliometer design equation was evolved. This equation, as shown below, incorporates a factor of safety and typlcal tire pressures in the correlation constant:

$$
T=K \cdot \frac{(T I)(00-R)}{\sqrt[5]{c}}
$$

where

$$
\begin{aligned}
M= & \text { thiclness (1nches) } \\
K^{\prime}= & .080=\text { correlation constant, } \\
& \mathrm{TI}= \\
\mathrm{R}= & \text { rraffic index, } \\
& \text { square 1nch) and }
\end{aligned}
$$




$$
c=\text { cohesiometer value (pounds per square inch). }
$$

An imaginary perement thickness composed entirely of gravel is usually calculated from this desinn equation as an infial step in determinins the rinal desien. This gravel equivalent thickness is then converted to actual thicknesses of surface, base and subbase components through gravel equivalence factors or through the following relationship:

$$
\frac{t_{\text {act }}}{t_{\text {Ge }}}=\sqrt[5]{\frac{c_{\text {. }} e}{c_{\text {act }}}}
$$

where

$$
\begin{aligned}
t_{\text {act }}= & \begin{array}{l}
\text { actual thickness of the pavement component } \\
\text { (inches). }
\end{array} \\
t_{\text {ce }}= & \begin{array}{l}
\text { gravel equivalent thickness of that } \\
\text { component (inches). }
\end{array} \\
c_{\text {act }}= & \begin{array}{l}
\text { cohesiometer value of the pavement component } \\
\text { (pounds per square inch) and }
\end{array} \\
c_{\text {ge }}= & \text { cohesiometer value of gravel (Dounds per } \\
& \text { square inch). }
\end{aligned}
$$

Parameters of the Stabilometer Design lethod. $(9,19)$

The effects of traffic are estimated in this design method by a traffic index paraneter which is calculated by the nathenatical expression:

$$
T I=1.30 \sqrt{\frac{R}{5}} r^{0.12}
$$

where

$$
\begin{aligned}
& M I= \\
W= & \text { theel load in lips for single axle arrangements } \\
& \text { with tandem arle wheel loads equal to } 1.10 \\
& \text { times an individual wheel load and. } \\
r= & \text { number of load applications. }
\end{aligned}
$$

In the actual stabilometer design process, all vehicles of the anticipated traffic strean are grouped into imposed 
wheel load categories. With appropriate equivalent 5-kip wheel load factors as derived from equation 18 and the bastc stabilometer desion equation 20, a. total equivalent 5-1sip wheel Joad guantity is determined. This equivalent wheel load value is calculated as the sum of the products of wheel load factors and corresponding wheel load repetitions for the various load Groupings. This traffic factor is primarily used to expedite the determination of the traffic index through the followine empirical relationship:

$$
T I=1.30(\mathrm{EWI})^{0.12}
$$

where $\quad I I=$ traffic index and

EWL $=$ total equivalent 5000-Ib wheel loads.

In the solis investigation prosram of the highway subgrade. a resistance value is determined to account for subgrade effects in the California Stabilometer design process. This resistance value of soil primarily indicates the ratio of applied vertical pressure to transmitted horizontal pressure. Greater resistance values imply better load carrying roadbeds and consequent]y thinner pavement structures. Other measurements of the subgrade material such as exvdation pressures or expansion pressures are made in the soils testing phase of the design process, but in this research these soil factors were neglected, and the resistance value was assumed to govern in determining the design thickness.

While cohesiometer values can be determined by breaking cylindrical test specimens, average cohesion values for 
paving materials are generally assumed in this procedure for designing the components of flexible pavements. This measure chiefly indicates the ability of pavement materials to resist deformation or displacement, but modvius of rupture values of the material multiplied by 45.0 are adequate approximations of the cohesiometer value.

\section{Rigid Pavement Design}

The load-carrying capacity of concrete highways is derived primarily from the "beam" characteristics of the slab rather than from the load distributing action which characterizes layered pavement systems. Consequently, flexural strensth of the pavement is a major factor considered in the formulation of the selected rigid design techniques. The modulus of rupture measure of flexural strength comoined with a measure of traffic loads and with a subgrade parameter is usually sufficient to determine desinn thickness. Although environmental effects are thought to exert a significant influence on the performance of flexible and rigid pavements, the AASHO Rigid, Corps Ricid and FCA Rigid techniques do not explicitly account for this factor in the principal design process examined.

\section{AASHO Interim Design Wethod for Risid Pavements}

Conceptual Development of the AASHO Interim Design Guide for Rigid Pavements. (2, 11) The AASFO Rigid pavement desien method ras developed from traffic load-pavement structure- 
pavement performance relationships that were established from the AASHO Road Test conducted at Cttara, IIlinols. A mathematical relationship among axle applications. serviceability trends and pavements structures was obtained from the same type of analysis that was utilized in the development of the AAsHo Flexible pavement design method. Written in specific terms of 18-rip single-axle load applications, initial and terminal serviceability indices and pavement thiclmess, that equation is shown below:

$$
\operatorname{Ios} \because=7.35 \operatorname{IoE}(D+1)-0.06+\frac{\log \frac{c_{0}-p}{c_{0}-1.5}}{1+\frac{1.624 \times 10^{7}}{(D+1)^{8.46}}}[22]
$$

where $\quad y=$ total number of 18 -irip single-axle load applications.

$D=$ concrete parement thiciness (inches),

$c_{0}=$ initial serviceability index and

$p=$ terrainal serviceability indox.

Eecause this equation only applies to those conditions which existed at ottawa, theoretical considerations were used to extend the Road Test findings to other subgrades and to varying concrete strengths. Tests of their physical properties established the concrete modulus of elasticity as equal to $4.2 \times 10^{6} \mathrm{psi}$. the modulus of subgrade reaction as equal to 60 pci and the concrete rnodulus of rupture as equal to 690 psi. Combining these values with theoretical stress analyses and empirical considerations of load applications, stress ratios and performance led to the following basic 
form of the AASiO Rigid pavement design equation:

$$
\begin{aligned}
\text { IоE } V= & 7.35 \log (D+1)-0.06+\frac{\log \frac{c_{0}-p}{c_{0}-1.5}}{1+\frac{1.624 \times 10^{7}}{(D+1)^{8.46}}} \\
& +(4.22-0.32 p) \operatorname{Ios}\left[\frac{\rho_{t}(D \cdot 75-1.132)}{690\left(D \cdot 75 \frac{15^{\cdot 25} 18.416}{25}\right)}\right]
\end{aligned}
$$

where

$$
\begin{aligned}
r_{t}= & 0.75 x \text { modulus of rupture of concrete }= \\
& \text { iorking flexural strength (pounds per } \\
& \text { square inch). } \\
r= & \text { modulus of suiperade reaction (pounds per } \\
& \text { cubic inch) and } \\
\mathrm{E}= & \text { modulus of elasticity (pounds per square } \\
& \text { inch). }
\end{aligned}
$$

Whickness design charts were prepered from this expression rom vexying traffic conditions, working flexurel strengtis and subgrade moduli. The puilished charts are reproduced in Apvendix D For a constant modulus of elasticity $(E=4,200,000$ psi) End tro values of terminal serviceability $(p=2.0$ and 2.5).

Parameters of the AABO Desim Vethod for Birid Pevements.

(2, 11) As evidenced from the basic desien equation 23 and the published desion charts, the concrete pavement thiclness depends on the number of 18-hip single-axle load applications, the initial and terminal serviceability indices, the flexural stronetis of concrete and the nodulus of subgrade reaction. Although the modulus of elasticity. Foisson's ratio and the radius or contact are possible design variables, all three 
are assumed rized values in the acturl design process. This reduces the pavins material parameters to a single working rlexural strength desisn variable which is calculated as the modulus of mupture modified by a factor of saiety.

Subgrade influences on $\triangle A B F O$ design thicknesses are estimated in terms of the modulus of subgrade reaction. Whie experienced judment or other correlated soil tests are often employed in determining this variable, actual evaluation is occasionaly required. Standard test procedures recommend that the pressure applied to a 30-in. diameter plate and divided by the resulting subgrade deflection adequately defines this subgrade parameter.

Traffic influences on pavement thichess are described by the equivalent 18-kip single-axle load application measure which sumarizes the traffic loods and repetitions anticipated for the service life of the pavenent. Determination of this parameter is dependent on the ricid pavenent equivalence fictors which convert axle loads of a mixed traffic stream to 18-kip single-arle loads. These equivalence factors differ from the AASIO Flexible equivalence factors, reflecting the difierences in the relative destructive effects of axle loads when imposed on flexible versus ricid pavements. The risid axle load equivalence factors are the ant1logarithms of equations 24 and 25 ror single and tandom axle arrangements:

$$
\log \left(W_{18} / H_{Y}\right)=4.62 \log [(x+1) / 19]+\frac{G}{\beta_{18}}-\frac{G}{B_{x}} \quad[24]
$$




$$
\begin{aligned}
\log \left(H_{18} / \mathrm{H}_{X}\right)= & 4.62 \log [(x+2) / 19]-3.28 \log (2.0) \\
& +\frac{G}{\beta_{18}}-\frac{G}{\beta_{x}}
\end{aligned}
$$

where

$$
\begin{aligned}
& W_{18}=\begin{array}{l}
\text { number of } 18-\text { lip single-axle load } \\
\text { applications. }
\end{array} \\
& W_{\mathrm{x}}=\begin{array}{l}
\text { number of } \\
\text { axle load applications, }
\end{array} \\
& x=\text { arle load in kips for which equivalence } \\
& \text { factors are being calculated, } \\
& G=\log \frac{c-D}{c-1.5}=\text { serviceability function, } \\
& \beta_{10}=1.0+\frac{1.624510^{7}}{(D+1)^{8.46}}=\text { beta function for } \\
& \text { 16-kip single-arie loads and } \\
& \beta_{x=}=1.0+\frac{3.63\left(x+I_{2}\right) 5.2}{(D+1)^{8.64 I_{2} 3.52}}=\text { beta function } \\
& \text { for the axle load and arrangement } \\
& \text { considered where } I_{2}=1 \text { for single } \\
& \text { axles and } I_{2}=2 \text { for tandem axles. }
\end{aligned}
$$

The surmation of the number of axle loads times the appropriate equivalence factors yields the total number of equivelent $18-$ Irip sincle-axle load applications.

The inclusion of the initial and teminal serviceability indices in the desien equation allows for explicit consideration of the road users' subjective denands. The initial serviceability index indicates the rating of a pavement just open to traffic, while the terminal serviceability index denotes the riding quality of pavements first judged inadequate. 
Corps of Engineers Ricid Pavement Desien liethod for streets and Roads

Conceptual Development of the Corps of Engineers Design Lethod for Risid Favements. $(6,13)$ The current Corps of Engineers rigid pavement design method was developed to permit greater flexibility in the evaluation of the influences on design of vehicle axle and wheel arrangements, load repetitions and various magnitudes of traffic loads. While previous Corps techniques employed a single design load to describe traffic loadine effects, the revised Corps Ricid method sumarizes the traffic characteristics into a design index parameter which is readily determined from visual measurements of traffic volune and composition.

Development of the Corps Rigid technique simificantly depended on empirical relations for afreield loading conditions; however, these relationships were adapted to hi ghway pavement design so that various trafric loads were quantified in terms of a 18,000-Ib base load. Ranges in the number of repetitions of thet base load specify design indices from 1 to 10. These values are eriployed in the design process to describe various combinations of road and street classifications and traffic caterorics.

Design thiclness is actually determined sraphically with the Corps Rigid design chart shown in Appendix E. While the chart was derived from the theoretical stress analyses of H. H. Westergaard, a mathematical solution to these sraphical relationships of desigin index, modulus of subgrade reaction 
and modulus of rupture is not available. Freparation of the design chart depended significantly on empirical data and included a 1.55 safety factor which compensates for load impact and for fatigue due to load repetition. Invironrental effects are not considered in the primary desien procedure, but separate procedures for delimiting the thiclness required to counter frost action are available.

Parameters of the Corps of Engineers Desian Method for Rigid Highway Pavements. $(6,13)$ Traffic, paving material quality and subgrade support are the three major factors in the Corps Rigid design process that are required to determine the thickness of pavement structures. These factors are estimated by the design index, the modulus of rupture and the modulus of subgrade reaction, respectively.

"Whe modulus of rupture is common to most prominent rigid pavement design methods and is determined by beam-breaking tests. Phe flexural strengtin fol a 28 -day curing tine is talen as the desien value. While the modulus of elasticity of concrete and Poisson's ratio are other parameters indicative or paving material properties, these factors were held constant at 4,000,000 psi and 0.20. respectively, throughout the development and in the application of the corps rigid technique. Whe modulus of rupture, therefore, is the primary pavine material desisn variable.

The modulus of subgrade reaction is the principal design variable describins supporting power. This soil varameter is 
determined by measuring the load placed on the subgrade in pounds per square inch and by dividing that pressure by the resulting subsrade deflection neasured in inches.

Traffic influences on the required pavement thickness are estimated by the design inder which reflects the number of coverages or repetitions of an 18,000-lo single-axle dualWheel loading. While development of the design indez paraneter was complicated by the adaptation of airfield pavement relationships to hichway conditions, the determination of index values to use in actual desien only requires ascertaining the volume and the composition of the anticinated traffic stream. Anticipated traffic volumes permit classification of the highway into twelve classes designated as a road or street of letter A, 3. C. D, E or F iclentification. This highway desicnation is primarily indicetive of traffic load repetitions. The vohicular composition of the traffic strean is measured by the percentase of passenser cars, pancl and piclup trucls, 2-axic trucks and buses, 3-axle, 4-axle and 5-axle truclss and categorizod into four traffic categories iclentified by roman numerals I, II. III and. IV. The design index parameter is determined from Taile $E 1$ of Appendix $\mathrm{E}$ for the selected highwy classification and traffic category.

\section{Fortland Cement Association Desich rethod for Rigid Pavement}

Conceptual Development of the FCA Rigid Iaverent Design Wethod. $(5,16,17,19)$ Theoretical studies by F. IV. hestercuard, G. Piclet and others were the primary basis for 
the Portland Cement Association design method for concrete slabs. In addition, field performance data from experimental pavements and existing concrete roads vere used to verify or modify the theoretical results. Studies of the flezural stresses induced in pevements by various vehicle load positions along with observations on the lateral distribution of vehicles in the traffic stream prompted the use of the equation below to calculate the govemine pavement stresses. This equation corresponds to the "protected corner" equation of earlier FCA ficia techiniques:

$$
\sigma=\frac{1.68 p}{d^{2}}\left[1.0-\frac{\sqrt{a / 1}}{0.925+0.22 a / I}\right]
$$

Where $\sigma=$ maximum tensile stress for a load anpliod at the slat comer formed by a transverse joint and the pavement edse (pounds per square inch),

$I=$ static desion load for dual meel axles (pounds),

$\mathrm{d}=$ pavernent thickness (inches),

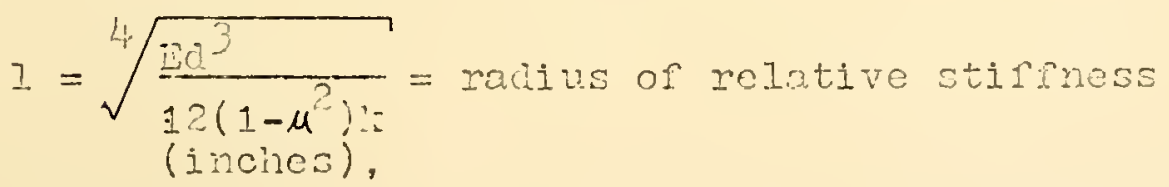

$E=$ modulus of clasticity of the paving concrete (pounds per square inch),

$\mu=$ loisson's ratio or the concrete and

$\mathrm{F}=$ mounius of smograte reaction (nownds per cuib incin).

Becausc hishay parcments exrericnce many repetitions of assorted vehiculam loading, fatioue cifocts are civen proninent consideration in the PCA Raid technque. Fatigne failure is observed vihen meny repetitions of stresses that 
are beloit the maximun static stress cause the pavement to rupture. The number of stress repetitions that can be sustained depends on the stress ratio. The measure is specified as the retio of the load-induced flexural stress, that is calculated by equation 26 , to the modulus of ruvture for the concrete. An mimited number of load renetitions is conceptually possible if the stress ratio is lass than 0.50 . When this ratio is greater than 0.50 , the allomable numer of stress repetitions as specified by rei sre shown in Fisure 1 of Appendiz: $\mathrm{F}$.

With stress ratios specifying the nuner of repetitions pomitted before fatione failure occurs, anticipoted arle load repetitions are compored to the allowale repetitions as a percentage ratio of "fati we resistance consured." The assurneci parement thiclness is aclequate if the sum of the percentages of anticipated to allombic repetitions (percentare of fatisue rosistance consumed) for all arle load classes is less than 125 percent.

larameters or the ECA Desim iethor ros Concrete Iavements. $(5,16,17,19)$ ioduzus of rupture, modulus of elasticity and Foisson's ratio are the three properties that are explicitly incorcorated into the Fortind cemend design equation 26. The lattex two parneters are scidom considered as vavenent desisn variables and are assumed to have constant values of $4,000,000$ psi and 0.15, respectively. Thus, the modulus of rupture becomes the primary measure for estimating the influence of 
the paving material on the required thickness of the concrete structure.

While flezural strencth accounts for resistance to the bending of the concrete slad, the modulus of subsrade reaction provides an estimate of the support offered by the suigrade and subbase matcrials. Lire most other parameters that measure soil properties, this modulus is si Gnificantly influenced by searonal weather effects. However, these enviromental factors are presently neclected in resolving pavement thicknesses. ¿olmal subrrade measurenents mace during; the sumer or fall are considered as reasonable desien values.

The Fortiand Cement Association desien procedure accounts for traffic conditions by estimating the nunber and reight (augrented by a factor of safety) of axle loads that are anticipated durin: the pevement service lifc. This information is then utilizec in detemining the fatiouc resistance consunca. Volume estinates are based on averace daily traffic measurements and on yearly rates of traffic erouth, traffic projection factors or on lane capacities. The weint characteristics of the anticipated traffic volune and the axie load information needed for design are deternined from loadoneter and vehicle classification surveys. While the radius of contact appears to be a desinn variable associated with traffic influences, it is seldom measured for specific design projects. Instead, averace values supplied by tire manufacturers are speciried by the PCA. 


\section{RESULTS}

The analysis of design techniques in this research investigation was devoted to identifying and examining those factors that significantly influence the desion of flexible and rigid highway pavements. Based on the findings of this analysis, a synthesis of parameter-thickness data was performed to develop simplified design methods for rigid and flexible pavements. Six selected techniques which are representative of current pavement design practice were the primary sources of information on which this study was predicated.

\section{Flexible Pavement Design}

The three flexible design techniques selected for investigation were the AASHO Flexible, the Corps of Engineers Flexible and the California stabilometer design methods. Each method was analyzed to determine a hierarchy of design logic, to develop a suitable model for the sensitivity analysis, to evaluate in the sensitivity analysis the relative theoretical and practical importances of the design parameters and to examine tolerable parameter variations. Iinear, quadratic and cubic models were fitted to parameter-thickness data that were assembled for each techntque. These equations afforded additional bases for analyzing flexible pavement design and enhanced the possibility of a simplified design method. 
AASHO Flexible Pavement Design

Design-Process Logic. The fundamental relationship between the total number of 18 -kip single-axle load applications, pavement thickness and initial and terminal serviceability indices is expressed by equation 11 which is presented in the Review of Design Methods. This relationship was extended to include environments and subgrades other than those of the Ottawa test site through the development of the design nomograph that is reproduced in $A$ ppendix $A$. Thus, graphically soil support value and regional factor are related to the traffic, serviceability and pavement thickness.

The hierarchy ordering of items involved in resolving flexible pavement thicknesses by the AASHO Flexible design process is illustrated in Figure 5. Explicit incorporation of the serviceability concept into the thickness design is evident in the logic of this procedure and is rationally appealing, but the derivation of actual thicknesses from the structural numbers by the use of layer property coefficients, which are presently undefined by laboratory tests, is also noticeable. Because of the uncertainties that accompany these coefficients, the soll support values and the regional factor parameters, the application of this design techniques is considerably weakened when applied to areas where environment. subgrade and paving materials are different from those at the AASHO Road Test site in Ottawa. Illinois.

The items of soil support value, initial and terminal serviceability indices, traffic factor and regional factor 
Find 1

Product
First
Second
Third
level
Level
l.eve]

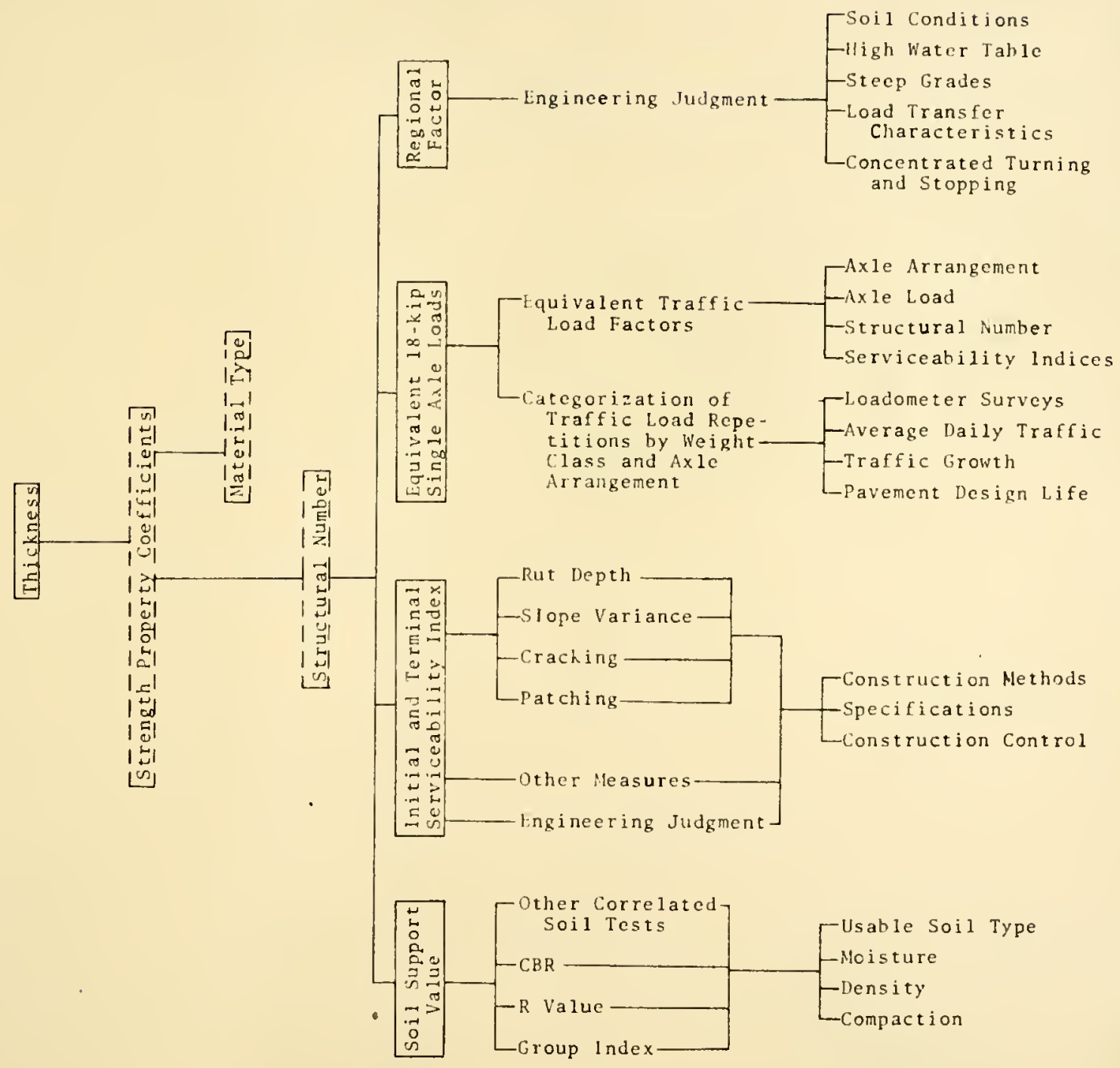

Figure 5. Hierarchy Structure of AASHO Flexible Design-Process Logic 
which are boxed in the hierarchy chart are the major design variables of the AASHO Flexible technique and consequently they were the principal factors evaluated in this study. Considerations of subgrade swelling pressures, frost heave, reduced strength or other special problems are not explicitly examined in the AASHO Flexible design method, and techniques other than those described in the AASHO Flexible procedure are required for the solution of these special design problems.

\section{Modeling of the AASHO Flexible Pavement Design Technique.}

A model of the MASHO Flexible design method that is totally expressed in a single mathematical equation was needed to carry out this research investigation. While avaliable nomographs graphically relate most of the design parameters employed in determining the required pavement thickness, the soil support value and regional factor are absent from the design equations presented in the literature. Therefore, the model desired for the sensitivity analysis was derived from the design nomographs and was based on the principal relationship expressed in equation 11. The derived AASHO Flexible model, which is symbolically written below, presents in equational form the design relationships which have only been graphically related.

$$
\begin{aligned}
\log (W)= & 9.36 \log (S N+1)-0.20+\frac{\log \frac{c_{0}-p}{c_{0}^{-1.5}}}{0.40+\frac{1094}{(S N+1) 5.19}} \\
& +0.37756(S S V-3.0)-0.97 \log (R F) \quad[27]
\end{aligned}
$$


where

$$
\begin{aligned}
\mathrm{SSV} & =\text { soll support value, } \\
\mathrm{RF} & =\text { regional factor }, \\
\mathrm{SN} & =\text { welghted structural number, } \\
\mathrm{c}_{0}= & \text { initial serviceability index, } \\
\mathrm{p}= & \text { terminal serviceability index and } \\
W= & \text { total number of equivalent } 18 \mathrm{k} k \mathrm{p} \text { single-axle } \\
& \text { applications. }
\end{aligned}
$$

Further explanation of the derivation of the above equation is presented in Appendix $A$. The validity of the derived sensitivity analysis model was substantiated by a comparison of weighted structural numbers calculated by the above equation with values determined from the design nomographs.

Sensitivity Analysis of the AASHO Flexible Design Method. The sensitivity analysis of the AASiO Flexible pavement design method evaluated the relative importance of the soli support value, initial and terminal serviceability indices, equivalent 18-kip single-axle load and regional factor as their significance affected the structural design of flexible pavements. These parameters were evaluated by a theoretical measure and by two practical measures of relative importance. These relative percentages of "a partial," "a thickness change" and "an actual thickness change" are defined in the Procedure of thic research report. For the sensitivity analysis of the AASHO Plexible design method, these measures of parameter importance are specifically indicative of the changes in. weighted structural number with respect to parameter changes. 
Partial derivatives of the weighted structural number with respect to the AASHO Flexible design parameters were needed to determine the theoretical and one of the practical measures of relative importance. These first-order partial derivatives are presented in Table A1. Because the MASHO Flexible first-order partial derivatives are dependent on the particular parameter values chosen for evaluation, the theoretical and practical parameter importance measures that directly depend on these derivatives are not constant but vary with the selected parameter values. Therefore importance measures were calculated for all combinations of a large array of design variable values but only the evaluations of the more common combinations are illustrated.

The theoretical parameter importance, that indicates the relative welght of each AASHO Flexible parameter in formulating the thickness function, was calculated for parameter value combinations encompassing the full range of possible soll support values, initial and terminal serviceability indices, regional factors and equivalent axle loadings. Summary plots of this sensitivity analysis are presented in Ficures 6, 7. 8 and 9 for parameter combinations of ten encountered in pavement design situations. The ordinate of these plots is the measure of relative theoretical parameter importance, and the abscissa is the AASHO Flexible traffic parameter as expressed by the equivalent daily 18-kip single-axle load applications. 


\section{AASHO FLEXIBLE DESIGN}

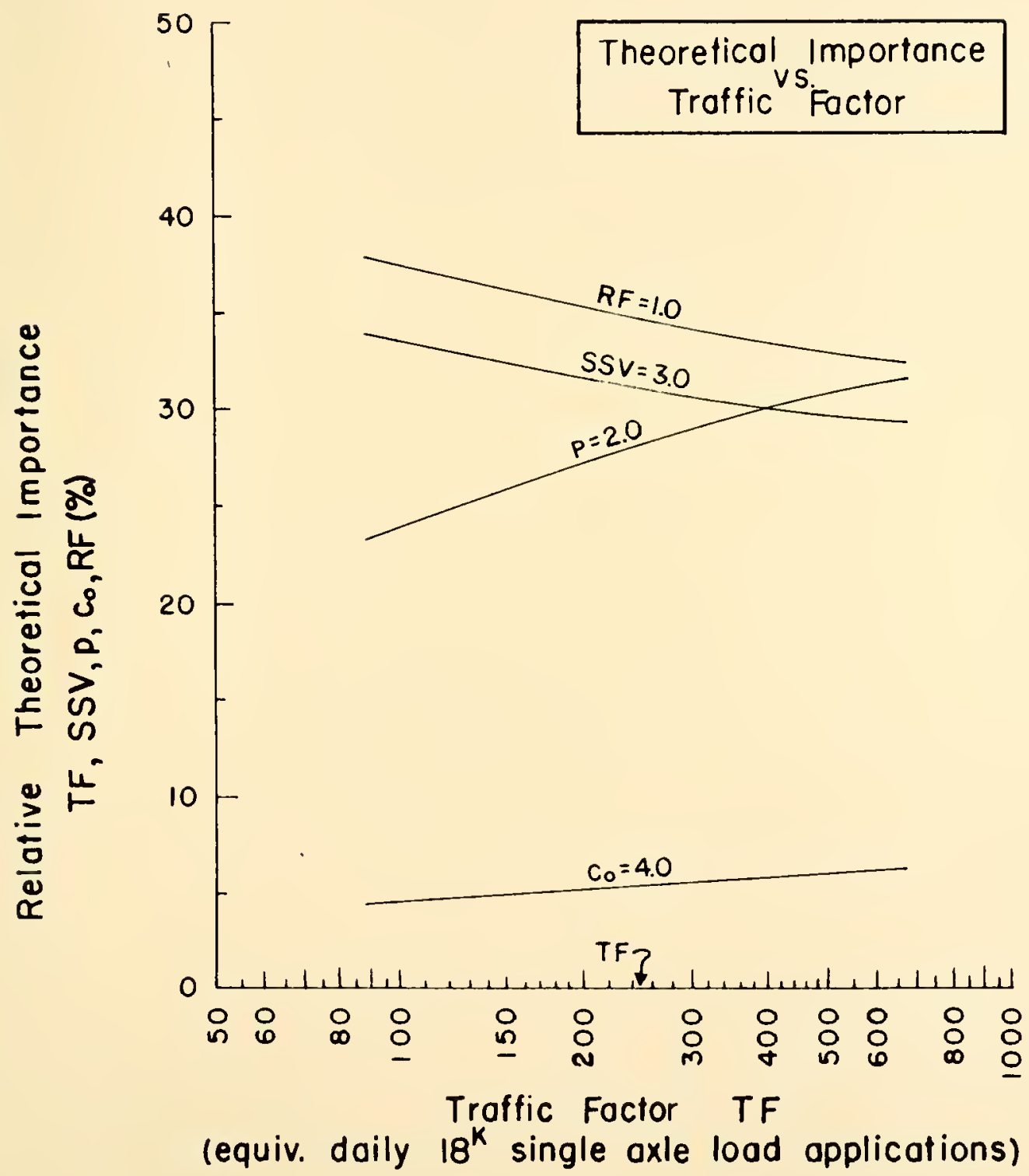

Figure 6. Relative Theoretical Importance of AASHO Flexible Design Parameters 
AASHO FLEXIBLE DESIGN

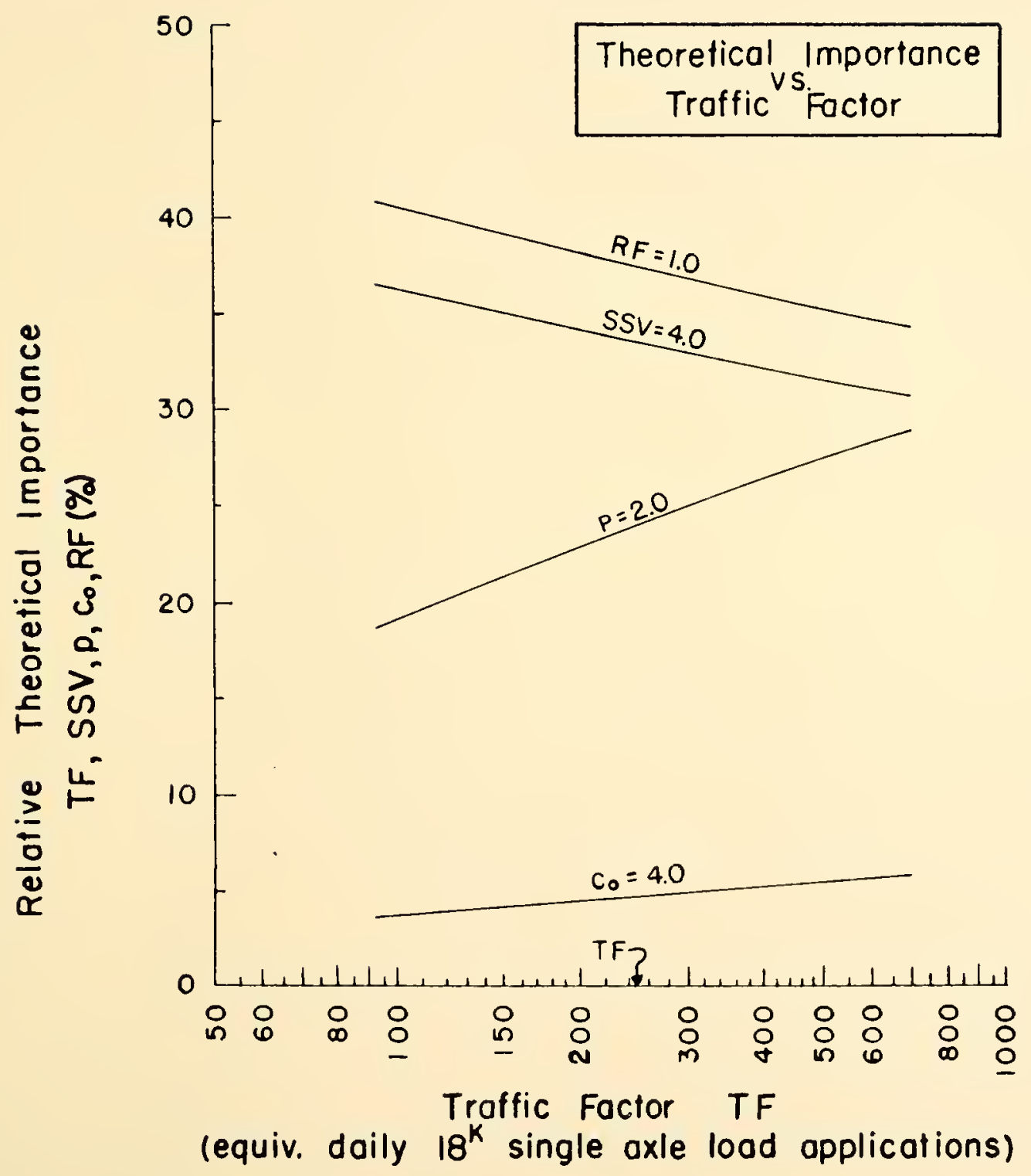

Figure 7. Relative Theoretical Importance of AASHO Flexible Design Parameters 


\section{AASHO FLEXIBLE DESIGN}

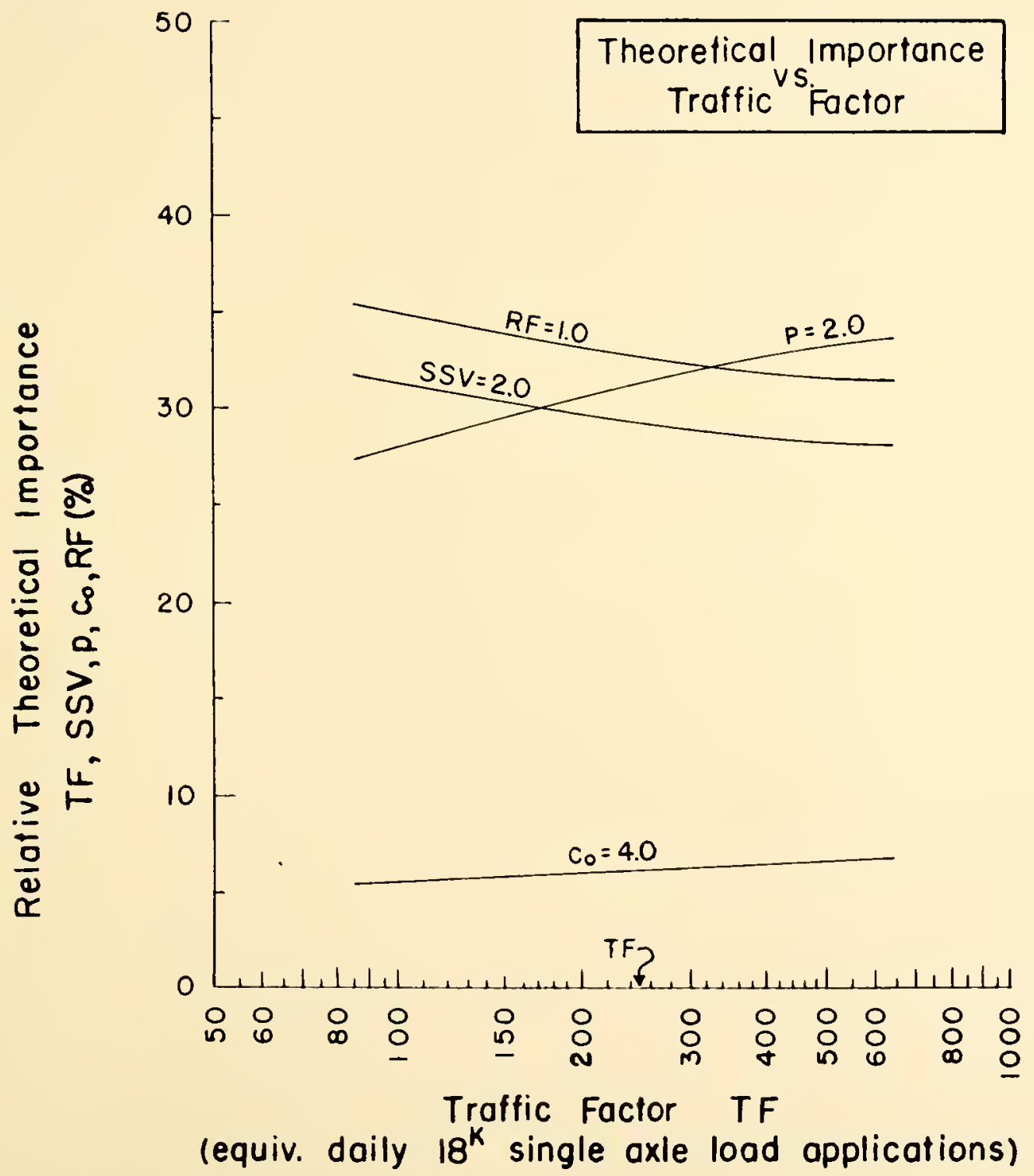

Figure 8. Relative Thearetical Importance of AASHO Flexible Design Parameters 
AASHO FLEXIBLE DESIGN

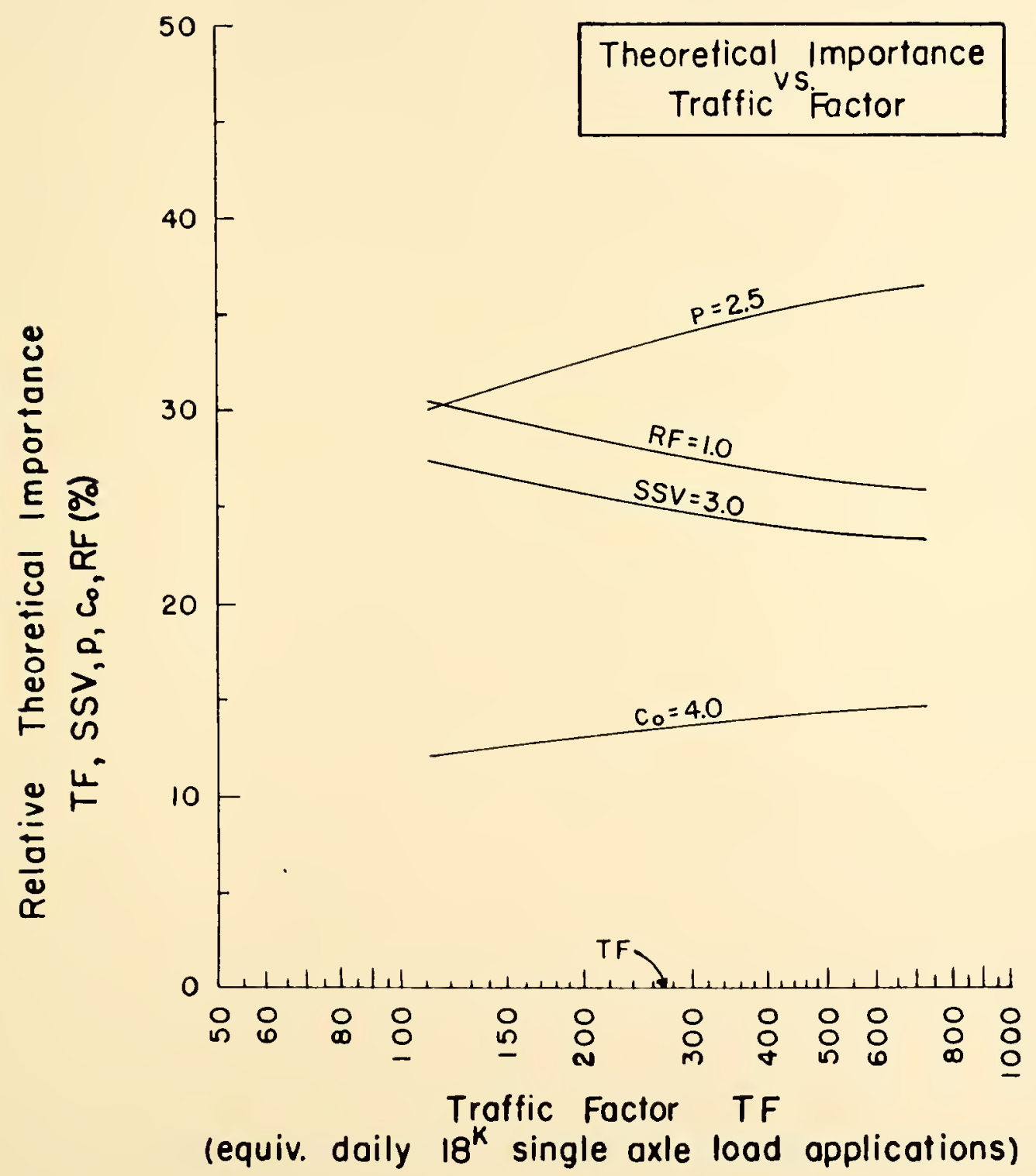

Figure 9. Relative Theoretical Importance of AASHO Flexible Design Parometers 
These plots of relative theoretical importance of AASHO Flexible parameters illustrate a measure of design factor significance with respect to the formulated thickness function for most traffic conditions. Because parameter values influence the theoretical "relative percentage of a partial" measure of parameter importance, each plot represents different combinations of practical values of the design parameters. An evaluation of parameter values reasonably indicative of average conditions for Indiana highways is shown in Figure 6 . Differences in Figures 7 and 8 from Figure 6 illustrate the magnitude of changes in the theoretical importance resulting from upper and lower deviations of soil support from an average value of 3.0. A change in terminal serviceability index from 2.0 to 2.5 causes the plot differences in Figure 9 as compared to the average conditions represented in Figure 6.

Examination of all four plots of theoretical parameter importance reveals the soil support value and reglonal factor to be most important in the formulated thickness function. A comparison of figures 6,7 and 8 indicates that stronger subrrades increase the importance of the soil support value and regional factor and diminishes the importance of the serviceability indices. However, a similar examination of Figures 6 and 9 discloses that with greater terminal serviceability index values an increase in the importance of both serviceability parameters occurs while subgrade and environmental factors assume less importance. If a soil support 
value of 3.0 , a regional factor of 1.0 , a terminal serviceability index of 2.0 , an initial serviceability index of 4.0 and a four-lane highway operating at 75 percent capacity for a trafflc stream composed of 20.0 percent trucks is regarded as a typical desion situation, then the approximate corresponding relative theoretical parameter importances are 31 percent for the soll support value, 35 percent for the regional factor, 28 percent for the terminal serviceability index and 6 percent for the inftial serviceablilty index. The AsSHO traffic parameter assumes a negligible degree of theoretical inportance. For increased volumes and magnitudes of traffic, the theoretical importance of the regional factor and soll support value decreases while the importance of the serviceability indices increases.

Two practical measures of relative importance were inst1tuted to evaluate pavement design factors in the context of the total design process. These measures represent a more realistic determination of parameter importance in the design process by accountine for the amount of variation that occurs in each factor. Finding representative parameter variations through experimentation is beyond the scope of this research project, and technical reports of these specific needs are lacking in the literature. However, rational determinations of parameter changes were made for reasonable variations encountered in usual design situations and are presented in Appendix $G$. Because the size of parameter changes influences 
the evaluation of practical importance, the chosen parameter increments were uniformly inferred to approximate one standard deviation of the "population" which the design value represents.

The incremental changes in the traffic factor are not a continuous function, but these values depend on increments of change in average dally traffic, percentage of trucks and weight classification of trucks. Ranges of practical 1mportance which represent various percentages of trucks and traffic volumes are depicted by the short horizontal lines and extended curves, respectively. For parameters of lesser importance, the short lines or extended curves are not distinguishable, and a single line adequately represents the ranges of these practical measures. The five short lines identify parameter importance for a traffic stream composed of 10-, 20-, 30-, 40- and 70-percent trucks, while, the three extended lines describe practical importance for a highway that carries the equivalent of 1200,1500 and 2000 cars per hour per lane. The capacity of a lane is established at $1500 \mathrm{vph}$. Because greater traffic factor values imply higher volumes of traffic or a larger vercentage of trucks, the conditions represented by each line can easily be ascertained. An illustrative example is shown in Figure 10 to indicate the arrangement of the figures for describing the practical importance of the various design parameters. Where similar presentations of practical importance measures occur this figure is referred to as a convenient means of 


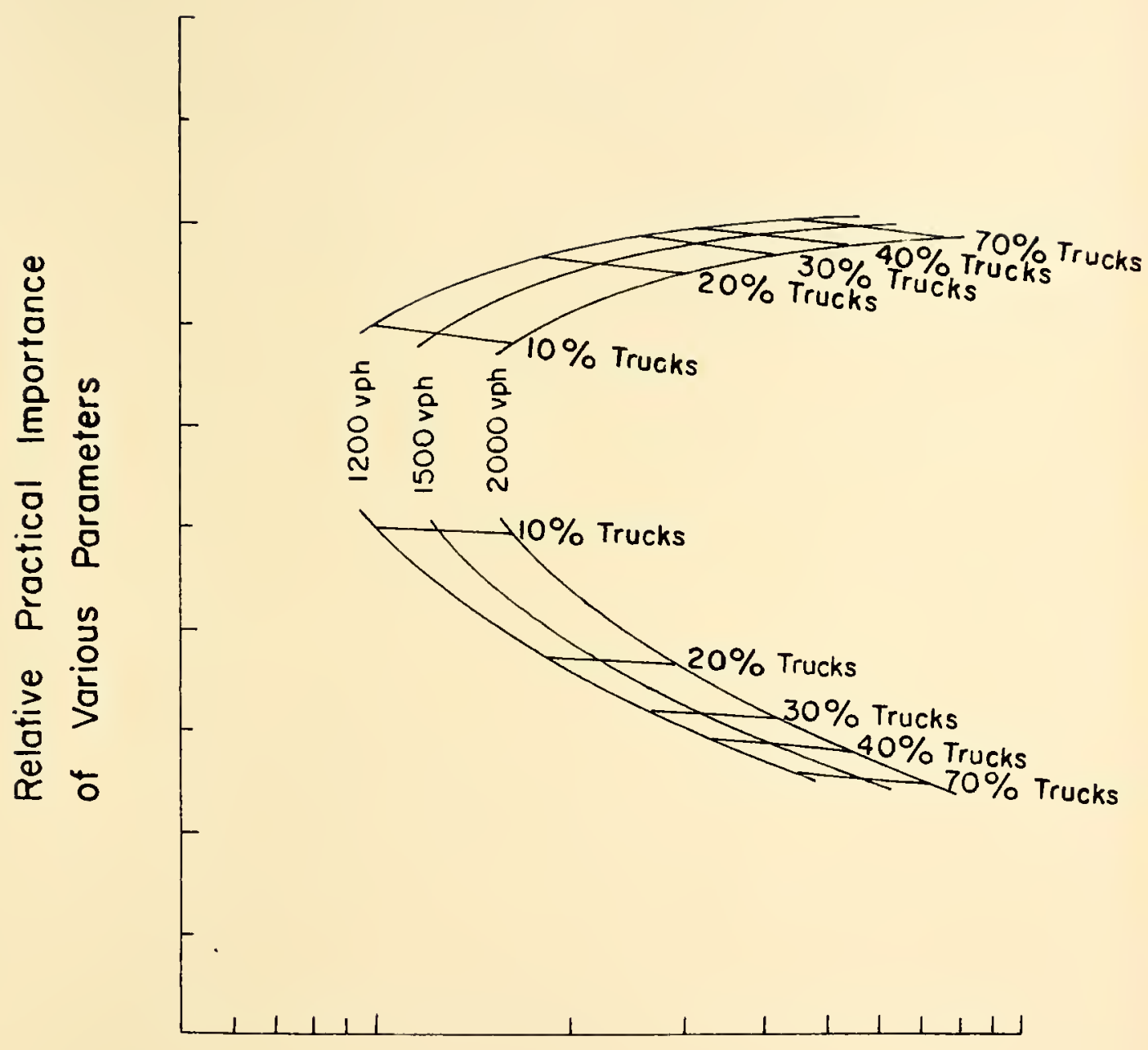

Traffic Parameter

Figure 10 Underlying Traffic Condition Indicated by Ronges of Proctical Parometer Importance 
identifyine the underlying traffic conditions indicated by each line.

The two practical measures of importance were determined for a large array of AASHO design parameter values. However, only evaluations of the more commonly occurring design situations described by various parameter values are presented in Figures 11, 12, 13, 14, 15, 16, 17 and 18. The first four plots of relative practical importance were prepared from data generated by the "portions of the total differential" approach which is described in the Procedure. The next four plots are founded on a corroborating "relative thickness change" determination. The near equivalence of the two practical measures, as evidenced by the calculations and as illustrated by the similarity of corresponding Figures reinforces the evaluated values of the relative practical importance of the desion parameters. The near equivalence also verifies the use of total differential for linear approximations of the AfSHO Flexible thickness function.

Because each plot of practical parameter importance versus traffic factor indicates the controlling importance of the AASHO traffic and subgrade parameters, the soil support value and the total equivalent 18 -kip single-axle load were concluded to be the two most important parameters influencing the design objective. As the weight and frequency of vehicular traffic increases, the traffic parameter becomes less important, and the soil support value and terminal 


\section{AASHO FLEXIBLE DESIGN}

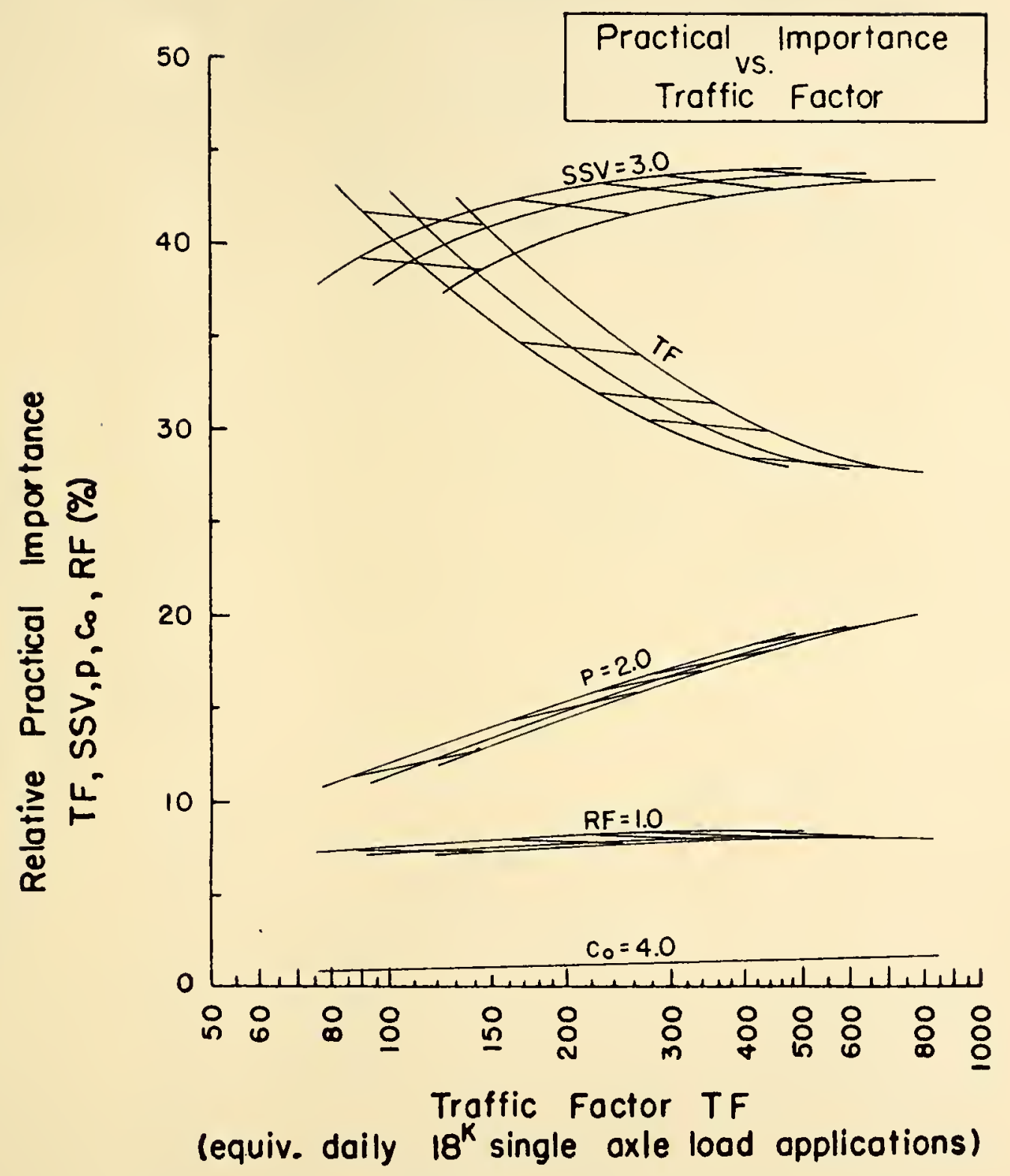

Figure 11. Relative Practical Importance of AASHO Flexible Design Parameters for the Total Differential Approach 


\section{AASHO FLEXIBLE DESIGN}

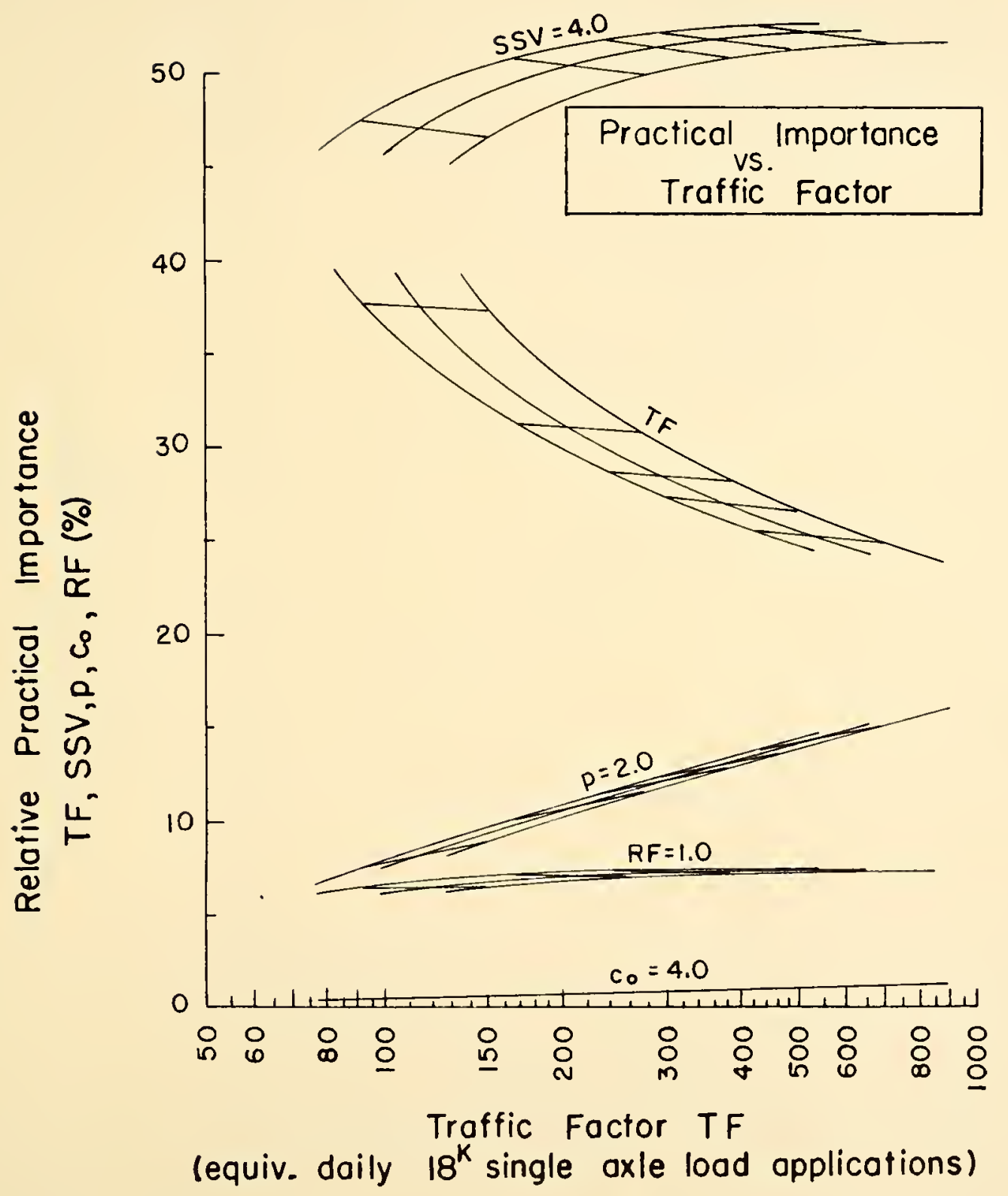

Figure 12. Relative Practical Importance of AASHO Flexible Design Parameters for the Total Differential Approoch 
AASHO FLEXIBLE DESIGN

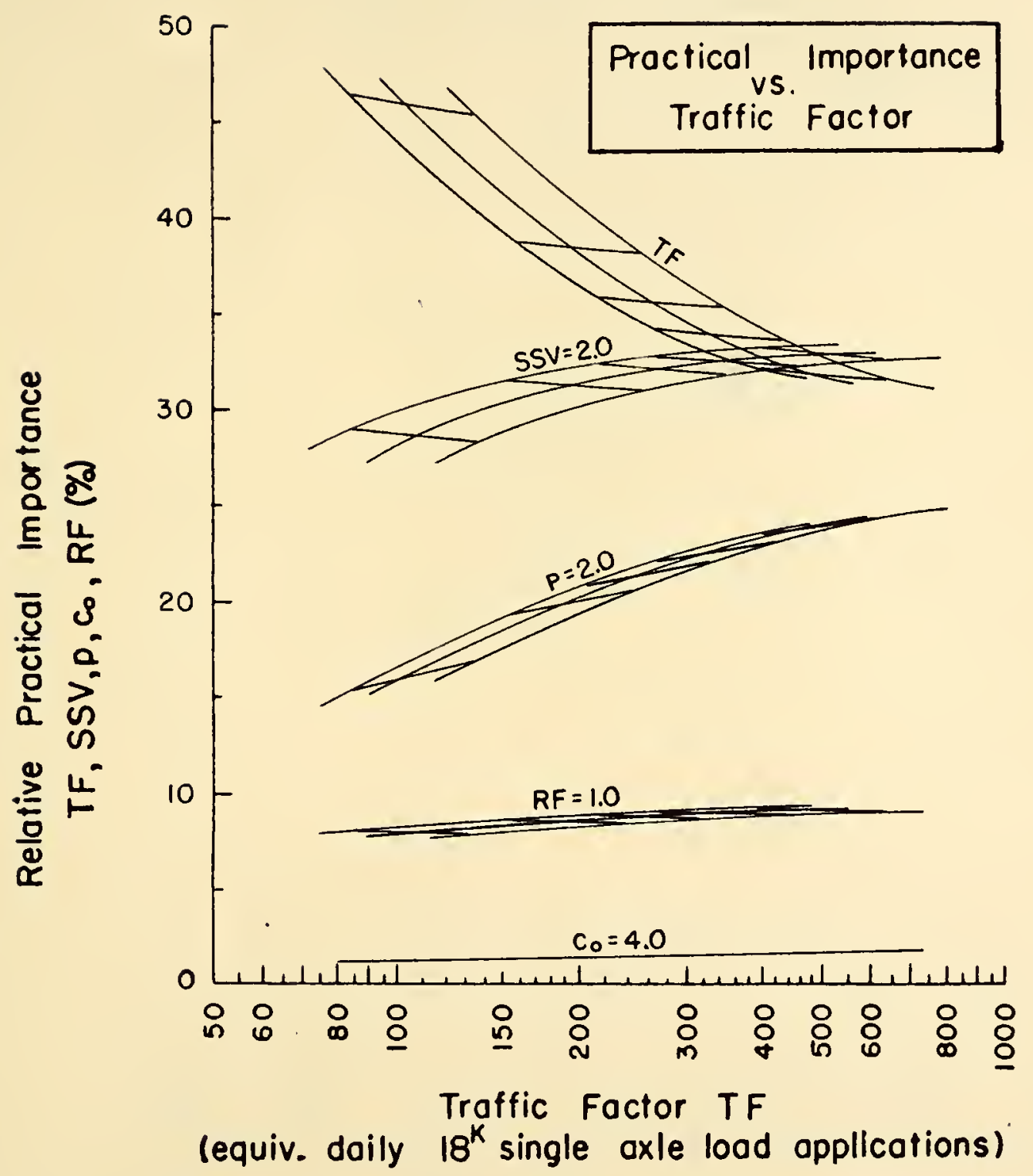

Figure 13. Relative Practical Importance of AASHO Flexible Design Parameters for the Total Differential Approach 


\section{AASHO FLEXIBLE DESIGN}

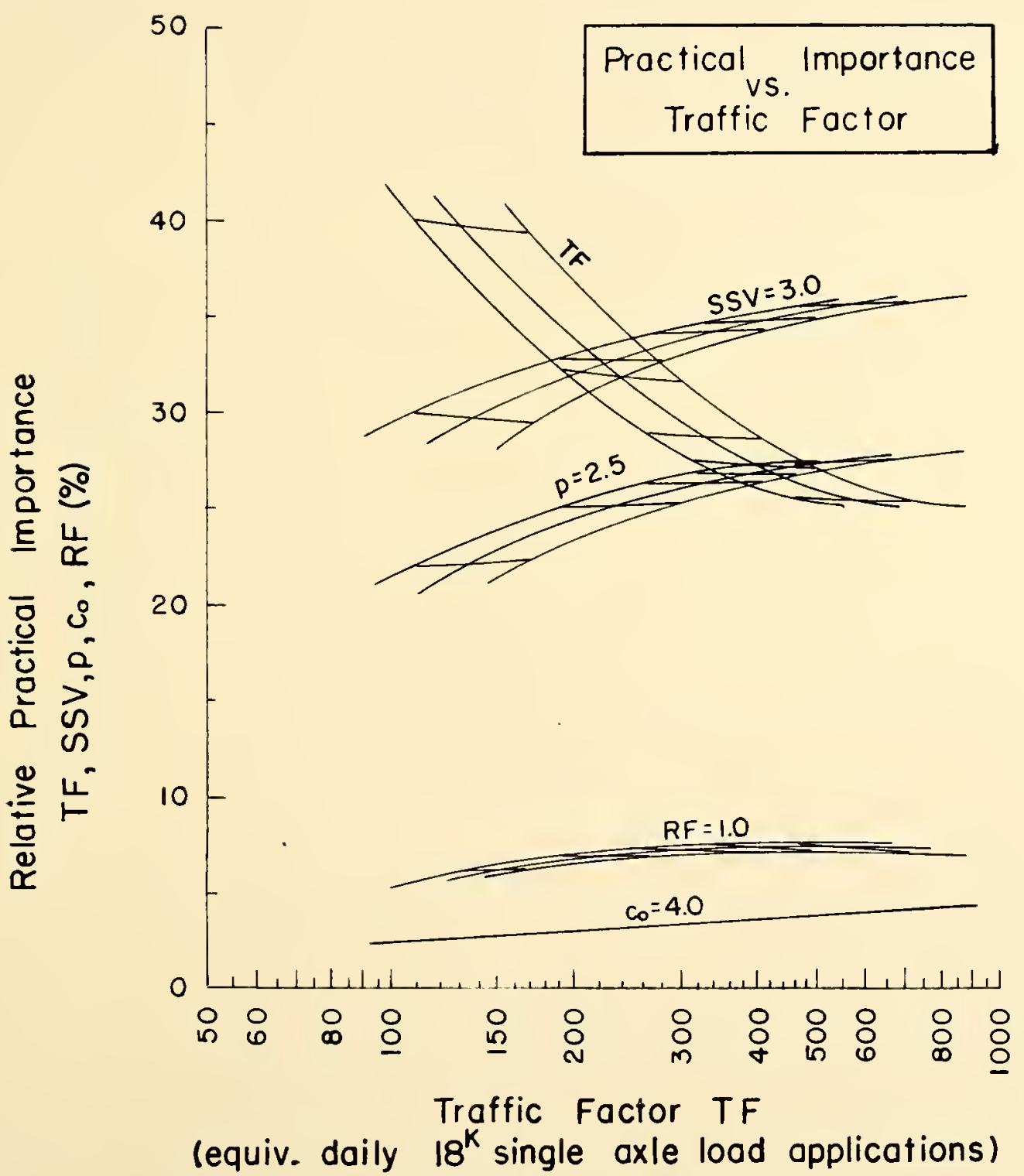

Figure 14. Relative Practical Importance of AASHO Flexible Design Parameters for the Total Differential Approach 
AASHO FLEXIBLE DESIGN

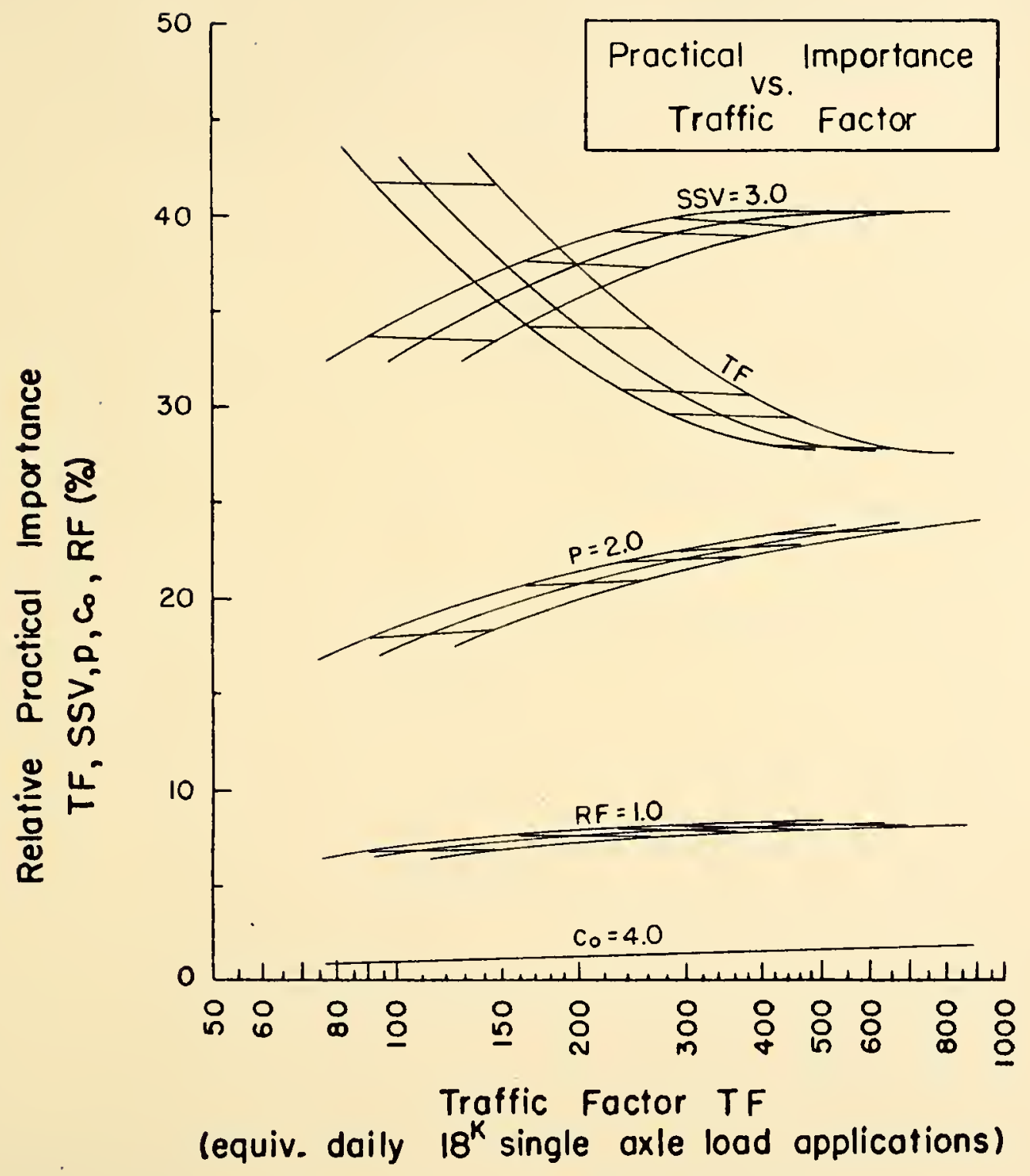

Figure 15. Relative Practical Importance of AASHO Flexible Design Parameters for the Actual Thickness Change Approach 
AASHO FLEXIBLE DESIGN

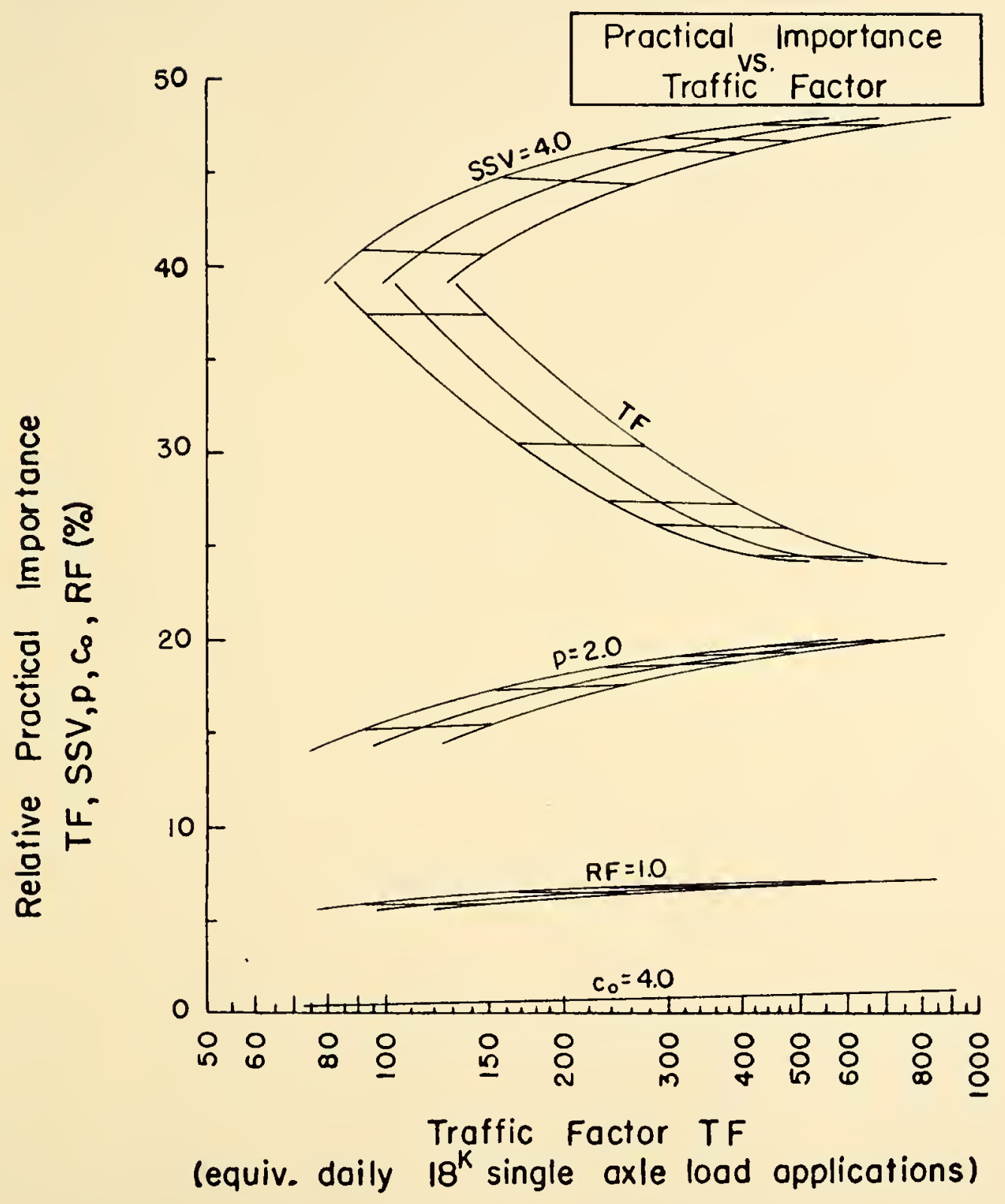

Figure 16. Relative Practical Importance of AASHO Flexible Design Parameters for the Actual Thickness Change Approoch 


\section{AASHO FLEXIBLE DESIGN}

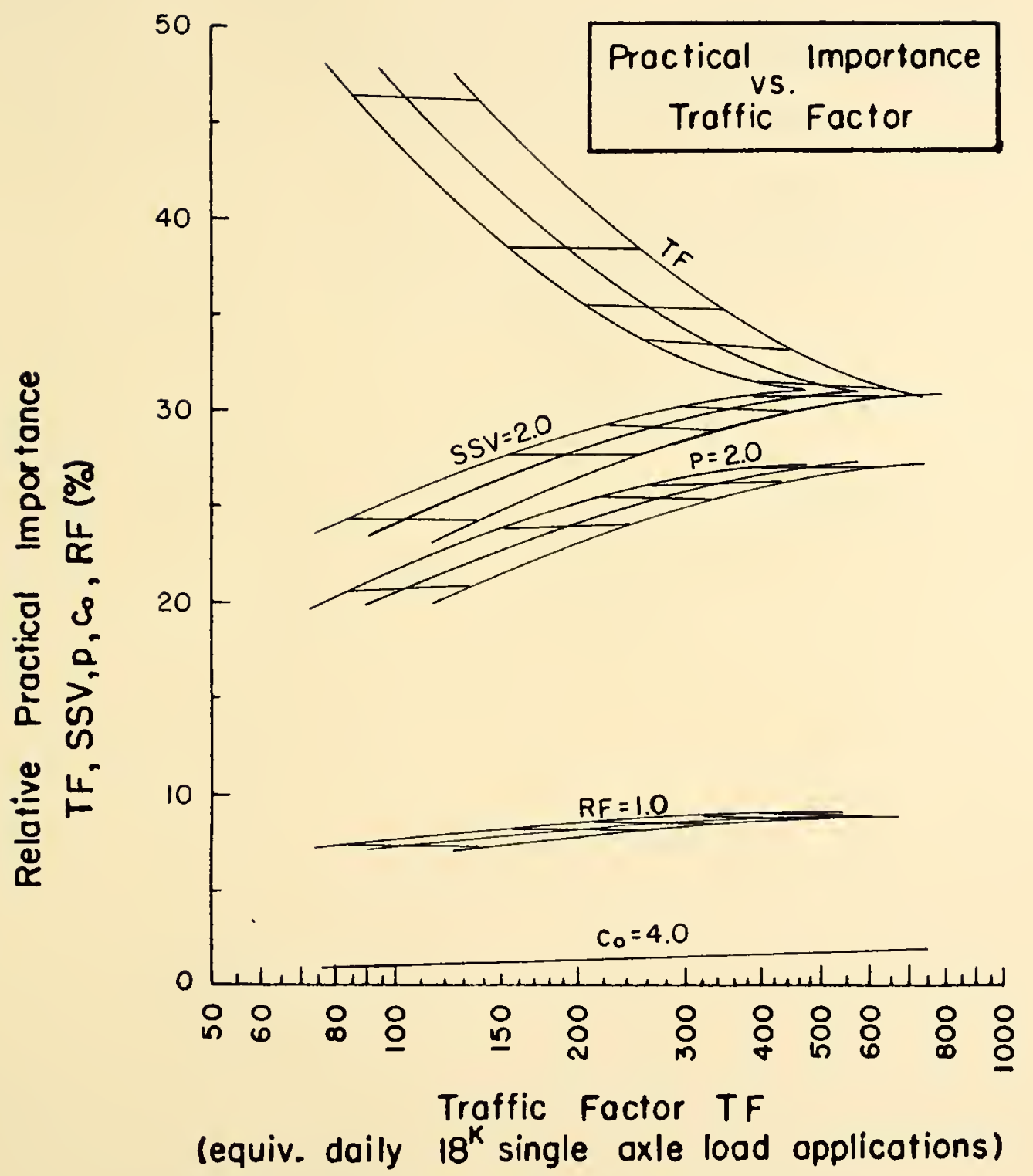

Figure 17. Relative Practical Importance of AASHO Flexible Design Parometers for the Actual Thickness Change Approach 


\section{AASHO FLEXIBLE DESIGN}

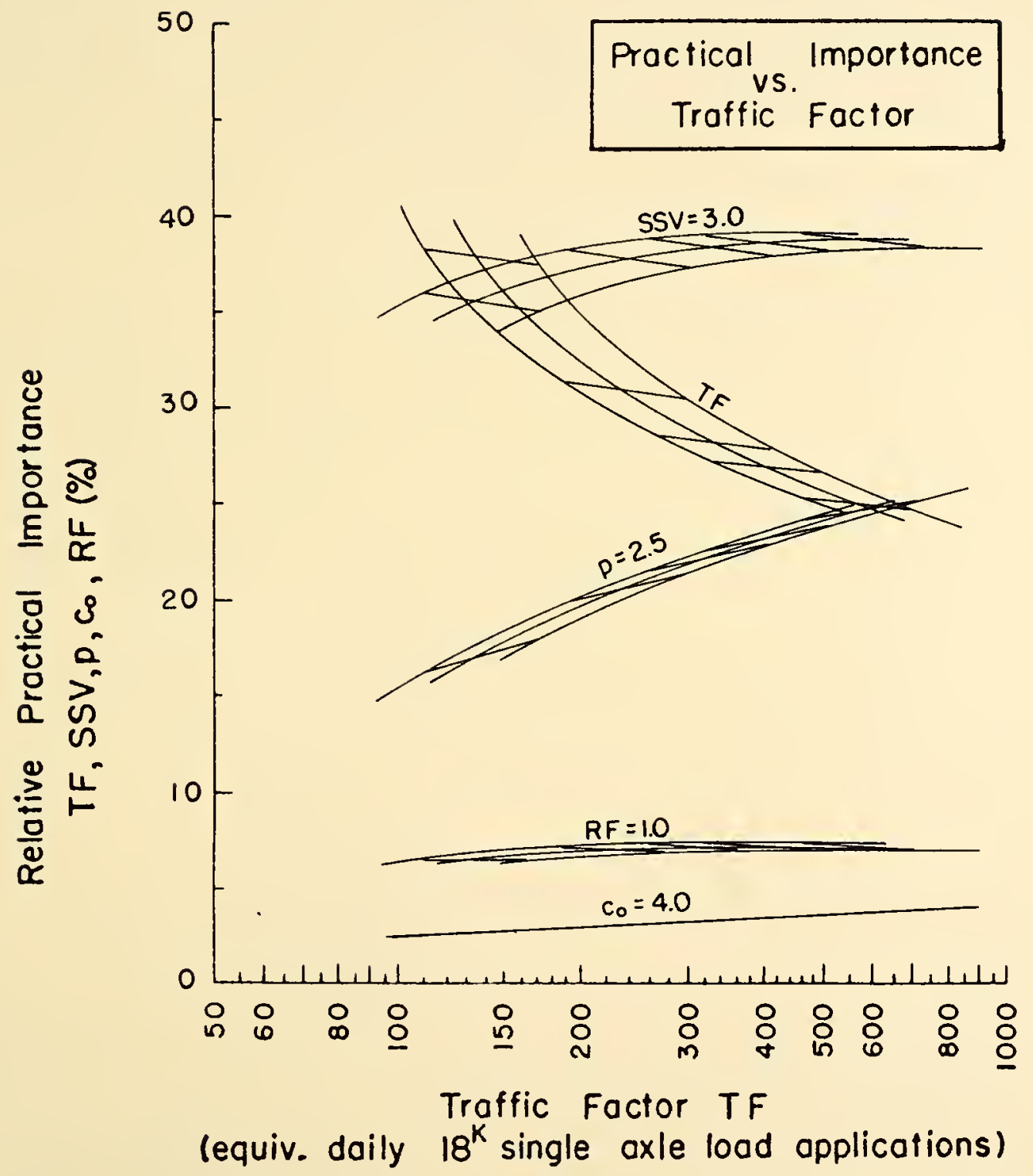

Figure 18. Relotive Practical Importance of AASHO Flexible Design Parameters for the Actual Thickness Change Approoch 
serviceability index assume an increasing importance in the determination of flexible pavement thicknesses.

If the same typical design situation as appraised for theoretical parameter importance was again assumed for a pragmatic evaluation of the AASHO design factors, then the relative practical parameter importances are 33 percent for the traffic parameter, 31 percent for the soil support parameter, 9 percent for the regional factor, 20 percent for the terminal serviceability index and 2 percent for the initial serviceability index. Differences of these percentages from those values discussed earlier in the theoretical evaluations are due to the comparable increments of changes determined for each parameter. While the AAsHo traffic parameter shows the most significant increase in practical importance as compared to the theoretical measure in which it had no influence, the regional factor exhibits the most prominent decrease.

Tolerable AASHO Flexible Parameter Varlations. To illustrate tolerable parameter variations, plots were developed for allowable precisions of one parameter versus that of another for 0.5-, 1.0- and 2.0-in. thickness changes. In addition, a major thickness change of $0.55 \mathrm{in}$. was selected to show precision requirements that are compatible with construction specifications and actual thickness variabilities. These selected constraints are expressed in terms of structural number changes which were assumed to be one-fifth the size of 


\section{AASHO FLEXIBLE DESIGN}

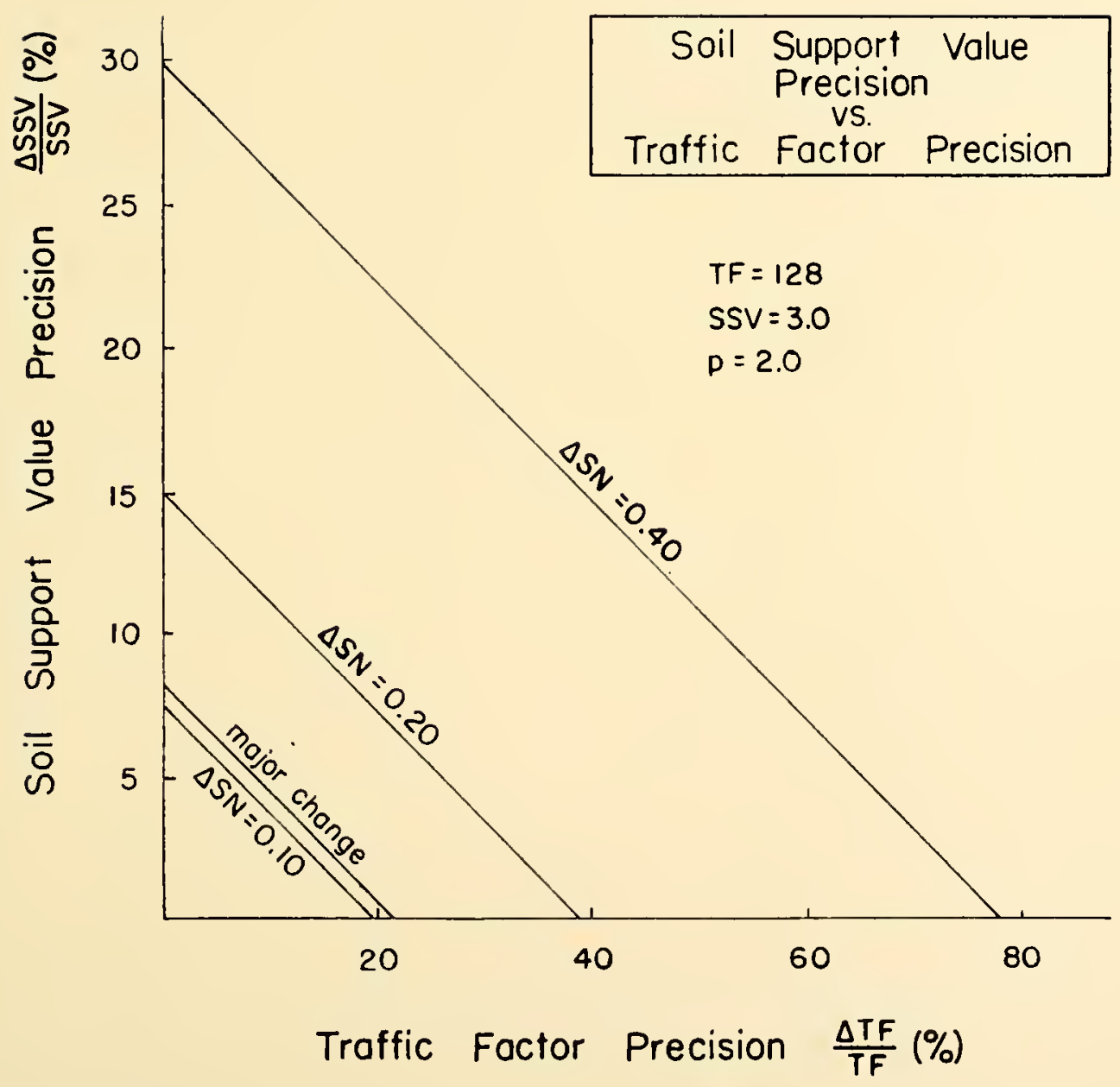

Figure 19. Tolerable Precision of AASHO Flexible Parameters 


\section{AASHO FLEXIBLE DESIGN}

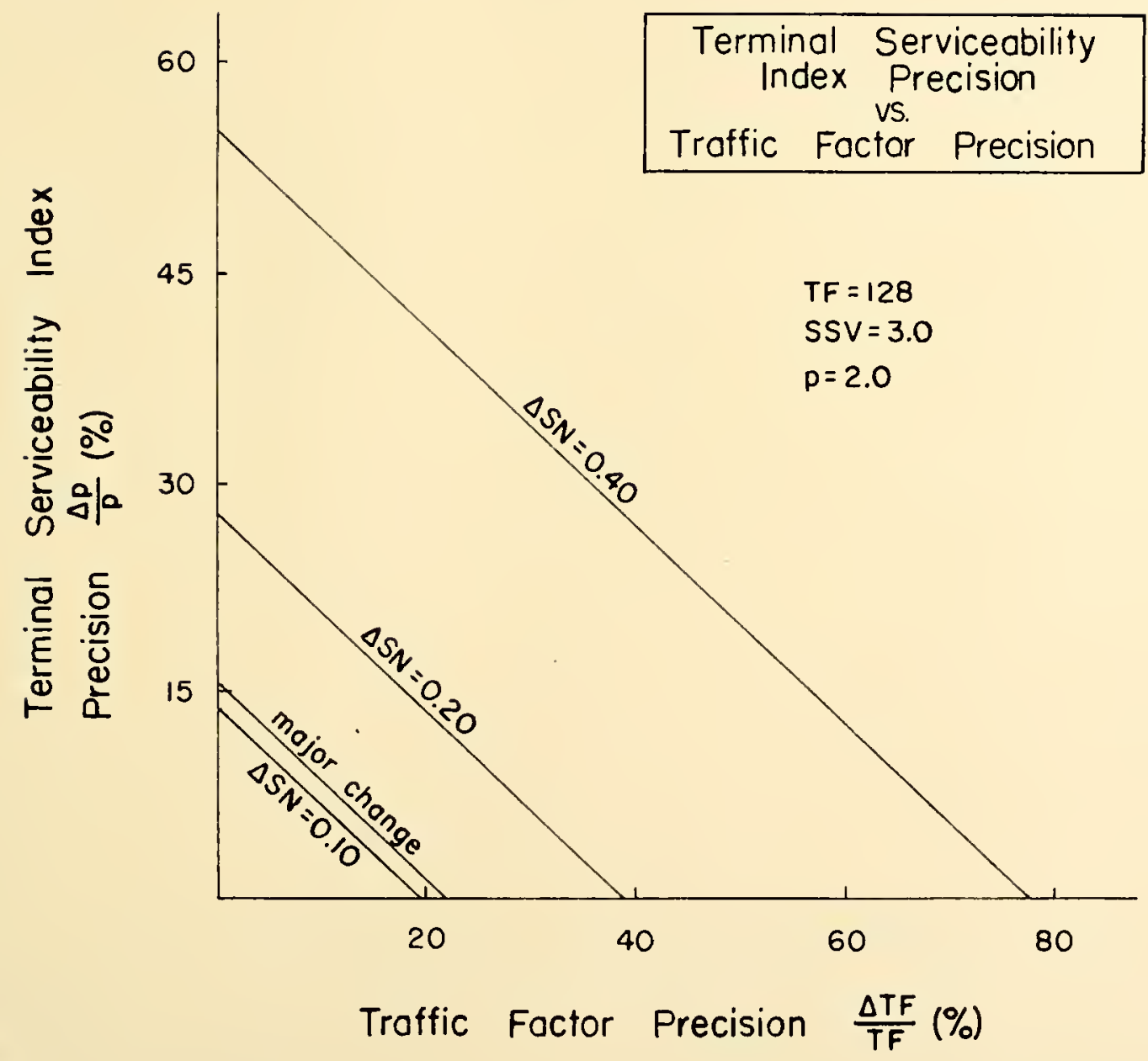

Figure 20. Tolerable Precision of AASHO Flexible Parameters 
the thickness increments. For average conditions, tolerable precisions of the AASHO traffic parameter versus that of soll support are shown in FIgure 19, and the precision of the traffic parameter versus that of the terminal serviceability index is 1llustrated in Figure 20. Each thickness constraint Iine indicates the various ways in which a given thickness can be divided between improving the precision of the traffic parameter estimate and providing more precise estimates of the terminal serviceability (or soll support valve).

Parameter precisions as dictated by the selected thicirness constraints do not compare favorably with the parameter variations of usual design situations. While a 1.0-in. change in thickness pernits a traffic parameter estimation to vary as much as 40 percent from the design value, usual variations in estimating the total equivalent $18 \mathrm{kip}$ single-axle load applications often approaches 80 percent of the selected design value. Similar areuments prevali regarding the precision of the soil support value, but the variation of the serviceability parameters are commensurate with the precision dictated by the 1.0-in. thickness change limitation.

Least Squares Analysis of the AASHO Flexible Destgn. Traffic and soil support were deternined to be the two more important AASHO Flexible design factors in the sensitivity analysis. The terminal serviceability index was recognized as approaching the importance of the soil support parameter. To generate the data applicable to linear, quadratic and 
cubic regression analyses, welghted structural numbers and subsequent total flexible pavement thicknesses were calculated for the following combinations of AASHO Flexible parameter values that correspond to California Bearins Ratio values of $2.0,4.0,6.0,8.0,10.0,15.0,30.0$ and $50.0 ;$ Corps of Engineers traffic categories of $I$ through IV and road and street classifications of A through $E_{\text {i }}$ terminal serviceability indices of 2.0 and 2.5 ; initial serviceability index of 4.0 and regional factor of 1.0 . These parameter-thichness data were then assembled in two groups corresponding to terminal serviceability indices of 2.0 and 2.5. A CBR value and an equivalent wheel load were associated with each calculated total thickness. The CBR measures were determined for the respective AASHO soil support values by using the correlation chart provided in The AASHO Interim Guide for the Design of Flextble pavement Structures, and the equivalent wheel load values were calculated according to the specifications of the California stabilometer design method.

The regression analysis of the AASHO Flexible parameterthickness data produced the equations and the corresponding coefficients of determination and standard errors of estimate. These results are summarized in Tables 1 and 2 . While all equations are conceptually valid, they were statistically more efficient but less simple from the linear to the cubic models. The improvement in the coefficient of determination from 0.95 to 0.99 or 0.92 to 0.99 is negligible when compared 


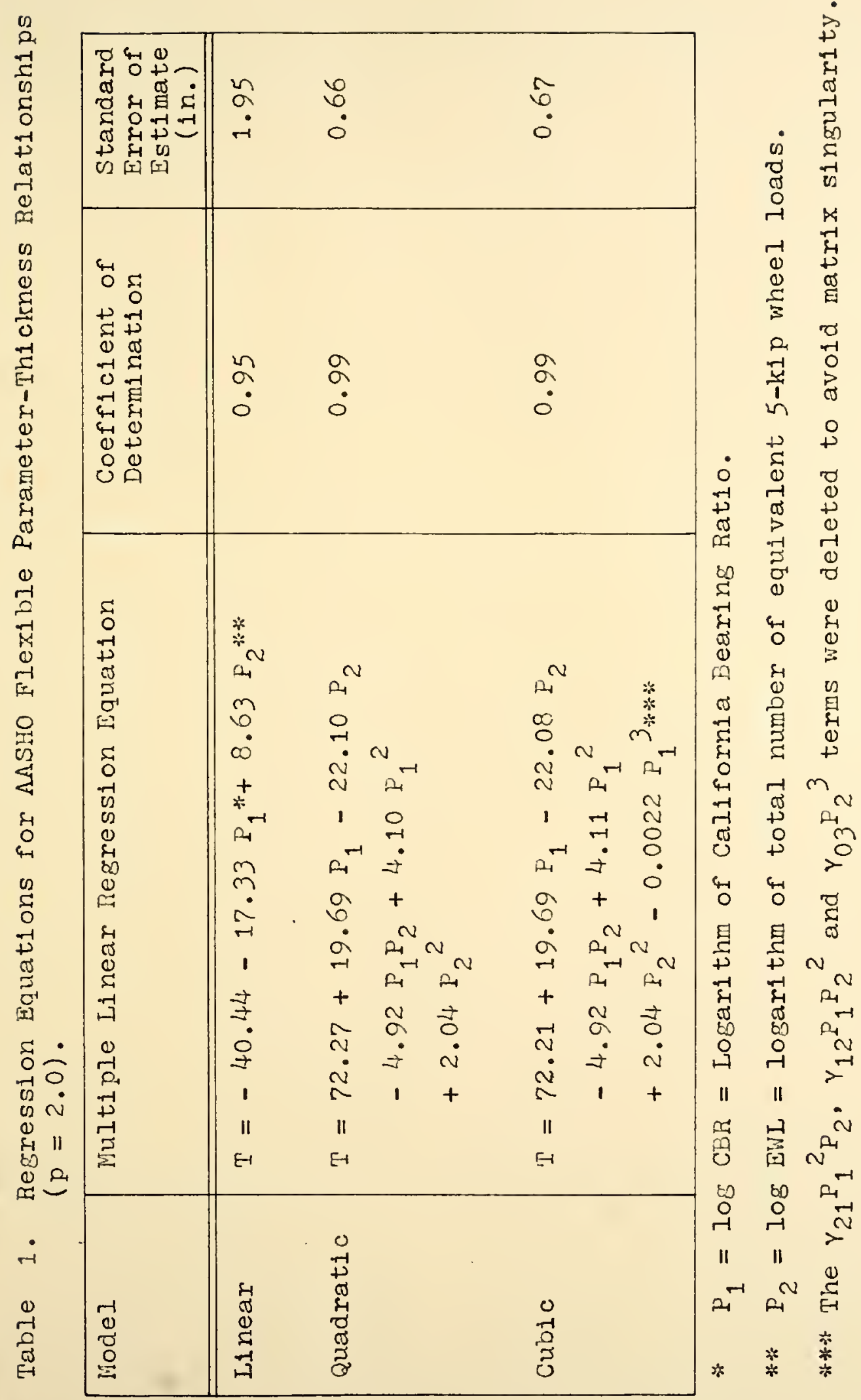




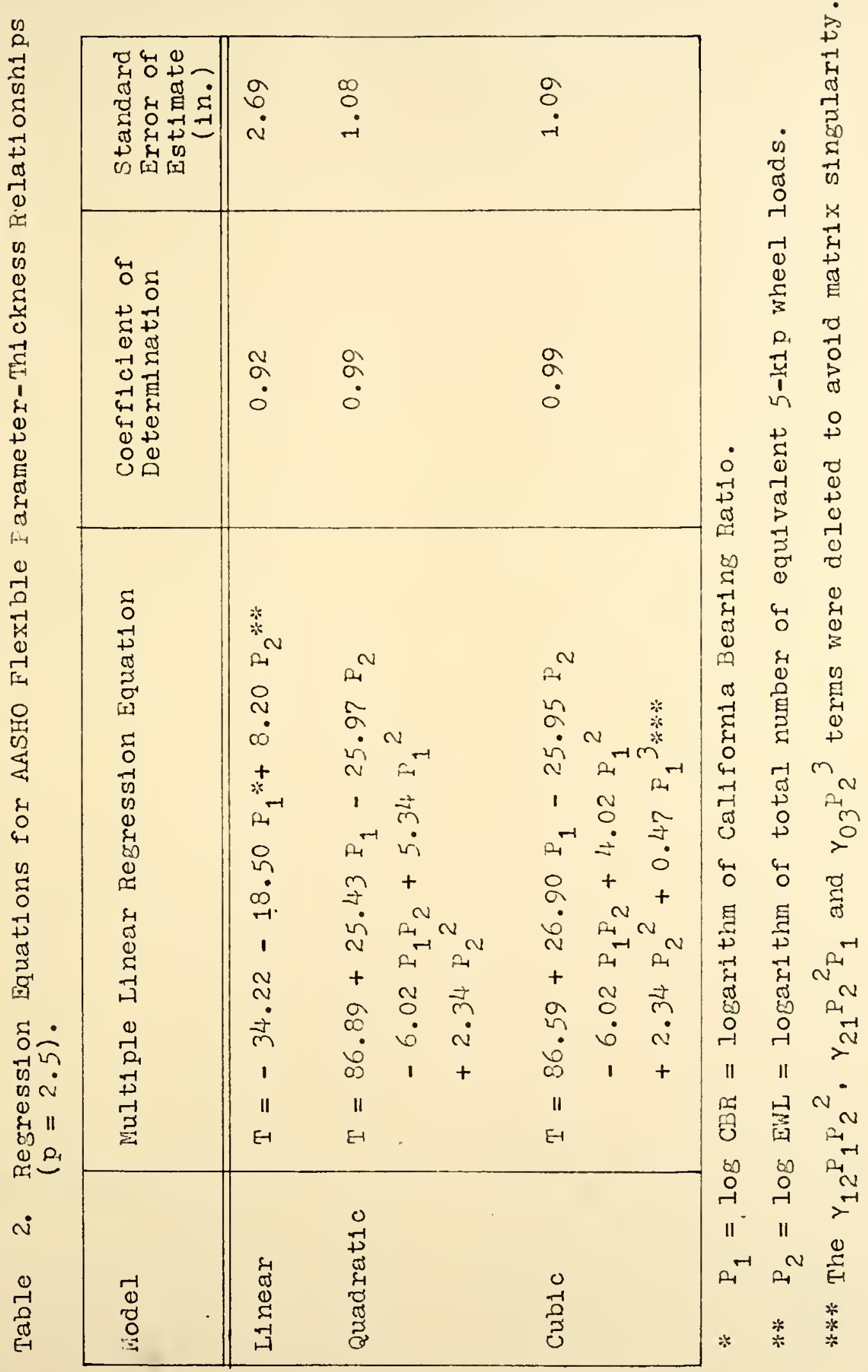


to the ability of the linear expression to clearly indicate the effects of the subgrade and the traffic on the thickness requirements for flexible pavements. Therefore, the linear model is the preferred expression of thickness-parameter relationships.

A comparison of the equations developed for the two groups of data shows a slight improvement in the statistical efficiency of models evaluated for the 2.0 terminal serviceability data over those models developed for the 2.5 terminal serviceability data. As indicated by a comparison of the regression coefficients of the two linear models, the subgrade factor assumes a Ereater importance at the lower terminal serviceability index, but the weighted importance of the traffic factor is nearly equivalent for both models.

Corps Flexible Favement Desisn

Design-Process Logic. In addition to minimum thickness, agsregate gradation, Atterbers limit specification and other special requirements, the pavement thickness required by the Corps of Engineers design criteria is determined by the California Bearing Ratios of subgrade and structural components and by the design index which assesses traffic effects. The logic of the Corps Flexible design process is structured into the hierarchy chart shown as Figure 21. This diagram illustrates the ranking of design factors according to the order in which they are considered in the determination of the required pavement thickness. 


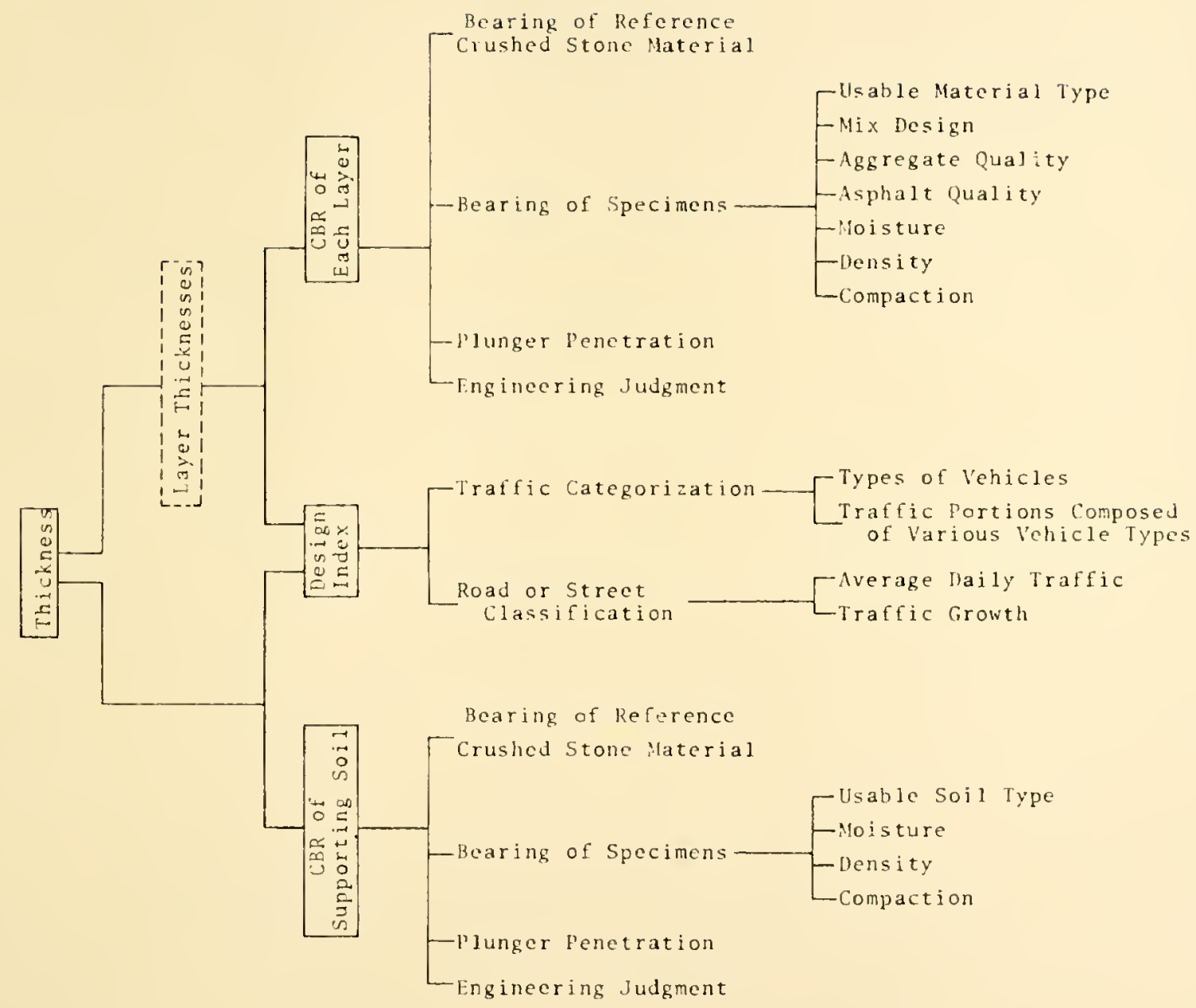

Figure 21. H1erarchy Structure of Corps Flexible Design-Process Logic 
The design objective is finally manifested in the total thickness proportioned into the required thicknesses of surface, base and subbase. The California Bearing Ratios and the traffic design indices represent the first level in the hierarchy considerations. The various material tests and traffic and street classifications are necessary to determine the design parameters and represent the second level of the hierarchy structure. Items that are recognized as affecting the secondlevel evaluations are ranked as factors in the third order. The salient features of the Corps Flexible design procedure are the use of CBR measures to estimate both subgrade and pavement supporting components properties, the absence of a safety factor which is explicitly employed in the design process and the determination of total thickness without knowledge of the materials composing the pavement structure. Separate determinations are made of the thiclness requirements for frost action or other special problems, but these exceptional cases were not considered in this research study. Modeling of the Corps Flexible Design Method. Because the development of the Corps Flexible design method substantially depended on empirical relationships, the design chart shown in Appendix B was judged as the best available model for the sensitivity analysis. Although a literature search uncovered several mathematical equations which were basic to this design technique, none of these equations could be utilized to yield information of the precision which was obtained by graphical interpretations of the design charts. 


\section{Sensitivity Analysis of the Corps Flexible Design}

Method. An evaluation of the importance of the primary design factors was premised on the supposition that the more important parameters cause greater changes in the design thickness. Instantaneous rates of thickness changes with respect to parameter changes were approximated by graphically interpreted first-order partial derivatives and were employed as measures of relative theoretical parameter importance. Practical parameter importance measures evidence individual effects of parameter variations of ten encountered in the design process as well as the formulated inclusion of parameters in the design charts.

Graphically determined thickness changes which correspond to selected small parameter changes were divided by the arbitrary parameter increments, and the resulting quotients were designated as the first-order partial derivatives of thickness with respect to the parameter that induced the specified thickness change: Derivatives were determined in this manner for all combinations of CBR values of $2,4,6,10,15,20$, 25, 30 and 40 and of design index values of 1,2, 4, 6, 8 and 10 .

Because the Corps Flexible model for the sensitivity analysis has only the two independent variables of $C B R$ value and design index, concurrent evaluation of the importance of the subgrade and the traffic parameters as well as the pavement component layer parameters was not attempted. Therefore, 
theoretical and practical importance measures were determined only for individual CBR values relative to design index values. This assessment of CBR importance pertained to either subgrade. subbase, base or surface property influences on thickness, but never to subgrade influences relative to pavement structure influences.

"Relative percentages of a partial" measures are plotted in Figures 22, 23, 24, 25 and 26 to illustrate the importance of $C B R$ values and design indices in the pavement thickness design charts. If $\mathrm{CBR}$ values of 4,6 and 2 , respectively, represent typical average and upper and lower limits of highway subgrades in Indiana, the evaluation of relative theoretical parameter importance for these situations are shown in Figures 22, 23 and 24. California Bearing Ratios of 20 and 40 were employed in determining the graphs shown in Figures 25 and 26 which illustrate the theoretical importance of structural component materials relative to design indices.

For a frequently encountered design situation described by a subgrade CBR value of 4 , a design index of 5 and a subbase CBR value of 40 , the subgrade has an approximately 60 percent theoretical importance measure relative to the design index parameter, and the subbase CBR parameter of 40 is about 20 percent important relative to the corps Flexible traffic factor. However, as traffic loads become greater, the relative theoretical importance of the CBR parameter increases with a corresponding decrease in design index importance. A comparison 
CORPS FLEXIBLE DESIGN

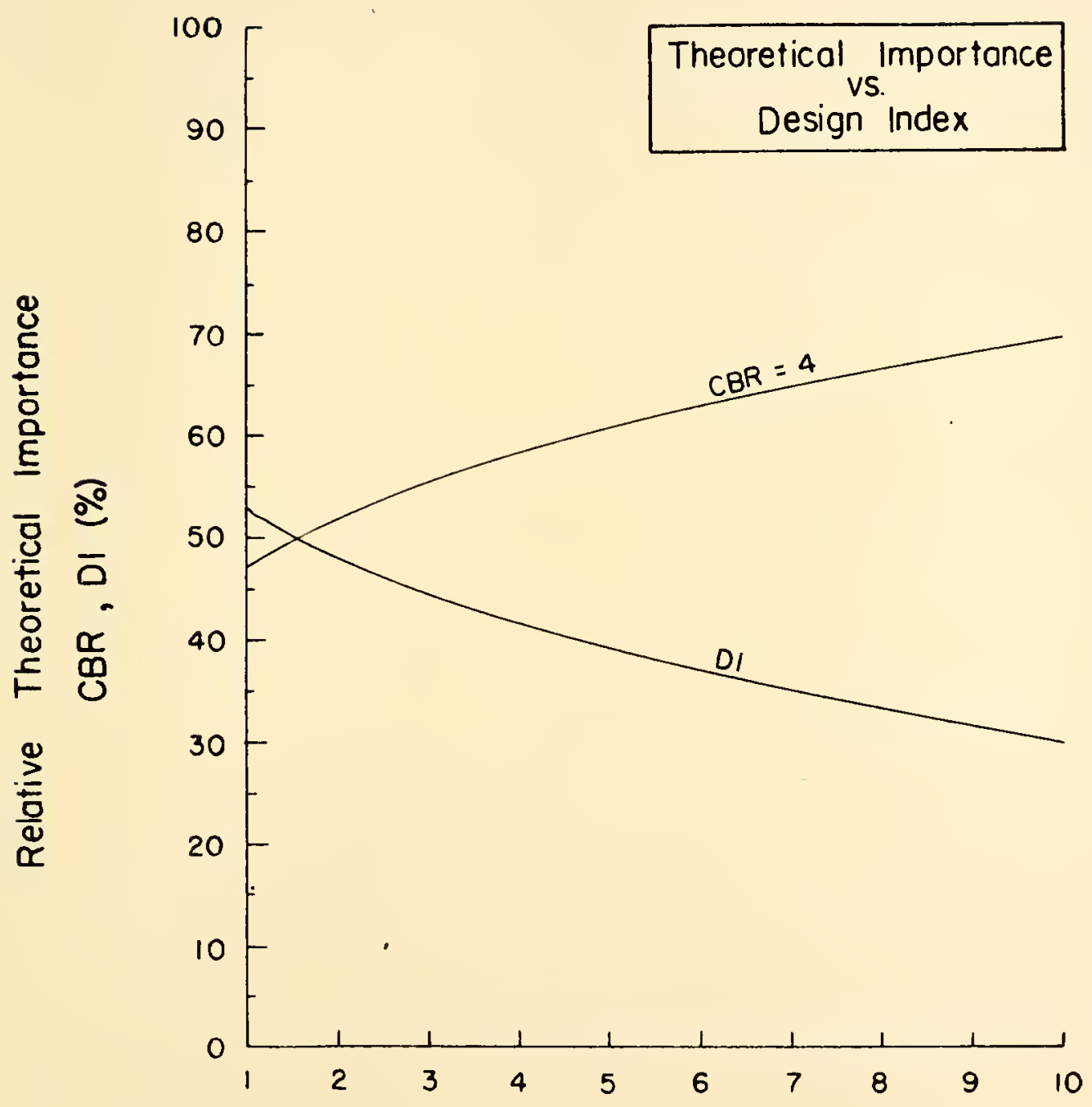

Design Index DI

Figure 22. Relative Theoretical Imporfance of Corps Flexible Design Parameters 
CORPS FLEXIBLE DESIGN

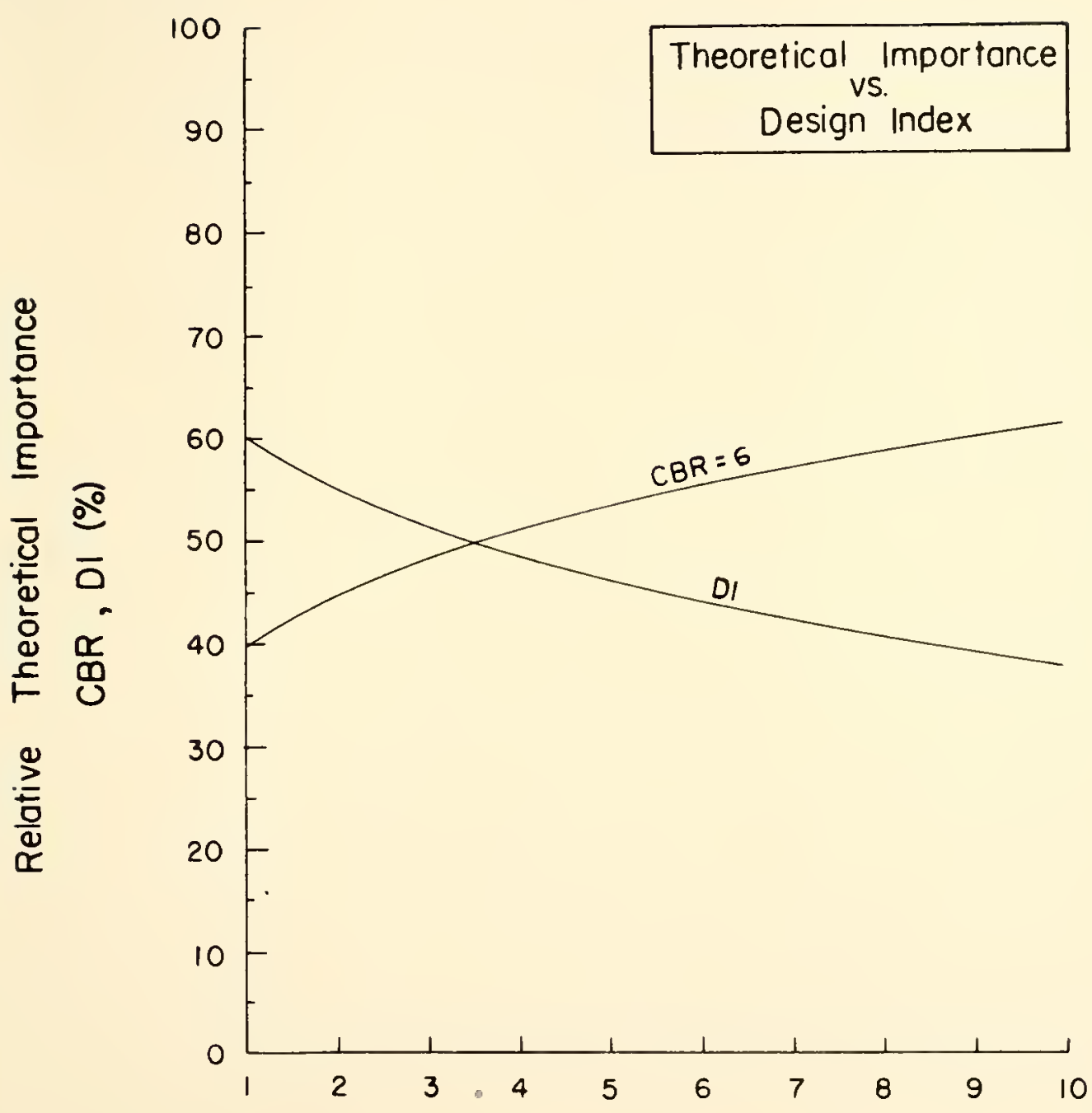

Design Index DI

Figure 23. Relative Theoretical Importance of Corps Flexible Design Parameters 
CORPS FLEXIBLE DESIGN

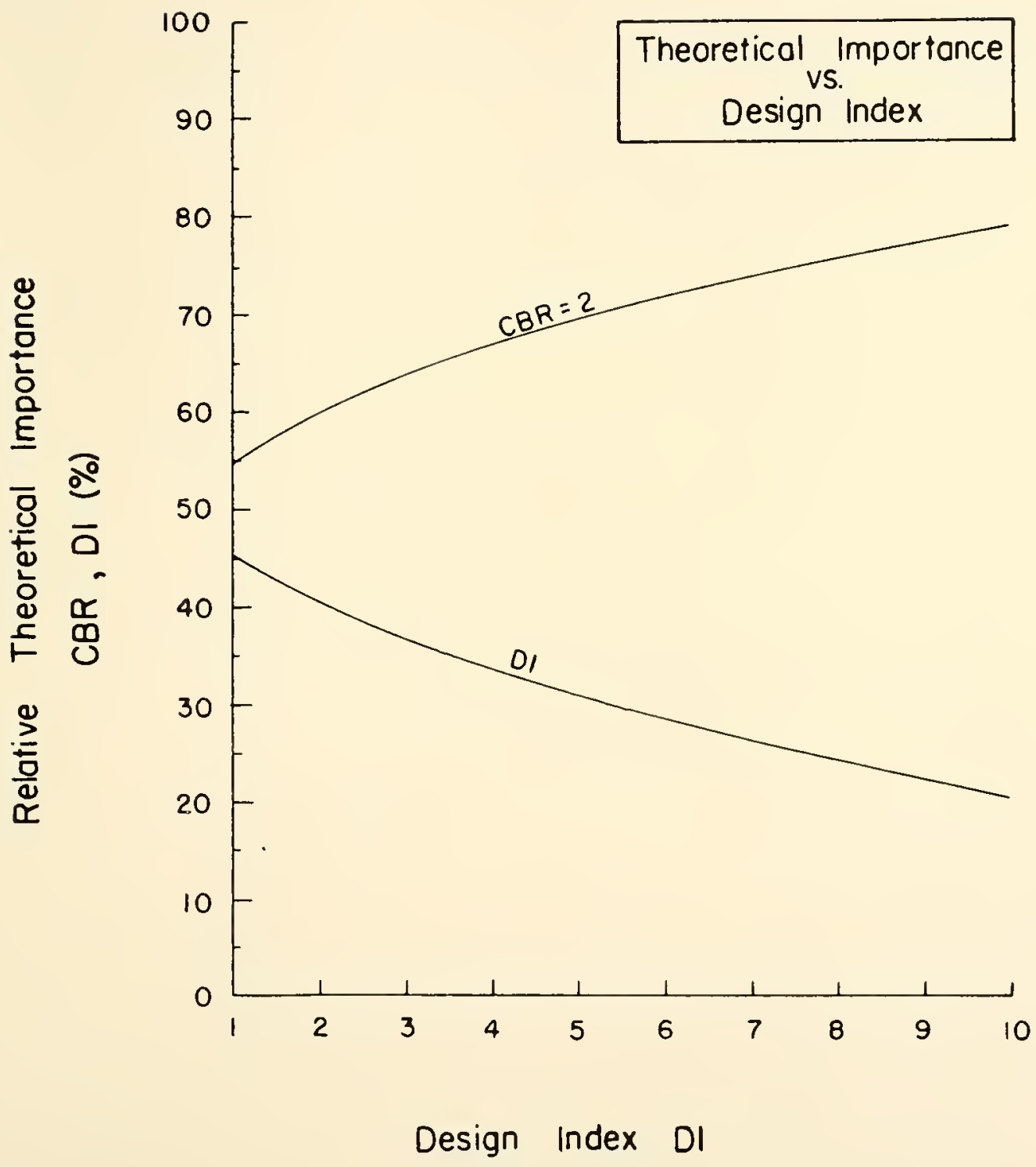

Figure 24. Relative Theoretical Importance of Corps Flexible Design Parameters 
CORPS FLEXIBLE DESIGN

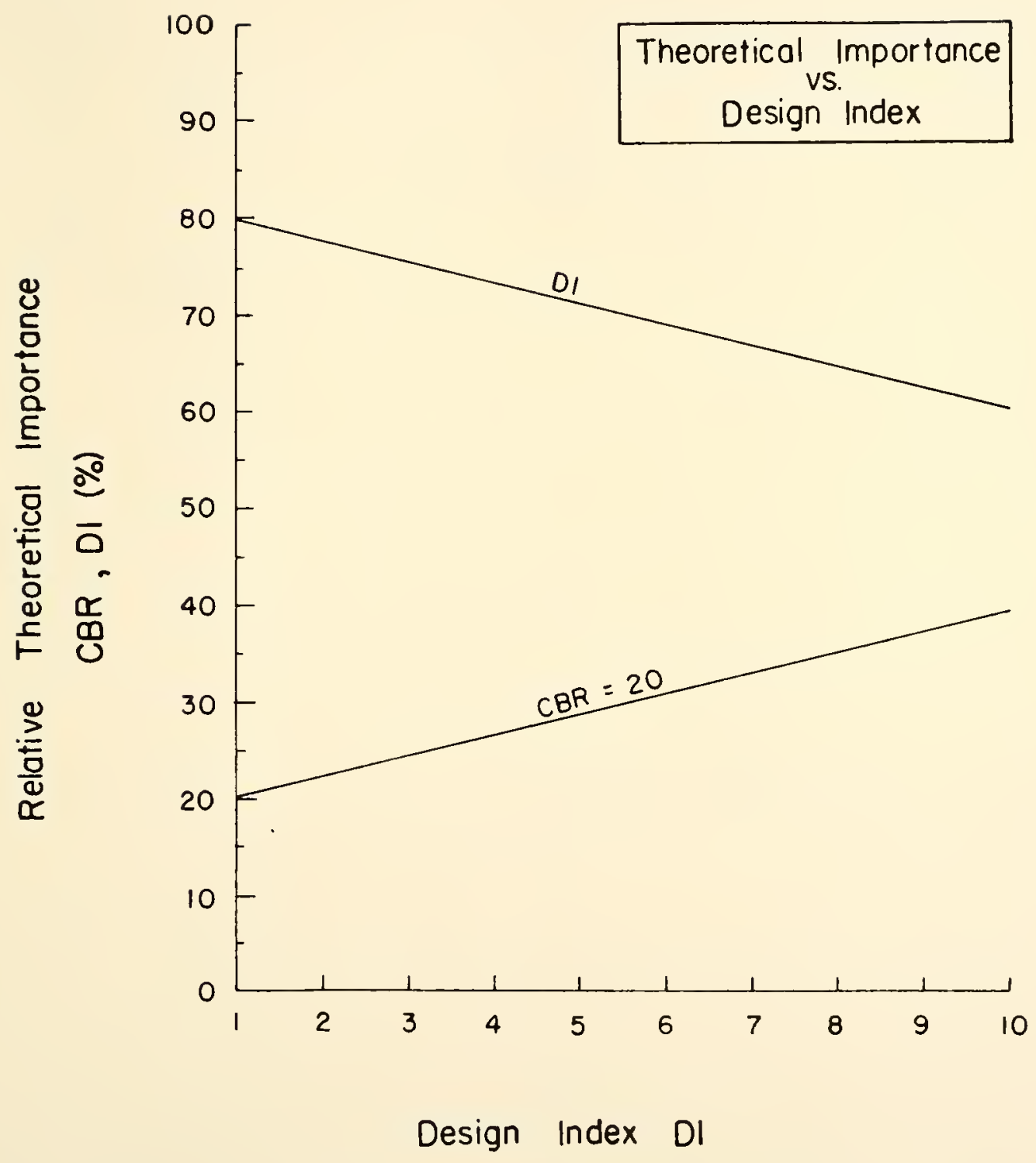

Figure 25. Relative Theoretical Importance of Corps Flexible Design Parameters 
CORPS FLEXIBLE DESIGN

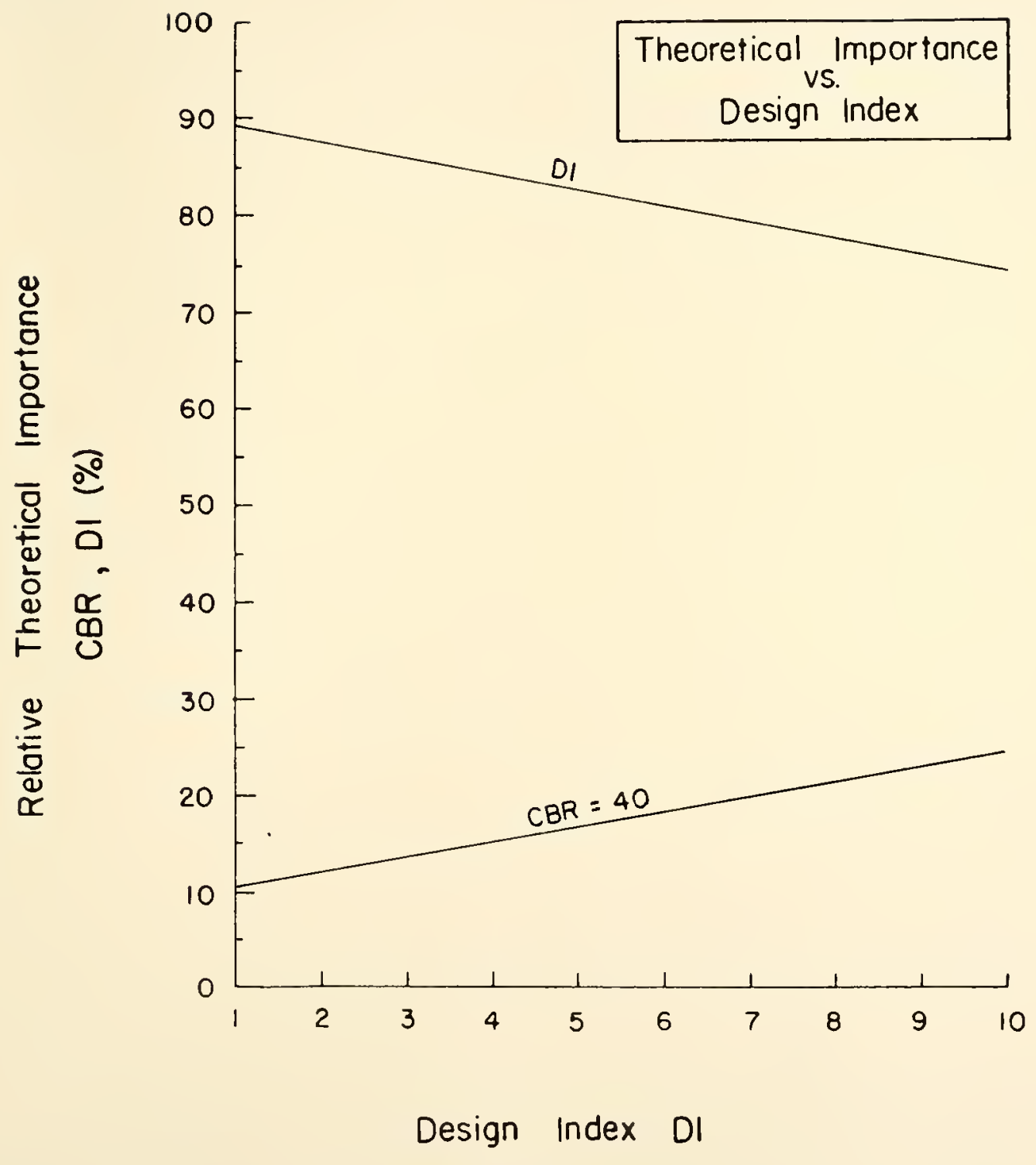

Figure 26. Relative Theoretical Importance of Corps Flexible Design Parameters 
among the plots of theoretical importance versus design index iliustrates a decrease of 1 mportance for the supporting material parameter with increasing CBR values.

Quantifications of the practical measures of parameter importance were graphically determined for the combinations of $1,2,4$ and 6 desien index values with 2, 4, 6, 20 and 40 CBR values. Design index values sreater than 6 do not apply to the usual pneumatic-tired vehicular traffic and consequently were neglected in the practical evaluation of the Corps Flexible design parameters. To predict representative variations in the Corps Flexible traffic parameter, the design index was assumed to be directly and Iinearly proportional to the california Stabilometer traffic parameter. Thus, readily determined variations in California stablometer traffic index were approximated by a continuous function of that traffic parameter and were translated into simlar approximate variations of the Corps Flexible design index parameter. This method of estimating Corps Flexible design index variations does not enable average dally traffic or percentage trucks to directly influence the increments of change, consequently ranges of practical importance do not occur for a given desien index.

Although both "portions of the total differential" and "relative thickness changes" approaches described in the Procedure of this report were used to determine relative practlcal percentages, only values calculated by the former method are shown in Figures $27,28,29,30$ and 31 . The two 
CORPS FLEXIBLE DESIGN

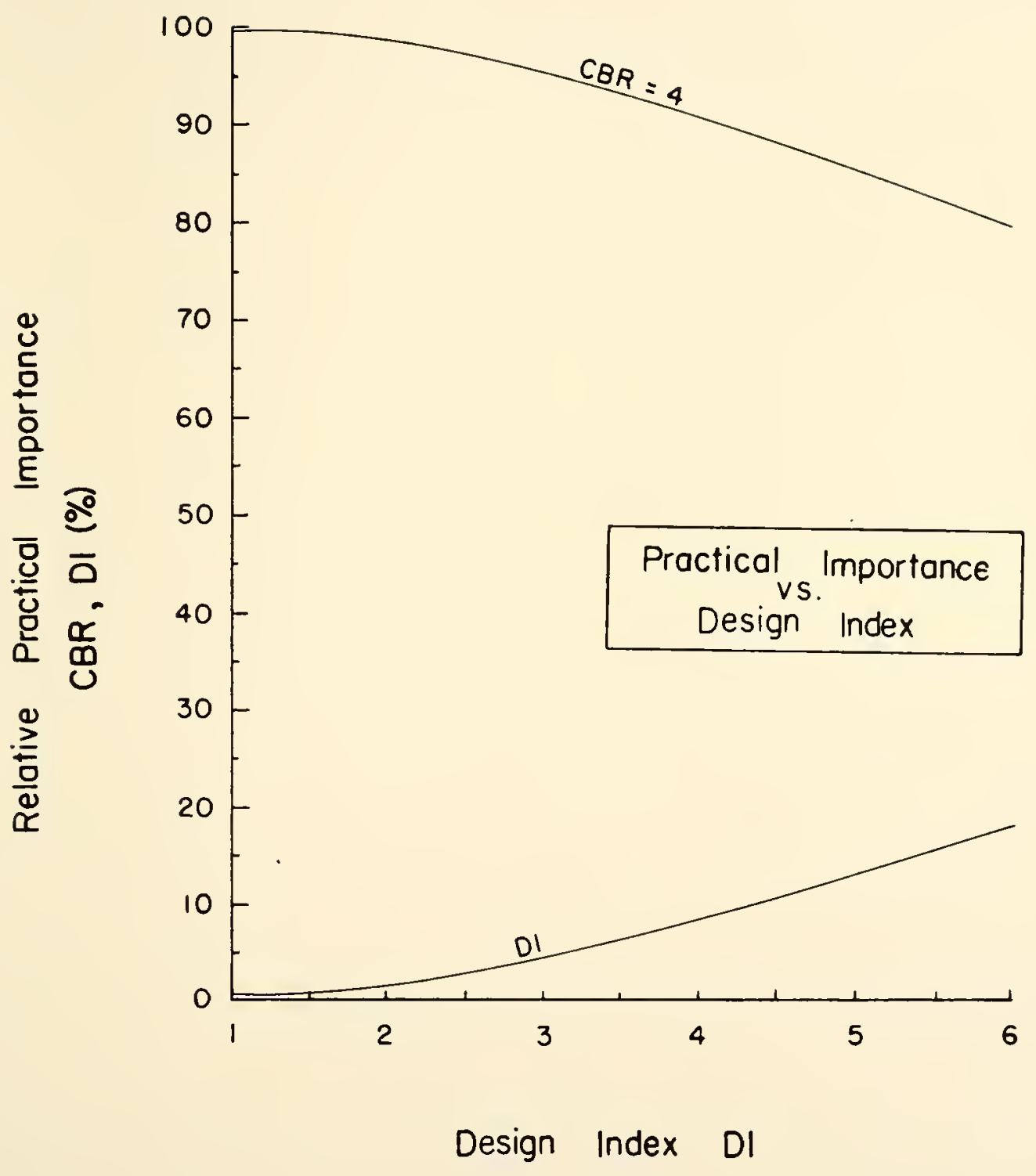

Figure 27. Relative Practical Importance of Corps Flexible Design Parameters 
CORPS FLEXIBLE DESIGN

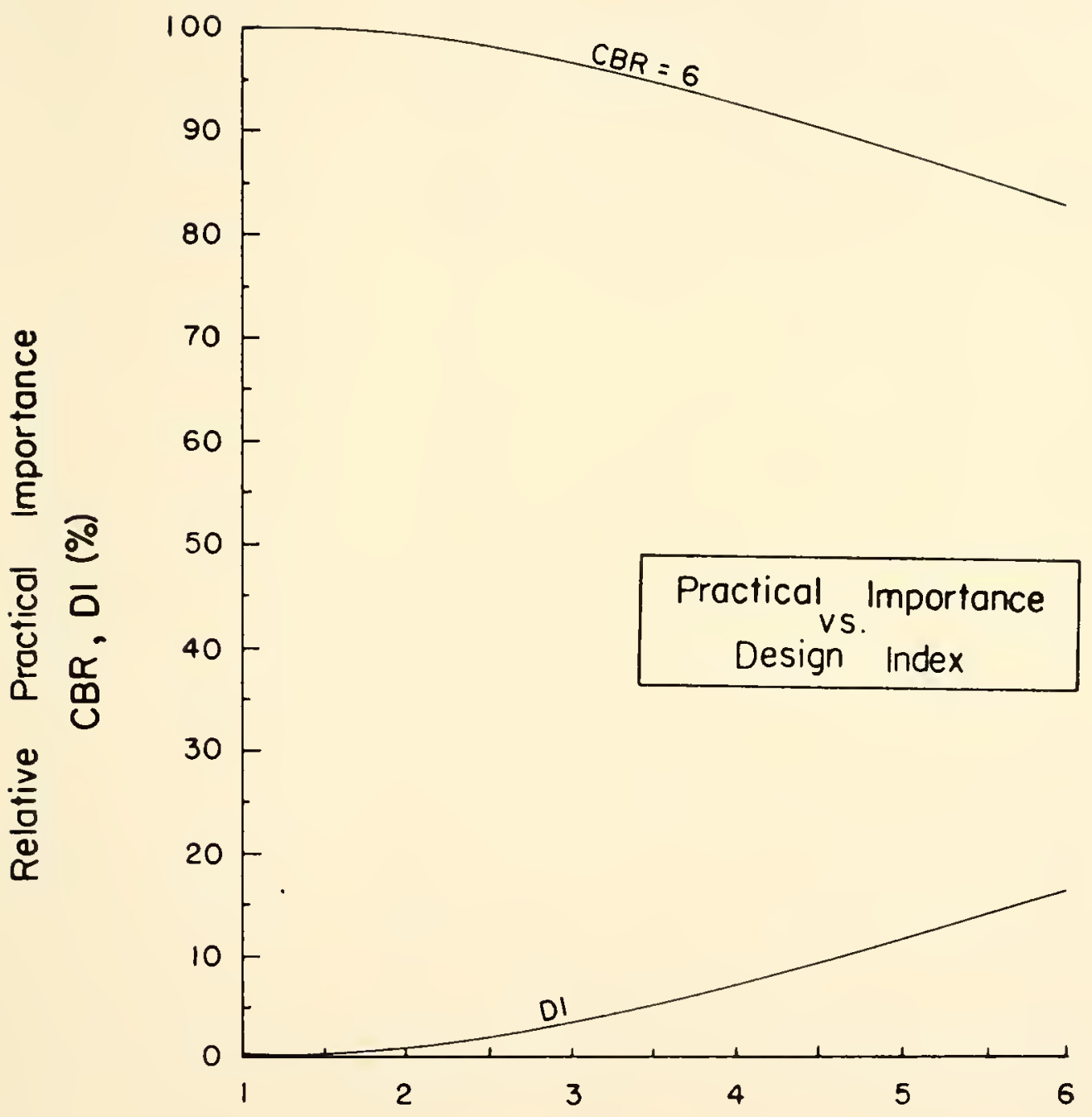

Design Index DI

Figure 28. Relative Proctical Importance of Corps Flexible Design Parameters 
CORPS FLEXIBLE DESIGN

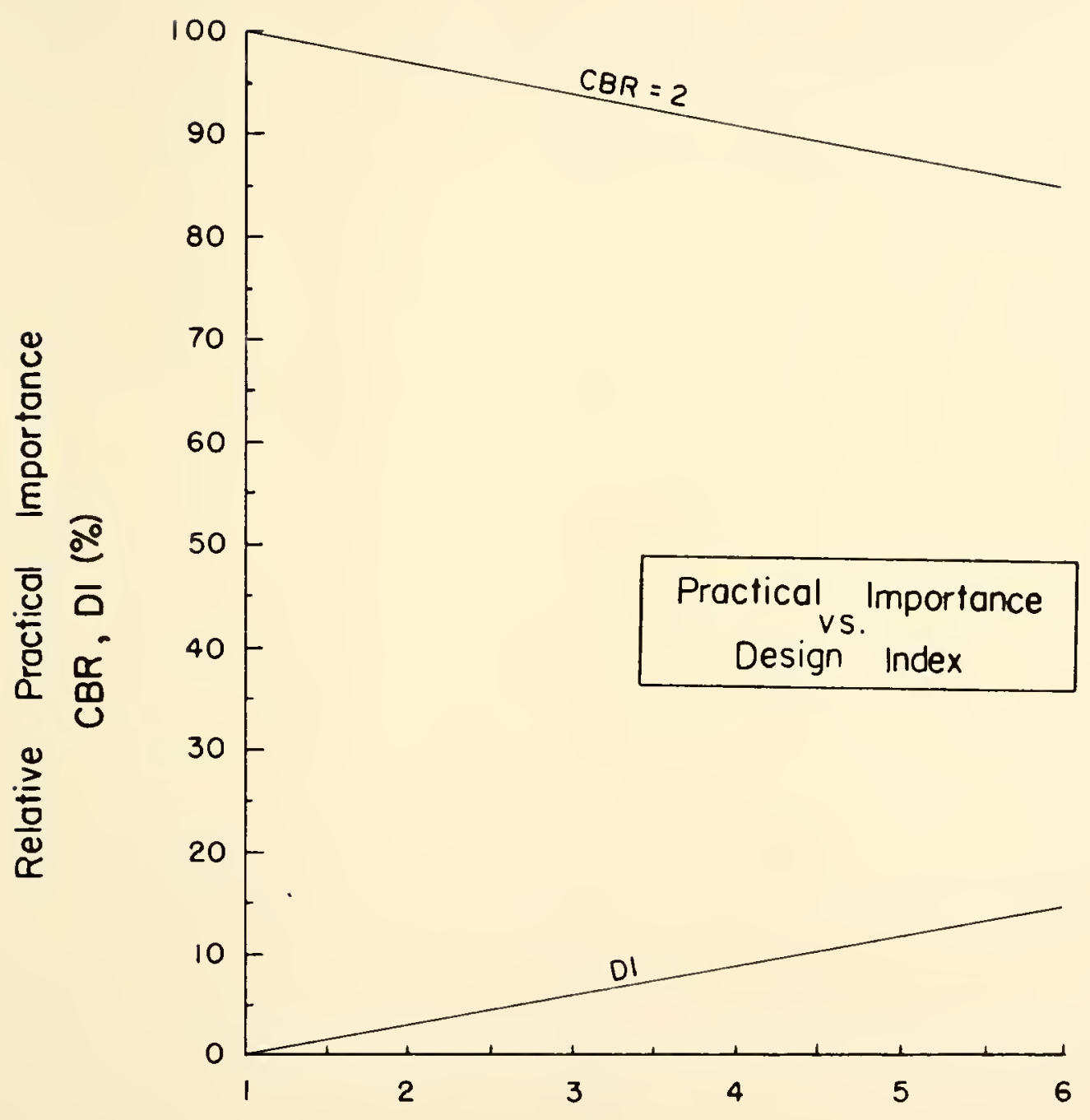

Design Index DI

Figure 29. Relative Practical Importance of Corps Flexible Design Parameters 
CORPS FLEXIBLE DESIGN

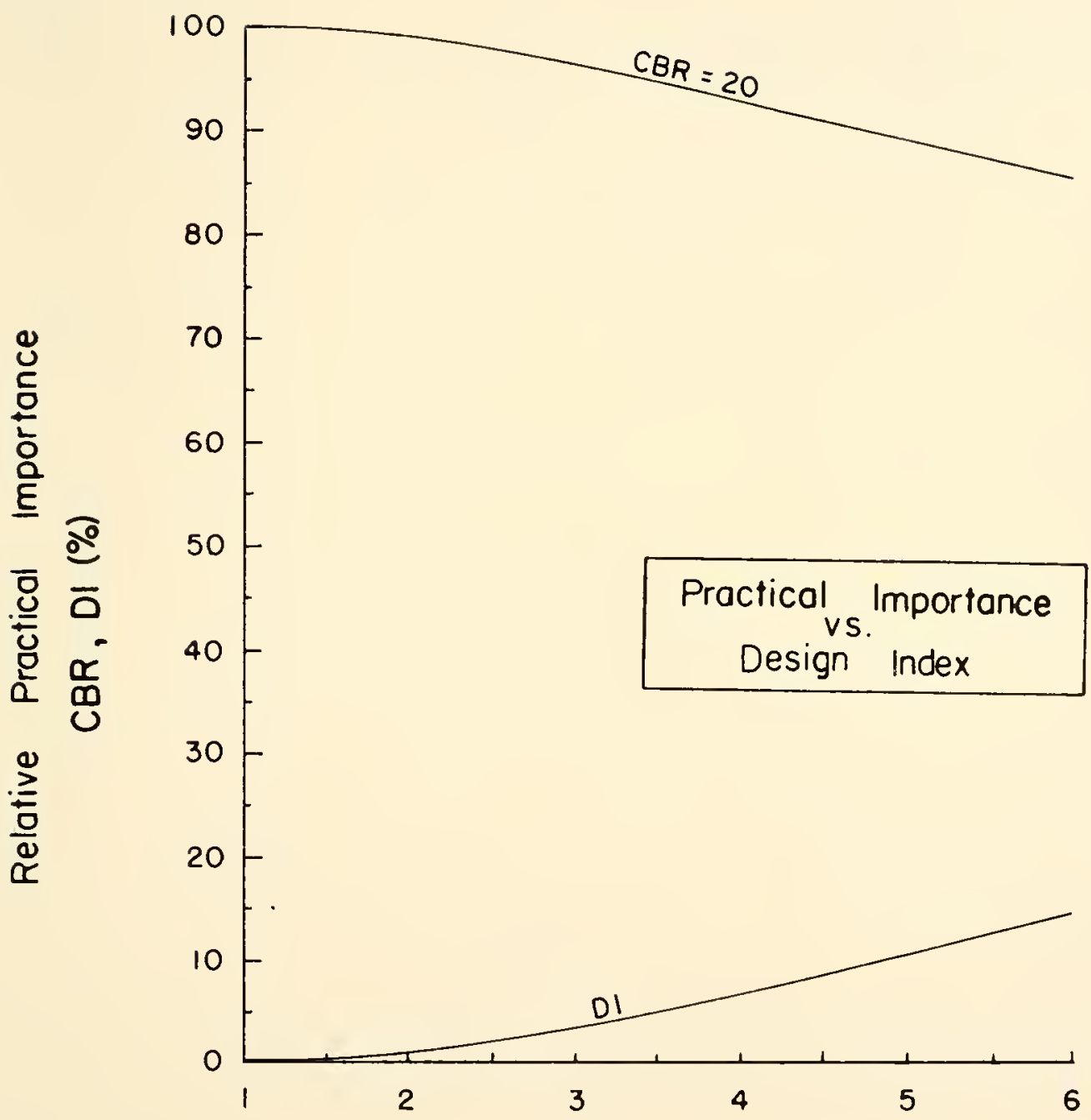

Design Index DI

Figure 30. Relative Practical Importance of Corps Flexible Design Parameters 
CORPS FLEXIBLE DESIGN

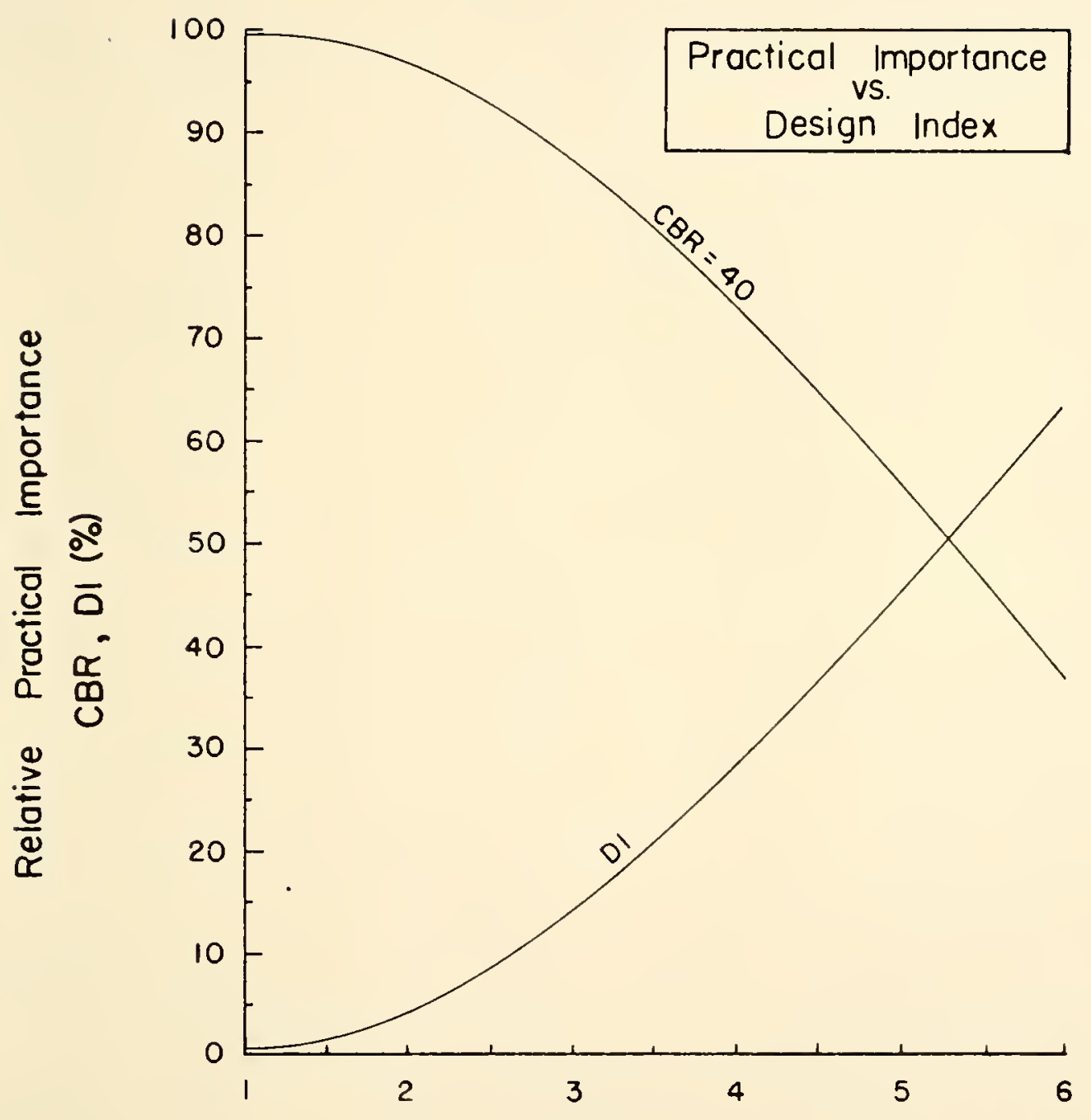

Design Index DI

Figure 31. Relative Proctical Importance of Corps Flexible Design Parometers 
measures were nearly identical and any discrepancles were due to graphical measurement errors. The relative practical importance of design indices and of CBR values representing typical Indlana subgrade desion conditions are plotted in Figures 27, 28 and 29. Practical measures of the significance of subbase materials which are characterized by CBR values of 20 and 40 are shown in Figures 30 and 31.

From an examination of the plots of practical importance for the Corps Flexible method, the CBR values that represent the strengths of subgrade materials have the greatest influence on pavement thicliness. As CBR values increase with the use of stronger supporting materials, only slight changes in practical importance occur for these two design variables. However, when practical importance is evaluated for a CBB value of 40 and a design index of 6 the traffic parameter is more important than the subgrade parameter. If the subgrade $\mathrm{CBR}$ value is 4 , the design index is 5 and the subbase CBR value is 40 , a typical example of the relattve practical importance of the Corps Flexible parameters indicates that the subsrade parameter has an 85 percent ratins relative to the design index and that the subbase parameter has a 55 percent practical importance measure relative to the traffic parameter. For the assumptions made in evaluating practical Importance, the California Bearing Ratio parameter has the greatest influence on thicknesses determined by the corps Flexible desion process. 
Tolerable Parameter Variations. Parameter variations permitted within selected design thickness change constraints were calculated to illustrate the precision of design parameter determinations that is commensurate with reasonable thickness variations in the design and construction of highway pavements. These variations for the important parameters are plotted in Figures 32 and 33. As illustrated in Figure 32, maximum deviations of 10 percent of the design index value and 8 percent of the CBR value are tolerated by the 1.0-in. thickness change constraint, provided the design situation is described by a design index of 4 and a CBR value of 4 . If the CBR value is increased to 40 , the maximum tolerable precision of the CBR parameter is about 31 percent and the maximum variation of the design index is 51 percent, as indicated in Figure 33. These tolerated parameter precisions are more exacting than the usual precision encountered in normal pavement design circumstances.

\section{Least Squares Analysis of Coros Flexible Design. Design} thicknesses were determined by the Corps Flexible desien criteria for alI combinations of $2,4,6,8,10,15,30$ and 50 CBR values and design index values corresponding to traffic categories I through IV and street and road classifications A through E. The graphically determined thicknesses and corresponding supporting material and traffic parameters were analyzed to determine the best fitting curve. - Related mathematical equations conforining to the seneral linear, quadratic and cubic models were selected to approximate the parameter- 
CORPS FLEXIBLE DESIGN

\begin{tabular}{ccc}
\hline CBR & Precision \\
vs. \\
Design Index Precision
\end{tabular}

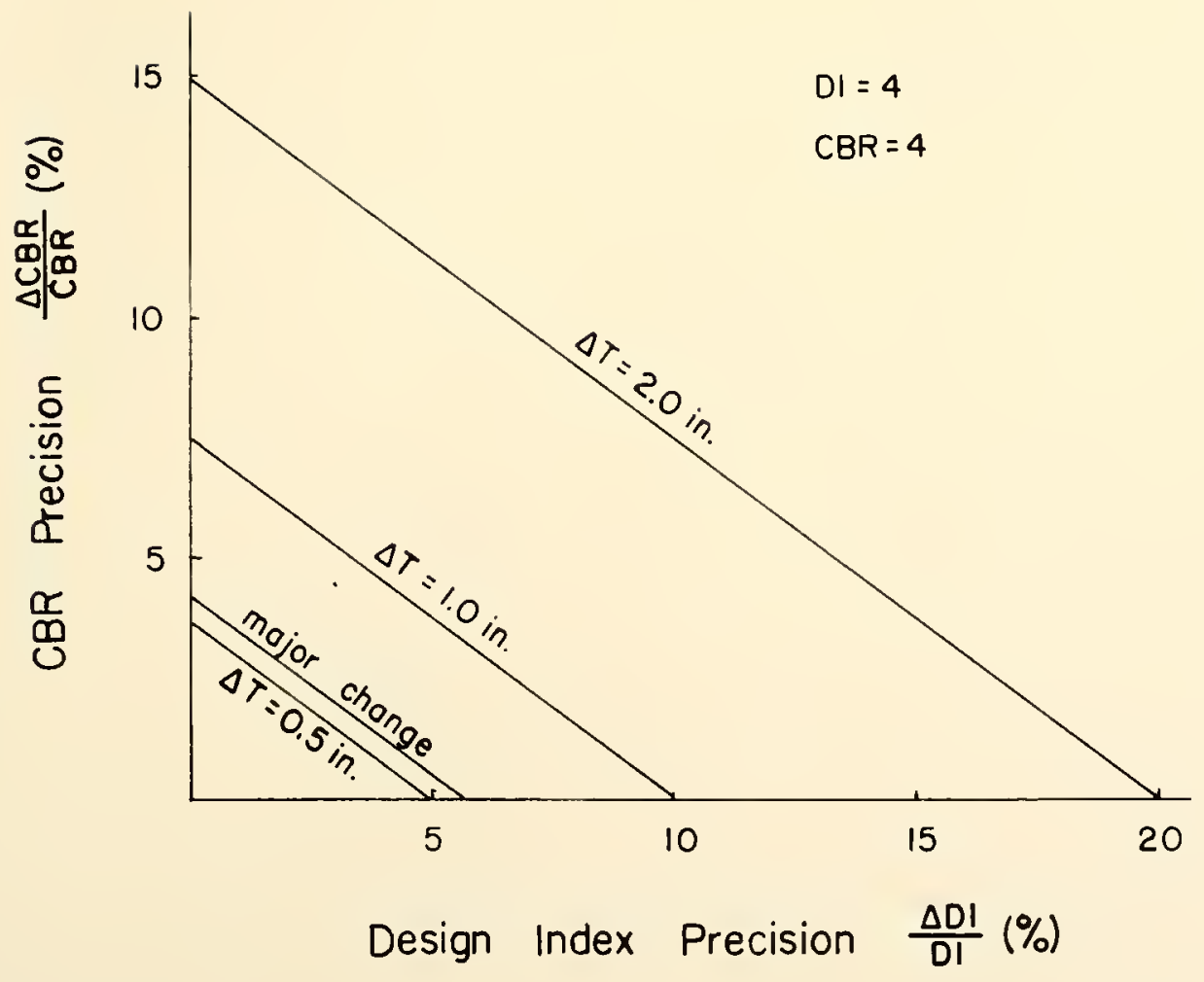

Figure 32. Tolerable Precision of Corps Flexible Parameters 
CORPS FLEXIBLE DESIGN

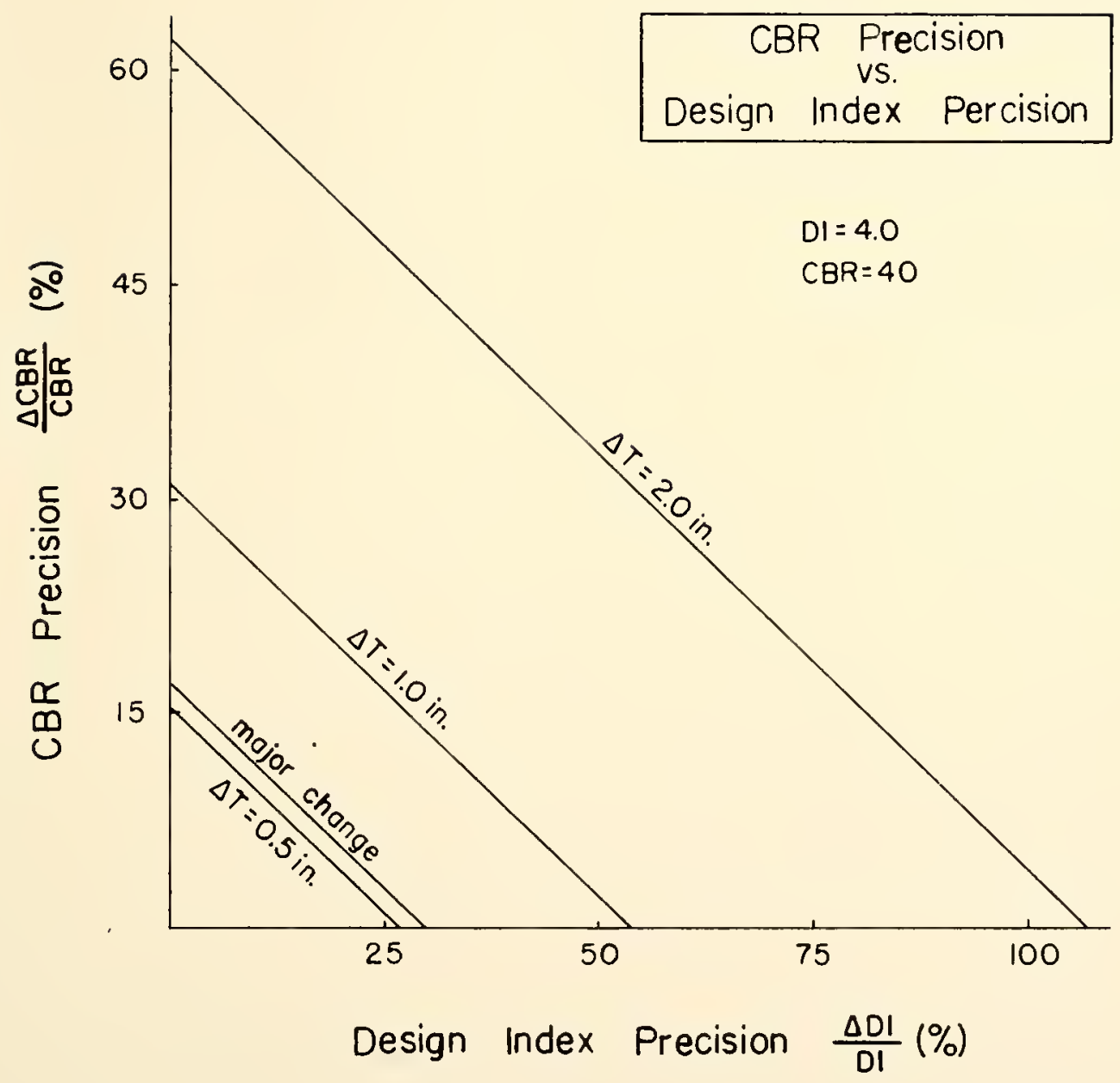

Figure 33. Tolerable Precision of Corps Flexible Porameters 
thickness relationships. The regression equations resulting from the least squares analyses of the generated parameterthickness data are listed in Table 3. A less than significant improvement in statistical efficiency as evidenced by the coefficient of determination and standard error measures occurs when linear, quadratic and then cubic regression models are fltted to the senerated data. The coefficients of determination of $0.96,0.98$ and 0.98 and the standard errors of estimate of 1.64. 1.06 and $1.05 \mathrm{in}$. are associated with the linear, quadratic and cubic models, respectively. Each model is a reasonable approximation of the Corps Flexible parameter-thickness data. but only the linear equation was amenable to a rational appraisal of parameter-thickness relationships.

California Stabilometer Design inethod

Design-Process Logic. The design-process logic of the California stabilometer technique is structured in Figure 34 to depict the logic employed in determining pavement thicknesses for various design situations. In addition, this designprocess logic illustrates those factors which affect design thicknesses and their levels of influence in the decisionmaking activity.

The seneric factors of traffic, soil support and pavement structural component qualities are prinary considerations in the California Stabilometer design process, and the parameters estimating these factors are shown at the first level of the hierarchy structure. The second level considerations consist 


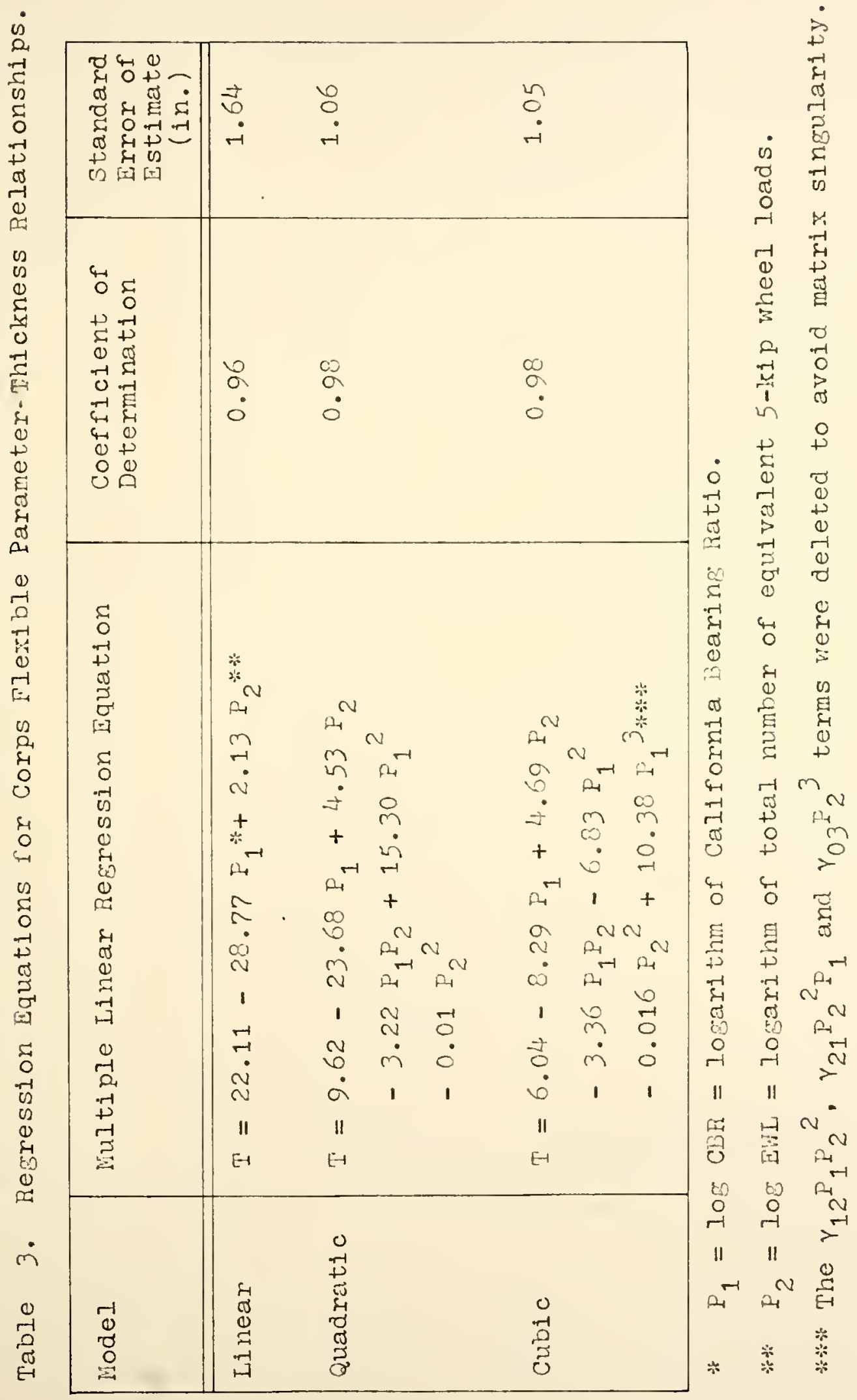




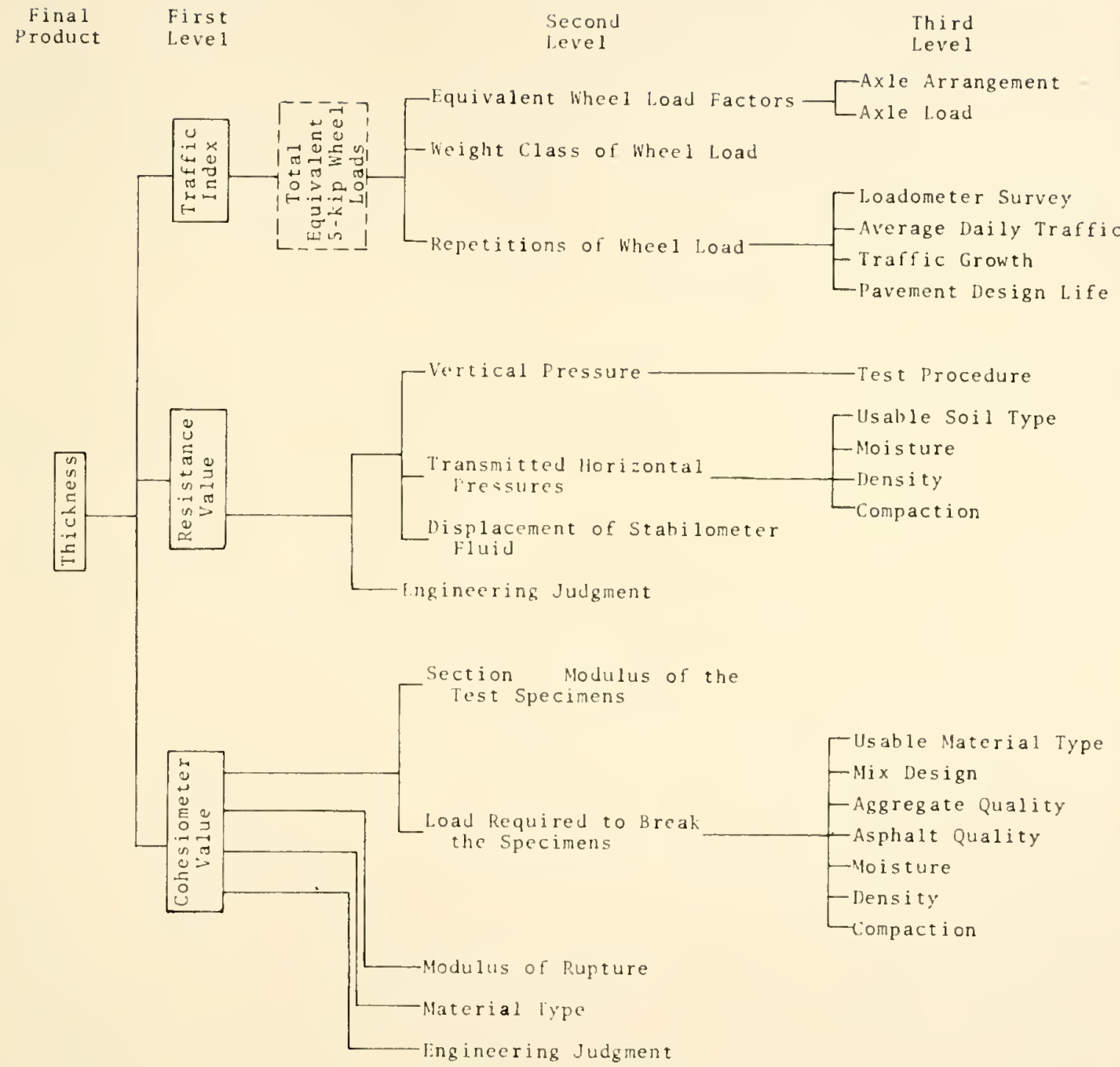

Figure 34. Hierarchy Structure of California Stabilometer Design-Process Logic 
of evaluations required to ascertain the design parameters of traffic index, resistance value and cohesiometer value. Traffic index is a function of an equivalent wheel load factor which also summarizes traffic load and repetition effects, however, the latter measure is regarded as a second level consideration. The resistance value is usually estimated by laboratory tests, but average values are generally assumed for cohesiometer values according to the types of materials to be used in the pavement structure. Third level hierarchy items are recognized to affect second level factors, and different third level items are surficient cause for making separate second level evaluations.

liodeling of the California Stabllometer Design Method. Further development of a thickness function model for use in sensitivity analysis of the California Stabilometer design technique was not necessary because the published design equation expresses the total design variable relationships to the degree of completeness required in this research. That basic expression, which is showr in the Review of Design liethods as equation 18, includes all California stabilometer design parameters in a single mathematical equation that is sufficient to prepare the appropriate design charts or to determine directly the structural design of a flexible pavement. The design variables expressed in this equation are boxed in the hierarchy structure of Figure 34 .

Sensitivity Analysis of the California Stabilometer Design Method. In the California Stabilometer technique for the 
design of flexible pavements, the primary factors are traffic. subgrade and pavement composition which are described by the traffic index, the resistance value and the cohesioneter value. While the basic California Stabilometer design equation relates these major factors to pavement thickness, the importance of these parameters relative to their effect on the design objective was evaluated in the sensitivity analysis phase of thes research investigation.

The relative theoretical importance of each parameter in the design equation is indicated by the first partial derivative of thickness with respect to each parameter and was quantified by the "relative percentage of a partial." Because the numerical value of the first-order derivative depends on the particular parameter values used, theoretical measures of importance were determined for all practical combinations of parameter values. However, to convey a reasonable impression of parameter importance, only typical combinations were selected for 1llustration.

Parameter values which characterize average design conditions in Indiana were evaluated to ascertain the relative theoretical importance of the design variables. The results of this analysis are plotted in Figure 35. The traffic parameter is the most important factor and accounts for relatively 85 percent of the instantaneous rates of thickness change produced by all the design parameters. The resistance value determines 15 percent of the rates of flexible pavement 


\section{CALIFORNIA STABILOMETER DESIGN}

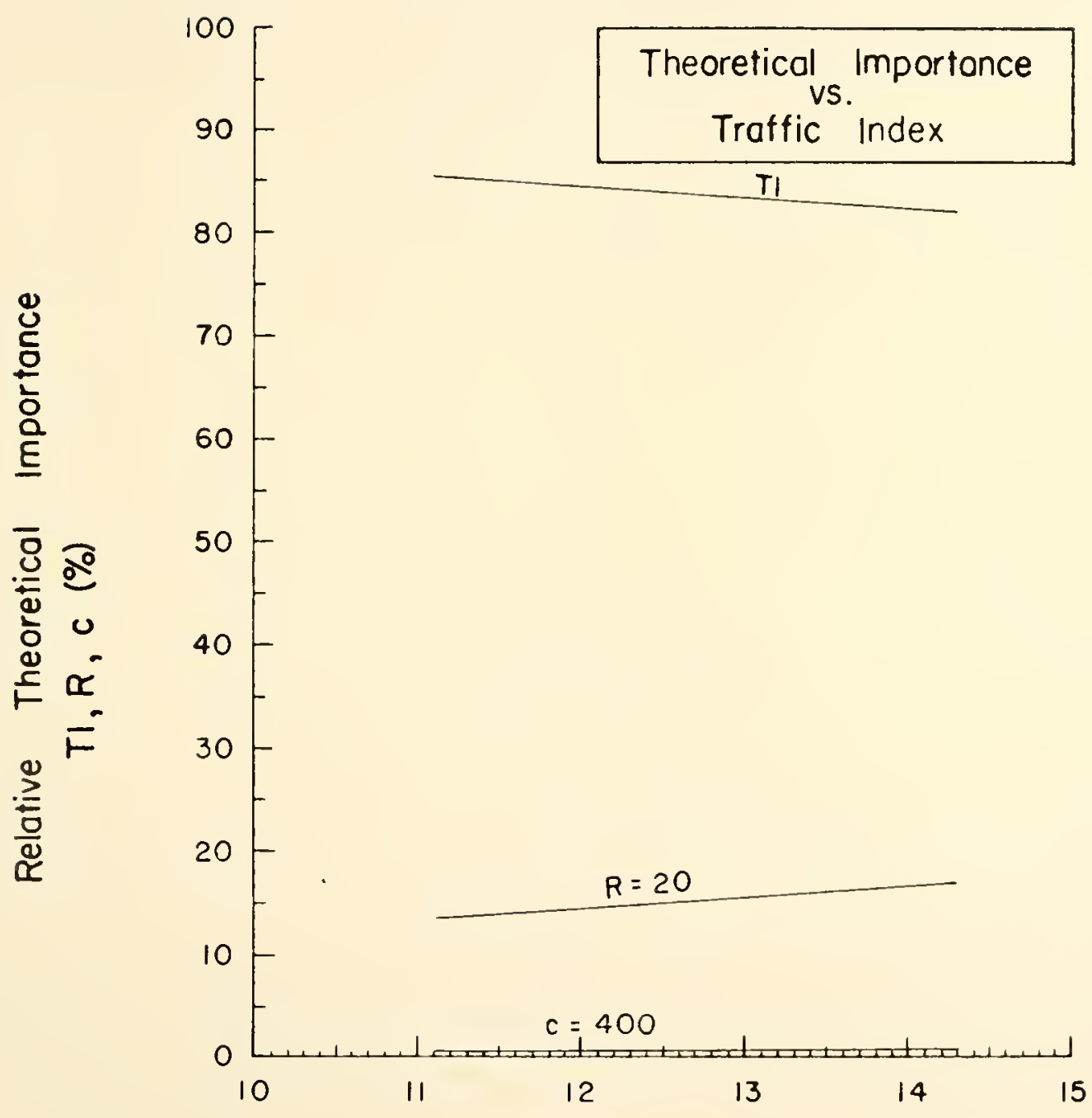

Traffic Index $\mathrm{TI}$

Figure 35. Relative Theoretical Importance of California Stabilometer Design Porameters 
thickness changes, and the cohesiometer value is of minimal theoretical influence by accounting for less than 1 percent of the rates of change. To 1 liustrate the parameter importance for a range of soil support conditions, high and low design resistance values representing one standard deviation above and below the average were plotted in Figures 36 and 37 . A comparison of these flgures with the graph of average conditions shows an insignificant increase in the importance of the subgrade parameter for higher numerical values of soll resistance. Changes in the relative importance measures are very small for a wide variation in cohesiometer values.

A practical evaluation of the 1mportance of Califoria Stabilometer parameters was also made for various combinations of these values, but only combinations encompassing typical design situations are illustrated. This practical measure of importance indicates a remarkable 1 ncrease in the importance of the cohesiometer value and a decrease in the importance of the traffic index as compared to the corresponding theoretical measures of relative importance. This phenomenor reflects the influence of parameter variations on thickness determinations. These variations were not examined by the relative theoretical importance evaluation.

The same parameter value combinations of Figures 35.36 and 37 were used in the evaluations of practical parameter importance illustrated in Figures 38,39 and 40 . Practical influence of different cohesiometer values is neEl181ble, and a figure illustrating this effect is not presented. 
CALIFORNIA STABILOMETER DESIGN

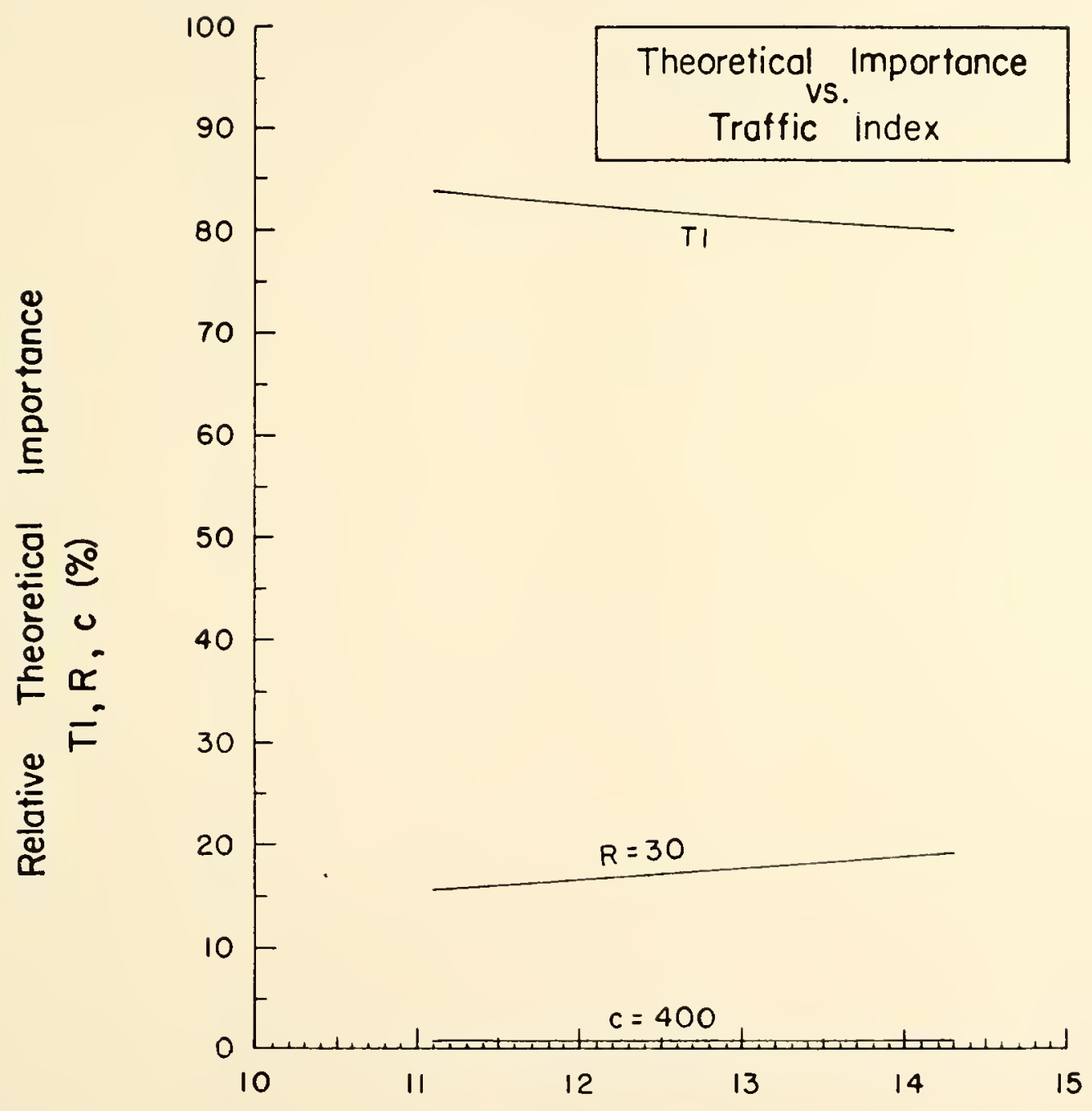

Traffic Index TI

Figure 36. Relative Theoretical Importance of California Stabilometer Design Parameters 
CALIFORNIA STABILOMETER DESIGN

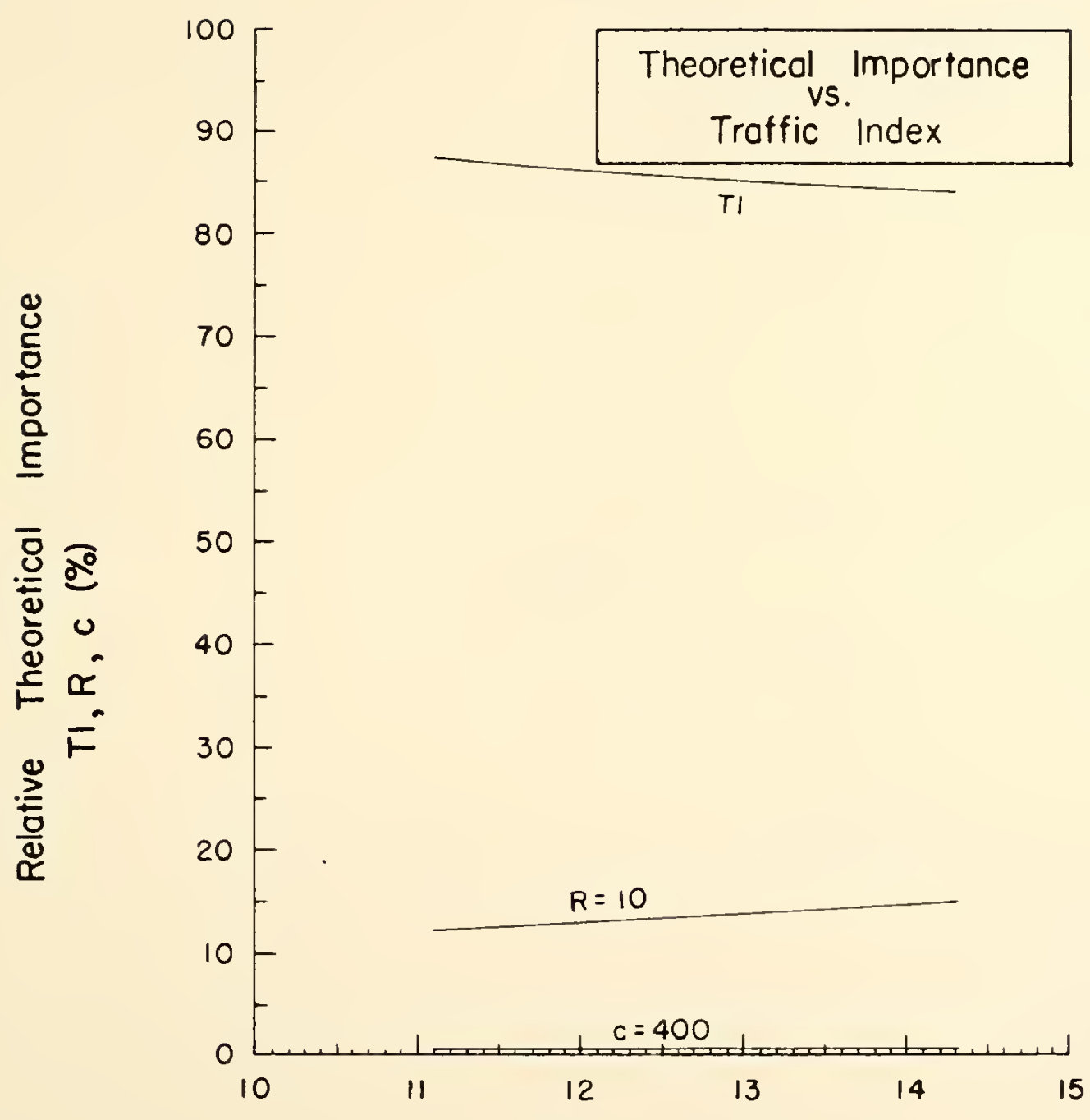

Traffic Index TI

Figure 37. Relative Theoretical Importance of Colifornio Stabilometer Design Porameters 
CALIFORNIA STABILOMETER DESIGN

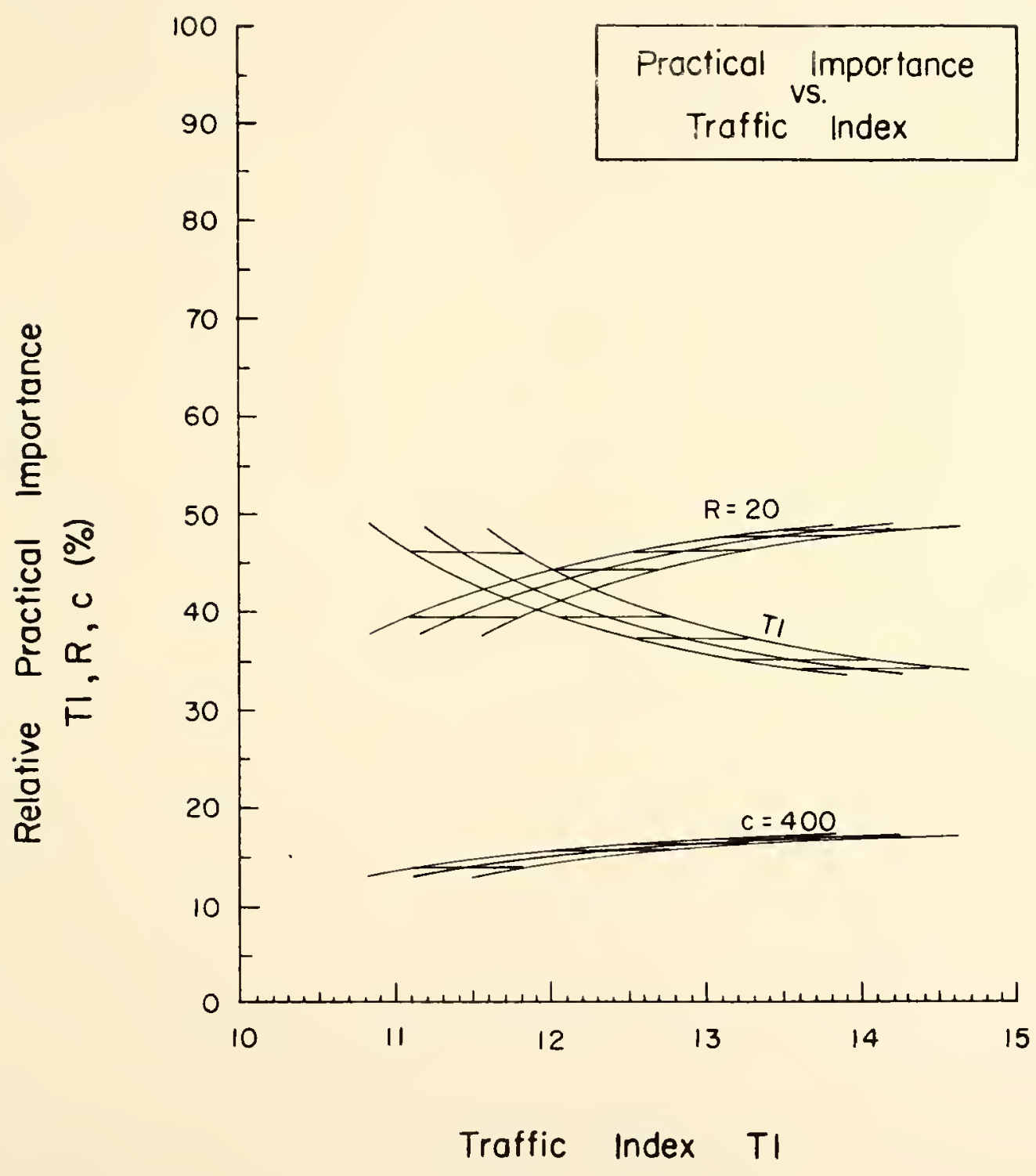

Figure 38. Relative Practical Importance of California Stabilometer Design Parameters 


\section{CALIFORNIA STABILOMETER DESIGN}

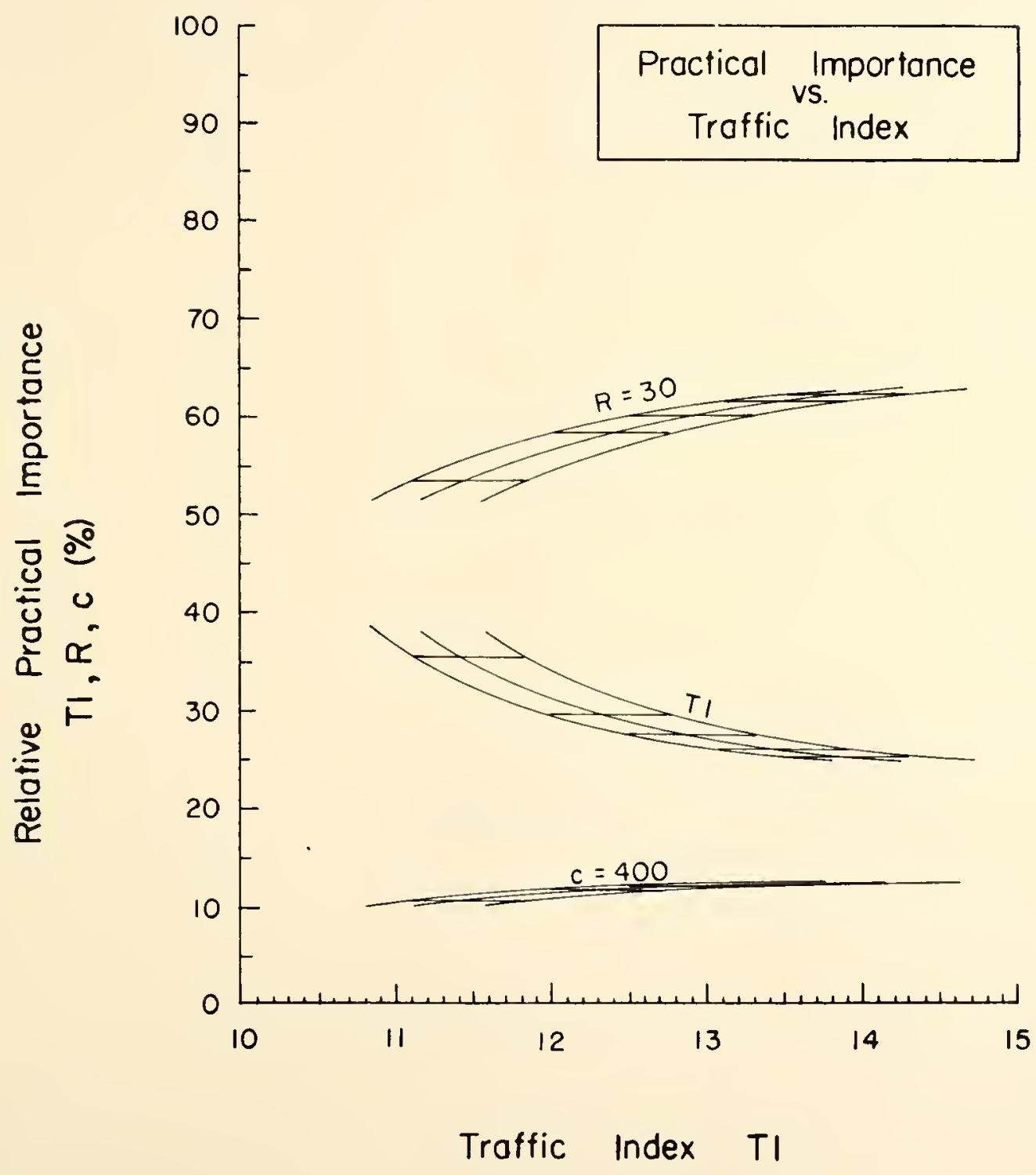

Figure 39. Relative Practical Importance of Californio Stabilometer Design Parameters 
CALIFORNIA STABILOMETER DESIGN

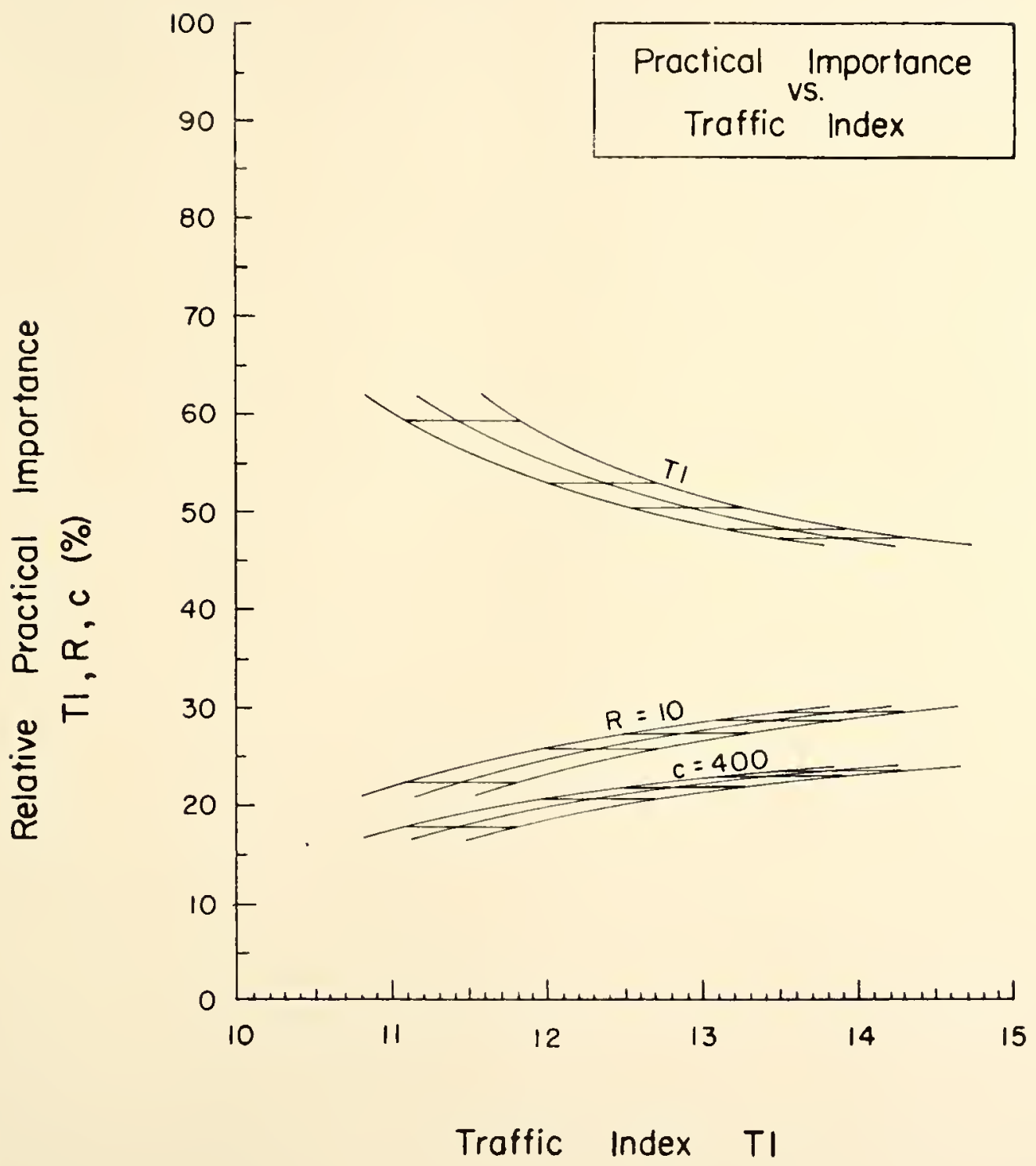

Figure 40. Relative Practical Importance of California Stabilometer Design Parameters 
If the parameter combinations of resistance value of 20.0 psi. cohesiometer value of 400.0 psi and traffic index of 12.0 is regarded as average then a reasonable image of practical parameter importance is obtained from Figure 38. A traffic index of 12 describes a traffic stream composed of 20 percent trucks traversing a highway that operates at 1200 vph for 20 yr. The appropriate lines of Figure 38 describing this traffic situation are explained by the reference Figure 10. The resistance value appears to be the most important parameter by accountine for 45 percent of the possible thiciness variations. Traffic index ranles a close second at 40 percent importance followed by the cohesiometer value which is of 15 percent importance in the California Stabilometer design process. Better subgrades increase the relative importance of their descriptive parameters, but higher cohesiometer values do not chance the relative practical importance of that parameter. The various curves of practical importance are flat which indicates the parameter influences on thickness do not vary appreciably with different traffic loads.

While two approaches were used to determine the relative practical importance of the various design parameters, corresponding results from these approaches are identical to the nearest 0.1 percent. Thus, the findings of either approach are represented in Figures 38, 39 and 40 and the first-order partial derivatives are concluded to be good approximations of the basic California Stabiloneter design equation over small ranjes of paraneter values. 
Tolerable Parameter Variations. In analyzing the pavement design process, the size of parameter changes which are permitted before significant changes in the design thickness are required offers an interesting evaluation. This determination strongly indicates the agreement of thickness design precision and construction tolerances with present ability to ascertain parameter values.

By substituting several selected thickness changes in the total differential of the California Stabilometer design equation, the size of tolerable changes in design parameters were determined for specified thickness changes. Tolerable parameter variations are illustrated in Figures 41 and 42 for the following combination of parameter values: a resistance value of 20 psi, a cohesiometer value of 400 psi and a traffic index of 12. The maximum percentages of parameter variation permitted in the subgrade and traffic factors for a 1.0-in. thickness change are about 10 and 50 percent, respectively, while the tolerabie change in the cohesiometer value is about 25 percent. This variation is contrary to that expected in the usual design process which ordinarily has a greater variation in subgrade support than in the structure quality of the pavement. The parameter variation for the major change criterion is considerably less than the usual variation associated with each parameter value in actual practice, and the precision demanded in the design and construction process is not harmonious with the precision of the data which forms the basis for selecting a pavement thickness. 
CALIFORNIA STABILOMETER DESIGN

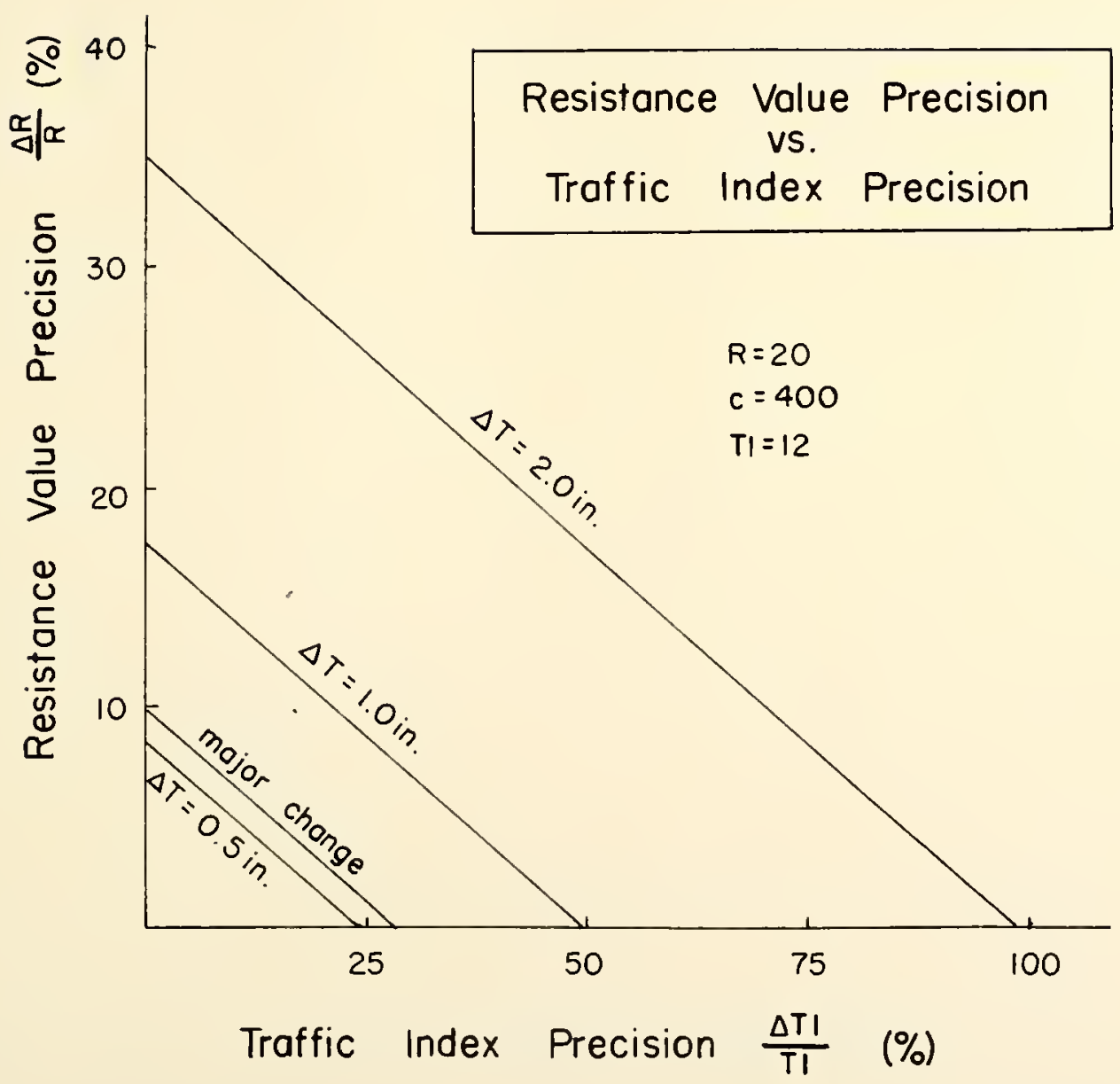

Figure 41. Tolerable Precision of California Stabilometer Parameters 
CALIFORNIA STABILOMETER DESIGN

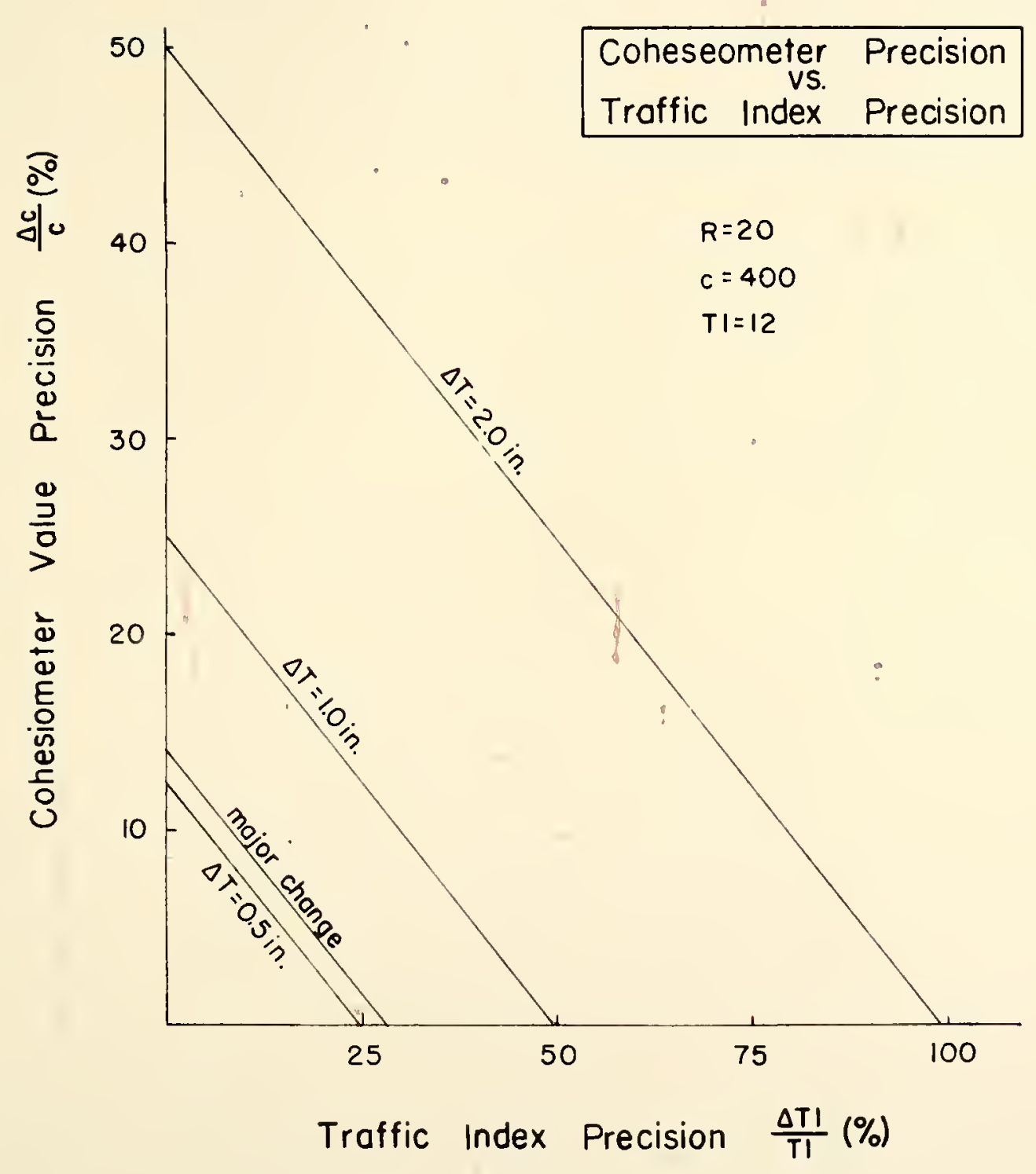

Figure 42. Tolerable Precision of California Stabilometer Parameters 
Least Squares Analysis of California Stabilometer Design.

Thicknesses that are determined by the parameters and criteria of the California Stabilometer design method were fitted by the selected linear, quadratic and cubic equations. These models relate thickness to the two factors of traffic and soli support which were judged to be the more important in the sensitivity analysis of the California stabilometer desion process.

To have comparable regression equations for all design techniques analyzed in this research study, each generic factor was quantified by the same paraneter. Therefore, the least squares equations for the California Stabilometer technique, as well as the other two selected flexible pavement design techniques, relate thickness to an equivalent 5000-Ib wheel load measure of traffic and to a California Bearing Ratio measure of soil support. These equations and their measures of statistical efficiency are presented in Table 4. The specific models determined for the California stabilometer design show a slight improvement in statistical efficiency from the linear to the quadratic to the cubic models. However, the linear model best demonstrates the influence of the selected parameters on the dependent thickness variable by clearly showing that required thicknesses increase with increasing traffic loads and decreasing bearing ratios. The positive or negative signs preceding the regression coefficients of the quadratic and cubic models do not readily indicate these basic trends in required thickness. 


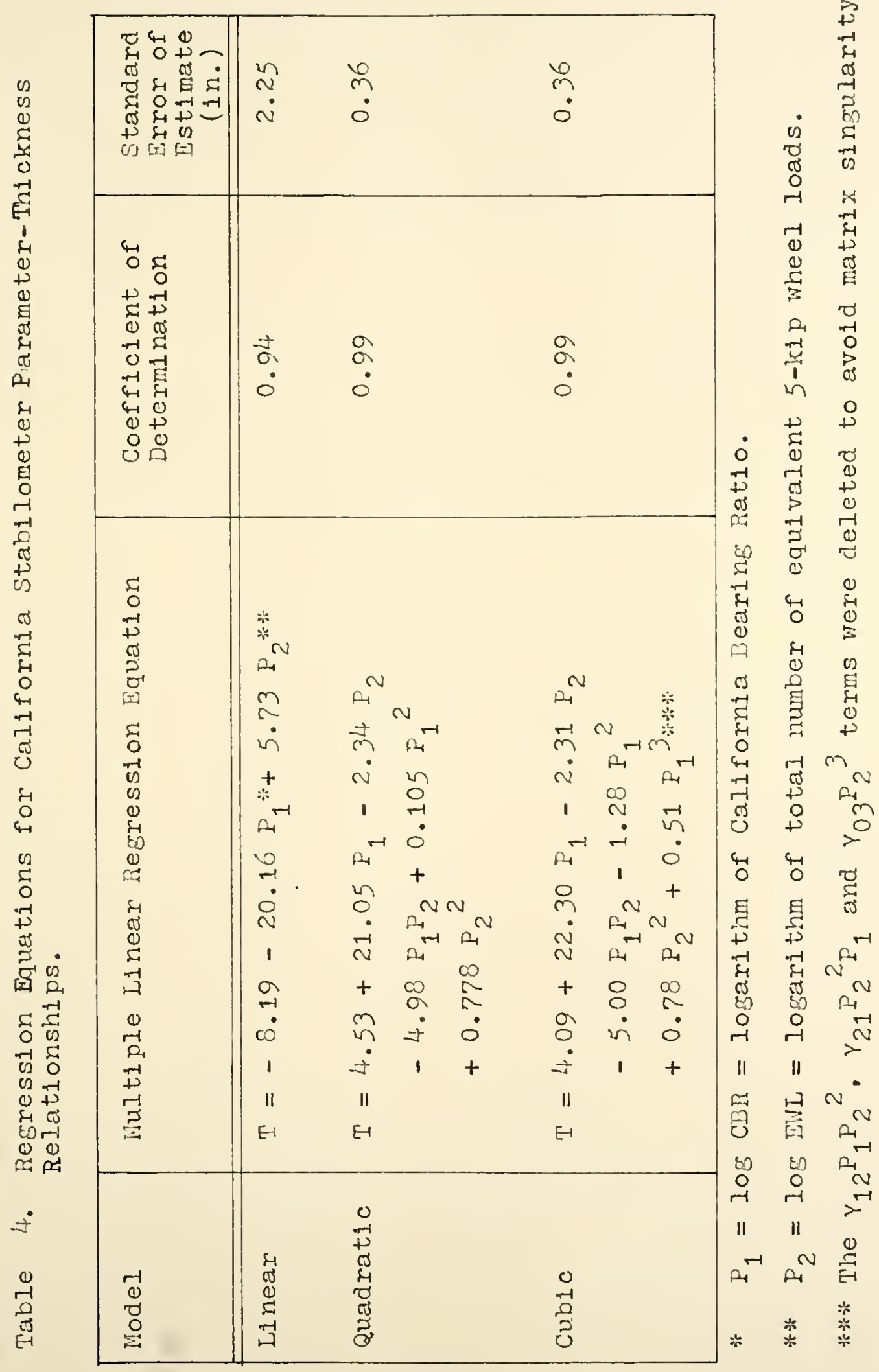


Summary of Flexible Pavement Design Results

The AASHO Flexible, Corps of Engineers Flexible and California Stabilometer design methods were analyzed to identify and examine the relative effects on thickness of the various factors considered in these pavement design processes. A hierarchy structuring of design-process logic, a modeling of the design technique, a measure of relative theoretical parameter importance, two measures of relative practical parameter importance, an evaluation of tolerable parameter variation and a least squares rexression analysis were employed in the investigation of these flexible pavement design methods. While the design objective of an adequate highway pavement to serve the imposed physical and subjective demands is common to all pavement design techniques, the factors considered and their manner of employment are particular to each design technique. Although subsrade characteristics, traffic loads, pavement material properties, environmental factors and performance criteria are generally regarded as the primary factors affectins pavement design, a comparison of the hierarchy structures of each technique reveals unique differences among design processes.

After a rodel of each technique which was adequate for the sensitivity analysis was formulated, a quantitative evaluation of the theoretical influences of major factors on thickness substantiates the limited similarity amons flexible design techniques. While the Corps Flexible and California Stabilometer traffic parameters are of considerable theoretical 
importance to their respective design techniques, the AASHO Flexible traffic parameter has a negligible influence in the formulated thickness function. A summarization of parameter importance for each technique is presented in Table 5. Percent importance values shown are for the average design situation as defined for each design method.

Average practical measures of parameter importance are also shown in Table 5. These realistic measures which account for parameter variations show a general agreement among design methods of the relative importance of the primary factors which influence pavement thickness. The traffic measures and the supporting soil parameters are ranked as the two most important factors in practical importance, and pavement material properties are third anong the flexible design procedures.

The tolerable parameter variations for selected thickness change constraints are somewhat peculiar to each destgn method. However, the parameter changes permitted before major changes in the final design thickness are required are considerably smaller than the variations usually associated w1th parameter design values. This disparity is not conclusively attributed to any particular circumstance.

Linear, quadratic and cubic models were fitted to parameter-thickness data generated for each design method. The coefficients of these least squares analyses afford a common basis for comparison of design factor importance among techniques. The equations resulting from this regression 


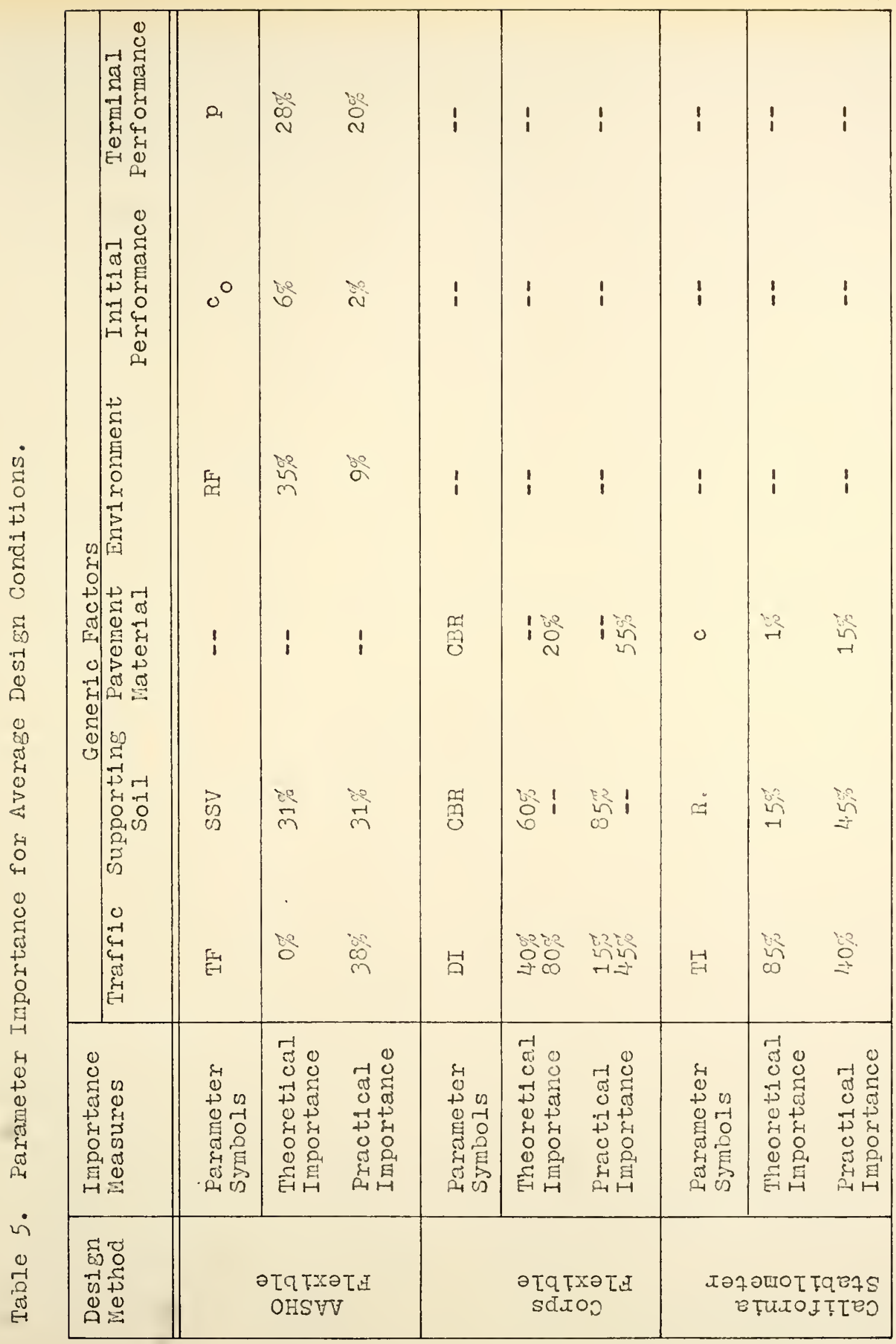


analysis are listed in Tables 1, 2, 3 and 4. A summarization of the linear models is presented in Table 6.

If the regression coefficlents in the linear model indicate the relative weight of the California Bearing Ratio subgrade parameter among design methods, then soll support is most important in the Corps Flextble design method, least important in the AASHO Flexible desion method and intermediate in importance in the California stabilometer technique. By the same reasoning the 5000-Ib equivalent wheel load traffic parameter is most important in the AASHO Flexible design method, intermediate in importance in the California stabilometer design method and least important in the Corps Flexible design technique.

\section{Higid Pavement Design}

The three rigid design techniques investigated in this research project are AASHO Rigid, Corps Rigid and PCA Rigid design methods. Each technique was studied to determine a hierarchy of design-process logic, to develop a design model adequate for the sensitivity analysis, to evaluate the 1mportance of design parameters by theoret1cal and practical measures and to examine tolerable parameter variations. An additional basis for analyzing rigid pavement designs is provided by the equations resulting from a least squares fit of Itnear, quadratic and cublc models to parameter-thickness data generated for each design technique. 


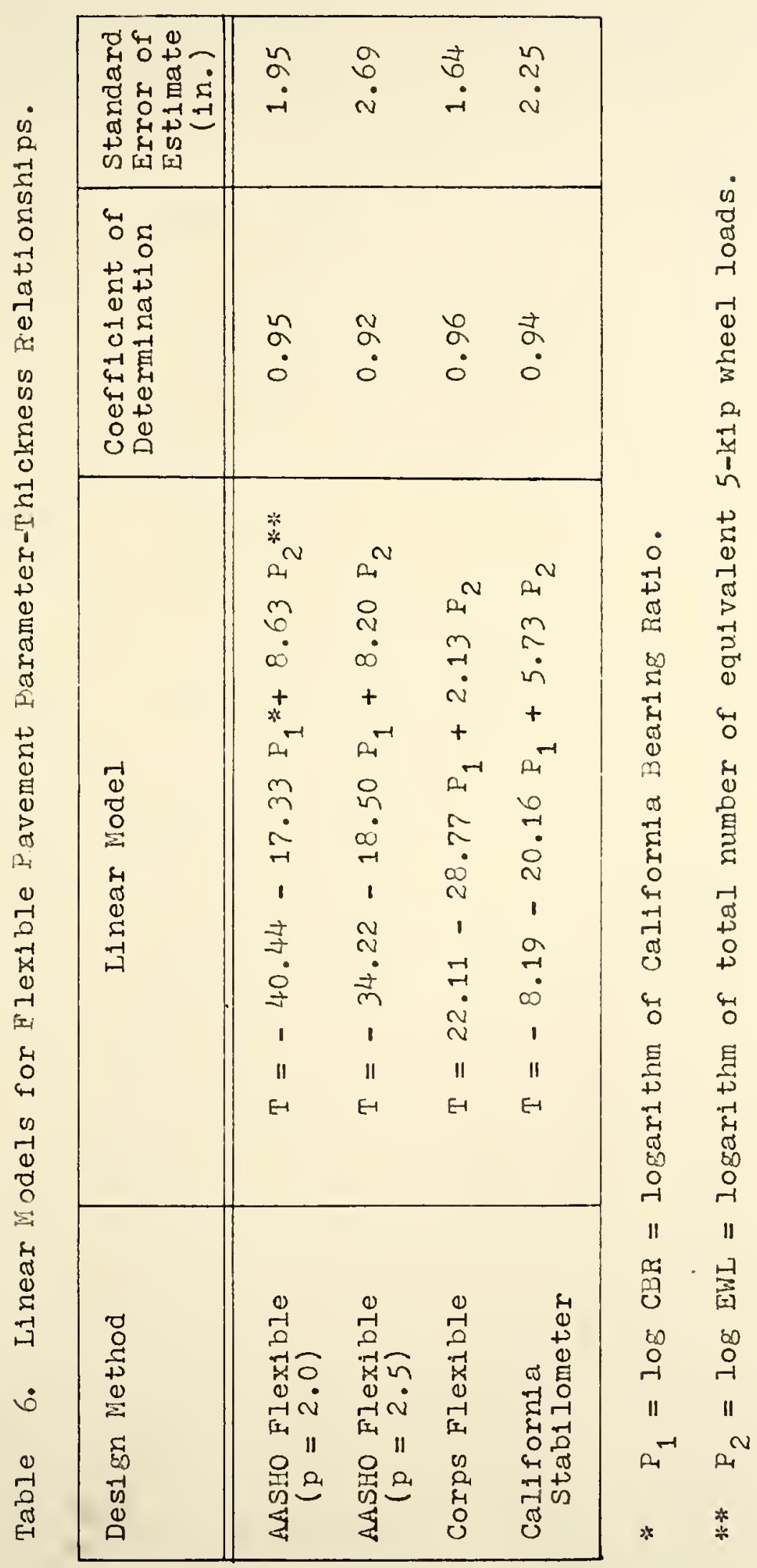




\section{A}

Design-Process Logic. The logic in resolving rigid pavement thicknesses by the AASHO design procedure is illustrated in Figure 43. This chart depicts the major design parameters and the subordinate factors which influence these values. Although this design-process logic stems from the same Road Test that spawned the AASHO Flexible design process, significant differences exist between the two procedures. Rigid pavement thickness is directly determined without the intermediate evaluation of a structural number, and environmental considerations, which are an integral part of the flexible pavement design rationale, are not explicitiy considered in the AASHO Rigid design process. In the development of the AnsHo Rigid design technique, theoretical as well as empirical relationships were employed in extending the Road Test findings to encompass a variety of subgrades and concrete qualities. The parameters employed in the design equation to make this extension were well established, measurable parameters Which contrasted with the soli support value, layer property coefficients and regional factor empiricisms of the AASHO Flexible technique.

The major factors of soil support, pavement material properties and traffic loads are described in the AASHO Rigid design process by the modulus of subgrade reaction, the working flexural stress of concrete and the total equivalent 18-kip single-axle load applications, respectively. The design value for each parameter depends directly on an 


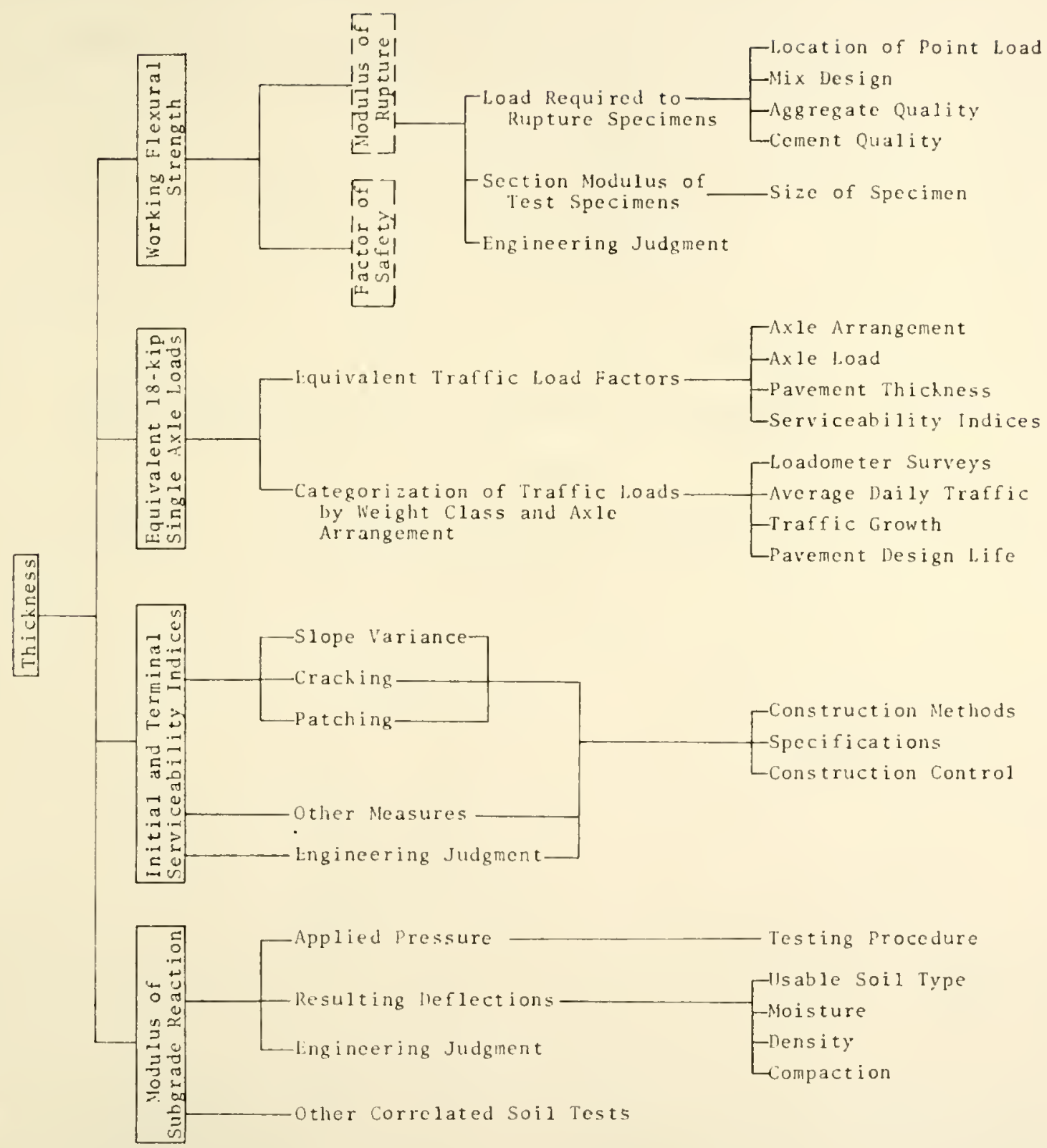

\section{Figure 43. Hierarchy Structure of AASHO Rigid Design-Process Logic}


evaluation of the second hierarchy level factors which are influenced by those 1 tems shown at the third level. The modulus of subgrade reaction and working flexural stress are explicitly defined by laboratory tests while the serviceability indices most of ten depend substantially on subjective judgment. Determination of the traffic parameter depends on the pavement thickness and selected initial and terminal serviceabilities as well as an estimation of the anticipated traffic. This interfacing of the traffic parameter with the pavement structural and performance qualities is unique to the AAsHo design methods. Modeling of the AASHO Rigid Design Method. The thorough formulation of the AASHO Rigid design process included the development of the design charts in Append1x D and a corresponding comprehensive design equation. That equation, written in terms of slab thickness, equivalent 18-kip single-axle load applications, subgrade modulus, working flexural strength, modulus of elasticity and serviceability indices, is shown In the Review of Design Methods as equation 23. Because all design parameters are related to the required pavement thickness in a single equation, no further development of that expression was required to obtain the thickness function model needed for the sensitivity analysis.

\section{Sensitivity Analysis of the AASHO Rigid Design Method.}

The hierarchy structuring of the design-process logic and the modeling of the AASHO Rigid technique were phases of the research completed preparatory to the sensitivity analysis which 
quantitatively evaluated the major factors influencing pavement thickness. Predicated on the premise that the more important factors produce a greater change in thickness, measures of theoretical and practical parameter importance were calculated for a wide range of parameter values which encompass most desisn situations.

The relative theoretical parameter importance measured the instantaneous rate of change (quantified by the firstoraer partial derivative) in the design thickness as produced by a particular parameter relative to that change produced by the other design parameters. Calculations of theoretical importance were made for most combinations of realistic subgrade moduli, initial and terminal serviceability indices. concrete flexural strengths and equivalent 18-kip single-axle load applications, but only those parameter value combinations that are reasonably indicative of usual design situations were evaluated for the illustrations in Figures 44, 45, 46 and 47 .

Trends evidenced in these plots of relative theoretical importance versus traffic factor indicate that the terminal serviceability index parameter completely dominates this comparative measure of importance. The initial serviceability index is ranked a remote second, and the traffic, subgrade and pavement material parameters are estimated to be of negligible relative importance by this theoretical measure. With heavier traffic loads the serviceability indices assume lesser importance; however, stronger pavements or subgrades increase 


\section{AASHO RIGID DESIGN}

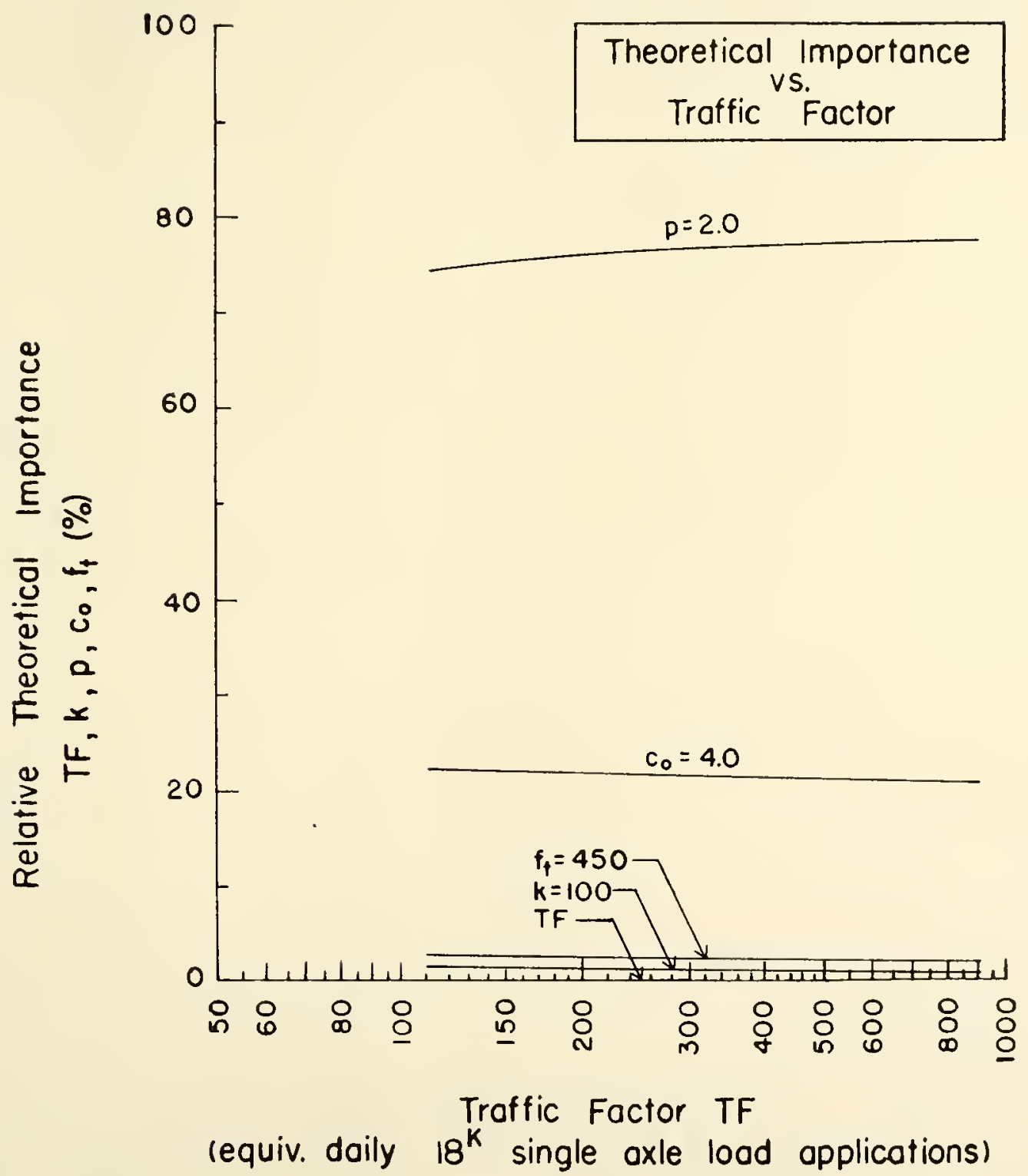

Figure 44. Relative Theoretical Importance of AASHO Rigid Design Parameters 
AASHO RIGID DESIGN

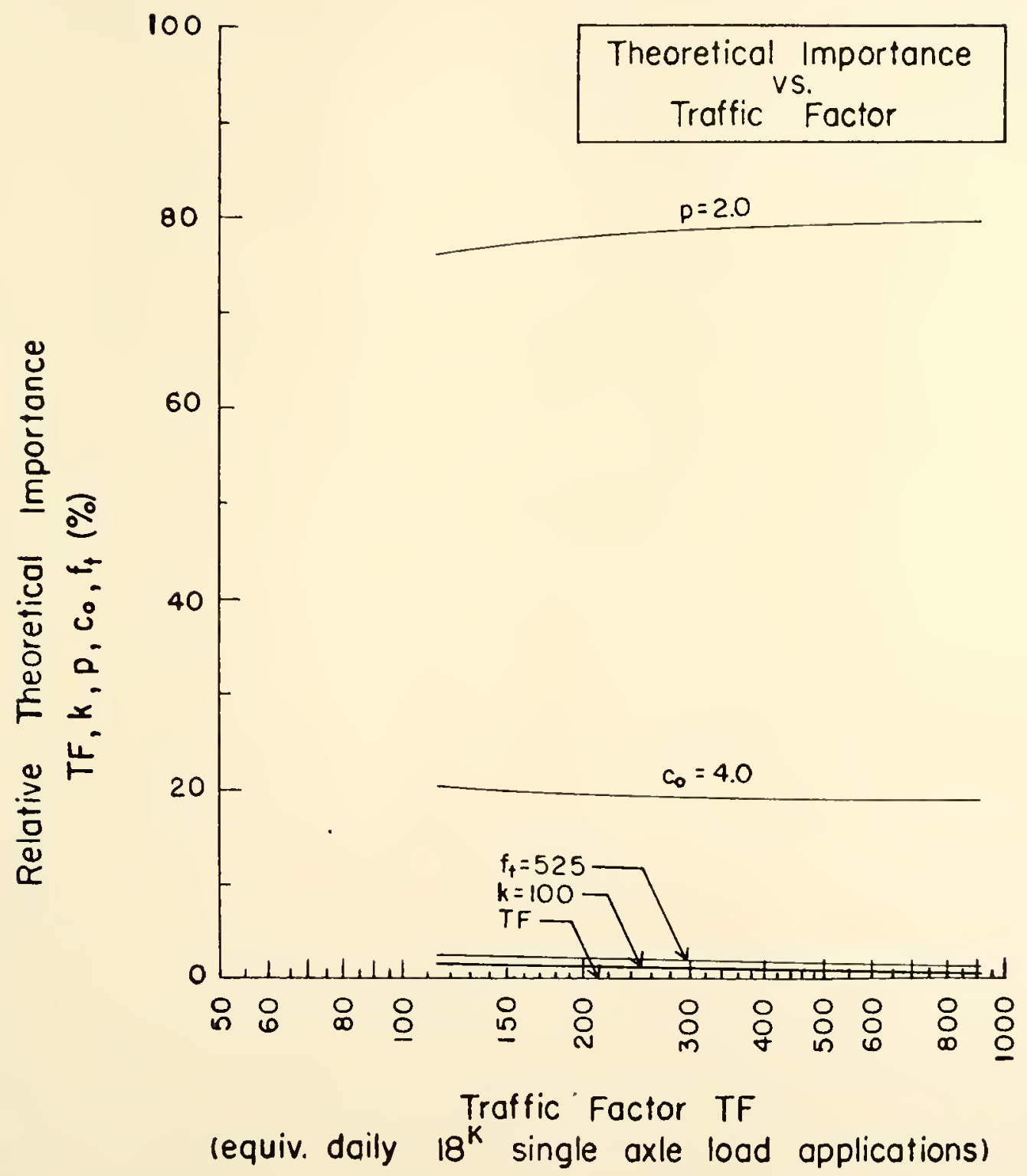

Figure 45. Relative Theoretical Importance of AASHO Rigid Design Parometers 


\section{AASHO RIGID DESIGN}

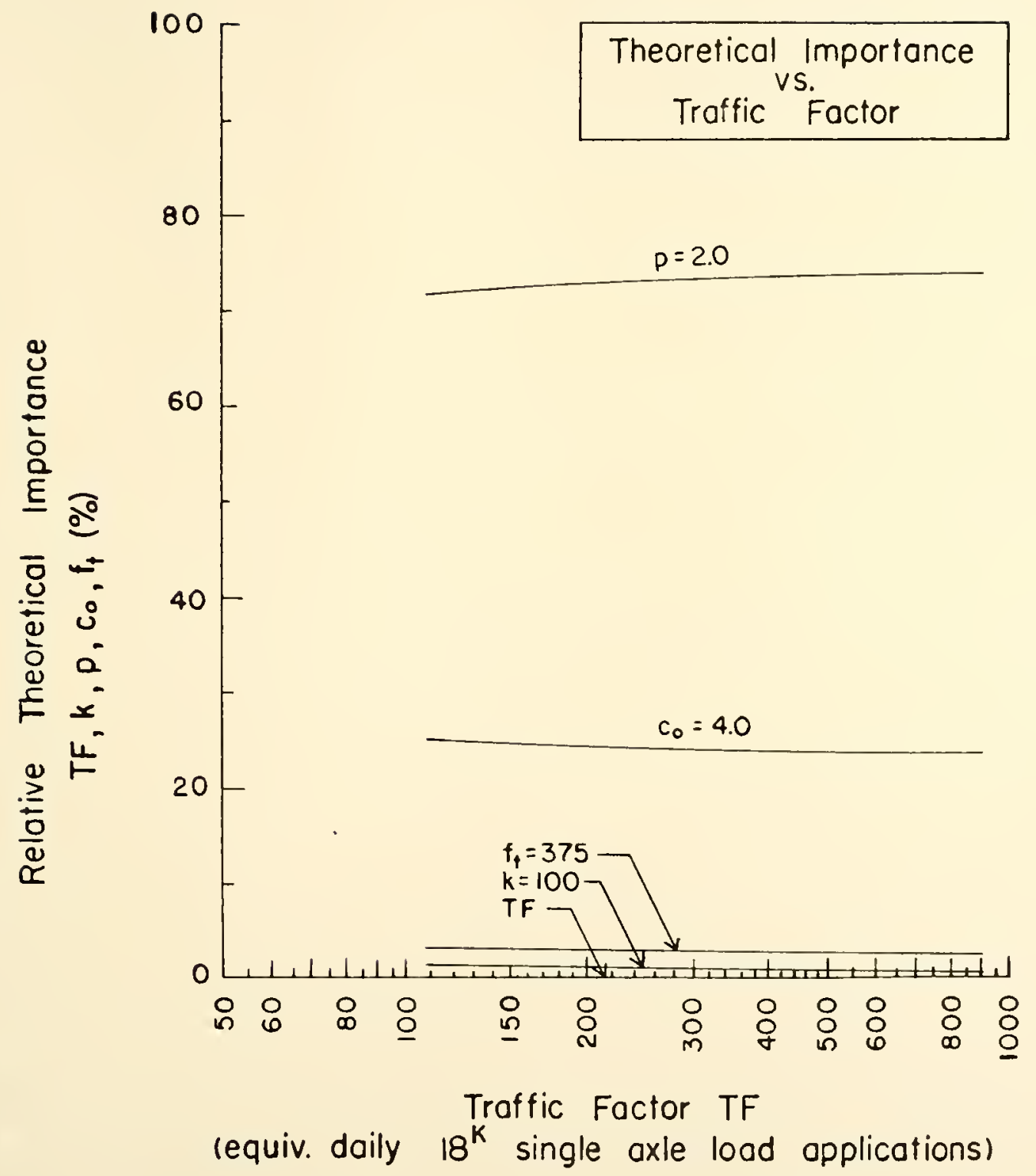

Figure 46. Relative Theoretical Importance of AASHO Rigid Design Parameters 


\section{AASHO RIGID DESIGN}

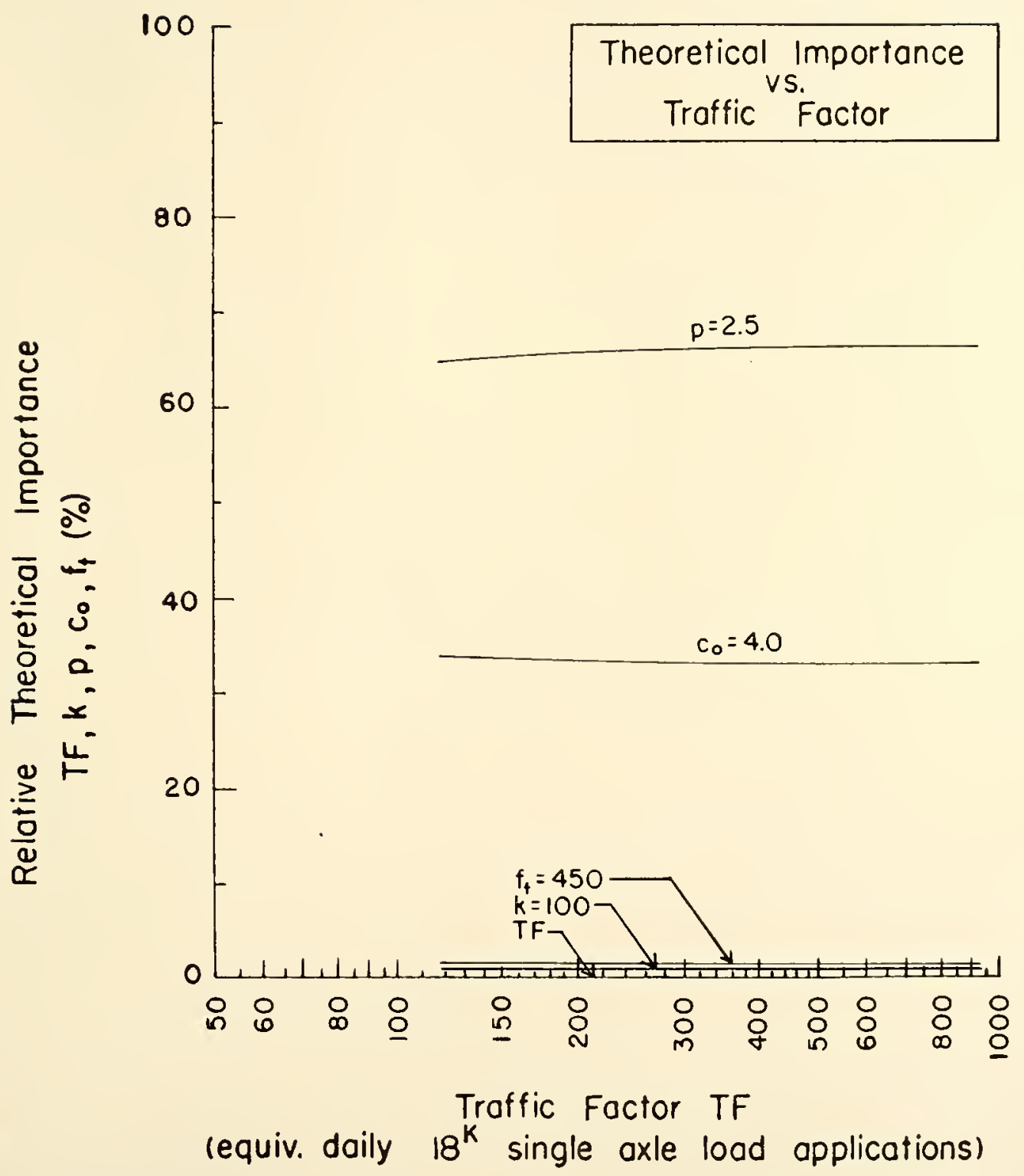

Figure 47. Relative Theoretical Importance of AASHO Rigid Design Porameters 
the relative theoretical importance of the serviceability parameters.

The importance of AASHO Rigid design parameters for average design conditions are shown in Figure 44. A traffic factor of about 200 equivalent daily 18-kip single-axle load applications reasonably describes a highway which operates at a peak volume of $1200 \mathrm{vph}$ and which carries a typical traffic stream with 20 percent trucks. If this condition represents average traffic loadings, then the terminal serviceability index is rated 77 percent in theoretical importance, and the initial serviceability index accounts for 21 percent of the relative rates of thiclness change. The remaining 2 percent are distributed amons the flexural strength, the subgrade modulus and the equivalent single-axle load parameters. Parameter combinations which encompass most design situations were evaluated for the plots of Figures $44,45,46$ and 47 . but no appreciable changes in the relative theoretical measures of importance occur for the various parameter values analyzed. In contrast to the dominance of the serviceability parameters in the evaluation of theoretical importance, the practical measure of relative importance provides an appraisal of parameter influence that was more agreeable with preconceived notions. The relative practical importance percentages were calculated for a wide range of parameter value combinations, but illustrative graphs of this practical measure were prepared only for those combinations that are representative of the more common highway design situations. 
For the average conditions shown in Figure 48, the design parameters and their relative percentage of practical importance are 60 percent for the equivalent single-axle parameter, 20 percent for the flexural strength parameter, 9 percent for the modulus of subgrade reaction and for the terminal serviceability incex and 2 percent for the initial serviceability index. The meaning of the short horizontal and extended curve lines are 1llustrated in Figure 10. From a comparison of Figures 48,49 and 50, increased values of flexural strength cause insignificant changes in the relative influence on thickness of the various AASHO Rigid parameters. As the terminal serviceability index is increased, implying roads of better ridins quality the traffic, subgrade and pavement structure parameters assume less importance, but initial and terminal serviceability parameters take on greater importance. These findings are evident from a comparison of Figures 48 and 51. The plots of practical importance in Figures 52, 53, 54 and 55 were developed from the "actual thickness change" approach. These second measures generally substantiated the results of the "portions of the total differential" aprroach. In every AASHO Rigid practical importance figure, except Figures 51 and 55 where the terminal serviceability index was above the average value of 2.0 , the traffic factor and flexural strength parameter dominate. Therefore these two factors are concluded to be the most important influences in the MASHO Rigid design process. 
AASHO RIGID DESIGN

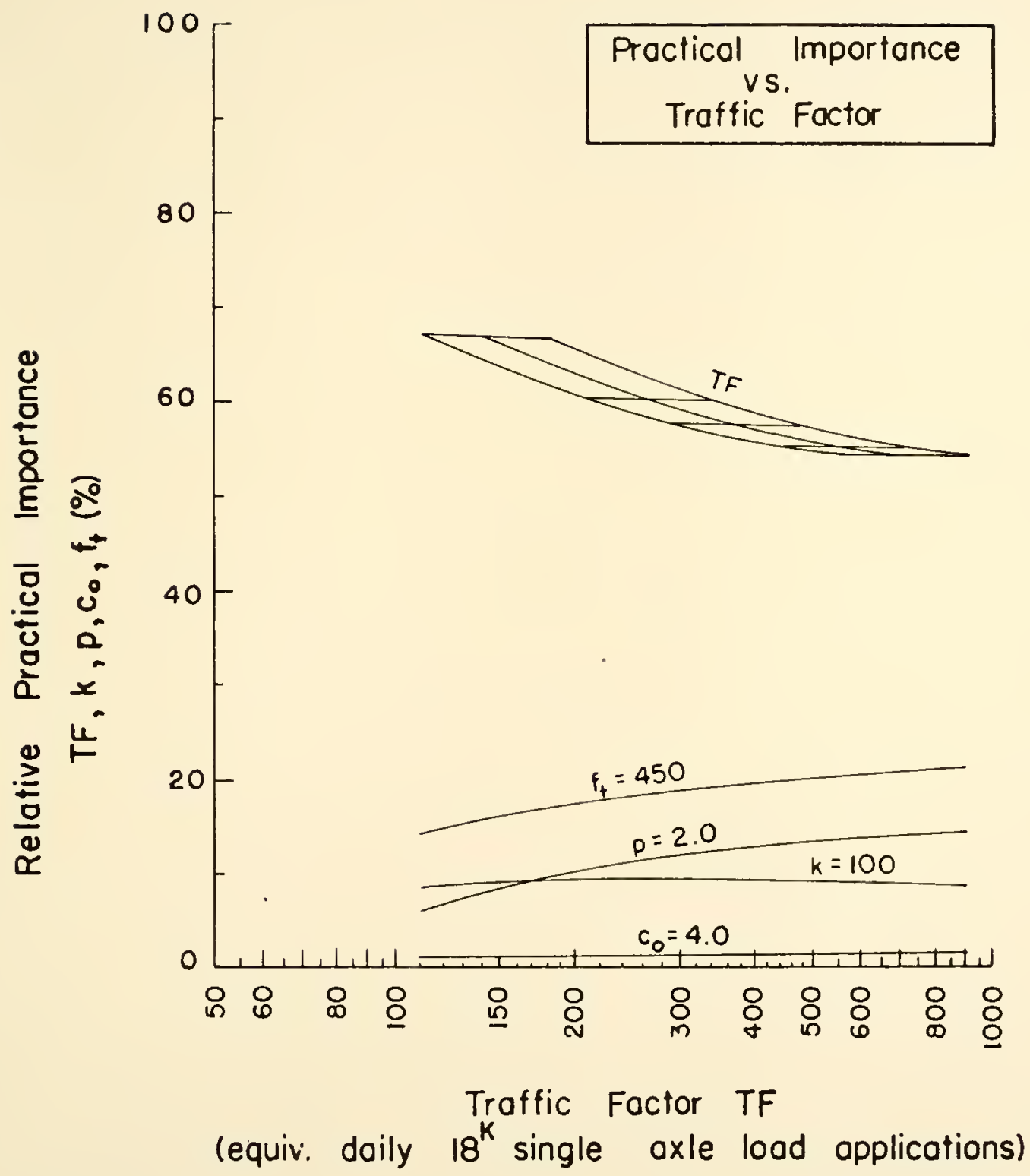

Figure 48. Relative Proctical Importance of AASHO Rigid Design Parameters for the Total Differential Approach 
AASHO RIGID DESIGN

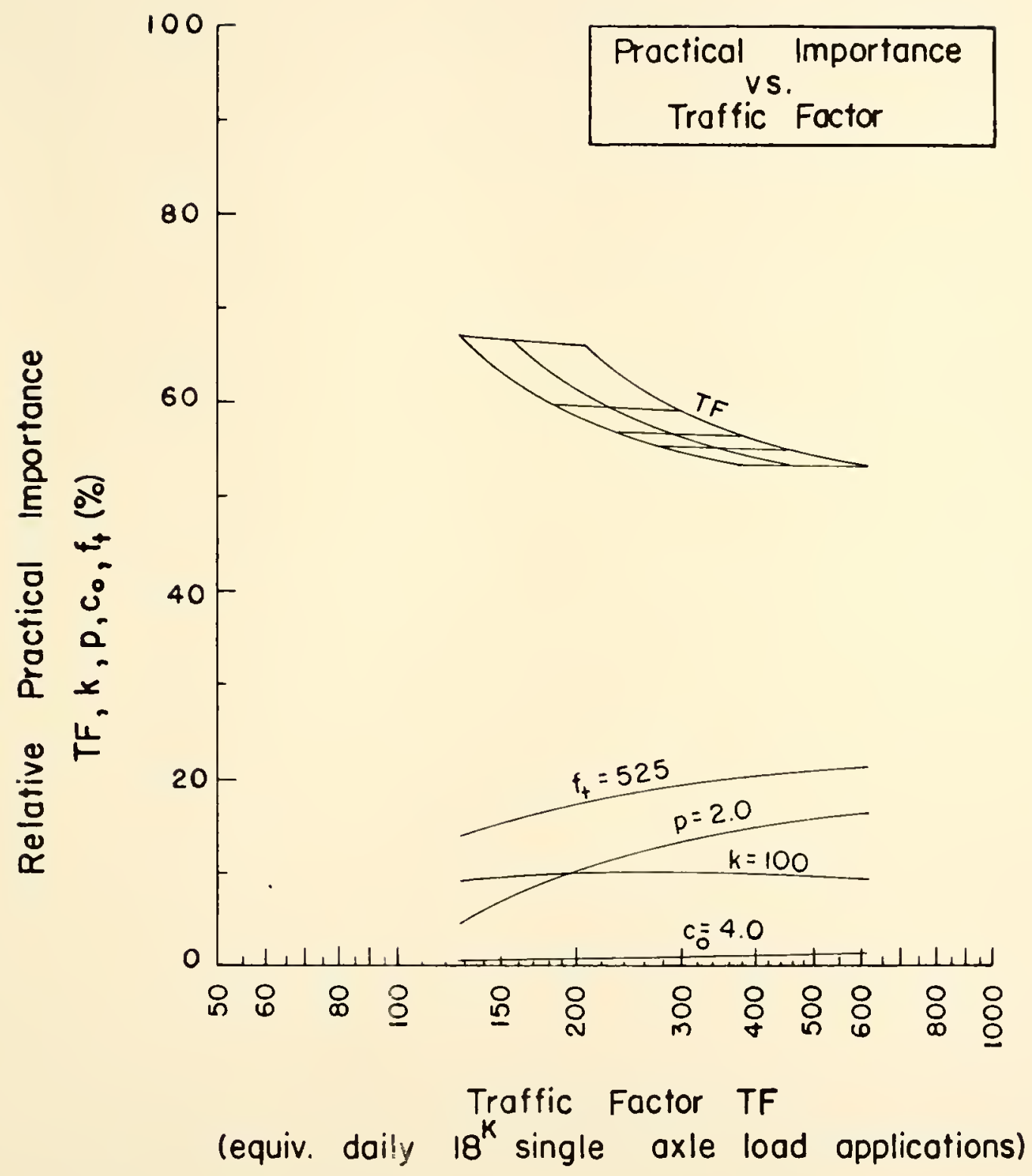

Figure 49. Relative Practical Importance of AASHO Rigid Design Parameters for the Total Differential Approach 
AASHO RIGID DESIGN

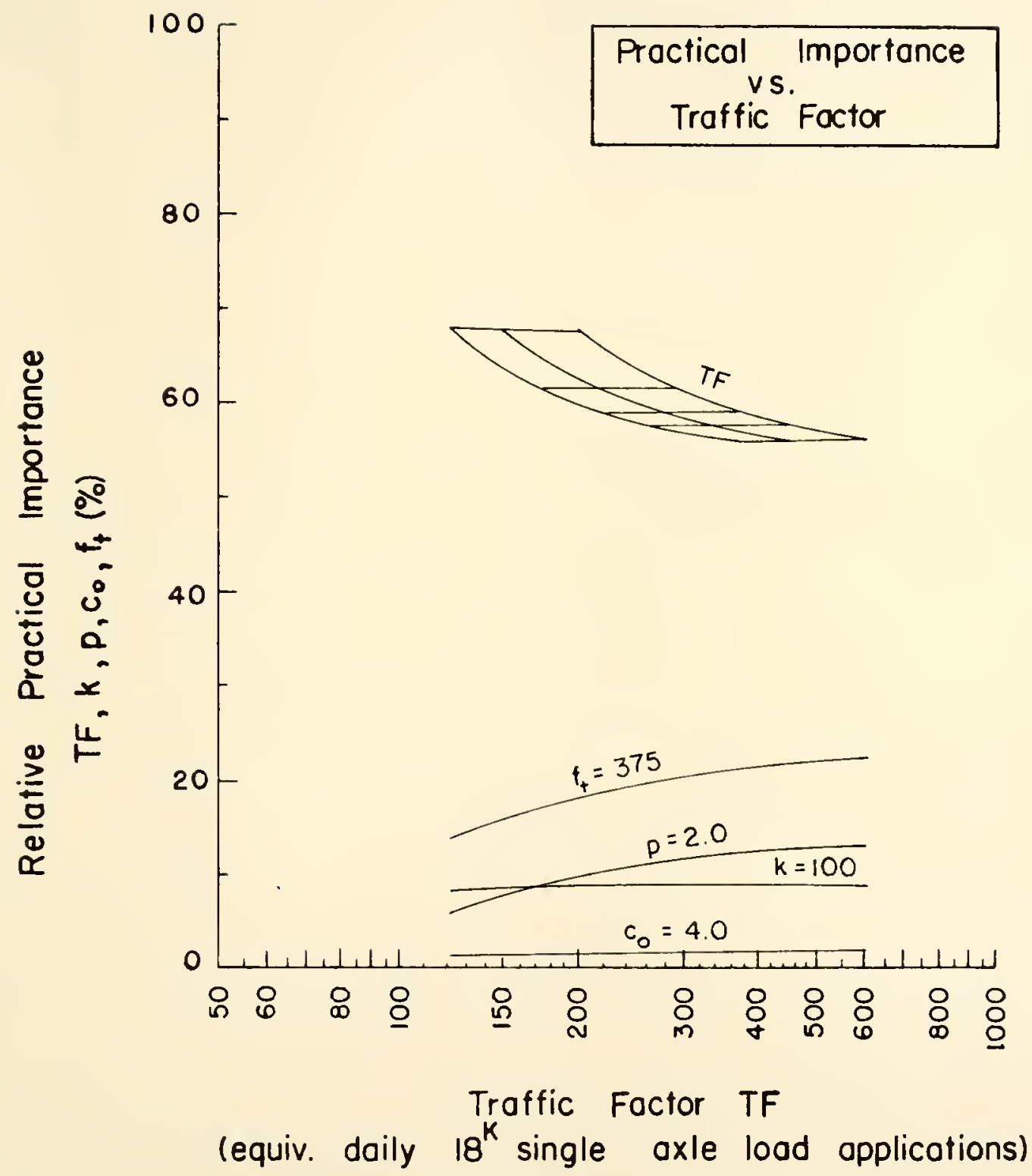

Figure 50. Relative Proctical Importance of AASHO Rigid Design Porameters for the Total Differential Approach 
AASHO RIGID DESIGN

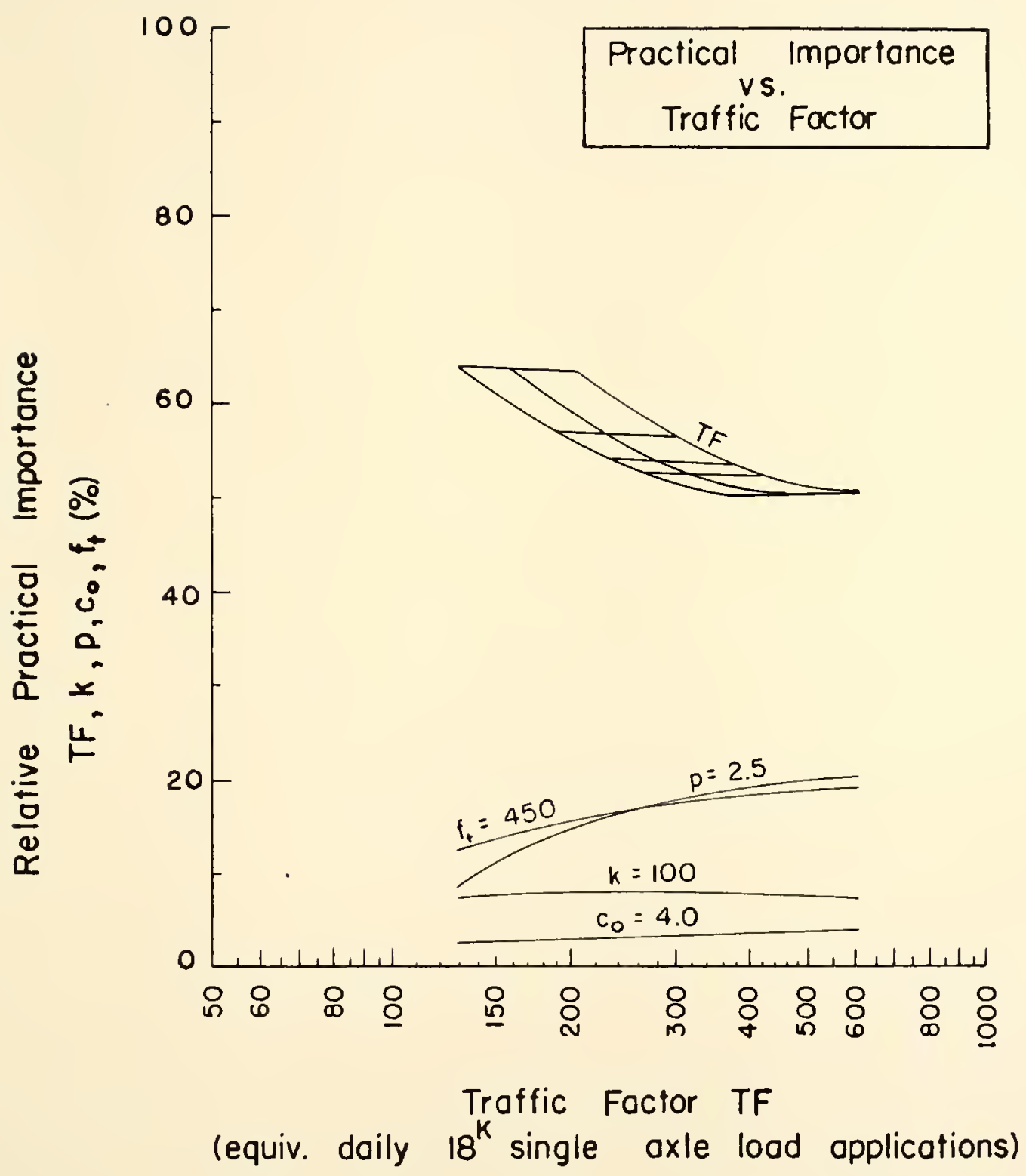

Figure 51. Relative Proctical Importance of AASHO Rigid Design Parameters for the Total Differential Approach 
AASHO RIGID DESIGN

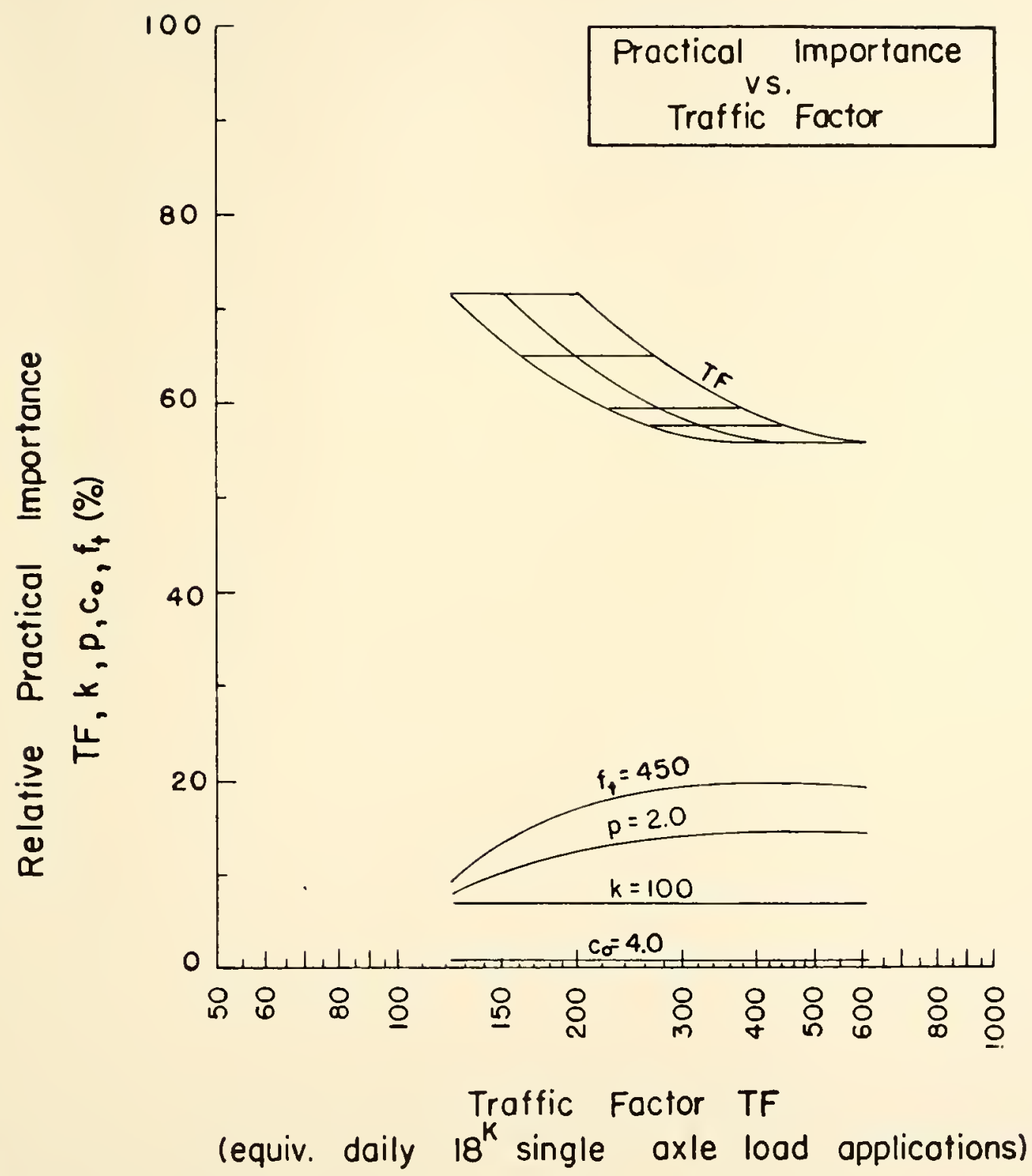

Figure 52. Relative Proctical Importance of AASHO Rigid Design Porameters for the Actual Thickness Change Approoch 


\section{AASHO RIGID DESIGN}

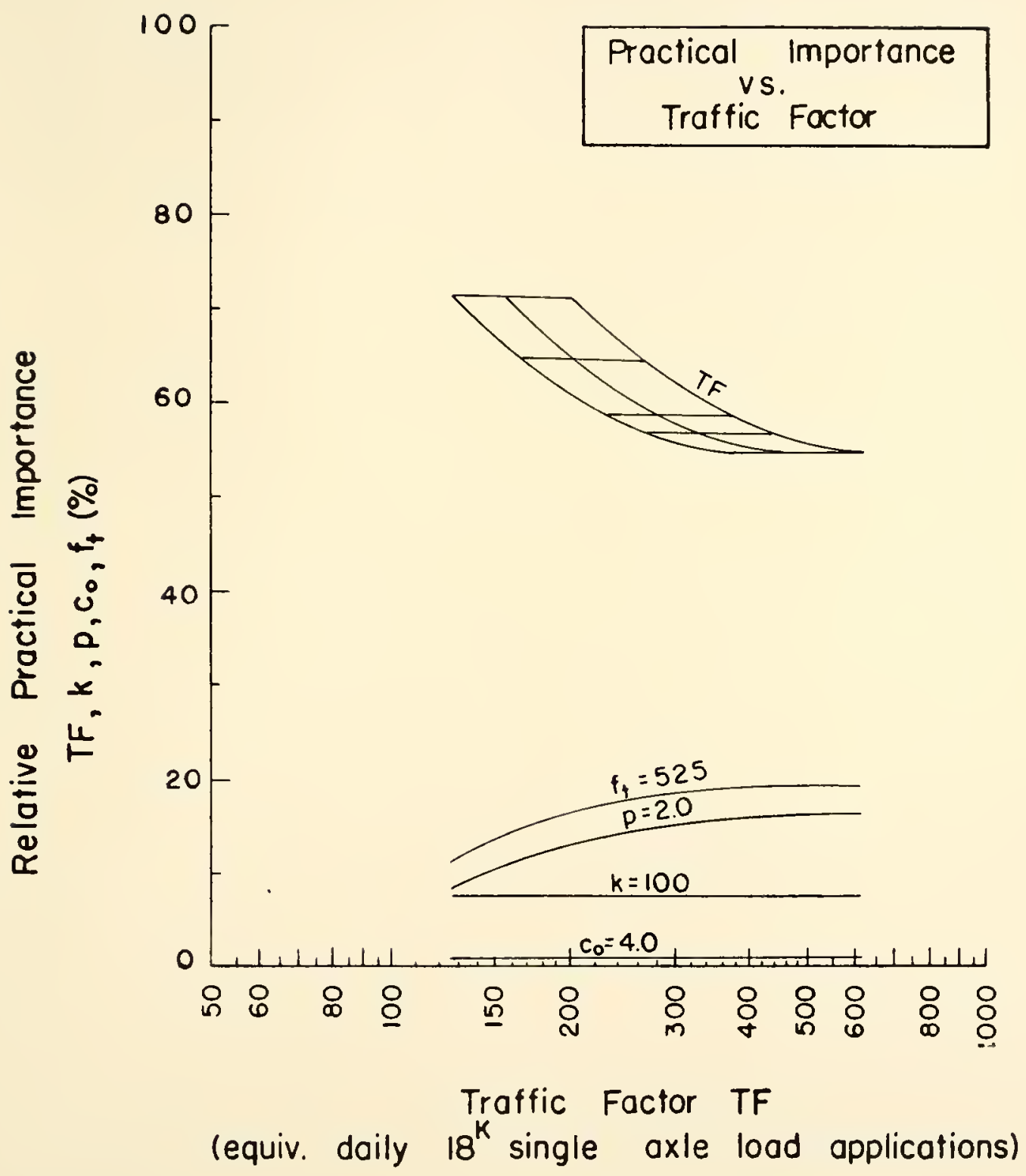

Figure 53. Relative Practical Importance of AASHO Rigid Design Parameters for the Actucal Thickness Change Approoch 


\section{AASHO RIGID DESIGN}

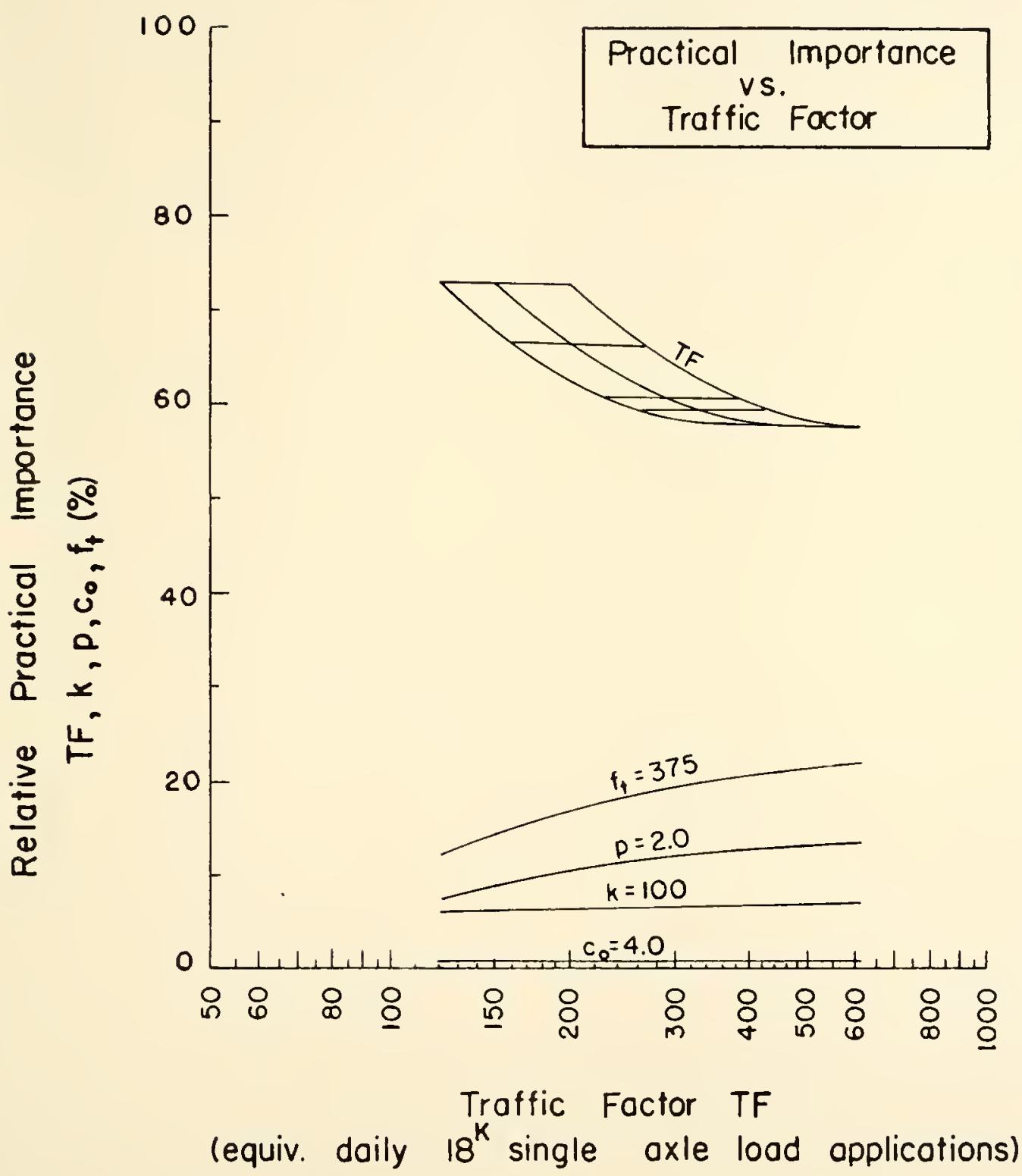

Figure 54. Relative Proctical Importance of AASHO Rigid Design Porameters for the Actual Thickness Change Approoch 


\section{AASHO RIGID DESIGN}

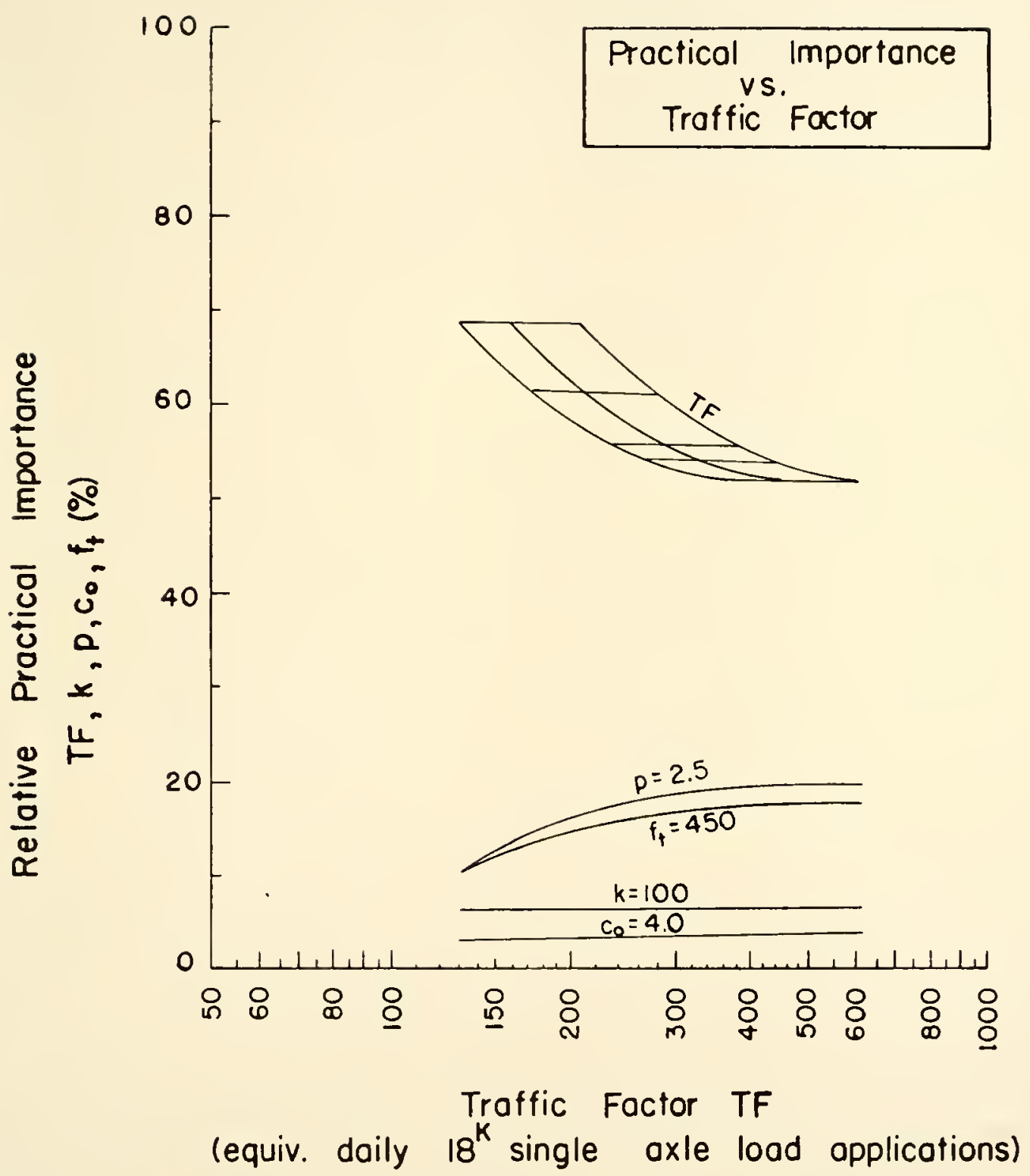

Figure 55. Relative Proctical Importance of AASHO Rigid Design Parameters for the Actual Thickness Change Approach 
Tolerable Parameter Variations. Typical examples of parameter variations within the constraints of several thickness change Iimitations are charted in Figures 56 and 57. These plots demonstrate the required precision of the traffic paraneter as compared to the needed precision of the terminal serviceability or flexural strength parameters for $0.5-1.0-$ and 2.0-in. thickness changes and for a 0.55-1n. major thickness change. By solving the total differential of the AASHO Rigid design equation for increments of parameter change corresponding to the selected thickness constraints, the size of the tolerable parameter variation was ascertained and was plotted as a percentage of the selected parameter design value.

For a design situation described by a subgrade modulus of 100 psi, a concrete flexural strength of 600 psi, a terminal serviceability index of 2.0 , an initial serviceability index of 4.0 and a traffic factor of 213 equivalent axle load applications, the allovable percentages of variations in the parameter values aṛe considerably less than normal variations in present-day measures. For the major thickness change limitation, the maximum tolerated variations are 10 percent for the terminal serviceability index, 16 percent for the flexural strength and 55 percent for the traffic factor. These percentages are compared, respectively, with 25 percent, ? percent and 80 percent variations that are estimated to occur concurrently in usual destgn situations.

Least Squares Analysis of AASHO Rigid Design. Linear. quadratic and cubic model approximations of the MASHO Rigid 
AASHO RIGID DESIGN

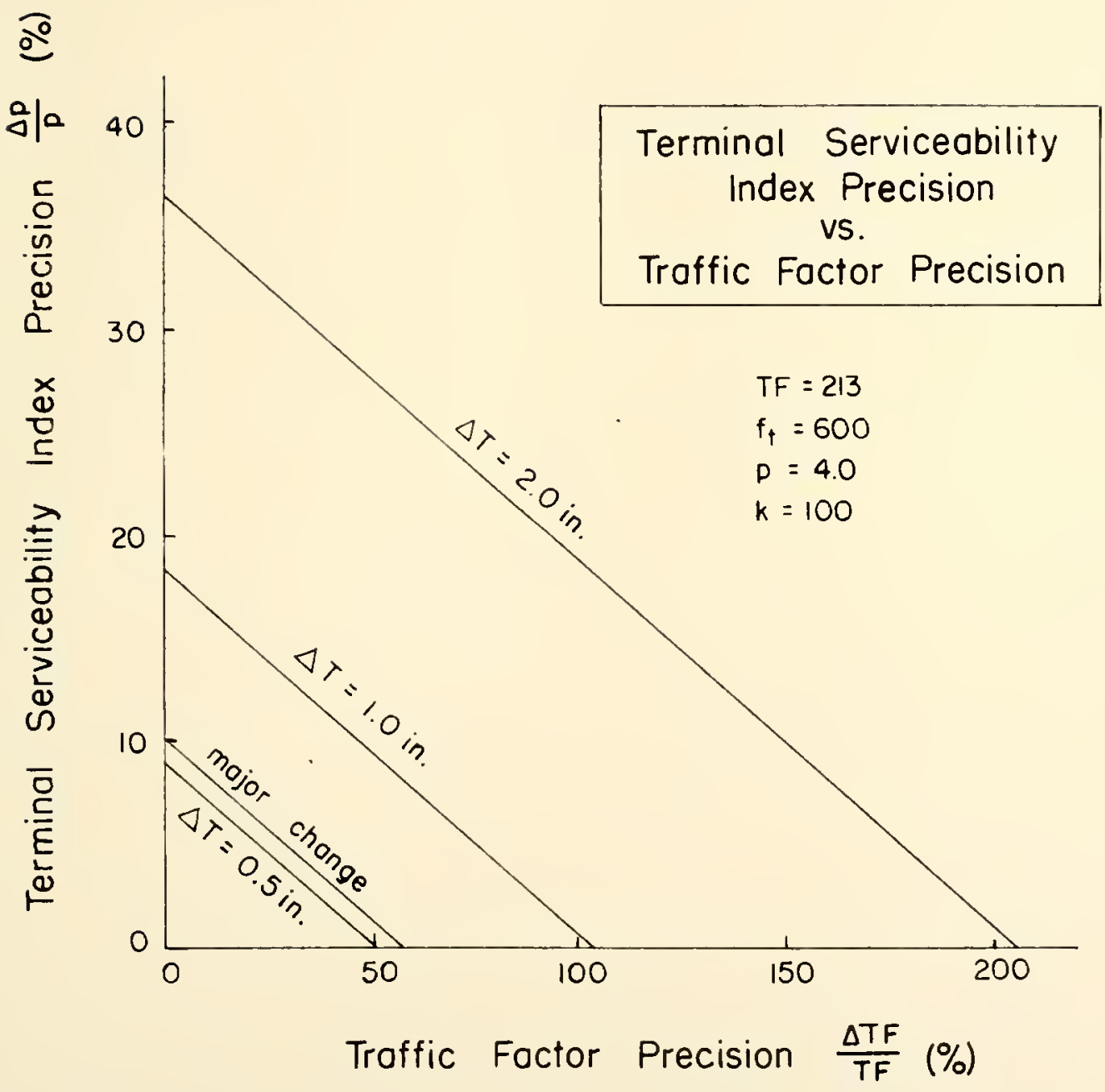

Figure 56. Tolerable Precision of AASHO Rigid Parameters 


\section{AASHO RIGID DESIGN}

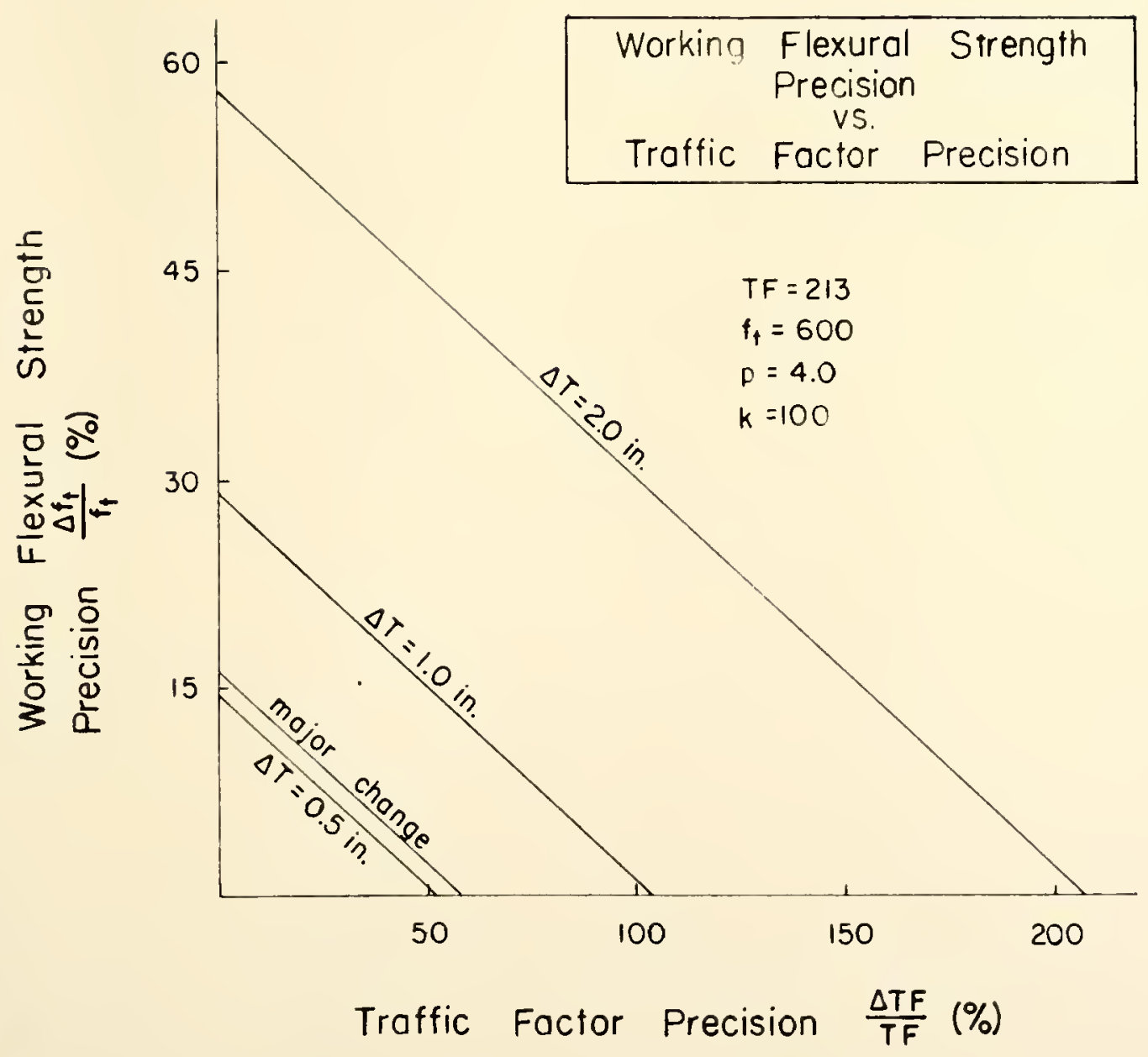

Figure 57. Tolerable Precision of AASHO Rigid Parameters 
design equation were determined as a prelude to the development of a simplified design method for rigid pavements. Thickness data for a wide range of design parameter values formed the basis for a least squares fitting of the pre-selected models.

From the sensitivity analysis of the AASHO Rigid parameters, the trarfic factor is the most influential parameter in the pavement design process. The flexural strength of concrete ranked second and was closely followed by the terminal serviceability index parameter. Because the latter two factors are so nearly equivalent in importance, the parameter-thickness data were srouped into thicknesses for terminal serviceability indices of 2.0 and 2.5. The two situations were analyzed separately to ezamine the differences in the various model approximations as they are influenced by these indices.

Results of the regression analyses are listed in Tables 7 and 8, which show the model types, the regression equations, the coefficients of determination and the standard errors of estimate. The parameter-thickness data for the 2.0 terminal serviceability index are better approximated by the selected models than data for the 2.5 terminal serviceability index. Both tables evidence only a slight gain of statistical efficiency in fitting the linear, quadratic and then cubic models to the data, and the parameter-thickness relationships expressed in the linear models exhibit greater stmplicity and logic. Therefore, the linear model of Table 7 is the preferred approximation of the MASHO Rigid design relationship. 


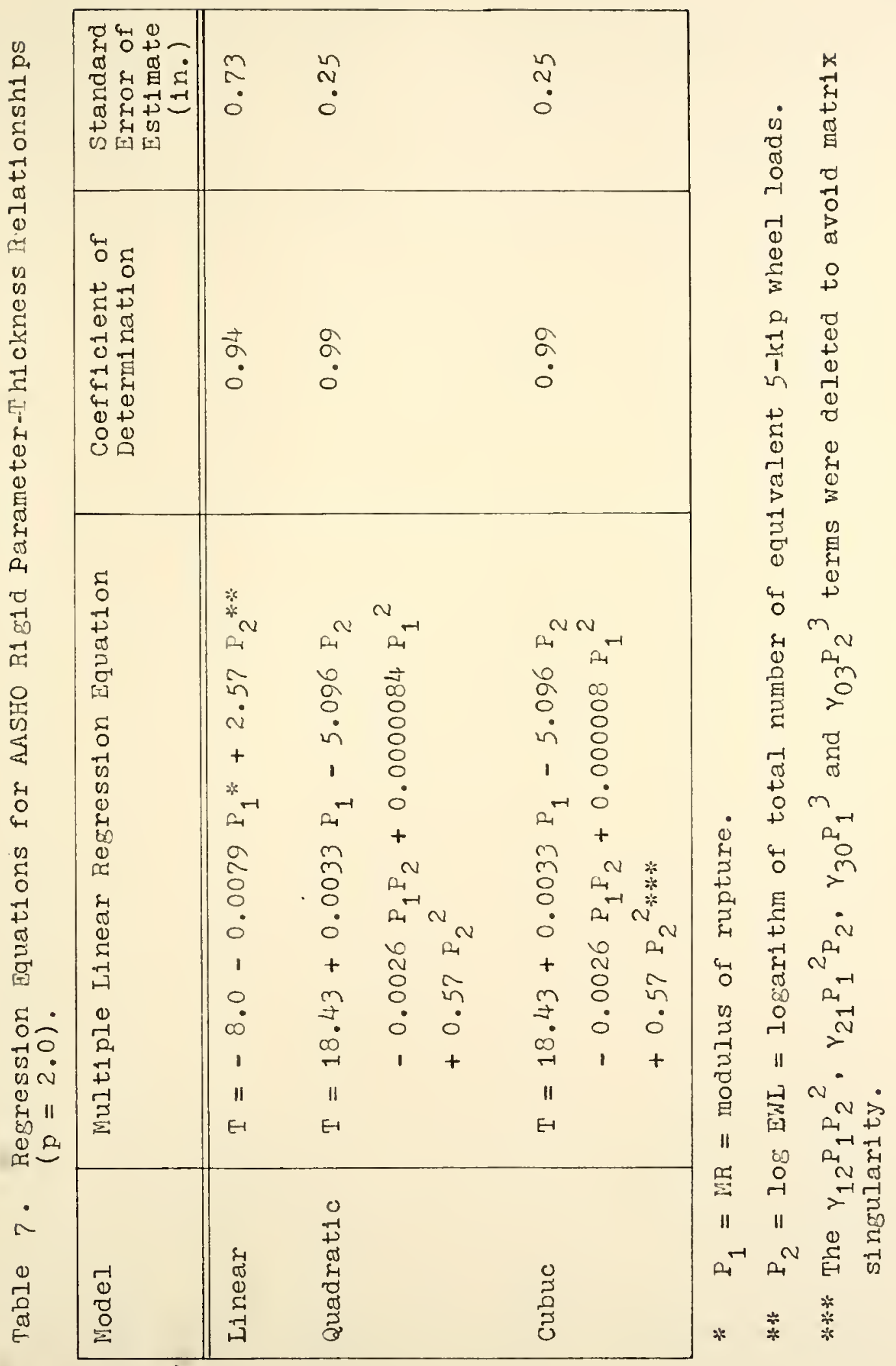




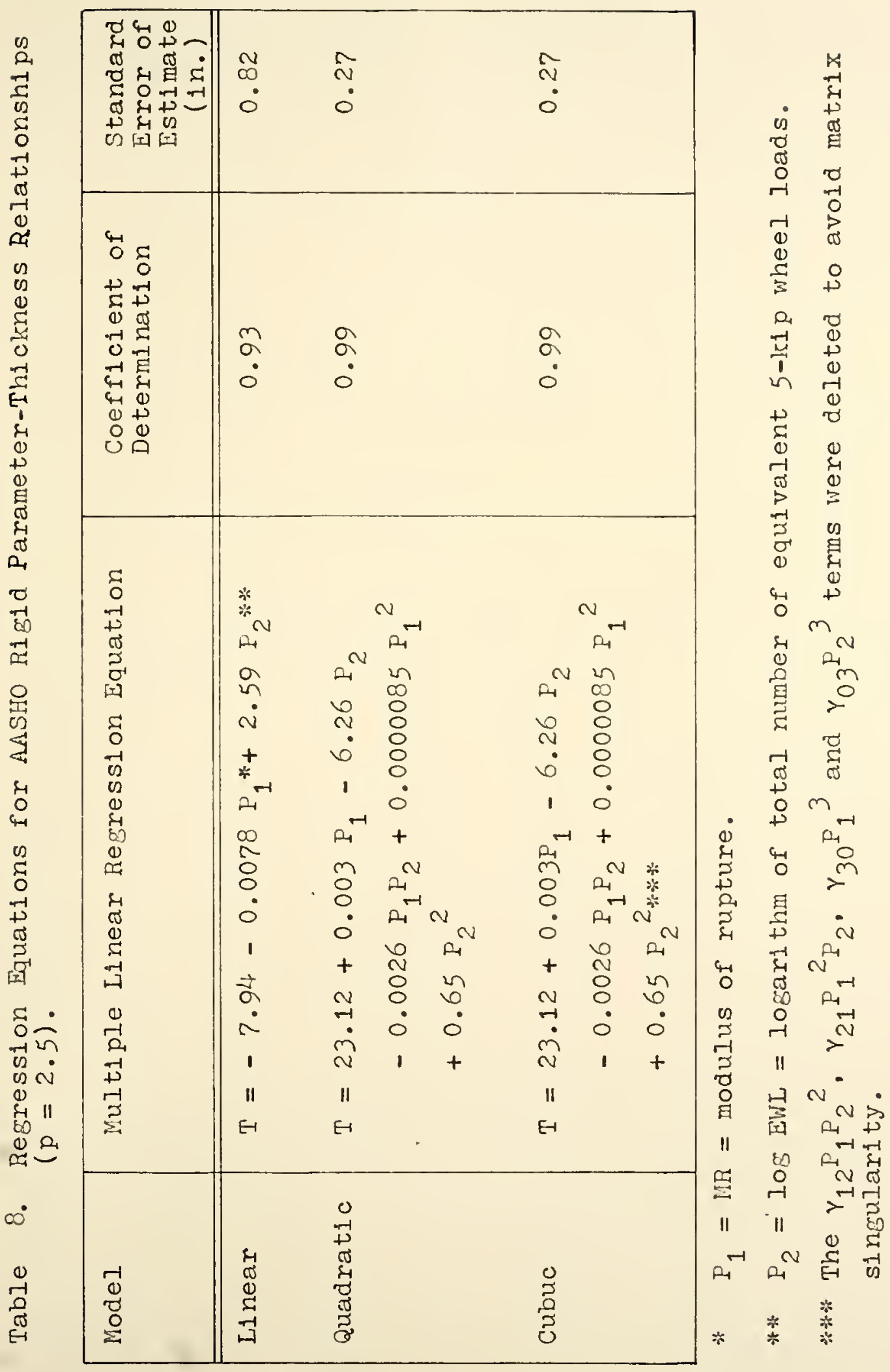


Corps Rigid Design Method

Design-Process Logic. Rigid pavement thickness requirements as developed by the Corps of Engineers design nethod are based on a resolution of design values for the modulus of subgrade reaction, the modulus of rupture for the pavement material and the design index parameter which sumarizes the imposed traffic loads. A sraphical illustration of this design-process logic is shown in Figure 58.

This hierarchy structure supplies a clear and effective picture which details the level of consideration and points of modification of those factors which influence the design of rigid pavements. The unajor design variables are indicated by boxes in Figure 58, and evaluations directly influencing these parameters are found at the second hierarchy level. Third level items are recognized to affect second level factors and are often sufficient reason for separate measurements to ascertain the design parameter value. Notably absent from the hierarchy structure is the explicit consideration of a safety factor to modify the selected design parameters. A factor of safety was incorporated into the design charts and effectively became a non-consideration in the design process.

Modeling of the Corps Rigid Design Method. Although further mathematical development of the equations for the Corps Rigid technique was desirable to perform a sensitivity analysis, the published design chart was appraised as a reliable model for obtaining the needed data in this analysis. The chart which is shown in Appendix $E$ was prepared without the benefit 


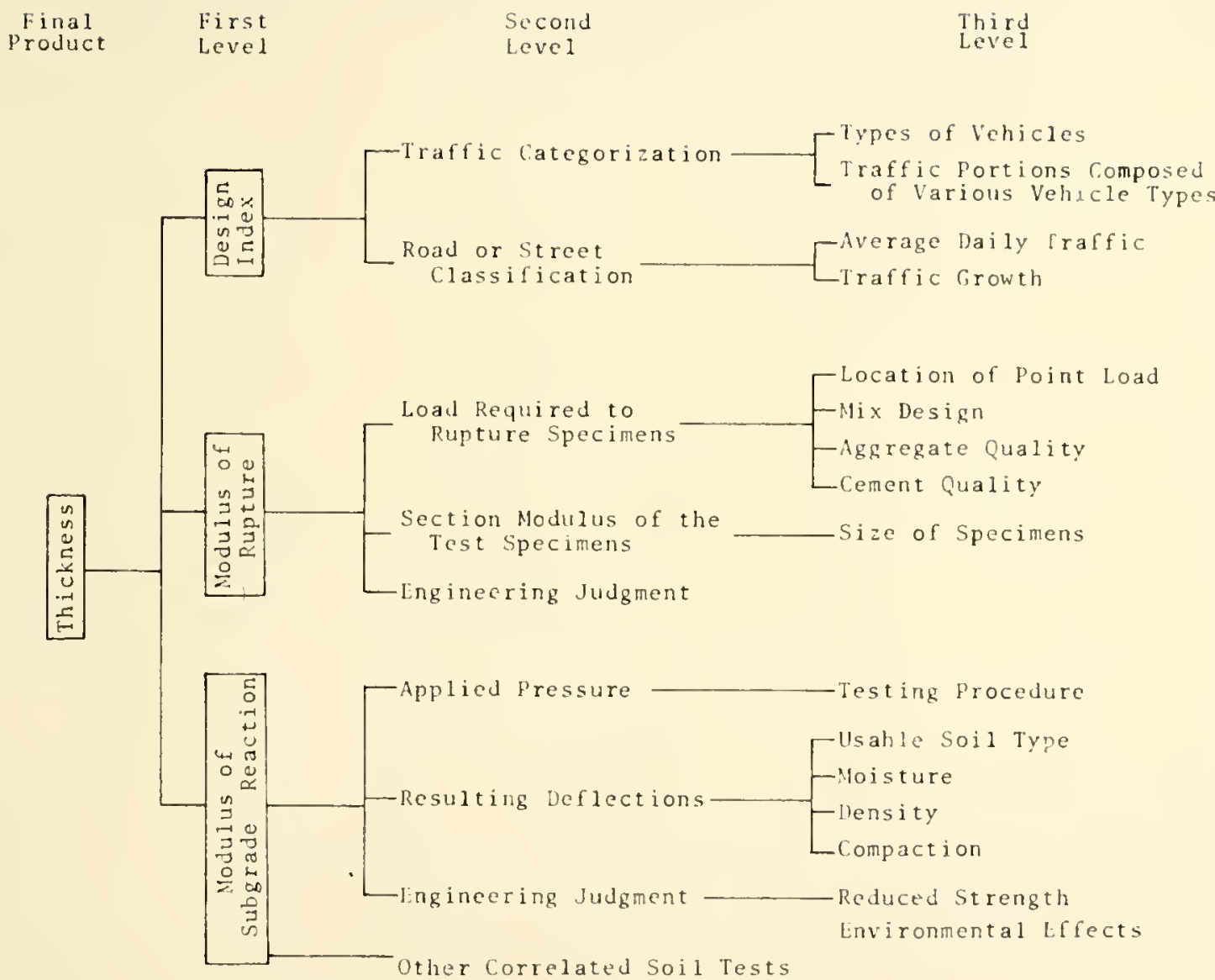

Figure 58. Hierarchy Structure of Corps Rigid Design-Process Logic 
of a corresponding design equation and is substantially based on plotted empirical relationships. The few mathematical equations pertaining to the design method do not express the relationships used to prepare the design chart.

\section{Sensitivity Analysis of the Corps Rigid Design Method.}

The principal design factors which occupy the first level of the hierarchy structure and which are the independent variables exhibited on the design chart, were evaluated for their influence on pavement thickness. This sensitivity analysis vas based on the premise that the most important parameters have the greatest effect on design thickness. Instantaneous rates of thickness change attributed to particular parameters indicate theoretical parameter importance, and net thickness changes resulting from comparable increments of parameter change evaluate practical parameter importance.

The first-order partial derivative of thickness with respect to each desion parameter was evaluated as a percentage of the sur of all partial derivatives and was defined as the "relative percentage of a partial." This measure of importance was calculated for a wide range of paraneter value combinations, but only several arrangements which encompass most design situations are illustrated in Figures 59,60,61 and 62. These plots depict the relative theoretical importance of the Corps Rigid parameters for design indices from 1 to 10 . - The importance of parameters under average design conditions are presented in Figure 59. Parameter importance evaluations are 
CORPS RIGID DESIGN

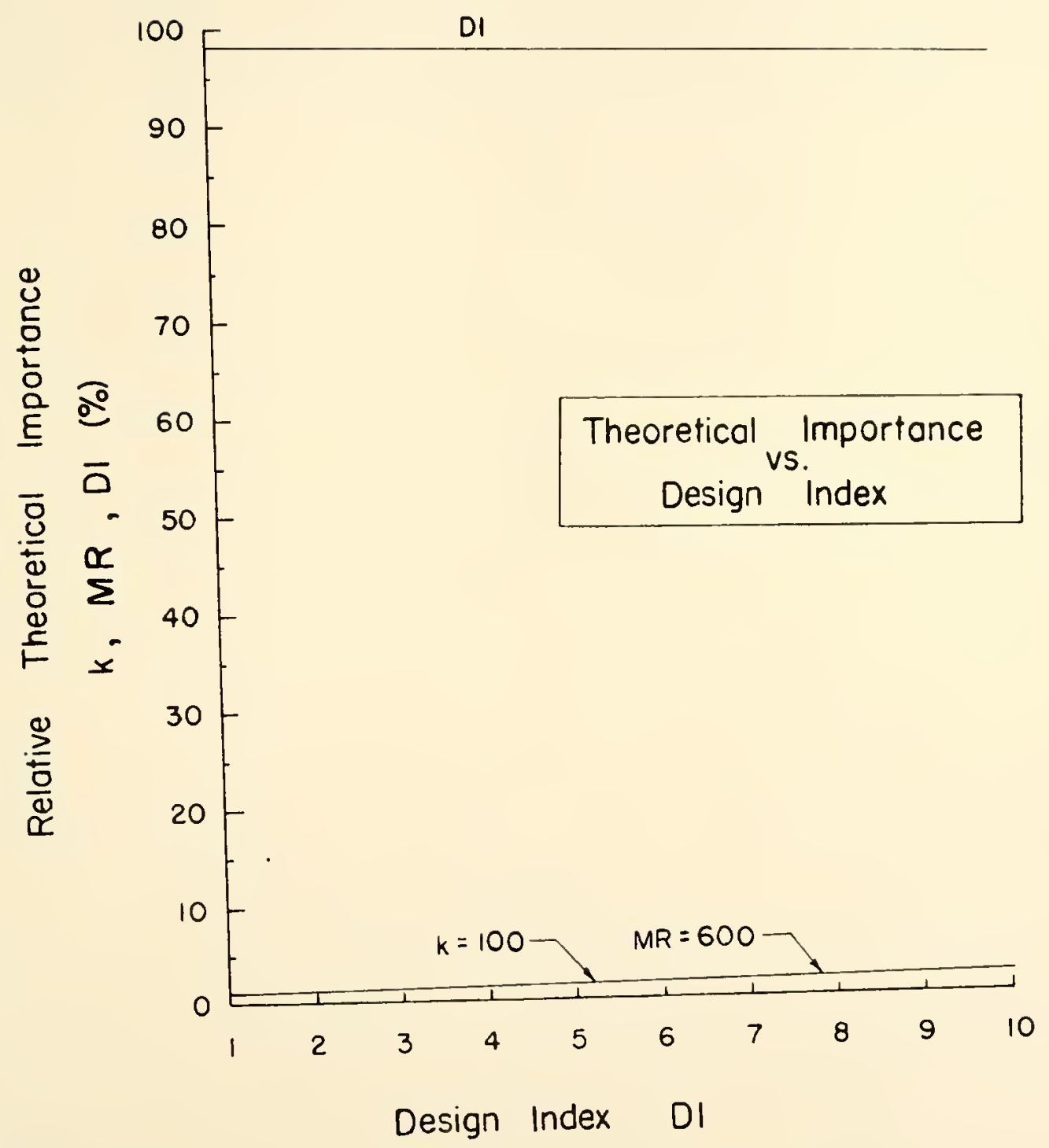

Figure 59. Relative Theoretical Importance of Corps Rigid Design Parameters 
CORPS RIGID DESIGN

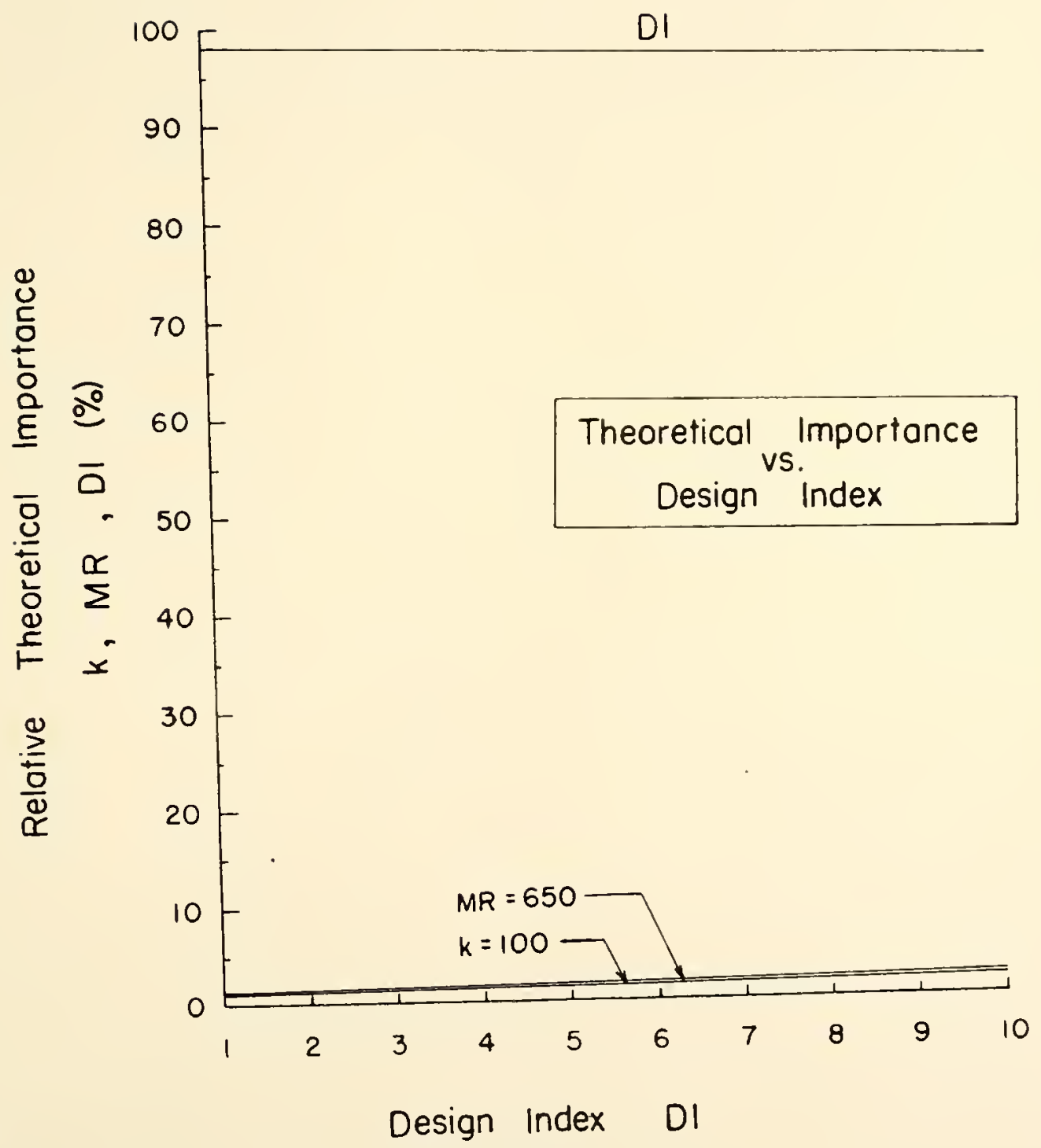

Figure 60. Relative Theoretical Importance of Corps Rigid Design Parameters 
CORPS RIGID DESIGN

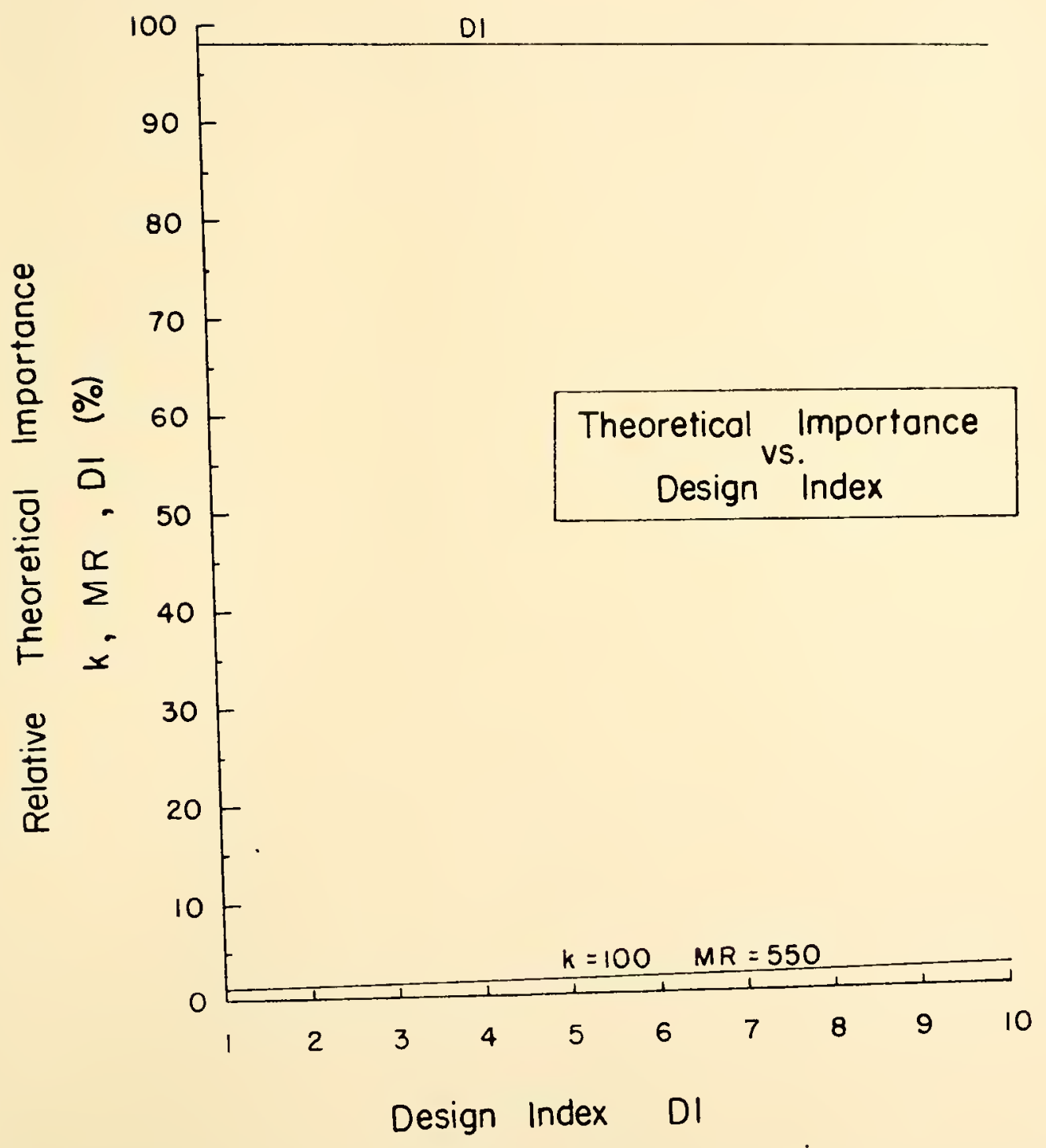

Figure 61. Relative Theoretical Importance of Corps Rigid Design Parameters 
CORPS RIGID DESIGN

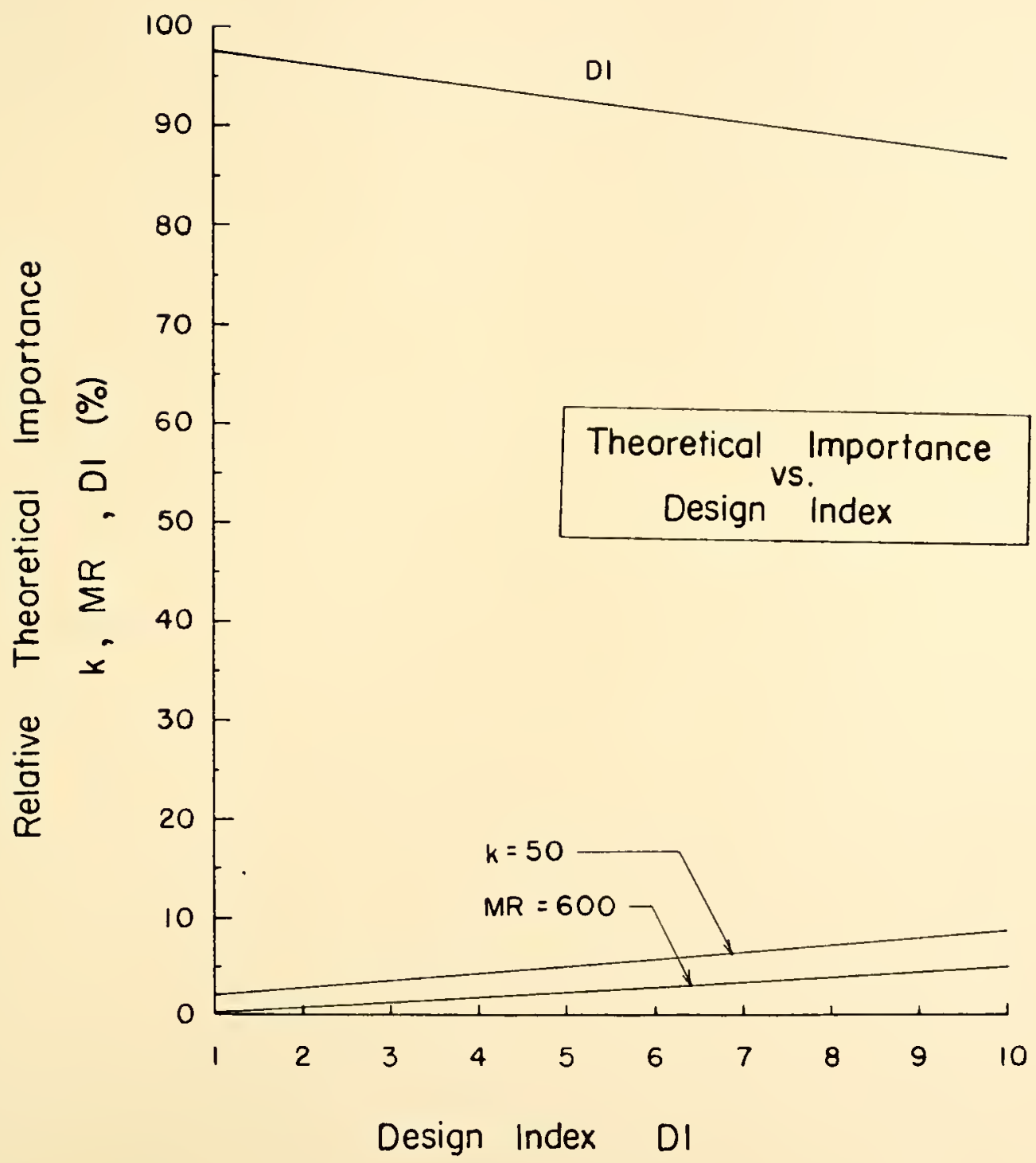

Figure 62. Relative Theoretical Importance of Corps Rigid Design Porometers 
shown in Figures 60 and 61 for weak and strong concrete pavement structures, respectively, and the effect of higher subgrade moduli on importance are demonstrated in Fisure 62.

Examination of these plots establishes the dominant importance of the design index for the illustrated situations and implies the overwhelming theoretical importance of this parameter for most other conditions. The importances of the subgrade modulus and the modulus of rupture do not even approach the influence of the design index parameter. For each 11lustration of theoretical Importance the design index accounts for greater than 95 percent of the relative rate of thickness change while the modulus of rupture and modulus of subgrade reaction account for less than 5 percent. If parameter variations are neglected, the Corps Rigid thickness requirements could essentially be quantified by a trafflc load estimation alone.

Parameter variations, however, are an integral part of the design process and were considered in developing the relative practical measures of parameter importance. Graphical determinations from the published design chart vere made for the first partial derivatives in the "portions of the total differential" approach and for those thickness chanzes induced by comparable parameter varlations in the "relative thiclness change" approach. The accuracy of Eraphically determinins the practical importance measures was not as precise as the mathematical evaluations made for other design methods. However, the illustrations presented give a valid 
Eeneral approximation of the influences on thickness of the Corps Rigid design variables. These neasures were determined for a variety of parameter values; however, only design indices of $1.0,2.0,3.0,4.0$ and 5.0 were combined with the practical range of subgrade modulus and nodulus of rupture values for this sensitivity analysis.

Several selected parameter value combinations, which correspond to those shown in the theoretical appraisal, were evaluated according to the practical importance of each parameter and are illustrated in Figures 63, 64, 65 and 66. The classifications of highways and traffic in determining the design index malies an evaluation of the design index variability difficult. However, the design index parameter was assumed to be directiy and I1nearly proportional to the California stabilometer trafic index. Rationally determined traffic index variations were converted to design index deviations and were employed in the evaluation of the Corps Rigid traffic parameter. The design index variations were a continuous function of the design index, consequently ranges in practical importance caused by deviations in average daily traffic or percent trucks did not occur.

For the average conditions described by a design index or 4.0 and shown in Figure 63, the relative practical parameter importance is approximately 38 percent for the modulus of rupture, 42 percent for the subgrade modulus and 20 percent for the design index. As the desion index value decreases, 
CORPS RIGID DESIGN

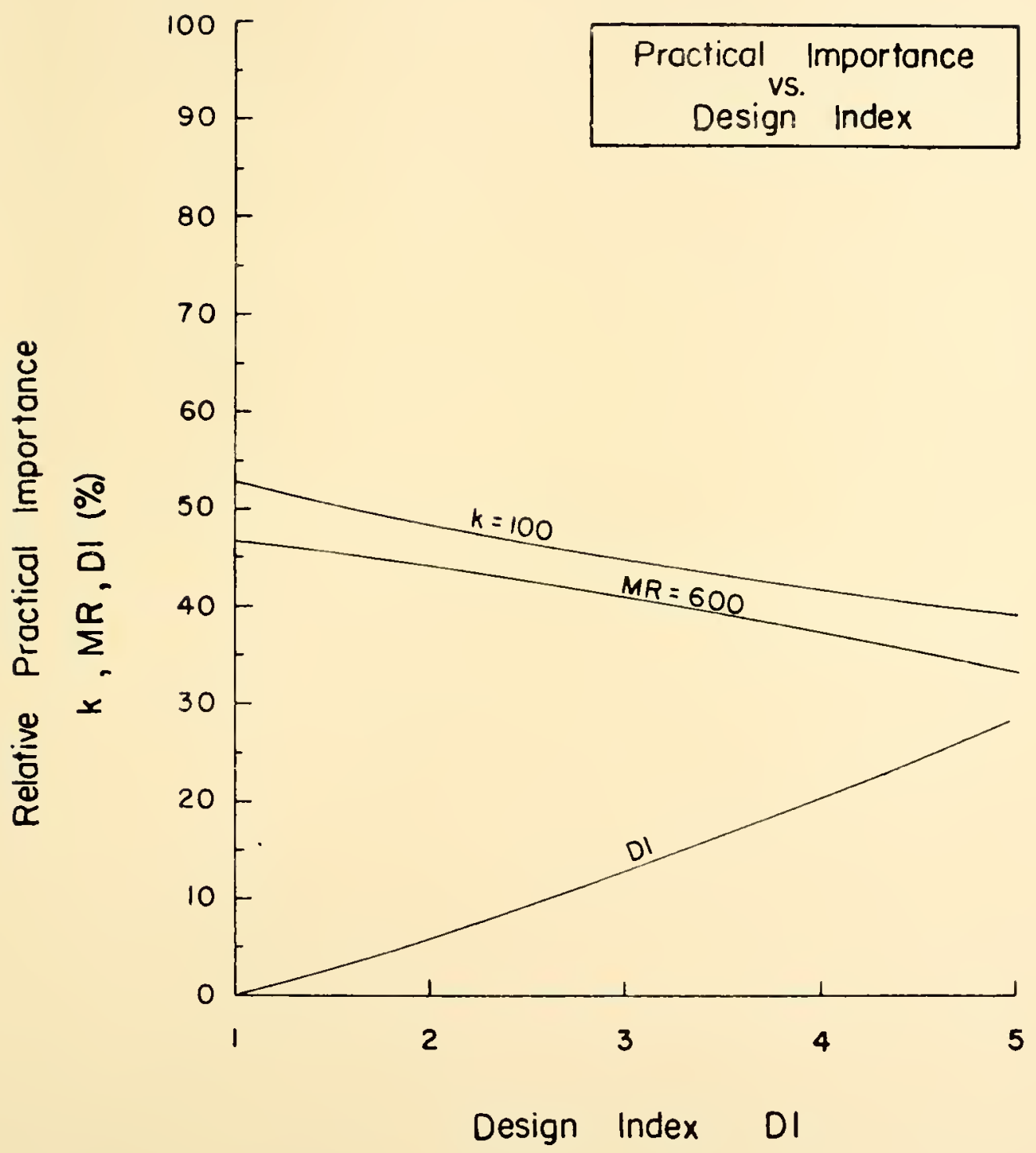

Figure 63. Relative Practical Importance of Corps Rigid Design Parameters 
CORPS RIGID DESIGN

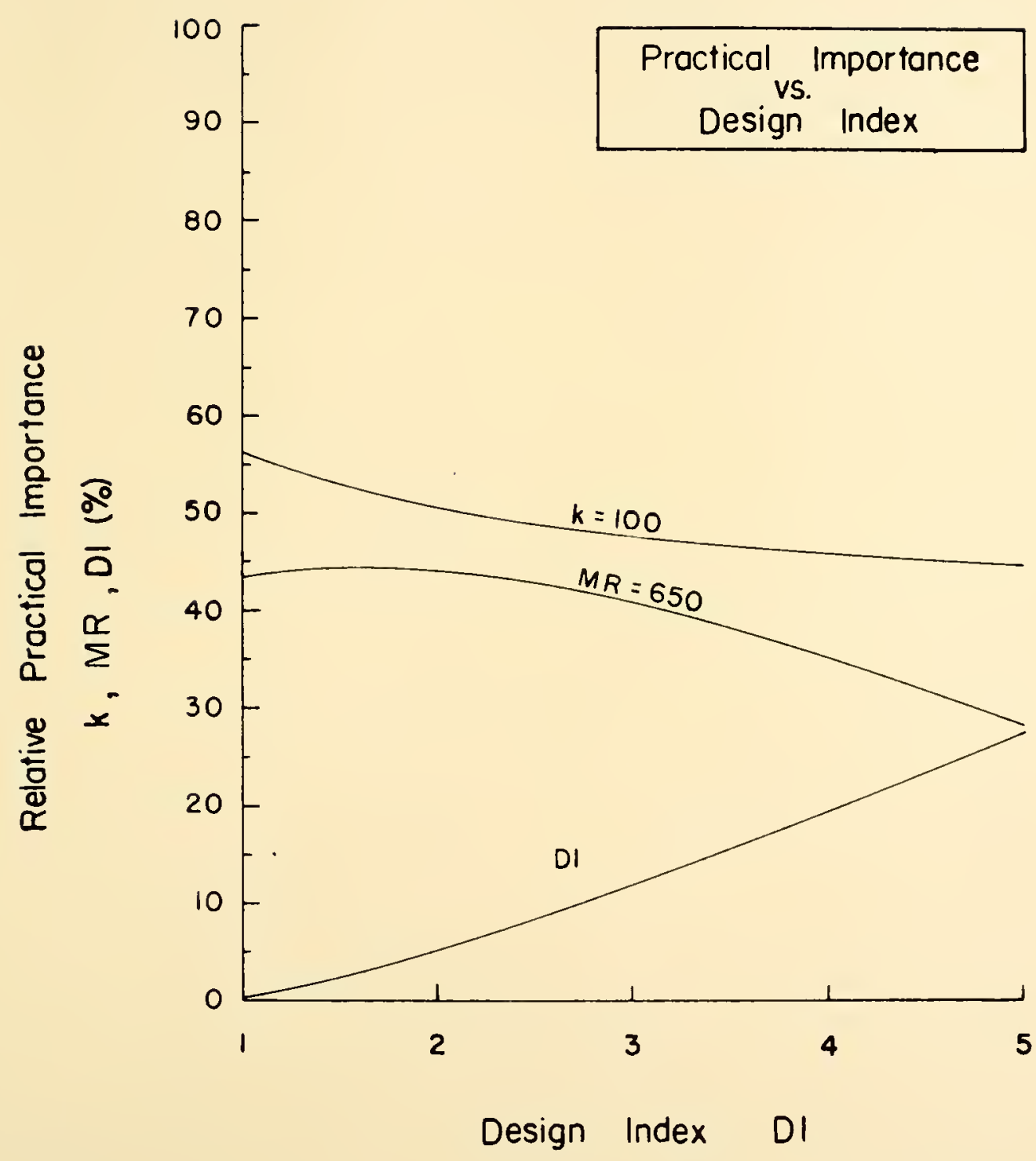

Figure 64. Relative Practical Importance of Corps Rigid Design Parameters 
CORPS RIGID DESIGN

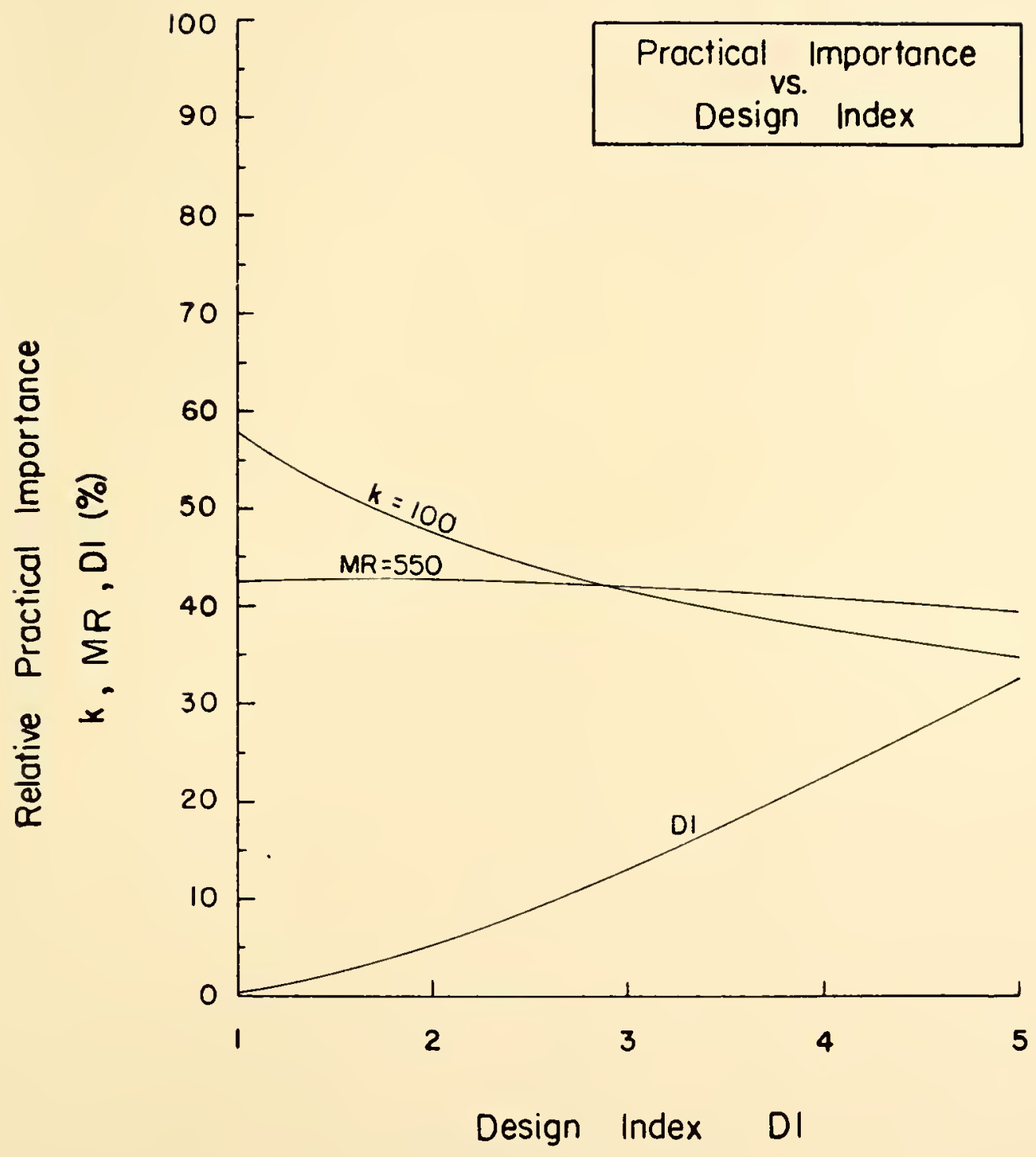

Figure 65. Relative Practical Importance of Corps Rigid Design Parameters 
CORPS RIGID DESIGN

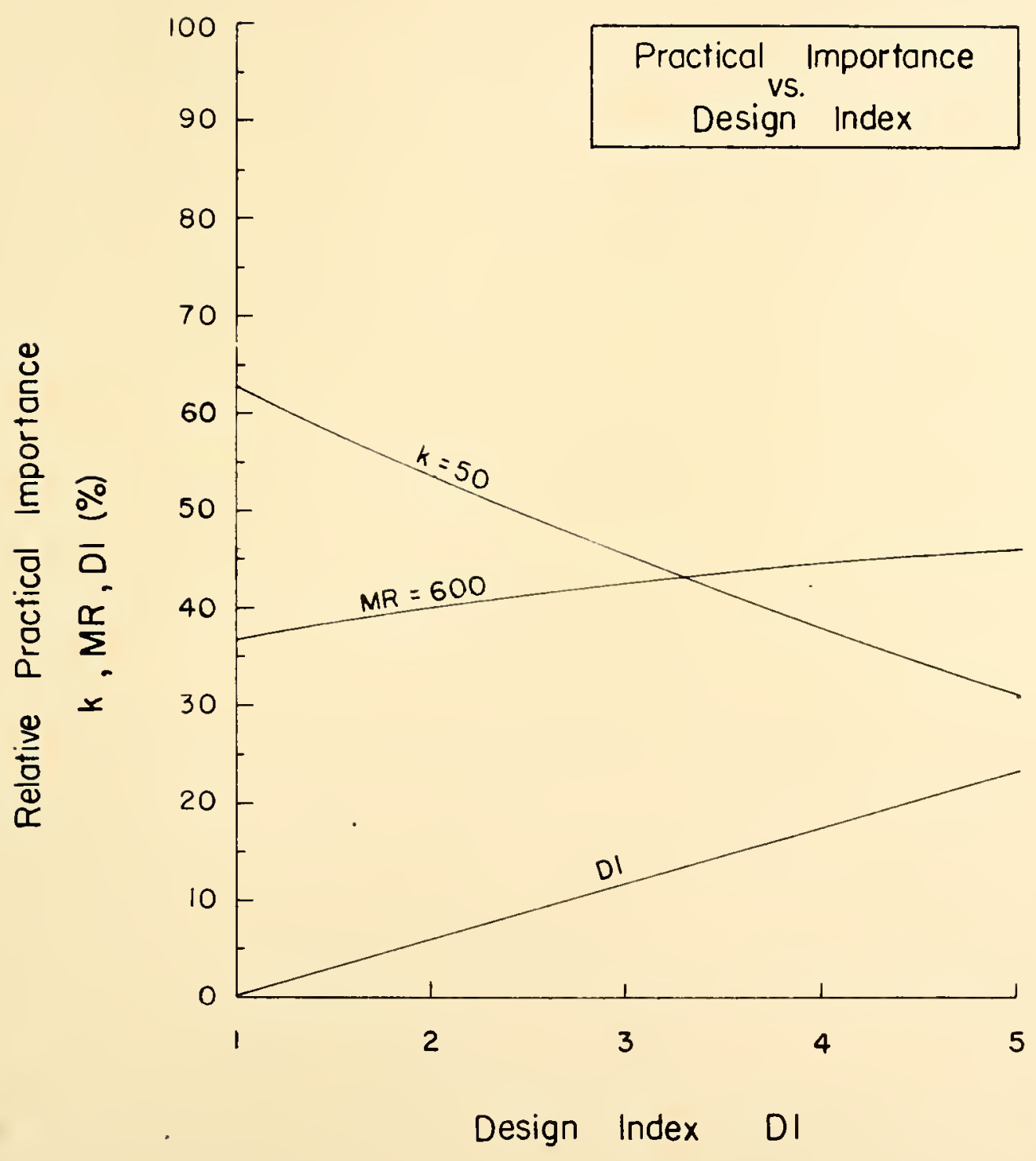

Figure 66. Relative Practical Importance of Corps Rigid Design Parameters 
there is a significant decrease in its importance. A comparison of Figure 63 with Figures 64 and 65 shows that an increase in the value of the modulus of rupture produces a slight decrease in the importance of both the design index and the modulus of rupture and a corresponding increase in the importance of the subgrade reaction as a determinent of pavement thickness. A decrease in the modulus of subgrade reaction which implies weaker supportine soils indicates a slight increase in the importance of that parameter, little change in the importance of the modulus of rupture and a decrease in the importance of the desien index.

For the Corps Rield design method, the modulus of subgrade reaction and the modulus of rupture are the most important design variables. The traffic parameter is ranked third based on the assumptions used in developing the practical importance measure.

\section{Tolerable Parameter Variations. An evaluation of the} Corps Rigid design. parameters examined the permitted changes in parameter values before a major alteration was required in the design thickness. This evaluation shows the precision required in one desien parameter relative to another for selected thickness change Iimitations.

The trade of $f$ traffic index precision with modulus of rupture precision is illustrated in Figure 67, and the precision of the traffic factor versus that of the subgrade modulus is shown in Figure 68 for the selected thickness constraints. The 
CORPS RIGID DESIGN

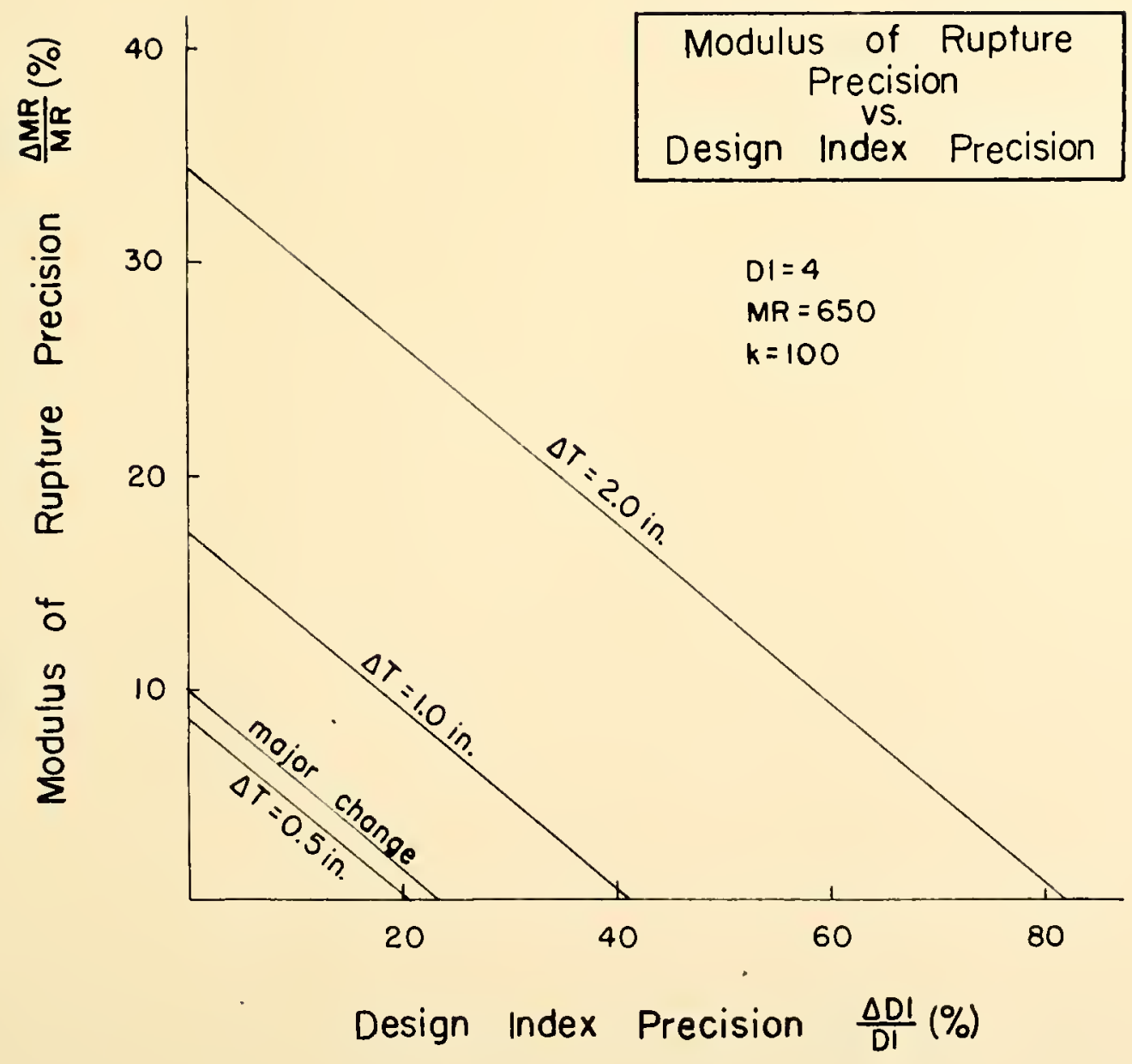

Figure 67. Tolerable Precision of Corps Rigid Parameters 
CORPS RIGID DESIGN

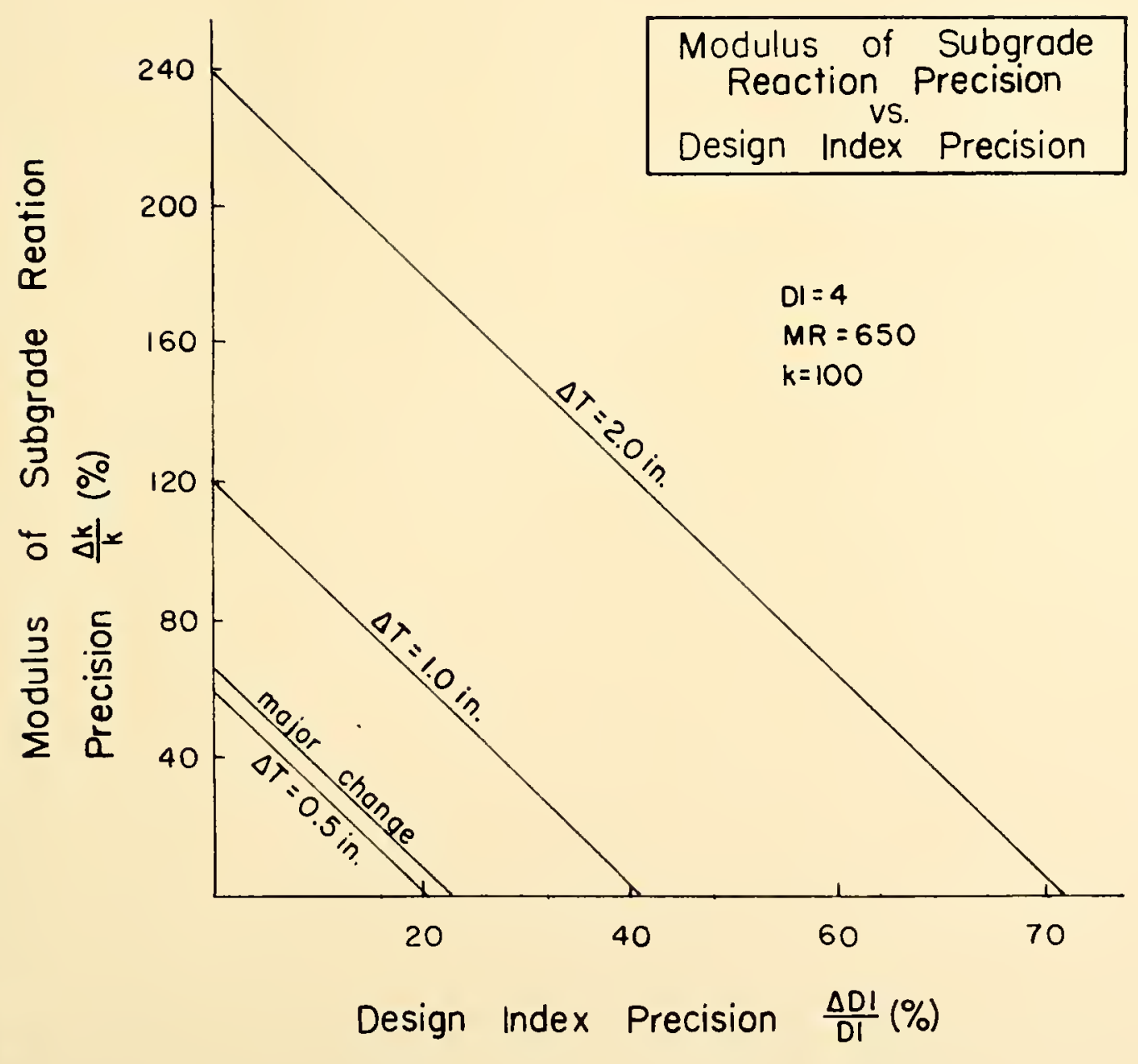

Figure 68. Toleroble Precision of Corps Rigid Porameters 
maximum parameter variation 1 s 22 percent for the traffic parameter. 66 percent for the subgrade parameter and 10 percent for the structure parameter for the major chanse Iimitation. These percentages are compared with the concurrent variations normally encountered of 9 percent, 40 percent and 7 percent, respectively. Although each concurrent variation of present-day measures are less than the maximum tolerable variations specified by the major thickness change Iimitation, design and construction tolerances are still more restrictive than present desion precision ability. According to Figure 68 a 9 percent variation in the desien index permits a 40 percent variation in the modulus of subgrade reaction, if the percent deviation in the modulus of rupture is near zero.

\section{Ieast Squares Analysis of Corps Rigid Design. Thiclsness} requirements by the Corps Rigid design method were deternined for every combination of suberade moduli corresponding to CBR values of 2,4 and 6 , design indices of $1,2,3,4$ and 5 and rupture moduli of $550,600,650,700,750$ and 800 psi. Regression coefficients were determined for linear, quadratic and cubic models for this parameter-thickness data. Although the modulus of subgrade reaction and the modulus of rupture were concluded to be the most important design variables in the Corps Rigid design technique, the regression models were expressea in terms of a traffic parameter and the modulus of rupture. The subgrade factor was neglected as an independent variable so that the developed models are comparable to the 
corresponding models of the other rigid pavement design techniques. Fowever, different required thicknesses corresponding to various subgrade moduli of reaction were incorporated into data which formed the basis for the remression models.

Listed in Table 9 are the model types, the regression equations for the senerated thickness data, the coefficients of determination and the standard errors of estimate. AlI models fit the data reasonably well, but a slight lmprovement in statistical efficiency occurs for the higher powered models. When this improvement is compared to the simplicity and rationale of the inear model, the linear equation is judzed the most appropriate for summarizing this research investieation. The coefficient of determination and the standard error of estimate are 0.84 and 4.63 for the linear model. 0.8 ? and 4.22 for the quadratic model. The cubic nodel was reduced to the same equations as the quadratic model to avold matrix singularity in solving for the cubic resression coefficients. The relatively large standard error of estimate reflects the influence of the subcrade parameter on the generated parameterthickness data.

FCA Rigid Design

Design-Frocess Logic. The Portland Cement Associations's approach to the design of rigid pavements is predicated on the fatigue effects of repeated axle load applications on the pavement slab. These influences depend on the stresses that are induced in the slab and on the strength of the slab. While 


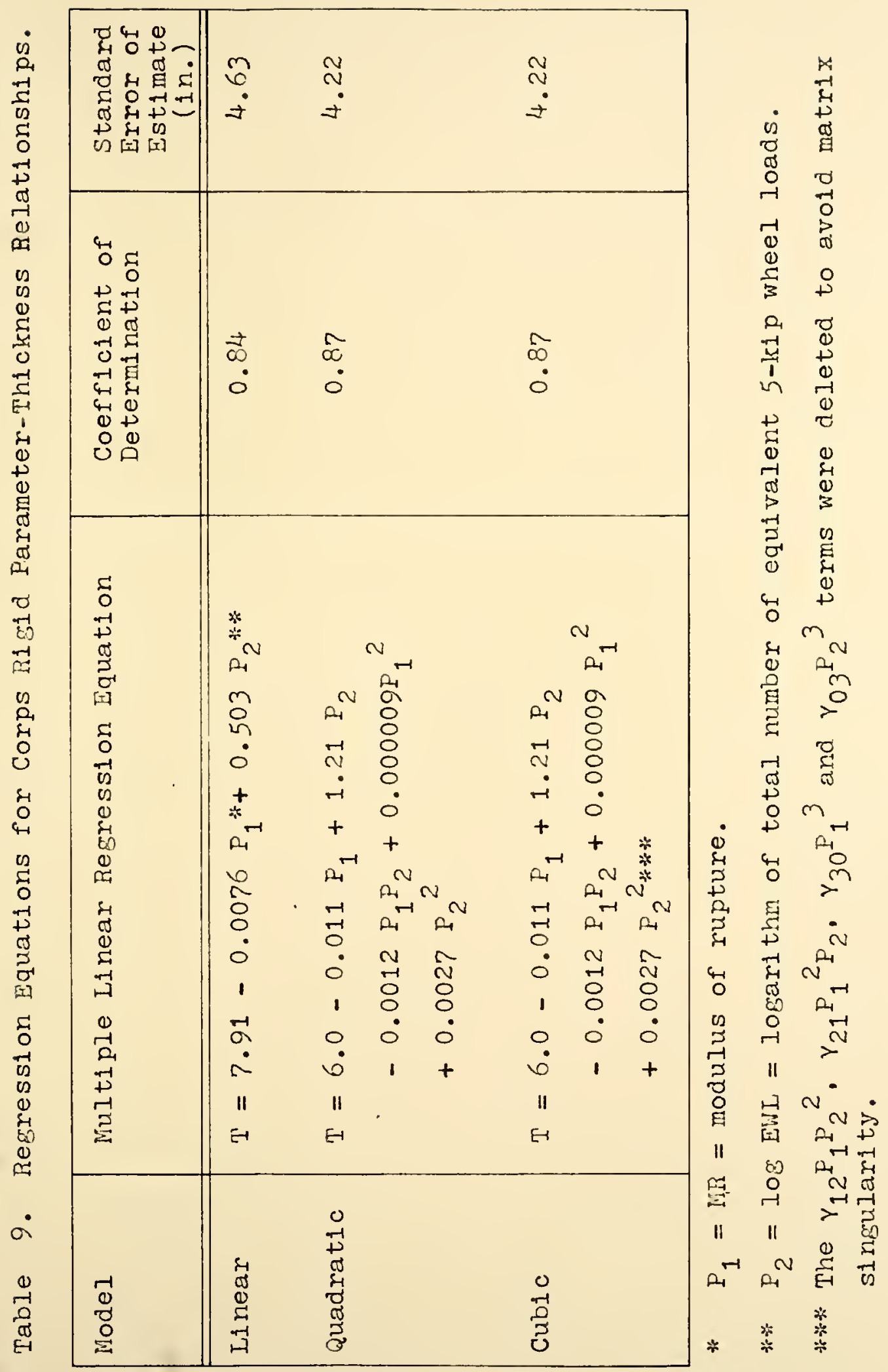


the stresses produced by the wheel loads are a function of the pavement thickness and the subgrade support, the slab strength is primarily affected by the strength properties of the concrete. The ratio of load-induced stress to flexural strength is defined as the stress ratio and dictates the allowable number of load repetitions. When allowable repetitions are compared to anticipated repetitions which are determined by an estimation of the traffic demands, a measure of fatigue resistance consured is calculated to gauge the adequacy of the trial thickness design. This process is repeated until an acceptable pavement design is achieved.

The hierarchy structure of this design-process logic is show in Figure 69 to graphically illustrate the primary design factors and to enumerate the modifying factors of the ICA Rigid pavement design technique. The PCA process of determining thickness requirements is not concordant with the seneralized hicrarchy structure that is proposed in the procedure, because considerable manipulation of the design parameters occurs in obtaining the fatigue resistance consumed. Therefore, those factors shown in Ficure 69 between the design parameters and the design objective are regarded as intermediate transition considerations separating parameters from objective. The modulus of subgrade reaction, modulus of rupture, average daily traffic, percent trucks and weight classification of traffic loads, which are outlined by a solid rectangle, are defined as design parameters and are ranked as first level hierarchy considerations. Laboratory tests and fleld 


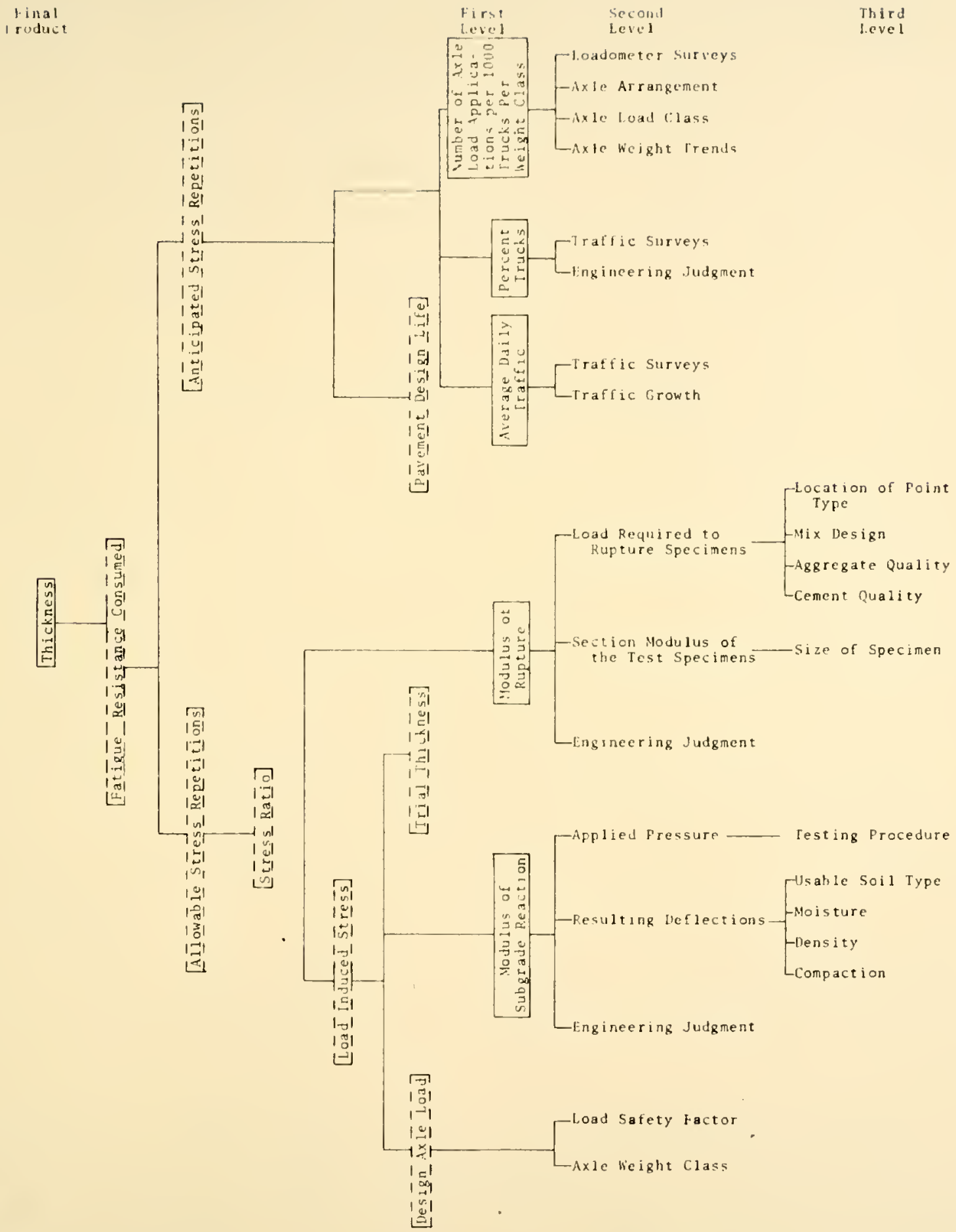

F1gure 69. Hierarchy structure of PCA Rigid Design-Process Logic 
measurements required to ascertain the parameter values are shown at the second level, and items recognized to affect the design parameter by influencines test results are at the third hierarchy level. Traffic considerations, which usually are ranked at the third level, were arbitrarily advanced to the second level because they directly modify the traffic design parameters.

Modeling of the PCA Rigid Design Method. The equation for the PCA design technique (equation 26) does not sufficiently express in mathematical terms the parameter-thickness relationships for the sensitivity analysis. The independent traffic design variables shom in Ficure 69 are laching. However, documented explanations of the design process afford enough information to develop the basic equation into an equation which mathematically encompasses the total design procedure. This newly formulated mathematical expression, as show below, served as the FCA design model for the sensitivity analysis.

$$
\begin{aligned}
& \operatorname{los}\left[A T D\left(P T T_{1}\right) A T_{1}\right]= \frac{20.24 P_{1}}{(N R) D^{2}}\left[1.0-\frac{0.2034\left(a_{i}\right)^{\frac{1}{2}}\left(k / D^{3}\right)^{\frac{1}{8}}}{0.925+0.0091\left(A_{i}\right)\left(k / D^{3}\right)^{\frac{1}{4}}}\right] \\
&-12.0 \\
& {[28] }
\end{aligned}
$$

where $A D T=$ average daily traffic in both directions (vehicles per day),

FTI = percentage of total traffic which is trucks, $A T_{1}=$ axles per 1000 trucks for axle load class (i).

$$
P_{i}=\text { design load equal to the midpoint of axle }
$$
load class (i) (pounds), 


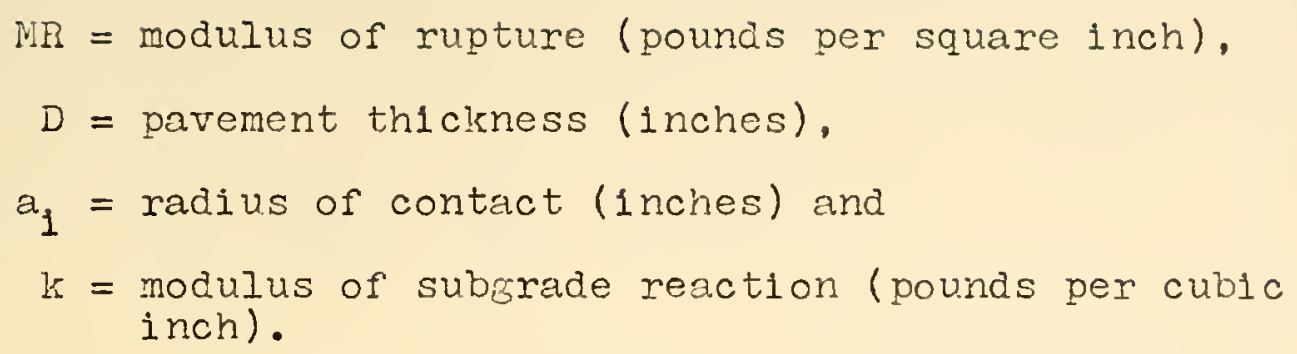

This design model relates the modulus of subgrade reaction, the modulus of rupture and the three factors charcicterizing traffic loads to the required thickness for a 125 percent fatigue resistance consumed failure criteria. In developing this equation for the sensitivity analysis, reasonable assumptions, which are detailed in Appendix $\mathrm{F}$, were made in resard to the lateral distribution of traffic, the axle load allocations among vehicles in the traffic stream and the design life of the facility.

\section{Sensitivity Analysis of the PCA Rigid Design liethod.}

From the hierarchy structuring and the design modeling of the PCA technique, five factors were selected as major design parameters. Three factors, which are averase daily traffic, percentage of trucks and axles per 1000 trucks, are related to traffic conditions, and the other two factors of subgrade nodulus and modulus of rupture relate to characteristics of the supportine material.

While relative theoretical importance measures were determined for a large array of parameter value combinations. only those arrangements describing usual design circumstances are illustrated in Figures $70,71,72$ and 73 . To facliltate the presentation of the relative importance measures, 
PCA RIGID DESIGN

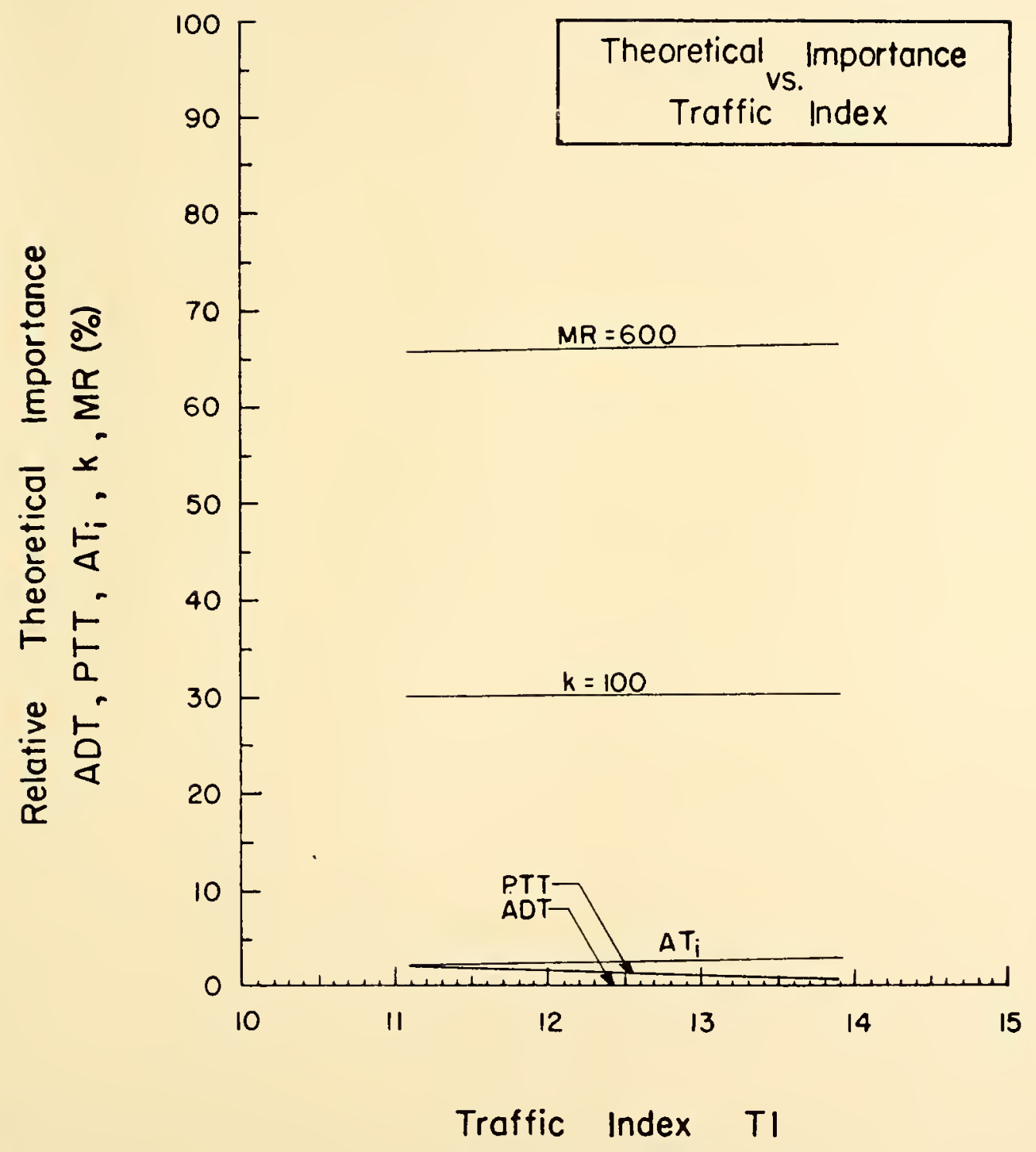

Figure 70. Relative Theoretical Importance of PCA Rigid Design Parameters 
PCA RIGID DESIGN

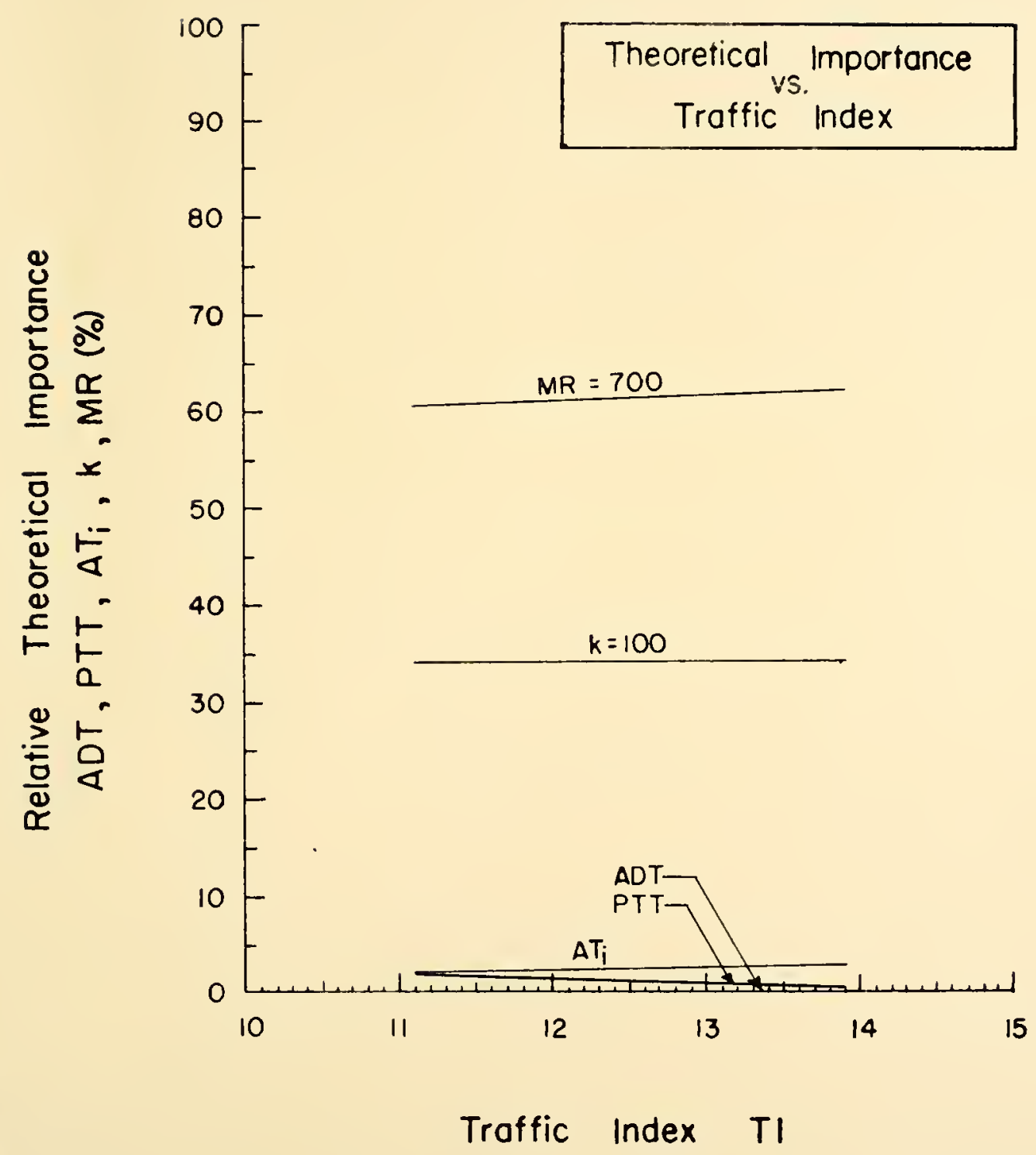

Figure 71. Relative Theoretical Importance of PCA Rigid Design Porometers 
PCA RIGID DESIGN

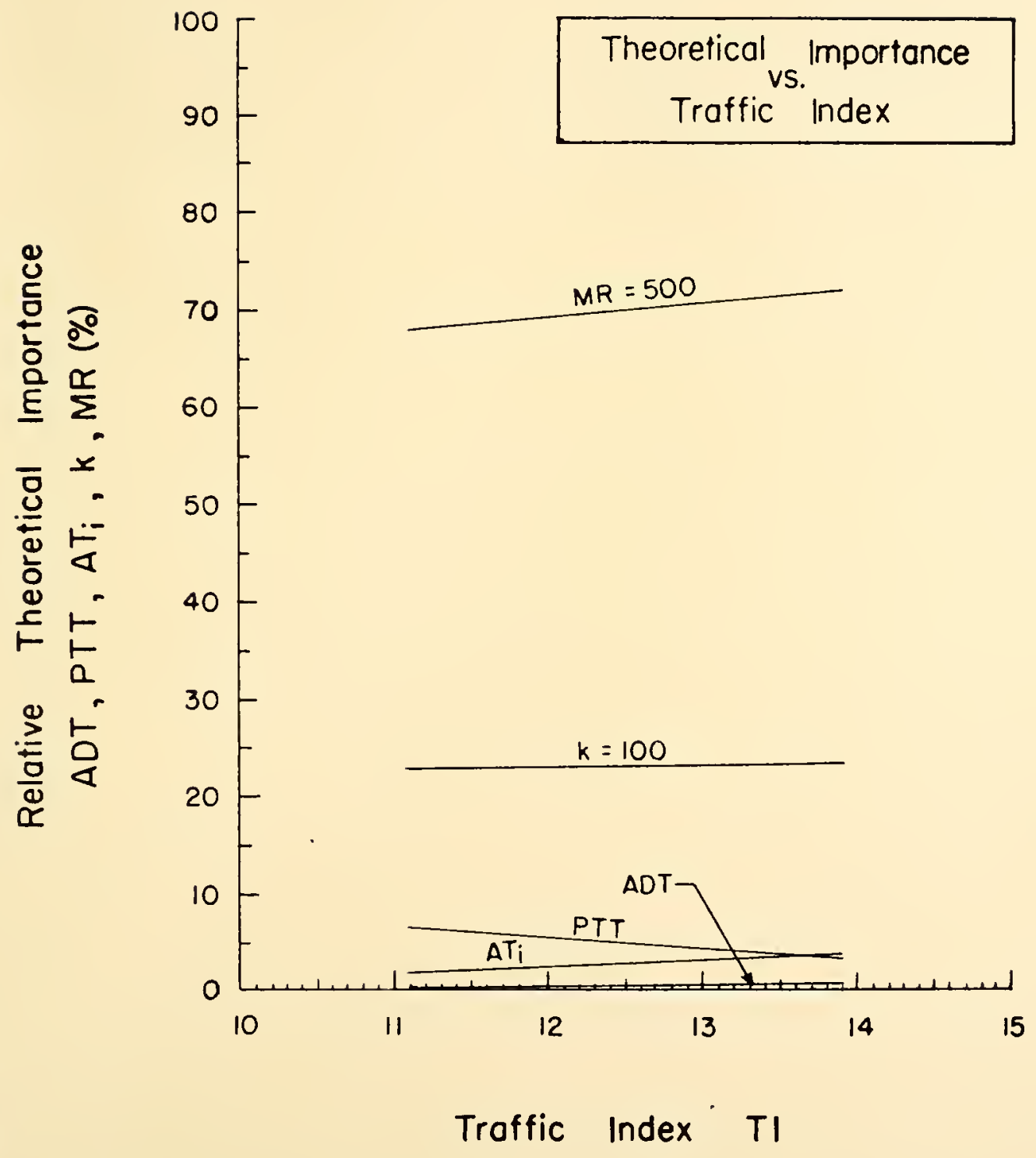

Figure 72. Relative Theoretical Importance of PCA Rigid Design Porameters 
PCA RIGID DESIGN

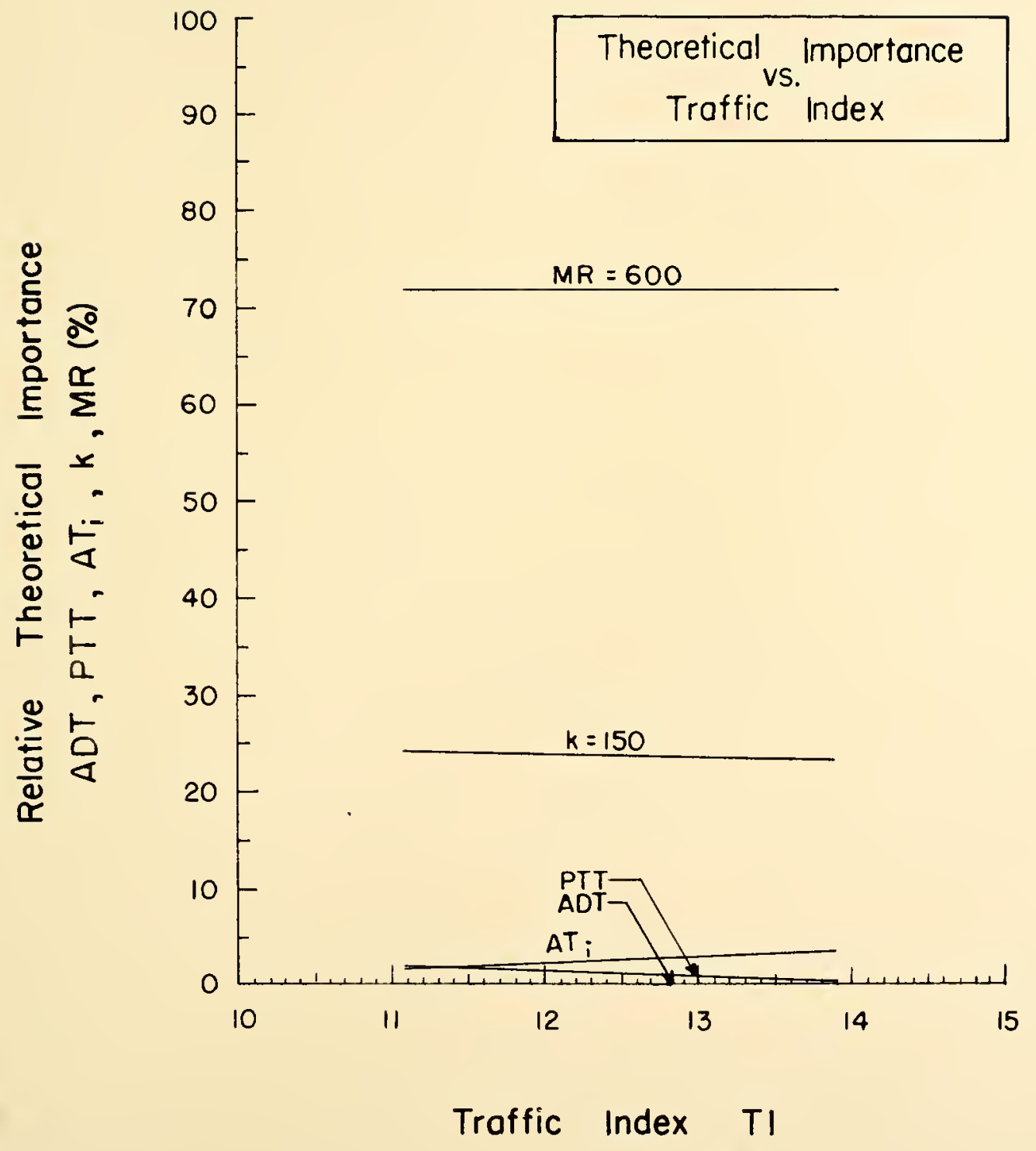

Figure 73. Relative Theoretical Importance of PCA Rigid Design Parameters 
appropriate California Stabilometer traffic index values were selected to summarize the traffic parameter for the three PCA factors which describe traffic conditions. Average conditions were described by a modulus of rupture equal to 600 psi and a modulus of subgrade reaction equal to 100 psi. For a traffic index equal to 12.0 , which characterizes a typical highway traffic loading, the relative theoretical importance measures are about 66 percent for the modulus of rupture, 31 percent for the subgrade modulus, 2 percent for the axle per 1000 truck parameter, 1 percent for the percentage of trucks and negligible importance for the average dally traffic.

The effects on importance of high and low deviations from the average modulus of rupture are evidenced by a comparison of F1gures 71 and 72 with F1Eure 70 . For increasing moduli of rupture, the theoretical importance of that parameter decreases and the importance of the subgrade parameter increases while little change in the importance of the traffic parameter occurs. The higher subgrade modulus va.Iues depicted in Figure 73 produce a decrease in the importance of that parameter but an increase in the modulus of rupture and virtualiy no change in the traffic parameters.

Measures of practical parameter importance are 11Iustrated in Figures $74,75,76$ and 77 . Only the "total differ. ential" approach was used to evaluate practical importance because the PCA design process specifles that trial thicknesses are selected in $0.5-1$ n. Increments. Because the results of 
PCA RIGID DESIGN

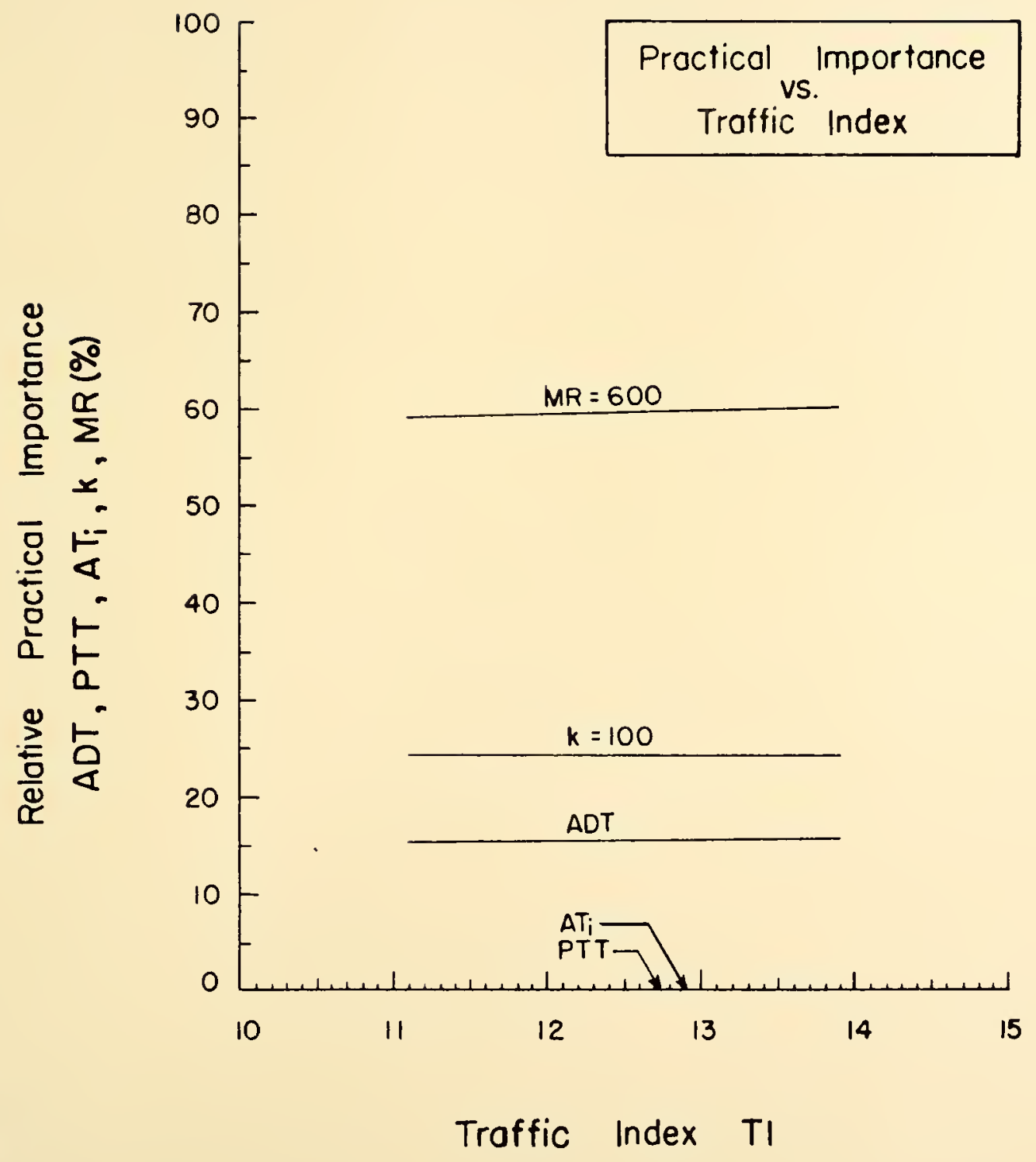

Figure 74. Relative Practical Importance of PCA Rigid Design Parameters 
PCA RIGID DESIGN

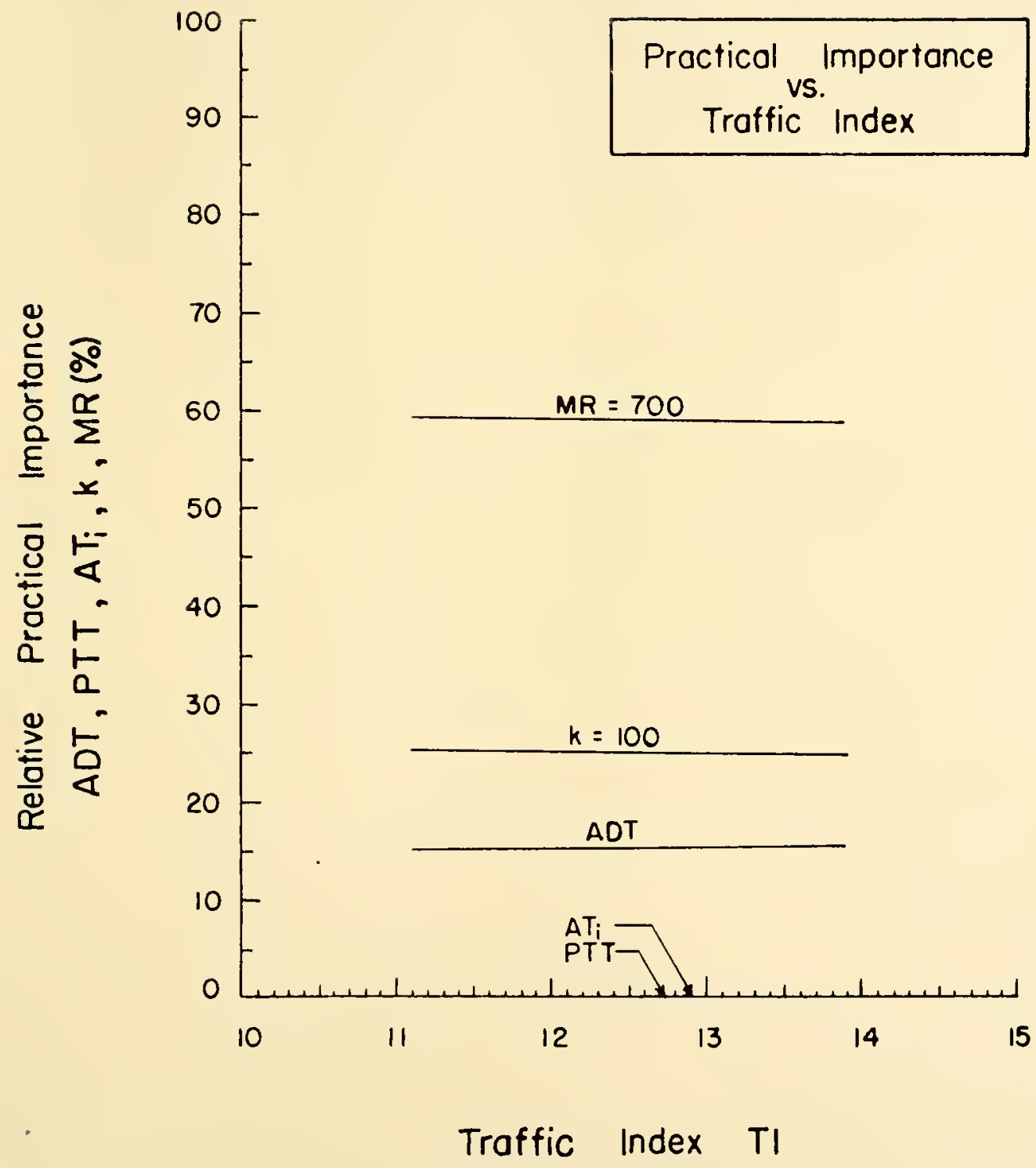

Figure 75. Relative Practical Importance of PCA Rigid Design Parameters 
PCA RIGID DESIGN

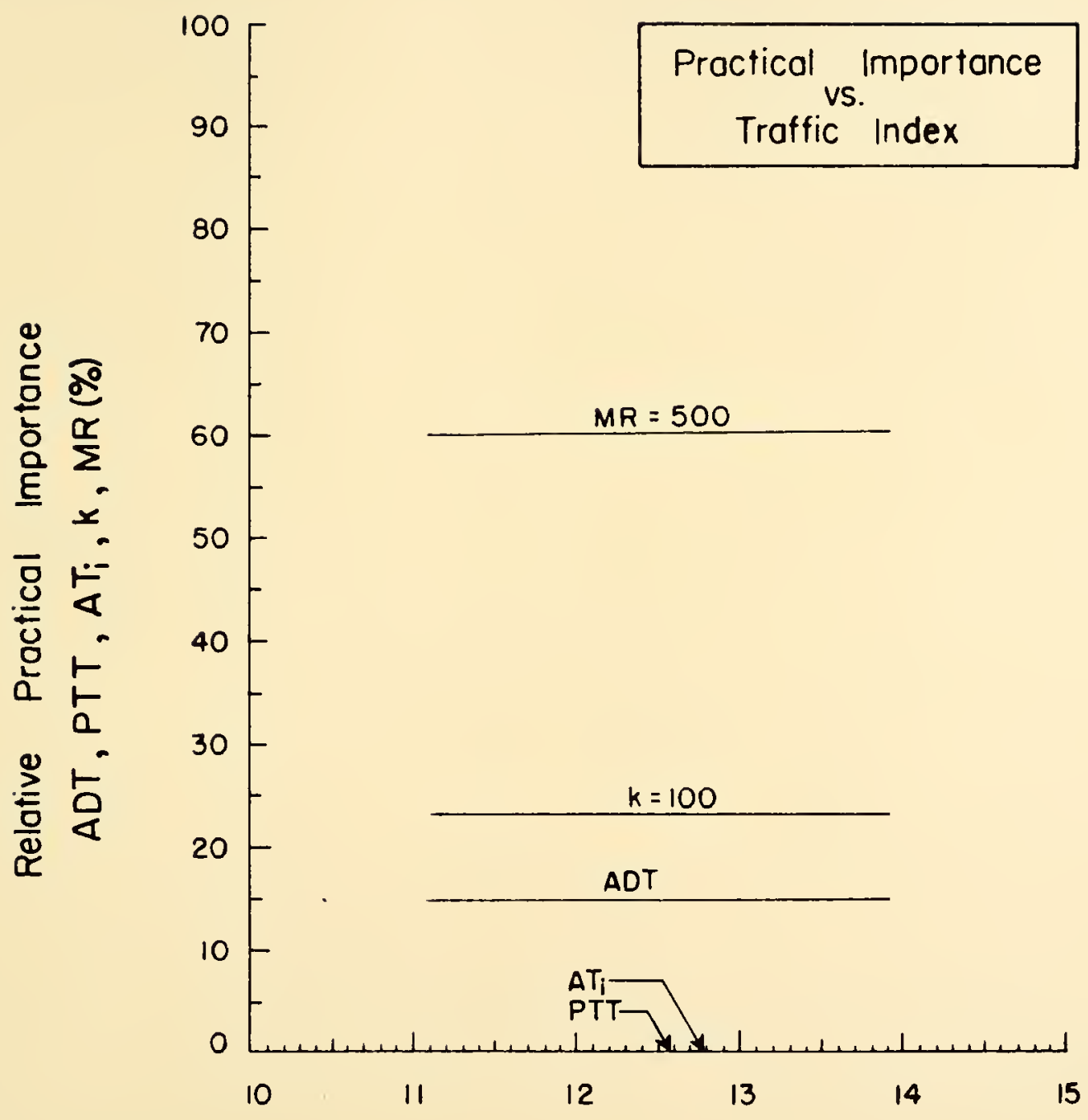

Traffic Index TI

Figure 76. Relative Practical Importance of PCA Rigid Design Parameters 
PCA RIGID DESIGN

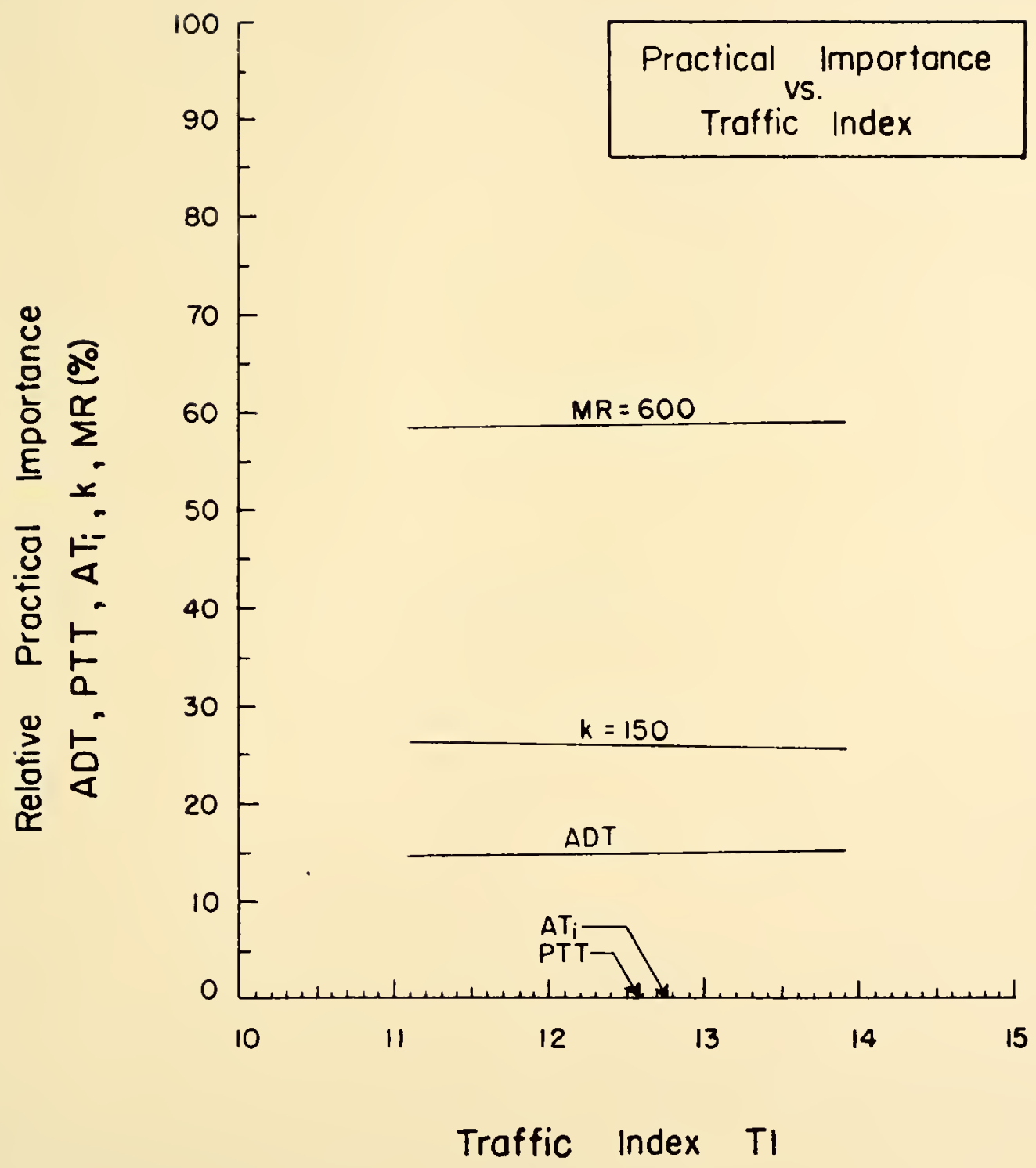

Figure 77. Relative Proctical Importance of PCA Rigid Design Parometers 
the "relative thickness change" approach are greatly affected by this $0.5-i n$. specification, this corroborating measure of practical importance was omitted from the study. For average conditions, the relative practical importances are 60 percent for the modulus of rupture, 25 percent for the suberade moduIus, 15 percent for the average daily traffic and at negligible amount for the other two traffic factors. If the pavement is bullt of stronger concrete or on subgrades of higher moduli of reaction, the importance of the supporting material parameters increase but that of the traffic parameters decrease. The modulus of subgrade reaction and the modulus of rupture are the most important parameters in the PCA Rigid desien process.

Tolerable Parameter Variations. Illustrations of the precision required for one parameter versus that of another for selected thickness change constraints are shown in Figures 78 and 79. The maximum precisions required by the 0.5-in. constraint are about 4 percent, 50 percent and 35 percent of the design values for the modulus of rupture, percentage trucks and averase daily traffic parameters, respectively. These percentages compare favorably with the 7 percent, 25 percent and 30 percent concurrent variations usually encountered in most design situations.

Least Squares Analysis of PCA R1sid Design. Pavement thicknesses were calculated for all combinations of moduli of rupture equal to $500,550,600,650,700,750$ and 800 psi, 
PCA RIGID DESIGN

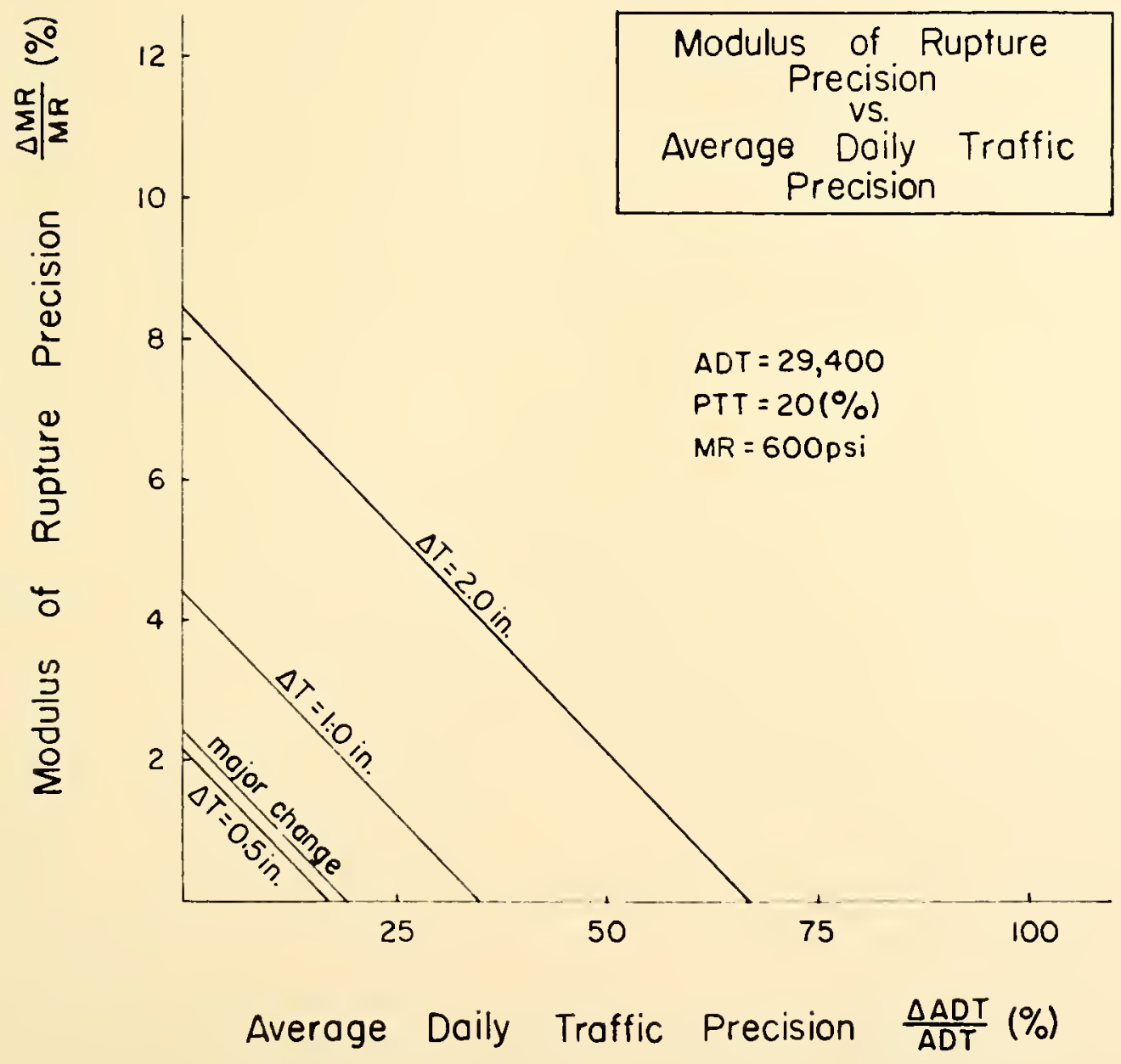

Figure 78. Tolerable Precision of PCA Rigid Parameters 
PCA RIGID DESIGN

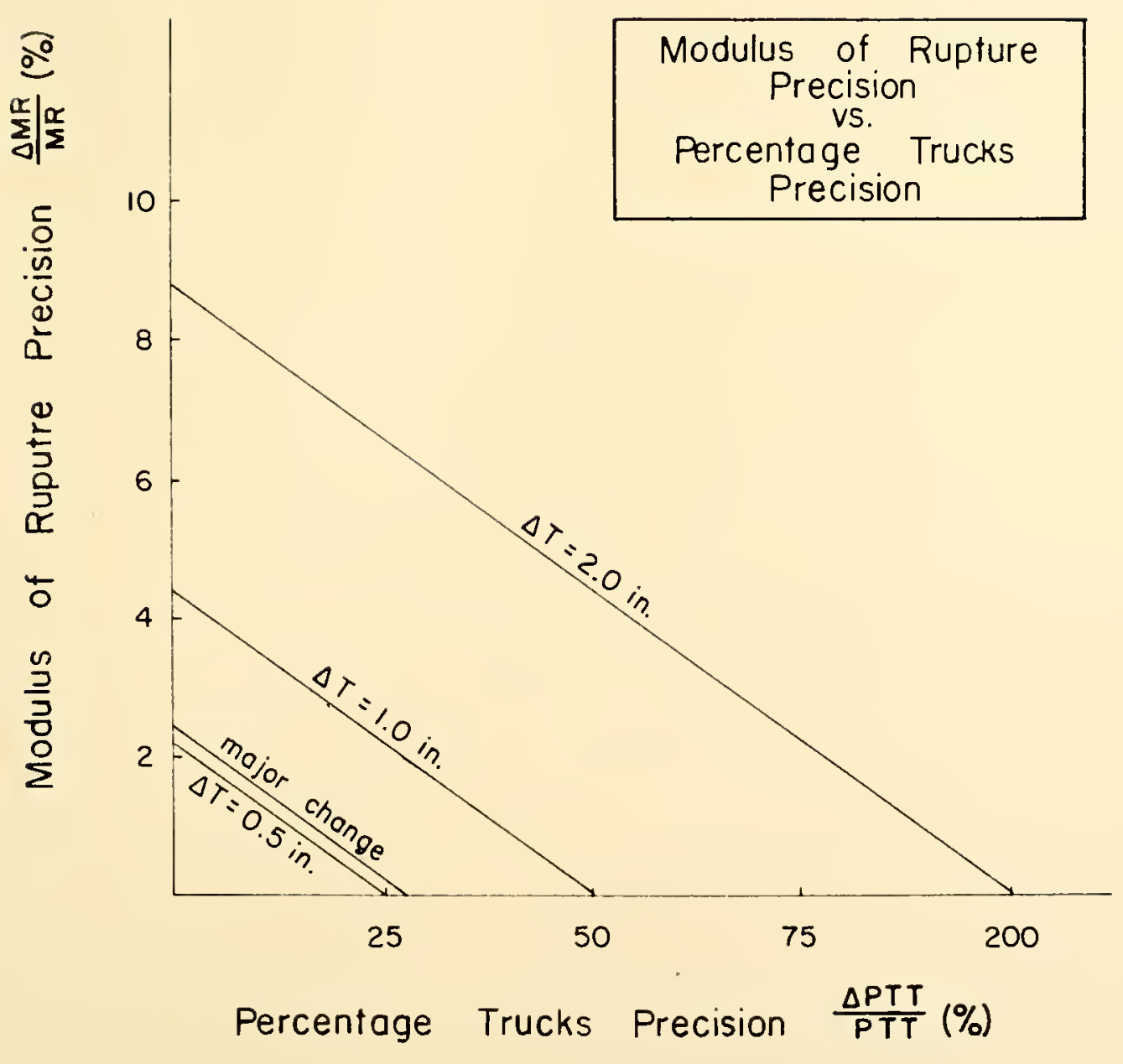

Figure 79. Tolerable Precision of PCA Rigid Porameters 
traffic factor values corresponding to the Corps of Enzineers A through E road and street classes and I through IV traffic categories and subgrade moduli corresponding to CBR values of 2, 4 and 6. A least squares analysis was performed on these thicknesses and the corresponding traffic and pavement structure parameters to determine the best fit of selected linear, quadratic and cubic models. The subgrade factor influenced the parameter thickness data but was not included as an independent variable in the regression analysis. Deletion of the modulus of subgrade reaction from the regression models was done so that comparable nodels are developed for each technique. Results of the regression analysis are tabulated in Table 10 which shows little improvement in the statistical efficiency of the quadratic or cubic models over the simpler linear model. The Iinear model is, therefore, to be preferred over the other nodels as an approximation of the PCA parameterthiciness relationships and as an interpretive tool for the evaluation among design methods of relative parameter importance. The coefficient of determination and standard errors of estimate are 0.96 and $0.39 \mathrm{in}$. for the linear model. and 0.97 and $0.33 \mathrm{in}$. for the quadratic model. The equation and measures of statistical efficiency of the cublc model is the same as that of the quadratic model because the variables of the cubic model which were deleted to avoid matrix singularity were those which differentiated the cubic model from the quadratic model. 


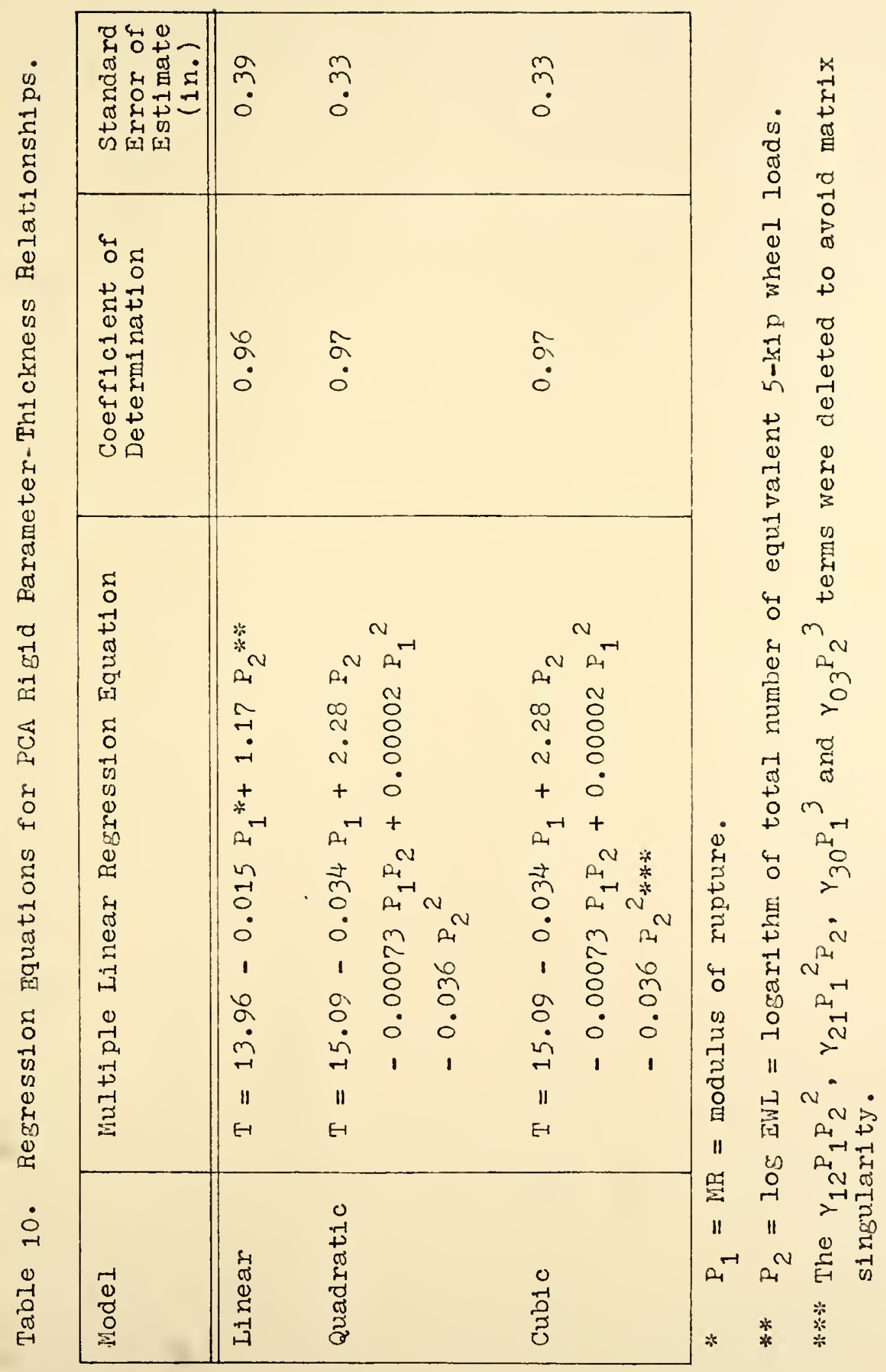




\section{Sumnary of Rigid Pavement Design Results}

To further the linowledge of pavement design, three techniques for the design of rigid highway pavements were critically studicd to determine the essential factors of each method and their influence on thickness requirements. The MASHO Rigid, Corps Rigid and PCA Rifid design methods were structured into a hierarchy of design-process logic, modeled mathematically or graphically for the sensitivity analysis, analyzed as to the theoretical and practical importances of design parameters and employed to senerate parameter-thiclness data to which Iinear, quadratic and cubic equations were fitted.

The orderine of design factors is illustrated for each design technique in a hierarchy of design-process locic. Although the objective of rigid parement desion is consistently manifested by the required concreto slab thicliness, each hicrarchy structure is distinct in the items considered and in the manner of resolving thichness. However, cach desion procedure primarily bases the required thiclness on the magnitude and frequency of traffic, the soli support of the subgrade and the strength of the concrete pavenent structure. While no sinfle traffic parameter is comon to these design methocs, the modulus of subsrade reaction neasures soil support in all three techniques. The modulus of rupture or a factor of safety modification quantifies the pavement structure propertios in each method.

Further development of thicleness models for the sensitivity analysis of the AASHO Rigid and Corps Rigid processes was not 
necessary, but a mathematical model of the total PCA Rigid design process was formulated in this research investigetion. With the establishment of adequate models a quantitative evaluation was made of deslgll parameter influences on pavement thicliness.

Parameter influences were judged by the first-order partial derivative of thickness with respect to each parameter and were quantified by a relative theoretical inportance measure. A comparison among corresponding plots for each design technique evidences a vast difference in theoretical importance amone the design parameters estimeting the same ceneric factor. These dissimilarities, which are also tabulated in Table 11 for average conditions rurther establish the uniqueness of each design method.

The relative practical importance measure accounts for nomal perameter variation and is considered a nore comprehemsive and realistic appraisal of design parameter influence on thickness. A greater consistency of parameter importance within and among design methods is obtained through this measure. In seneral, the parameters of traffic effects and those descriptive of concrete strength are regarded as the most important factors in rigid pavement desigin. Typical practical importance values are shown in Table 11. Although two of the three techilques rank the traffic factor third in importance, the dominating influence of the traffic factor in the AASEO Rigid technique is sufficient reason to regard traffic as one of the most important factors in the risid pavement desigin process. 


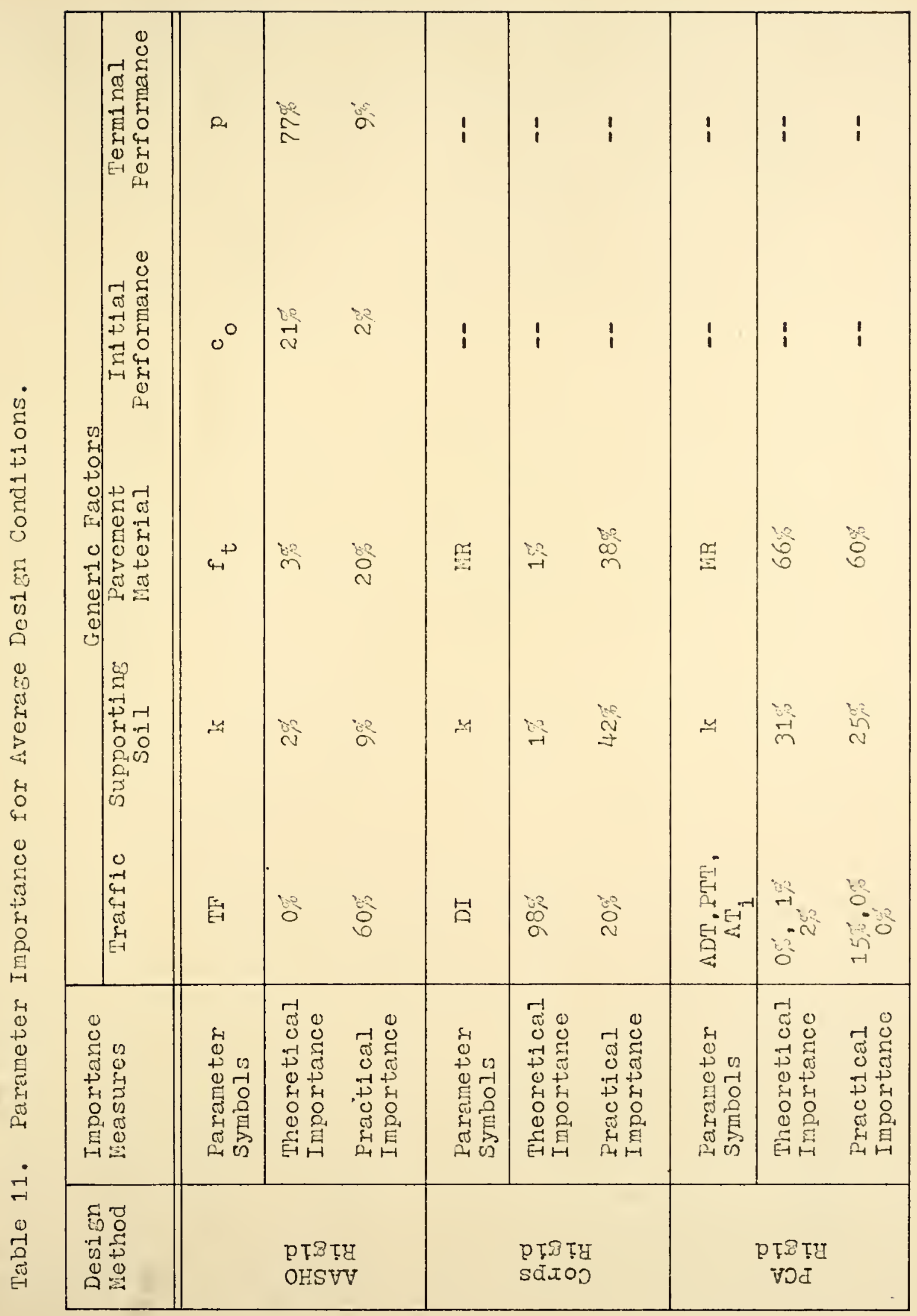


The parameter variations permitted for selected thichness change constraints were determined and are illustrated for each desicn method. The tolcrable parameter variations are usually smoller than those deviations normally encountered in actual practice. While the discrepancies exist between tolerable and actual variations, a definite evaluation of these ranifications vis not possible within the scope of this project.

The regression analysis for each design technique shows an improved fit of the data by the progressively hicher powered model. With this improvement in statistical efficiency comes a sreater number of regression coefficients and parameter functions to confuse the relationships betreen thiclenoss, traffic, structural strength and subgrade. Therefore, the lincar regression equation is preferred as the best balance of simplicity and statistical erficiency. The linear models of each design method and the corresponding measures of statistical efficiency are shown in Table 12. A comparison of the regression coefficients for the modulus of rupture variable in the various linear models indicates that the flexural strength is more important in the AASHO Rigid design method that in the Corps Rigld technique and is of least importance in the PCA Rigid design method. The relative influence of the number of equivalent 5-litp wheel loads among design methods is greatest in the AASHO Rieid method, least in the Corps Rigid technique and intermediate in the PCA Rigid. method. 


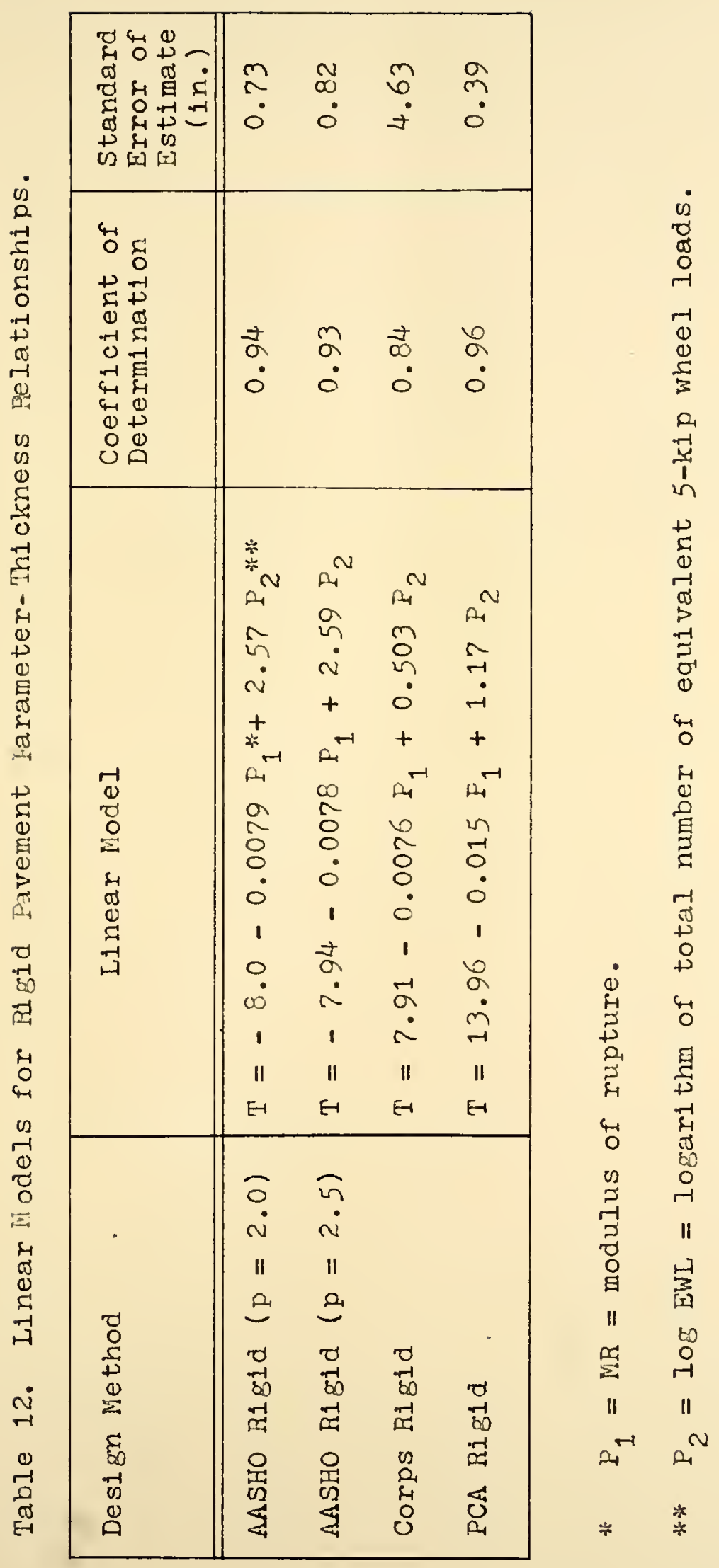




\section{General Summary of Results}

In summary, practical measures of importance, tolerable parameter variations and regression analyses of each technique demonstrate eneral similarities for flezible and for the rigid design methods which were not foreordained when only the differences exhibited in the hierarchy structuring of design-process logic and in the evaluation of theoretical parameter importance are considered. On the basis of these results, however, the development of a simplified method for the design of flexible or rigid pavements was judged feasible. 


\section{DEVELOPHENT OF SIMPLIFIED}

DESIGN METHODS

In the early stages of this research, isometric plots of the equations for the six selected design methods were prepared to sain an intuitive appreciation of the paraneter-thickness relationships. These three-dimensional graphs, shown in Figures $80,81,82,83,84$ and 85 aided in forming the analysis techniques and in developine the concept of a simplified design technique. Whon the three flexible or three rigid isometric plots were superimposed, the possibility of an average thickness surface representing a simplified thickness function was apparent as a research objective.

In outlining the procedure for developing this final research activity, several requisites for the simplified design methods were specified. These methods were to provide a technique compatible with present parameter variations, to encompass the representative design methods, to delete from the design process any unimportant design variables and to simplify existing design models within the allowable precision of pavement thickness determinations. The proposed synthesis of the three rigid or the three flexible design methods adequately fulfills these designated requisites. The feasibility of the synthesis procedure was especially 


\section{AASHO FLEXIBLE DESIGN}

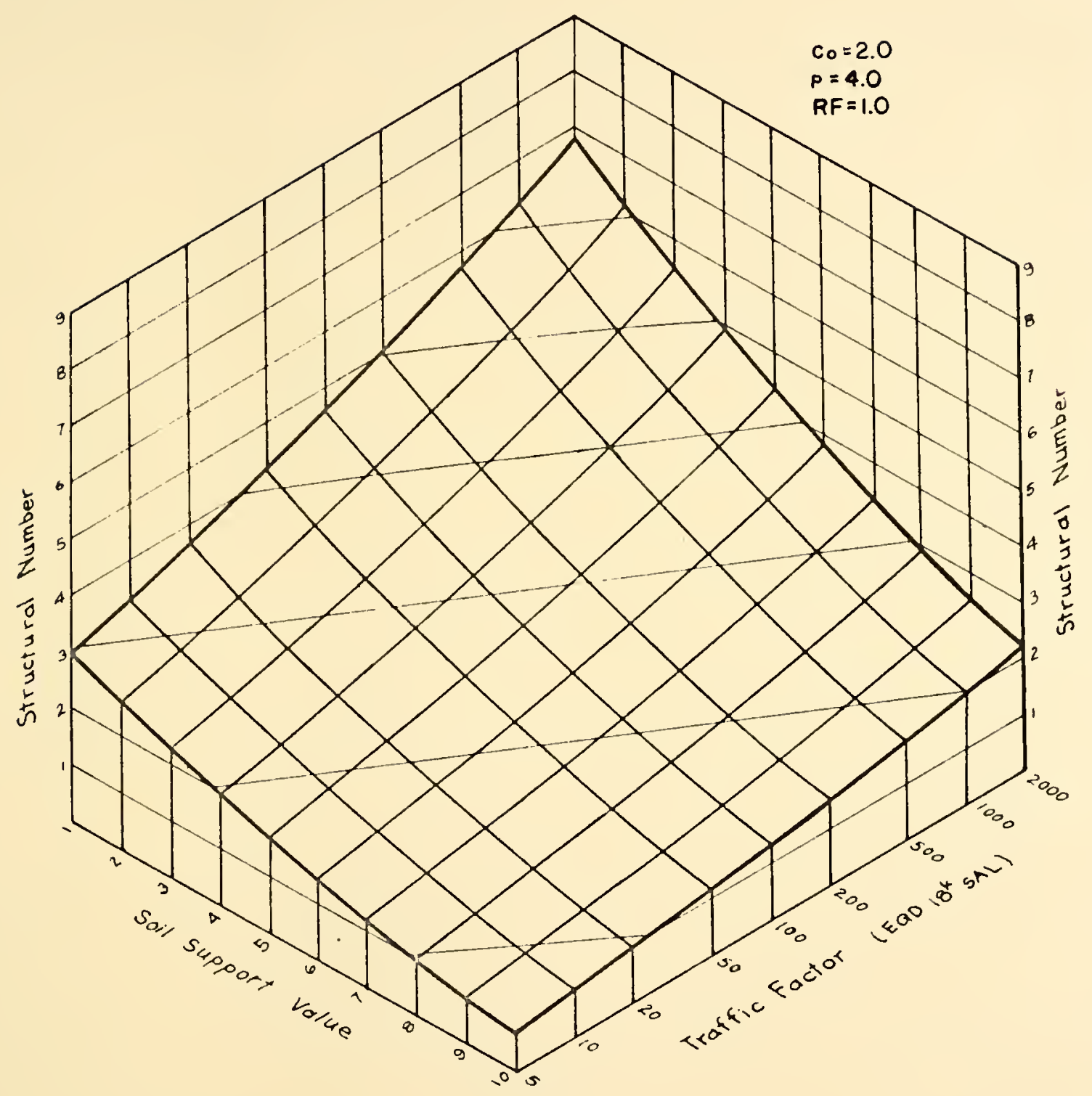

Figure 80. Isometric Plot of AASHO Flexible Design Relationship 
CORPS FLEXIBLE DESIGN

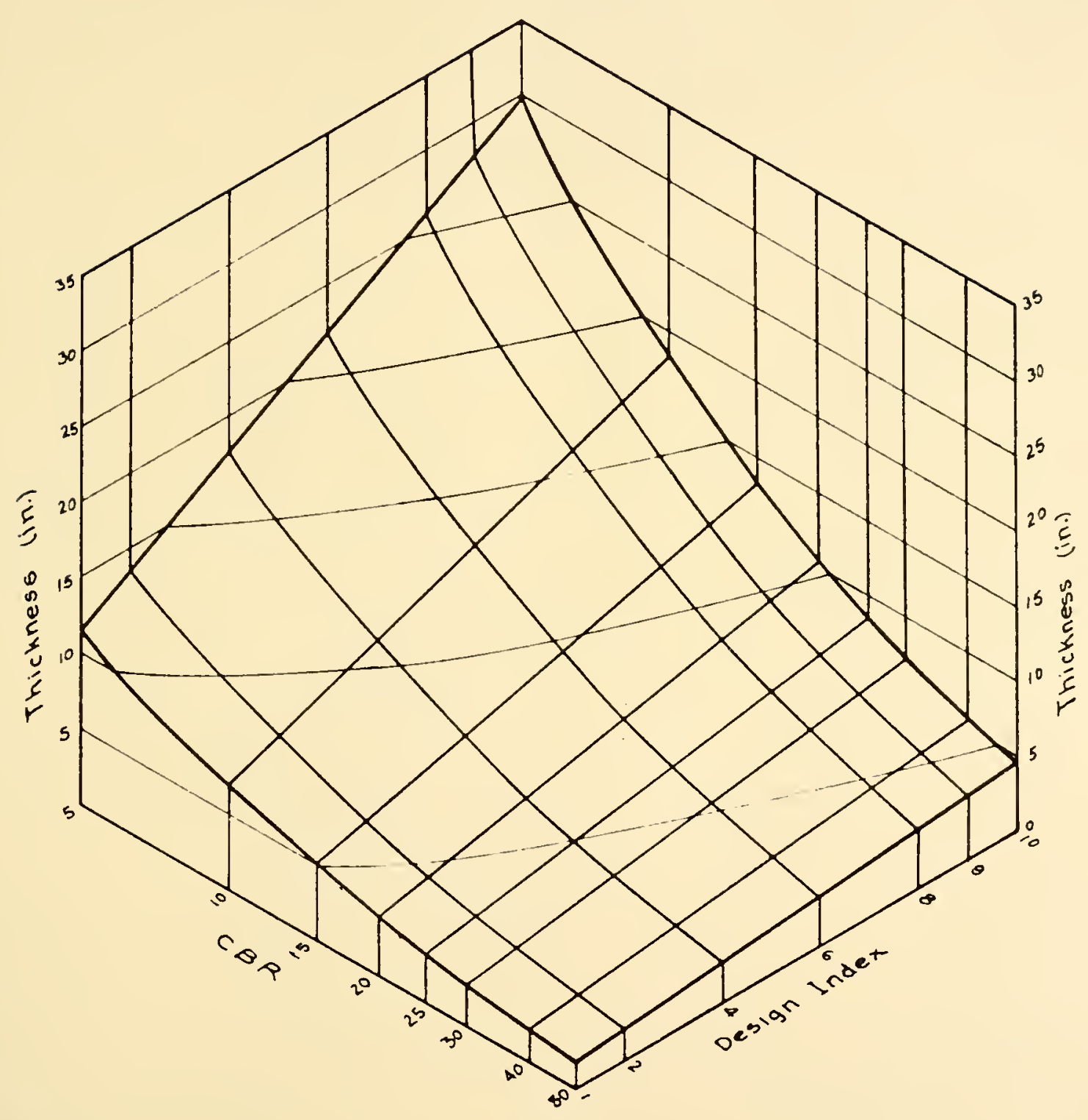

Figure 81. Isometric Plot of Corps Flexible Design Relationship 
CALIFORNIA STABILOMETER DESIGN

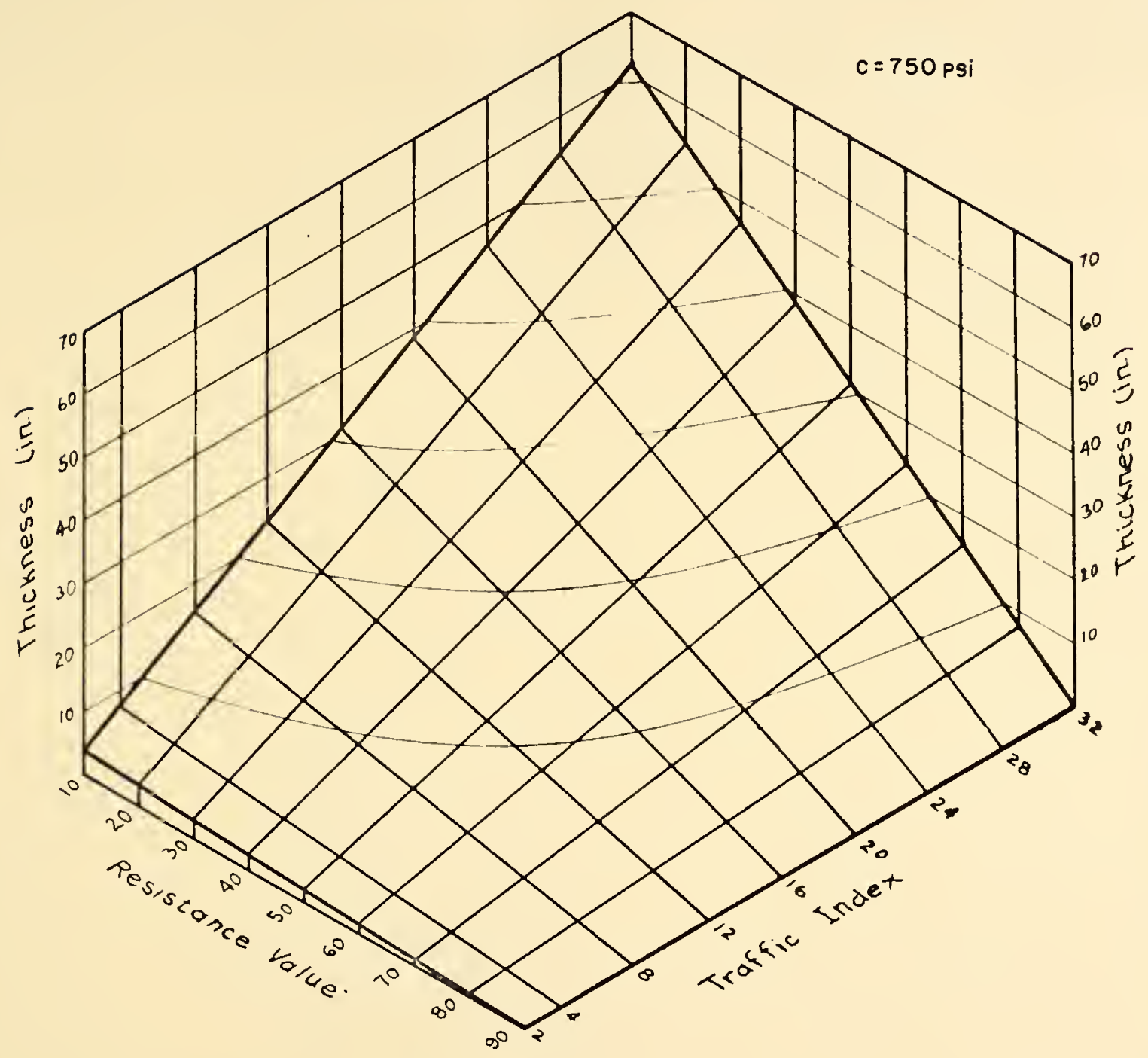

Figure 82. Isometric Plot of California Stabilometer Relotionship 


\section{AASHO RIGID DESIGN}

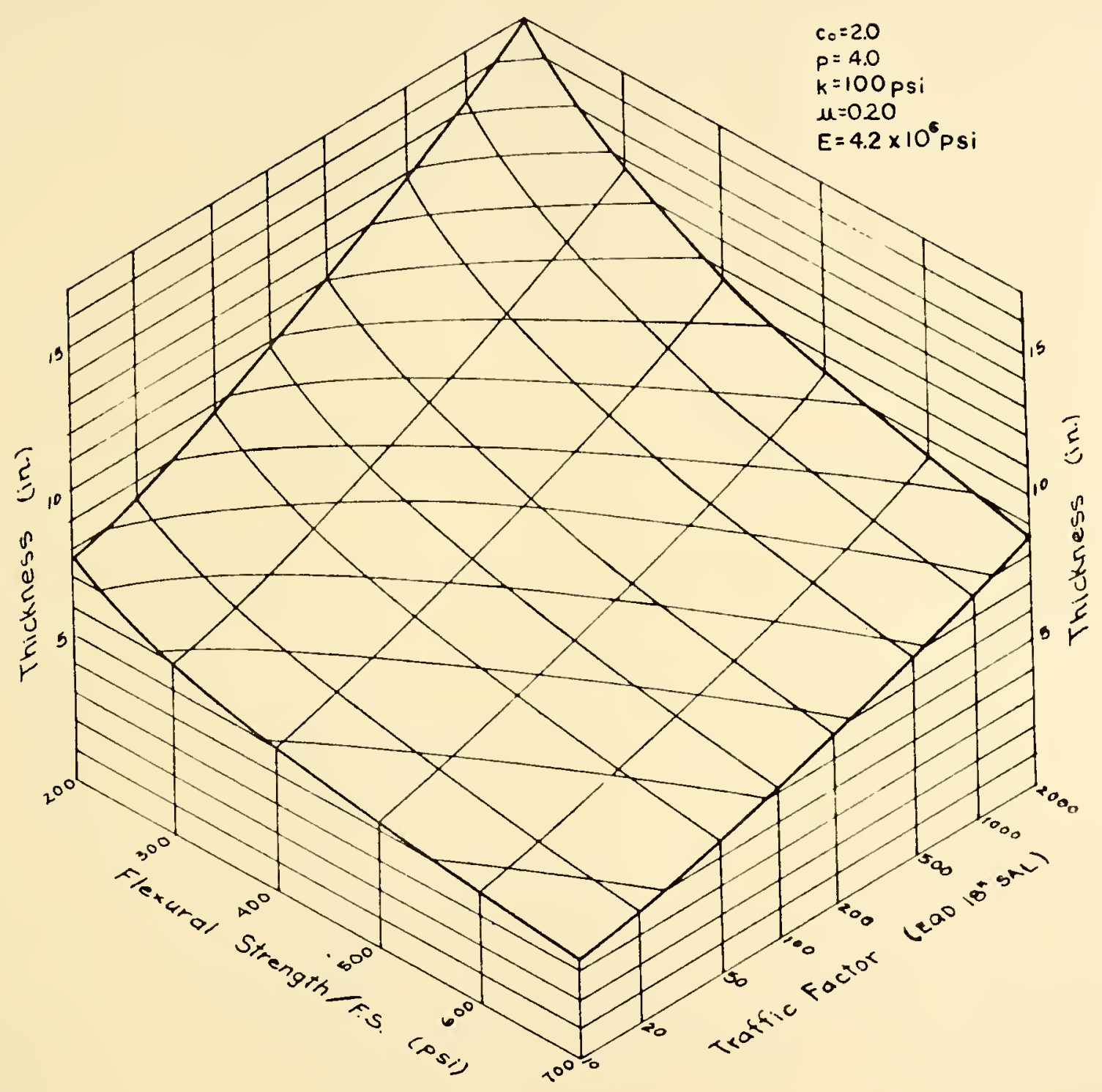

Figure 83. Isometric Plot of AASHO Rigid Design Relotionship 


\section{CORPS RIGID DESIGN}

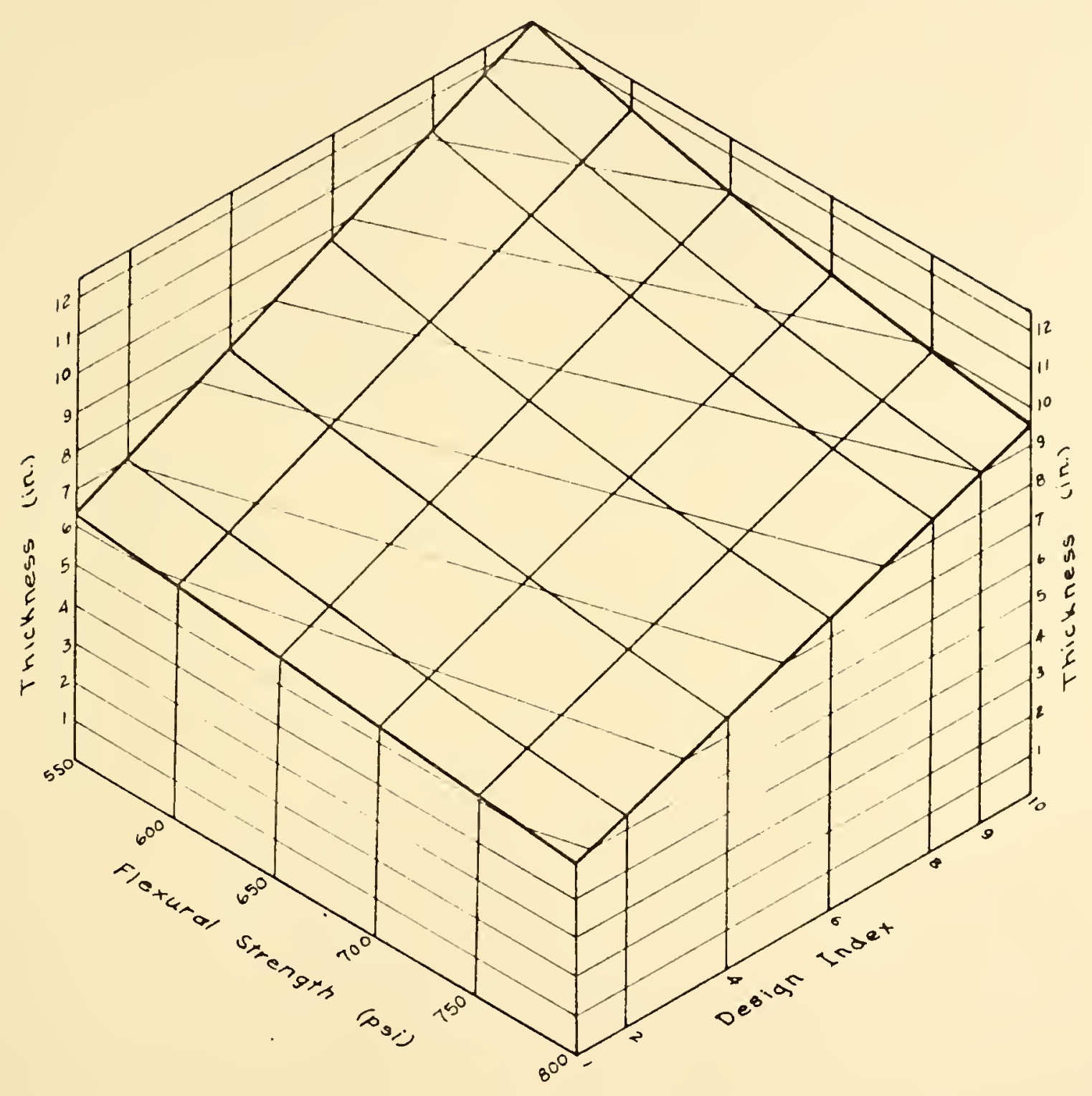

Figure 84. Isometric Plot of Corps Rigid Design Relationship 
PCA RIGID DESIGN

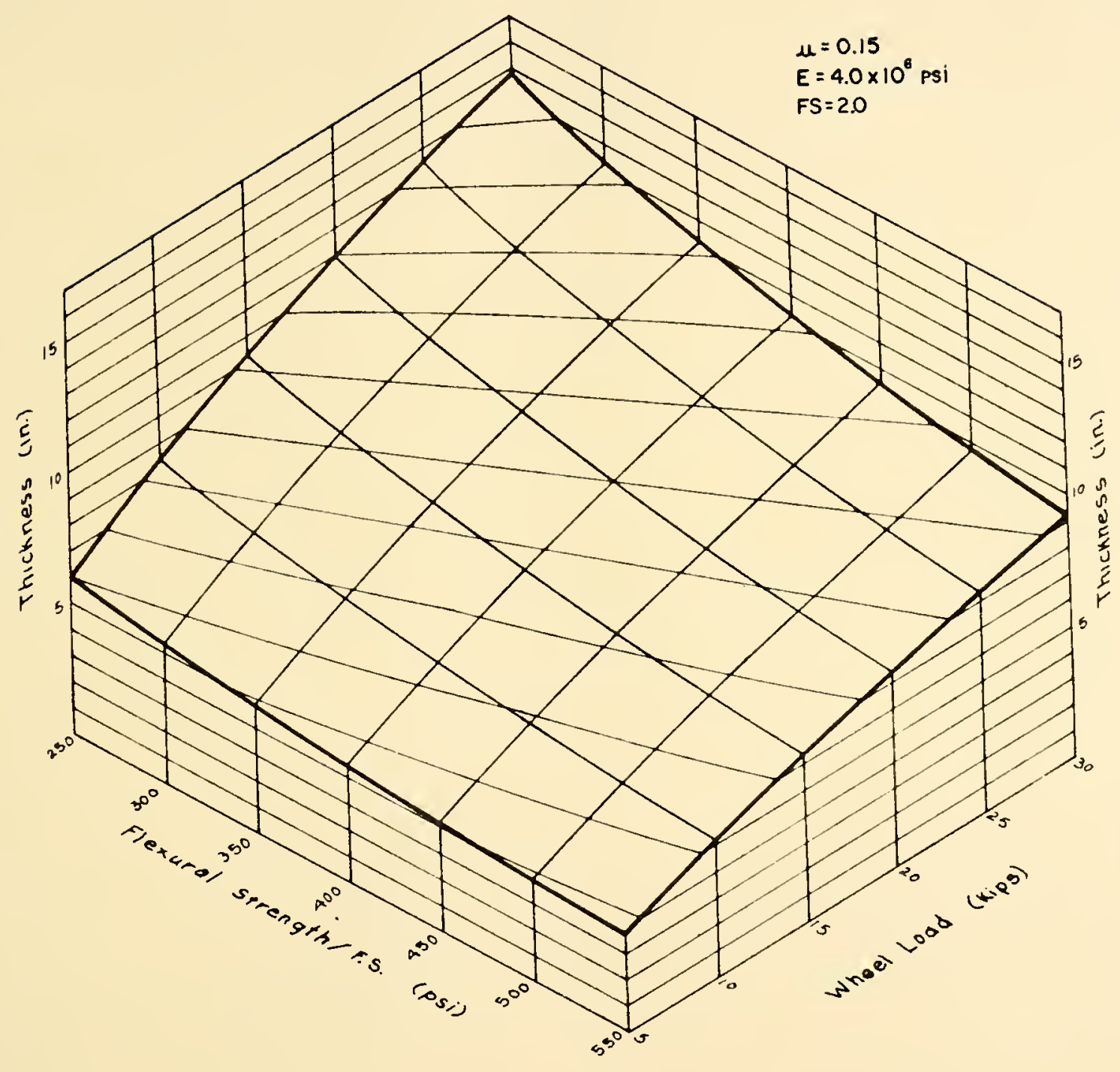

Figure 85. Isometric Plot of PCA Rigid Design Relationship 
enhanced by the results of the least squares analysis which showed high coefficients of determination and low standard errors of estimate for the regression equations that were ascertained for each design technique.

Actual development of the simplified methods depended on the preceding sensitivity analysis, in which the two more important variables in the flexible or rigid design process were determined. The various paraneters used to estimate either of these factors were related by direct correspondence, and one parameter for each generic factor was selected as the design parameter to be employed in the simplified method. Parameter-thickness data for each desisn criteria were then cenerated for a large array of simplified design parameter value combinations. By combining the information representative of the three flexible or three rigid techniques, a synthetic Group of data were amassed and fitted by Iinear, quadratic and cubic equations. The equation representative of the simplified design method for flexible or for rigid pavements was then chosen as the optimum balance of statistical efficiency and model simplicity.

\section{Simolified Flexible Design}

Traffic loadins and soil support are the two more important factors in flexible pavement design as evidenced from the results of the sensitivity analysis and from the examination of tolerable parameter variations. Each seneric factor is estimated by three different parameters that are associated 
with the AAstio Flexible, Corps Flexible and California Stabilometer design methods. To obtain compatible parameterthickness data, parameters for estinatins either traffic loadinss or soil supports were related by direct correspondence to produce comparable independent variable values. To crenerate comparable dependent variable values, total thicknesses composed of $3.0 \mathrm{ln}$. of plantmix asphalt surface, $5.01 \mathrm{n}$. of crushed stone base and various amounts of sandy eravel subbase were calculated for the independent variable combinations. Establishing mutual parameter value combinations and comparable pavement thicknesses permitted the generation of the necessary data for the synthesis of flexible pavement desien techniques.

\section{Correlation of Flezible Design Farameters}

Soll support is estimated by the soil support value, the California Bearing Ratio and the resistance value respectively, in the MSHO Flexible, Corps Flexible and Califomia Stailometer techniques. The soli support value parameter of the MASHO Flexible design method is not physically defined but relies on the correlation of other standard soli tests to specify its value. The correlation chart for the MAsHo technique relates the California Bearins Ratio to the resistance value and to the soil support value (1). The California vearing Ratio, which is determined by a relatively simple and versatile soil testing procedure, was arbitrarily selected as the soll support parameter for the simplified design method because this measure has rather wide use among agencies responsible for the design of highway pavements. 
Correlation of the three traffic parameters was made by assuming a variety of traffic loading conditions and by detemining that value of each parameter which describes the selected conditions. Because the Corps Flexible design index is a discrete rather than a continuous parameter and is based on highway and traffic classifications, the other traffic parameters of equivalent 18-kip single-axle load applications and traffic index were calculated to correspond to forty different combinations of Corps highway classes and traffic catecories.

The total number of equivalent $5-1$ p wheel loads was arbitrarily selected as the traffic parameter for the simplified design method because this traffic measure has been extensively used and is simple to determine. This equivalent wheel load neasure is the factor employed in the Califormia stabllometer technique and is calculated by the following formula:

$$
E W L=\sum_{i=1}^{n}\left[\begin{array}{ll}
{\frac{W_{i}}{5}}^{\frac{25}{6}} & r_{1}
\end{array}\right]
$$

where $\quad E W L=$ equivalent 5-kip wheel loads,

$$
\begin{aligned}
& w_{1}=\text { design wheel load of class ( } 1 \text { ) (kips) and } \\
& r_{i}=\text { number of load applications of class (i). }
\end{aligned}
$$

For single-axle arrangements, the design wheel load is the midpoint of the axle load class interval. For tandem axles the design wheel load is equal to 1.1 times that midpoint value to account for the superimposed stress effects produced 
by the proximity of wheel loads in a tander axle arrangement. While the Corps Flexible technique specifies the veight and dimensions of design vehicles that reprosent passenger cars, panel and pickup trucks, 2-axle trucks and buses, 3-axle trucks, 4-axle trucks and 5-axle truclis, the corps traffic categories do not adequately define the distribution of these vehicles within broad specifications for percentage of trucks. Therefore, a reasonable distribution of particular vehicle types within each category was assumed to refine the traffic category descriptions so that equivalent 18-kip applications, traffic indices and equivalent $5-k i p$ wheel loads could be determined.

Development of a Simplified Flexible Thiclness Equation After the various soll support and traffic parameters were related by direct correspondence, comparable parameterthickness data were generated for each flexible design method. These data were then collated so that three thicknesses exist for each combination of CBR values of $2,4,6,8,10,15,30$ and 50 and of equivalent wheel load values for Corps road and street classes A through E anà traffic categories I through IV. If any thickness points were less than a rinimum of 8 in., these values were removed from the synthesis alone with the other two correspondins data points. Linear, quadratic and cubic equations were fitted to the parameter-thickness data by the least squares technique.

Because the terminal serviceability index of the AASHO Flexible technique has considerable influence on thickness 
as show in the sensitivity analysis, two groups of parameterthickness data representing terminal indices of 2.0 and 2.5 were combined with the Corps Flexible and California Stabilometer data. Results of these syntheses are presented in Tables 13 and 14. The linear model shown in Table 13 has a coefficient of determination of 0.70 and a standard error of estimate of 2.66 in. While the quadratic and cubic models exhibit a slight improvement in the two goodness of fit measures, the linear model affords the simplest explanation of the pavement design process. The equations and statistical measures of Table 14 indicate similar results but show a slisht improvement in statistical efficiency over the equations of Table 13. Therefore, the following linear model was selected as the relationship for the simplified design of flexible pavements:

$$
T=-10.37-23.29 \log (\mathrm{CBR})+5.85 \log (\mathrm{EWL}) \quad[30]
$$

Where $T=$ total flexible pavement thickness (inches). CBR = California Bearing Ratio and EWL = total number of equivalent 5-kip wheel loads. The equivalent wheel loads and the California Bearing Ratios are calculated by the procedures specified in the California Stabilometer and the Corps of Englneers Flexible pavement design techniques, respectively.

\section{Applications to Practice}

A design chart based on equation 30 was prepared to facilitate the application of the simplified method to design practice for flexible pavements. While the design chart 


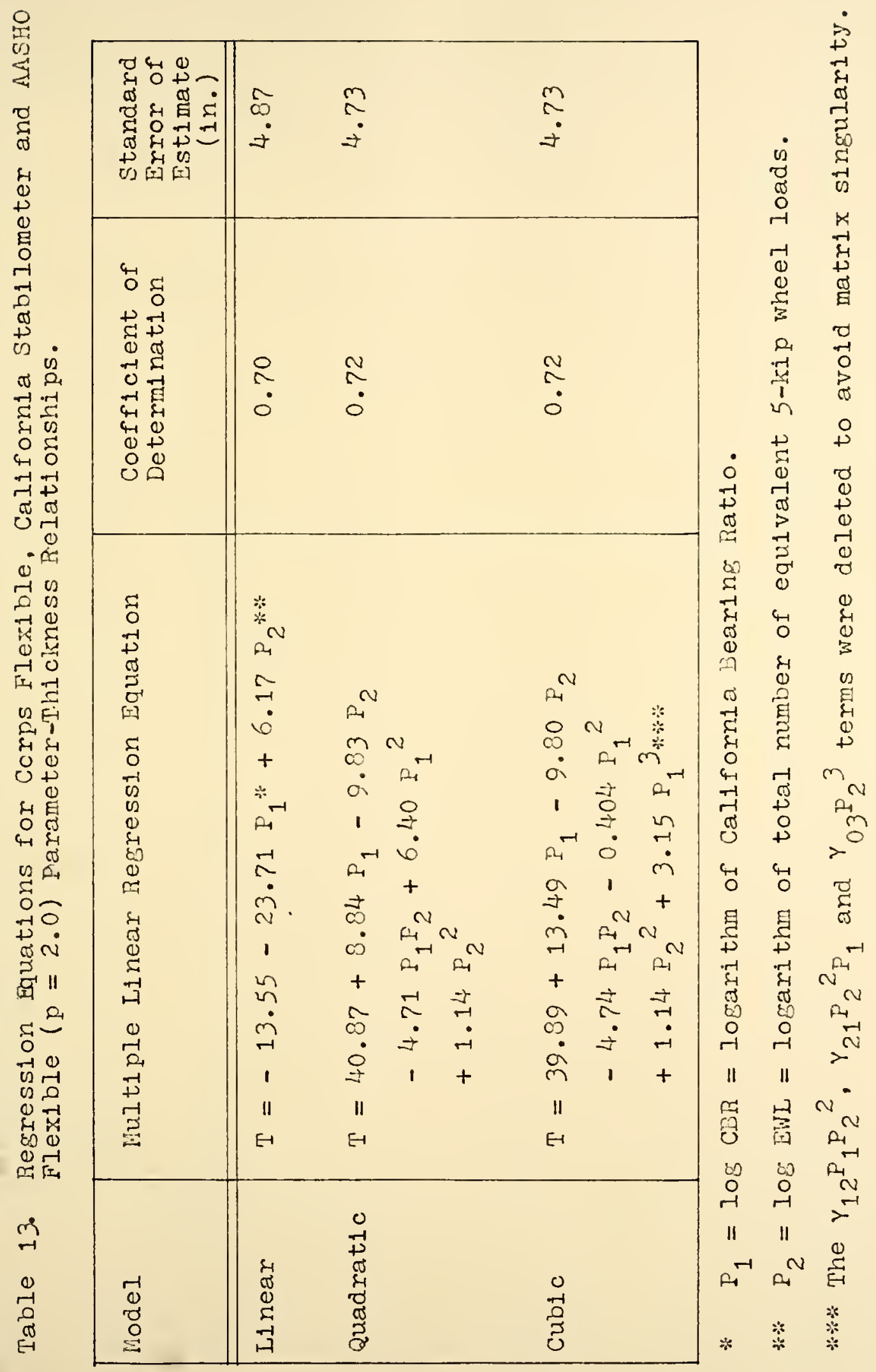




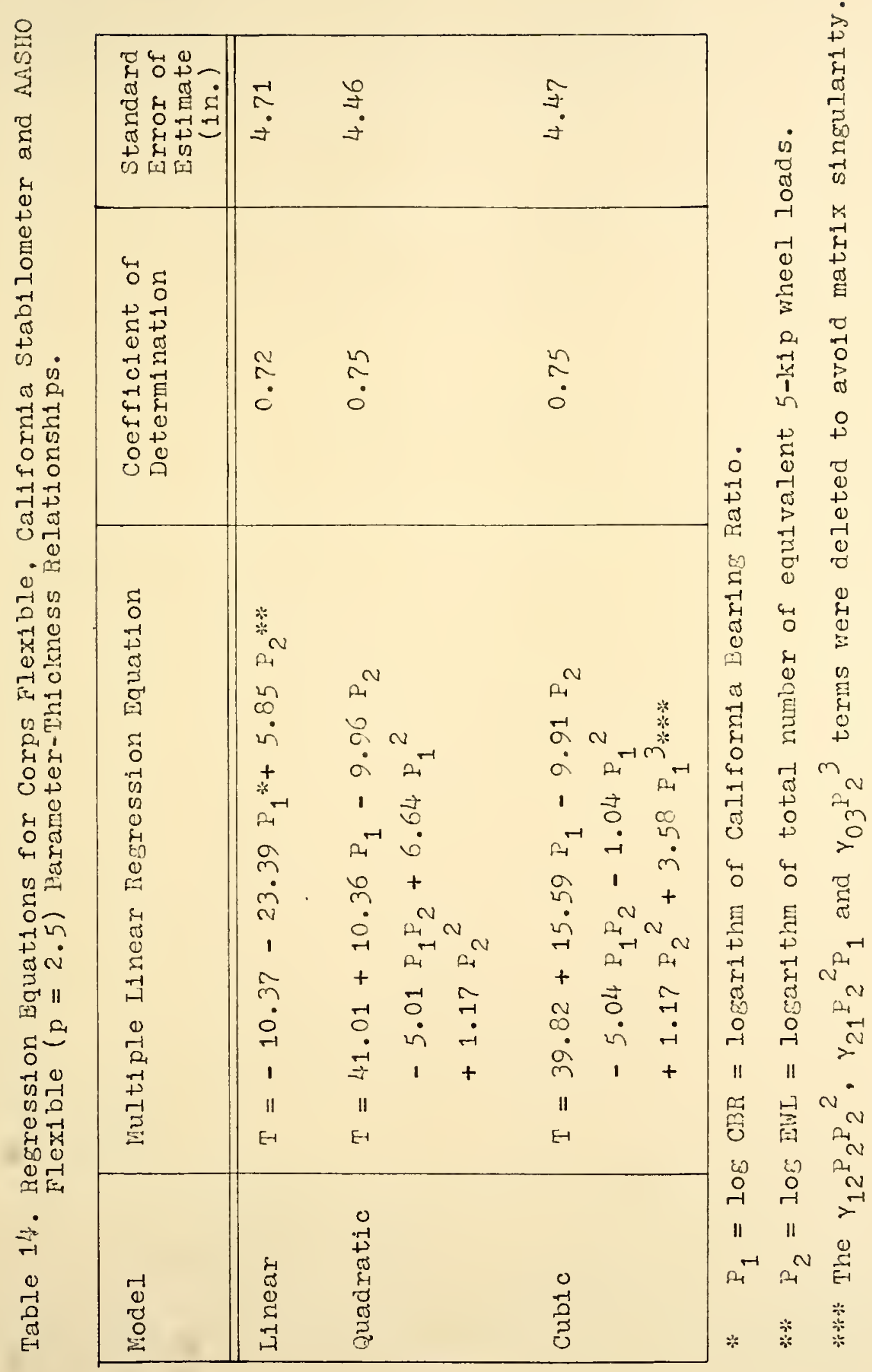


shom in Figure 86 encompasses most design situations, excessive extrapolation of the linear relationships is not recommended because the straisht lino representation is not valid for extreme values of soil support and traffic loads. At present, the simplified desion method for flexible pavements is suited for expedient approximations of pavement thicknesses. Val1dation of this technique is necessary to ascertain its overall reliability.

\section{Simplified lisgid Design}

Analysis of the three rigid pavement design techniques revealed the factors of traffic loading and pavement strength as the more important considerations in the desien of rigid pavements. The various design parameters of the AASHO Ririd. Corps Rigid and FCA Rigid procedures are similar for pavement streneth, but the traffic parameters differ considerably. To carry out the synthesis of rigid pavement desicn tecmiques, these reneric factors were related to each other, and thicluness data peculiar to each design method were generated for a larse array of parameter combinations. Selectod models were fitted to the combined data, and an optimum choice was made of the equation to represent the simplified design method for rigid pavements.

Correlation of Risid Desisn Farameters

The flexural strensth of the pavement is recoenized as an important factor in risid pavement design. Consideration of this factor in the corps Rifid and PCA Rigid design 


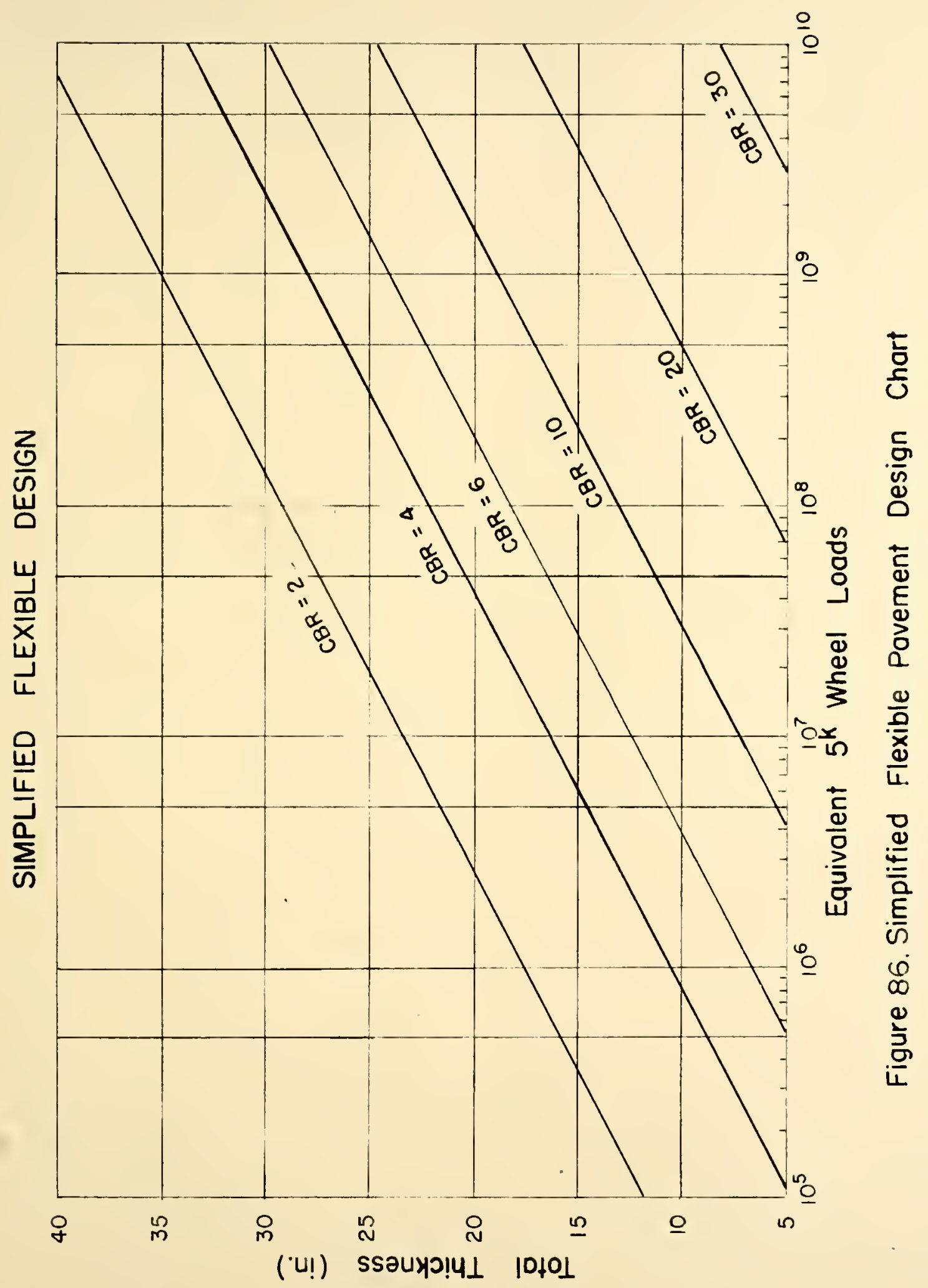


techniques is by the modulus of rupture, but the AMSHO Rigid method utilizes a modulus of rupture that is modified by a factor of safety. Because the properties of the pavement material are quantified by some form of the modulus of rupture for concrete in all three methods, correlation of that factor is directly possible among desien procedures. The modulus of Iupture also was logically selected as the pavement material parameter for the simplified design method.

Various measures are used by the investigated design methods to describe the traffic loading conditions. The $\mathrm{FCA}$ Rigid technique employs average daily traffic, percentage of truclis and axles per 1000 trucles as traffic parameters. The MASFO Rigid and Corps Rigid methods use single measures of equivalent 18-lkip single-axle load applications and design index, respectively, to sumarize traffic loadings. These measures were correlated with each other by assuming vaxious traffic conditions and by determining the appropriate descriptive parametex or parameters in the case of the PCA design method. The traffic conditions were specified by forty combinations of ten Corps hichray classes and four Corps traffic categories. For the simplified rigid pavement design nethod, the equivalent 5-kip wheel load measure of the California Stabilometer technique was used to quantify all traffic loads.

Develonment of a Simplified Rigid Thiclness Equation For each rigid pavement desien method, thicknesses were determined for every combination of moduli of rupture equal 
to $500,600,700$ and $800 \mathrm{psi}$, of equivalent 5-kip wheel load values representing Corps road and street classes A through $E$ and traffic categories I through IV and of suberade moduli values equivalent to CBR values of 2,4 and 6 . Synthesizing the data of each technique into an agsregate group of collated data points permitted the development of several equations that encompass the MASHO Rigid. Corps Rigid and FCA Rigid design methods. When a thickness was less than a specified 4-in. Ininimum, that data point along with the other corresponding points were discarded from the synthesis.

Determination of possible thickness equations involved a least squares fitting of Iinear, quadratic and cubic models to the generated data. Results of this regression analysis are presented in Tables 15 and 16. As in the development of the simplified flexible method, two Eroups of combined data Which differ only by the data contributed by the AASHO Rigid technique were andyzed. The results of this analysis for a terminal serviceability index of 2.0 are shown in Table 15 . and the results that apply to data for a terminal serviceability of 2.5 are given in Table 16.

Resardiess of which gloup of data was analyzed, the linear, quadratic and cubic models all exhibit small coefficients of determination and high standard errors of estimate. This situation occurred even though separate least squares analyses of each technique indicated that the linear, quadratic or cubic models were excellent approximations of the original parameter-thiclmess relationships. Apparently, the incorporated 


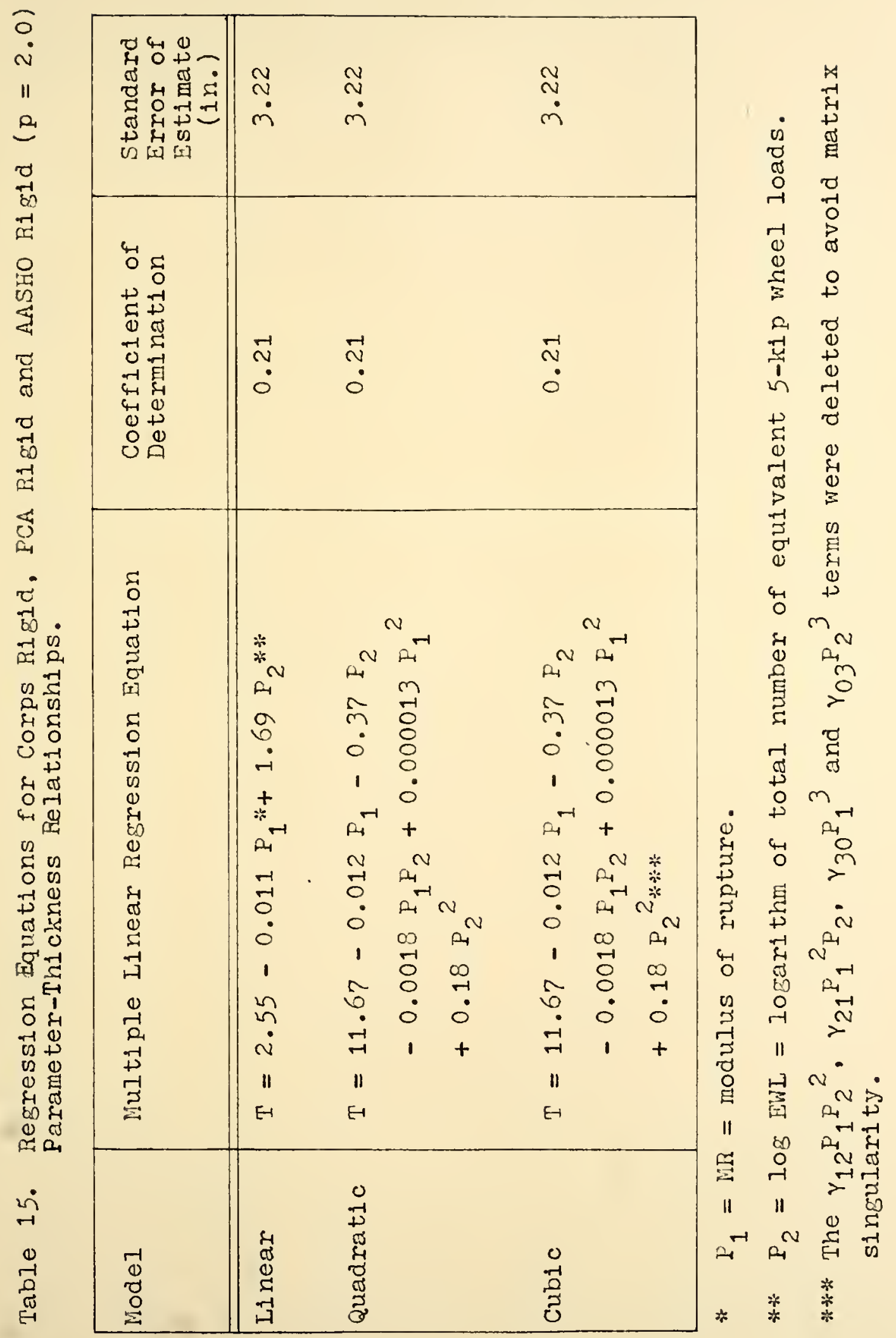




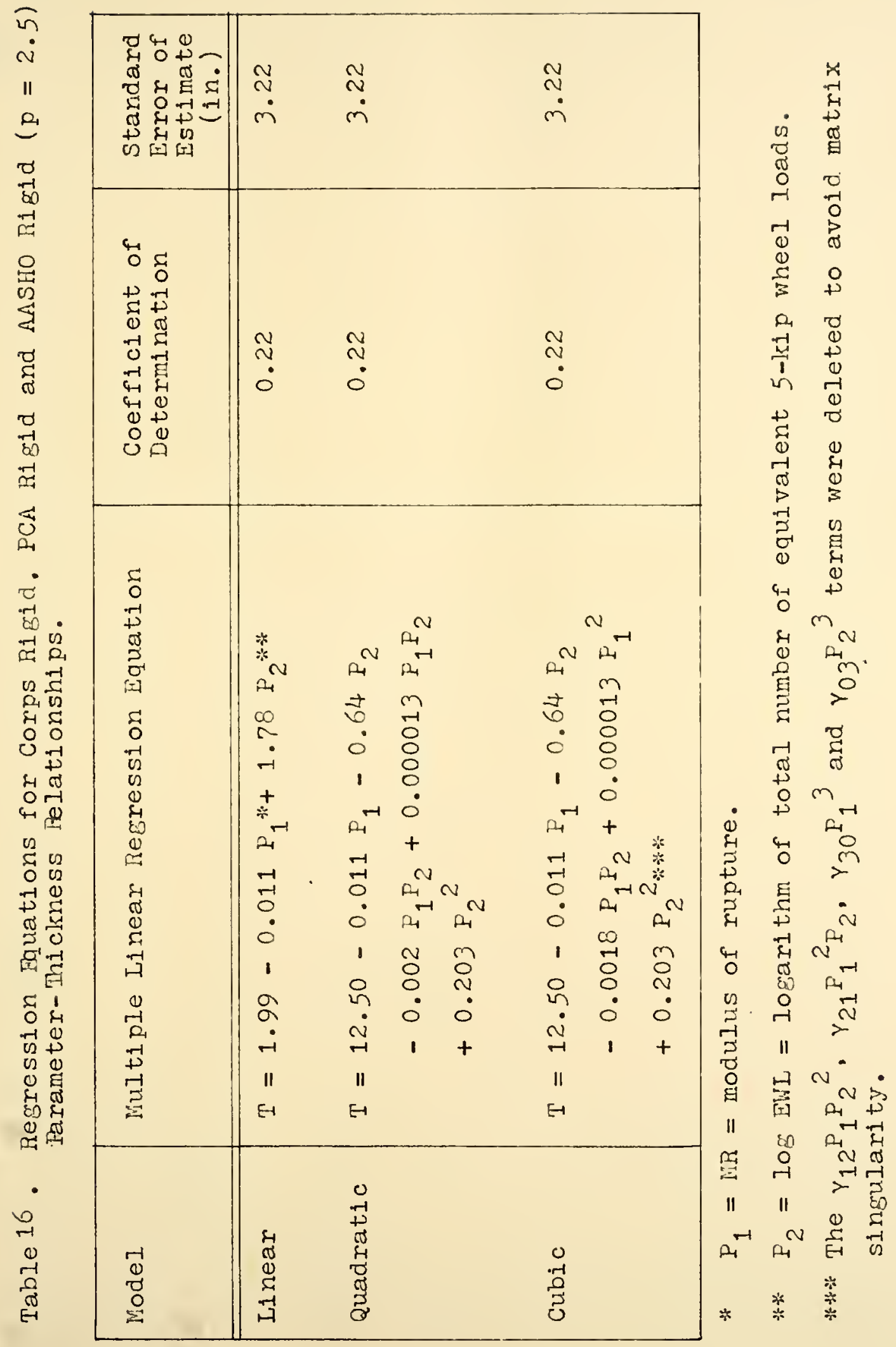


FCA data were the primary source of data variation because the thicknesses required by the FCA Risid design criteria were considerably lareer than the correspondine values for the AAStio Ricid and Corps Rigid methods. In addition, PCA thicknesses were below the mininum level for every Corps hishray class that was combined with traffic categories I and II. To avold erroneous results, the PCA Rigid data were deleted from the synthesis of pavement design techniques, and simplified equations were fitted to the remaining data. Results of this modiried synthesis of design techniques are presented in Tables 17 and 18. While the regression antysis of the data, which included the PCA Rigid thiclmesses, exhibit coefficients of determination of 0.2 and standard errors of estimate of 3.2 in., the corresponding measures of statistical efficiency shom in Tables 17 and 18 are about 0.7 and $1.3 \mathrm{in}$.

The cubic models of Tables 17 and 18 exhibit no statistical advantage over the quadratic and. in fact, are the same nathematical expression as the quadratic model due to the deletion of veriables to avoid matrix singularity. The quadratic models were only slightly more efficient than the Iinear models. Therefore, the linear equation affords a realistic represcntation of the rifia pavement parameter-thicliness relationships for the simplified design method. Fecause the linear equation in Table 17 is slightly more efficient than that equation in Table 18, the follovine expression was chosen to represent the sirplified design equation for risid pavements: 


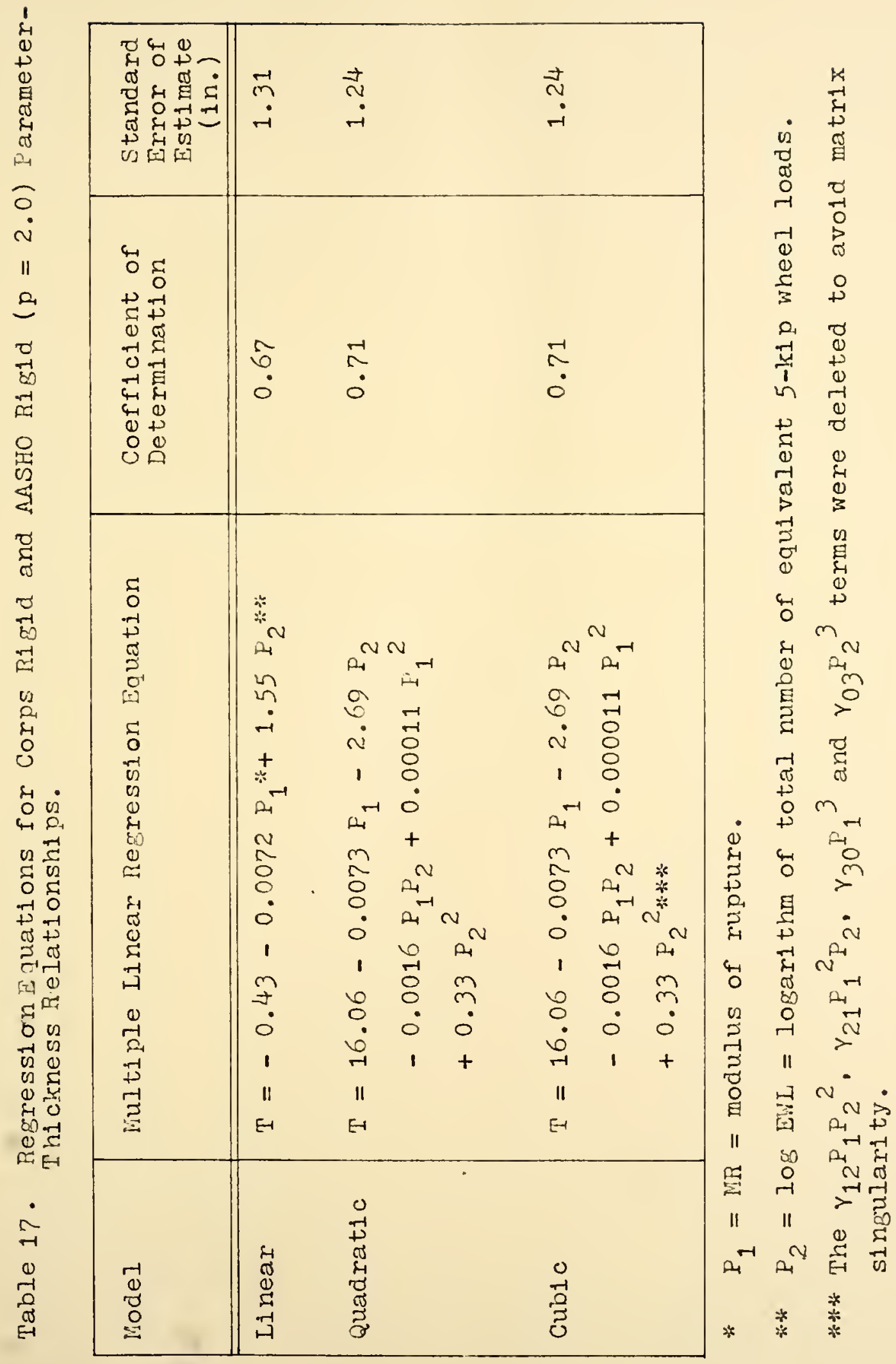




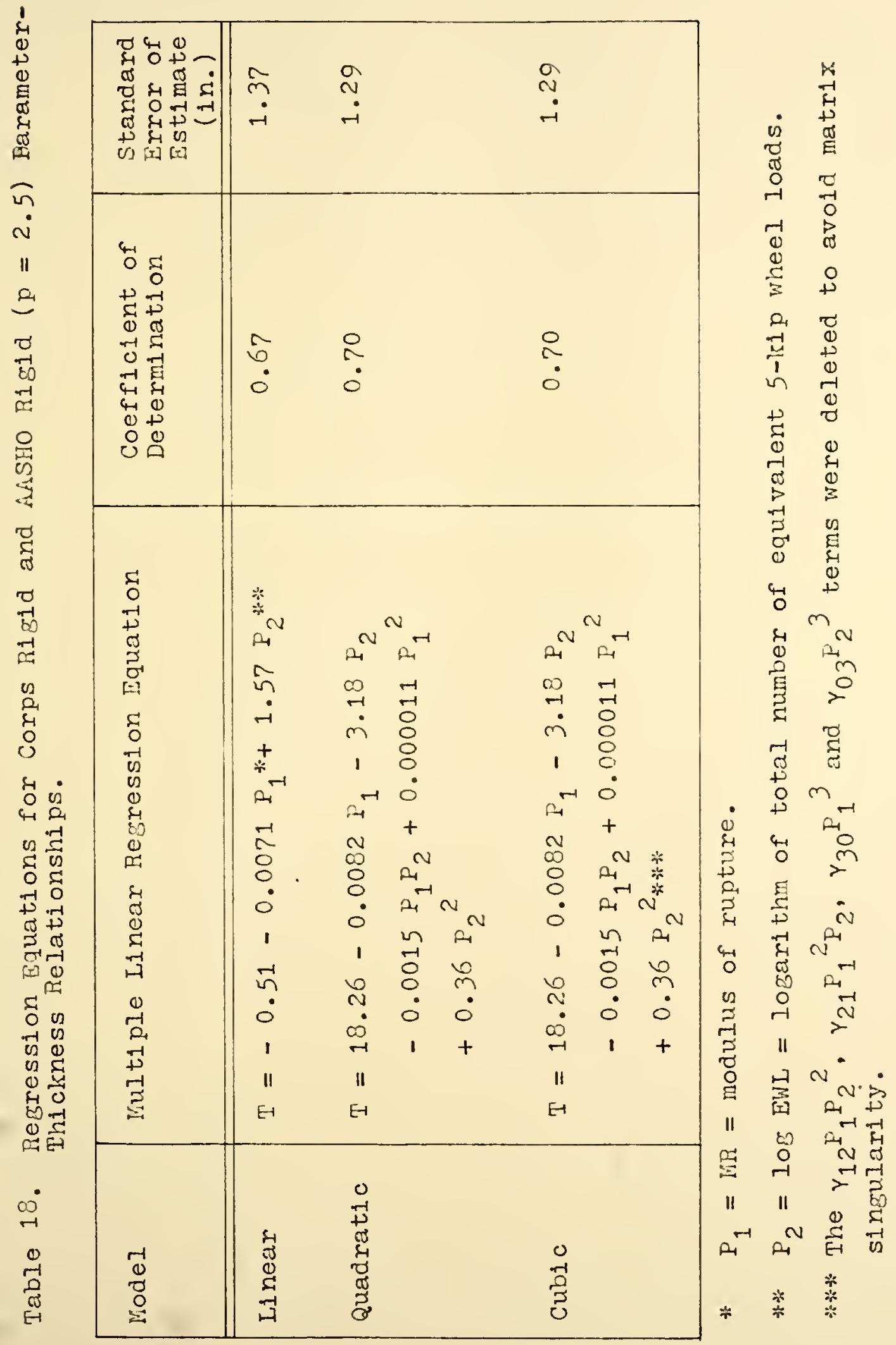




$$
T=-0.43-0.0072(\mathrm{NR})+1.55 \log (\mathrm{E} d \mathrm{~N})
$$

where $T=$ slab thiciness (inches),

$$
\text { ViR = modulus of rupture (pounds per square inch) and }
$$$$
\text { EWL = total number of equivalent 5-kip wheel loads. }
$$

The modulus of rupture is estimated by standard laboratory tests on concrete beams. The equivalent wheel load parameter is specified in the California Stabllometer design method.

\section{Applications to Practice}

Although a design chart shown in Figure 87 was developed to expedite slab thickness determinations, judicious use of the simplified design is recommended for extraordinary design situations. The assumptions of this research and the correlations of the various design parameters have considerable bearins on the final simplified thickness equation, and extrapolation beyond the limits of the linear relationshins of the desien chart is not suegested. Confident application of the simplified method follow repeated successful use of this technque. Presently this sinplified method does offer an expecient means of approximating risid pavement thicknesses. 


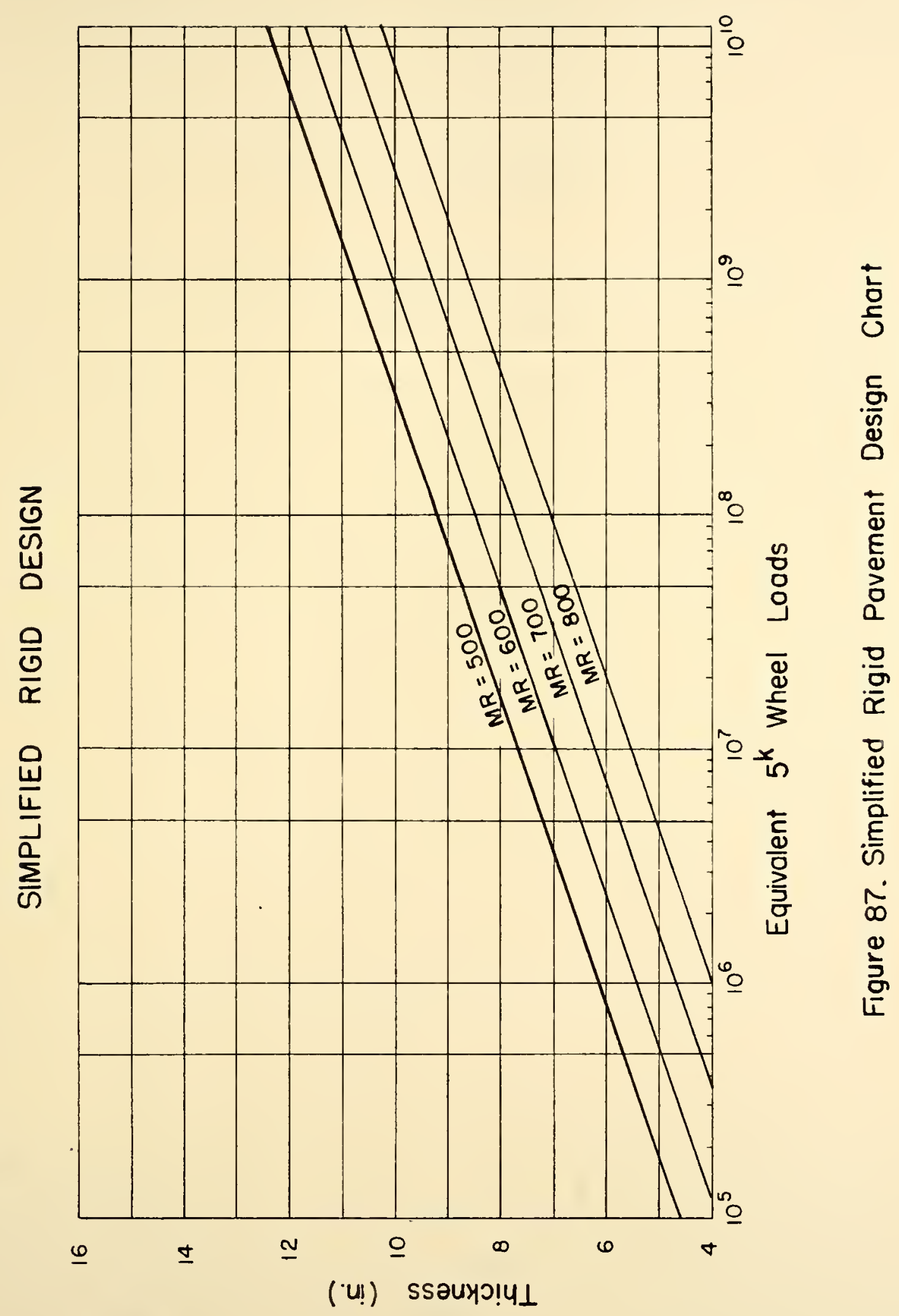




\section{SUMMARY AND CONCLUSIONS}

In this research investigation, the AASHO Flexible, Corps Flexible, California Stabilometer, AASHO Rigid, Corps Rigid and FCA Rigid highway pavement design methods were analyzed to identify and examine the major factors which influence thickness requirements. Simplified design methods for rigid and flexible pavements were developed from a synthesis of parameter-thickness data that were generated for the selected techniques. For the procedures and assumptions in this analysis and synthesis, the following conclusions appear justified.

1. Each flexible or rigid design method exhibits unique differences in the design-process logic of resolving the required pavement thickness. Theoretical design parameter importance measures also evidence this uniqueness by indicating that varlous parameters estimating the same generic factor have remarkably different influences on thicknesses among design methods.

2. While the formulation of equations or charts is particular to each design process, a realistic appraisal of practical parameter influence on thickness demonstrates a reasonable consistency among design methods and attests to a general similarity among flexible or rigid techniques. These practical parameter importance measures, which account for 
the usual variation in parameter values led to the conclusion that traffic load and subgrade support are the more important design factors in the design process for flexible pavements. For rigid pavement design, traffic load and pavement flexural strength are the more important factors. At least 66 percent of the possible variation in flexible or rigid pavement thickness determinations are explained by these important factors for usual desion conditions.

3. Tolerable parameter variations for selected thickness change constraints are generally less than actual parameter deviations normally encountered in design practices. This discrepancy indicates either one or a combination of the following possibilities:

a. The precision of parameter determinations needs to be refined.

b. Design and construction thickness tolerances and penalties imposed for violating these restrictions are not commensurate with design precision, and

c. Pavement design techniques incorporate explicit or implied factors of safety which compensate for the imprecision of parameter values.

4. Based on the evaluations of relative parameter importances and tolerable parameter variations, the need for highly sophisticated design techniques was not substantiated, and the desirability of simplified design methods was apparent for the quality of information that is presently utilized in 
pavement design. The following equations express the parameter-thickness relationships developed for the simplified methods.

For flexible pavements:

$$
T=-10.37-23.29 \log (C B R)+5.85 \log (E N L) \quad[30]
$$

For rigid pavements :

$$
T=-0.43-0.0072(\mathrm{IR})+1.55 \log (\mathrm{EWL})
$$

where $T=$ total pavement thickness (inches),

$\mathrm{CBR}=$ California Bearing Ratio of soil support, $M R=$ modulus of rupture of concrete (pounds per square inch) and

$E W L=$ total number of equivalent $5-k i p$ wheel loads. Parameter-thickness relationships demonstrate reasonable linear tendencies with only slight improvement in the statistical efficiency of quadratic or cubic approximations. Judicious use of the developed equations is recommended because the simplified techniques lack significant theoretical or empirical substantiation. However, these equations do offer an expedient procedure for predicting required pavement thickness. 
RECOMMENDATIONS FOR FURTHER RESEARCH

As a result of this analysis and synthesis of pavement desion techniques, further research appears warranted in several areas of highway pavement design. The following research topics are proposed to expand the findings of this study by improving the understanding of highway pavement systems and their design.

1. The need still exists for continued research in the investigation of the influences on the design product of subjective juagment, correlation constants and other factors, such as modulus of elasticity or Polsson's ratio, which are held constant in the design equation, environmental considerations and factors of safety. These implicit or assumed factors apparently, have a significant effect on design requirements.

2. Discrepancies exist between parameter variations normally encountered in the design process and the smaller deviations permitted by reasonable thickness change constraints. Therefore, an investigation of inherent parameter variations is needed to determine possible improvements in the precision of prediction. Further development of allowable parameter precision would include a cost-effectiveness analysis of the improved precision. 
3. Further study of the differences between design and construction thickness tolerances and actual design precision is recommended. This investigation would be directed principally toward an economic evaluation of the penalty incurred by the design agency or the contractor for thicknesses above or below the desion value. A pavement design procedure which balances the economic penalties for failures against the costs of avolding these risks should be pursued in this study.

4. While estimates of traffic magnitudes and repetitions represent the most important consideration in the design process, the schemes for determining these design parameters are the least consistent among desion techniques. The quality of data on traffic characteristics appears inadequate for pavement design purposes, and the development of valid procedures for estimating traffic effects is suggested for future research.

5. Because pavement types do not exhibit distinctly a rigid or a flexible behavior, a single design method that is applicable to all pavements may be possible and practical. Current pavement design techniques describe soll support by one parameter; therefore, a similar universal description of pavement structure properties (whether rigid or flexible) is needed for the proposed design method. This universal pavement material parameter could be a combination of existing rigid or flexible parameters or an entirely new measure of pavement structural properties. 
While many possibilities exist for future research. those delimited above are most appropriate for expanding the specific findings of this report. Further research directed toward developing a fundamental understanding of highway pavement structures is mandatory if pavement design is to become an increasingly quantitative science. 


\section{BIBIIOÜTALTIY}

1. AASHO Committec on Design, AsSiO Interim Guide for the Desim of Flexible pavoment Structures. American issociation of state ili hray orficials, 1961.

2. MSHO Comittee on Desion, fisio Interim unide for the Desim of Ricid rovement Structures. Americin Association

3. "AASEO Road Test; listory and Description of the Froject," Highway Research joand, Specian Report 61A, 1961.

4. Carcy, ...... Jr., and I. I. Irick, "The Iavement Serviccability-eriomance concont." Eavement Ierformance

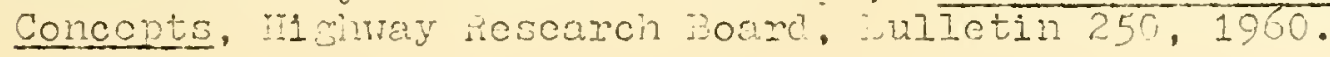

5. Concrete Earonent Dosi nor roads and strects Carryin AlI Classcs of Trasfic. Iortland cerent Associetion,

6. "Develoment of Hi jid Iavoment michess Requirenents for lilitar" roors na streets," Mechnal Report ".o. 4-1", Corns of Mnsinecrs, Ohio River Division Lanoratories, 1961 .

7. Foster, C. $\quad$. "juide for Interpretin" Corps of znmineers

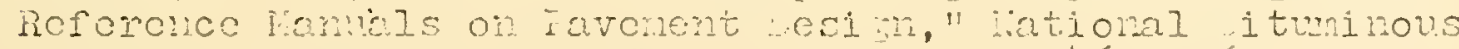
Concrete issociatior, II fublication i.o. 46, 1962.

- aude Snecipication for ilitary constuction, Ce-306 Revised Drait, Corps of Lneineers, ofrice or the chicf of Eruincers, 1954 .

9. iveem, F. I., and G. S. Sherman, "California lethod for the Structural Desim of Fexible avenents." Hroceedinss. Internationel Conference on Structural Desien of Asphalt lavenents, 1962.

10. Iricli, 1. E., U. l. Carey jr., and R. C. Hain, "A Retionale for Analysis of Favement Feriomance," MSIO Road Test Technical Staff Faners. Hi ghway Research Board, Special Report 66, 1961. 
11. Lanssner, G., T. S. Fuff, and U. J. Ijidde, "Use of Road Test Findings Dy AASHO Design Commi.ttee," ili ghtray Research joara. Special Report 73, 1962.

12. Neaman, D., and J.G. Iasuros, "Statistical quality Control in Fortland Cement Concrete Favements." vuality Control. Hishrey Research Board, Record 184, 1960 .

13. Rice, J. I., "An Evaluation of the Corps of Engineers Faver.ent Desion Criteria Utilizing the Results obtalned From the AAHO Road Tosts," Tochnical Report iio. L-41, Corps of Engineers. Ohio River Division Laboratories. 1966.

14. Shool., J. F., Wow iell can we Expect to Control rhicliness?--Experience on the AisHo Road Test." Irocoedincs. Association of Asphalt Faving, Technolocists, vol. 33, Fobruary 1064.

15. "Specifications for Construction of Bituminous Surfacing." American Association of State Highway Officials. Uashington, D. C., $10 \% 9$.

16. "Stress Pables for lise in the Dosimn and Evaluation of concrete Iifhroys and City Streets," Fortland Cement Association, Concrete Parchent Data INo. 1, 1060.

17. "Thichess Design for Concrete ivement," Portland Cement Association, Chicero, 1966.

13. Jedros, L. J., and D. K. Brom, "Svaluation or Apnlicahilty of MSFO Moad icst Results to Corps of Minineers Flezible averent Dosign Criteria," Technical Report Io. 3-721, Corps of Engineers, vatemays Expeniment Station, 1966.

19. Yoder, E Sons, Inc., Wew Iork, 1959. 
APPENDIX A

MASHO Flexible 


\section{Development of an AASHO Flexible Model for the Sensitivity Analysis}

The following description pertains to the development of a mathematical solution for the design charts $A 1$ and $A 2$. An equation was first evolved at the Road Test for the nomoEraphical relationship of the soll support value scale, the total number of equivalent daily $18-k 1 \mathrm{p}$ single-arle load applications scale and the structural number scale. This equation was then combined with the resional factor scale and the weighted structural number scale to formulate the thickness relationship for the sensitivity analysis.

From the arrangement of the nomograph scales, the general forrs of the soil support value-traffic factor-structural number relationship is:

$$
a f(S S V)+b f(\overline{S N})=f(W)+d
$$

where

$$
\begin{aligned}
f(\text { SSV })= & \text { SSV }=\text { linear function of the soil support } \\
& \text { value scale. } \\
f(\overline{S i})= & \text { function of the structural number scale, } \\
f(\mathrm{~W})= & \text { log( } \mathrm{H})=\text { logarithmic function of the } \\
& \text { traffic factor scale and } \\
a, b, d= & \text { constants. }
\end{aligned}
$$

When the soil support value is 3.0 , the total number of equivalent $18-k 1 p$ single-axle load applications is related to the structural number by the expression:

$$
\begin{aligned}
\operatorname{IOS}(H)= & 9.36 \log (\overline{S N}+1)-0.20 \\
& +\frac{G}{0.40+\frac{1094}{(\overline{S N}+1)^{5.19}}}
\end{aligned}
$$


where $\quad W=$ total number of equivalent 18-kip single-axle load applications,

$G=\log \frac{c_{0}-p}{c_{0}-1.5}=$ serviceability function,

$c_{0}=$ initial serviceability index and

$\mathrm{p}$ = terminal serviceability index.

In constructing the design nomograph, the axle load application scale was first established on a logarithmic basis. Rays from 3.0 on the soil support scale were drawn through calculated points on the load application scale to intersect the developing structural number scale at points which correspond to the appropriate structural number accordins to the relationship of equation A2. Therefore, the left-hand side of equation $\mathrm{A} 2$ is the function of the traffic factor scale. and the right-hand side is the function of the structural number scale.

When the structural number is 1.98, the logarithm of the total number of axle load applications is 4.22 for terminal and initial serviceability indices of 2.0 and 4.2, respectively. Substitution of the appropriate function values into equation A1 permits that equation to be written as follows.

$$
3.0 a+4.22 b=4.22+d
$$

In the preparation of the desion charts by the AASiO Design Committee, a 4.5-in. asphalt plantmiz surface of structural-number 1.98 and crushed stone base with a soil support value of 10.0 were assumed to carry $7.300,000$ equivalent load applications. If these numbers are converted 
into appropilate function values and are substituted into equation $A 1$, the following expression is obtained.

$$
10.0 a+4.22 b=6.86+d
$$

A third equation, which is similar to equation $A 3$, is determined to provide still another version of equation $A 1$.

$$
3.0 a+6.86 b=6.86+d
$$

After equations $\mathrm{A} 3, \mathrm{~A} 4$ and $\mathrm{A} 5$ are solved simultaneously for constants $a, b$ and $d$, equation $A 1$ is rewritten as.

$$
\frac{2.64}{7.0} f(\text { SSV })+f(\overline{\text { SI }})=f(W)+3.0 \times \frac{2.64}{7.0}
$$

This expression relates the soil support value, the number of equivalent 18 -litp single-axle load applications and the structural number as follows.

$$
\begin{aligned}
\operatorname{Iog}(\mathrm{W})= & 9.36 \operatorname{Iog}(\overline{\mathrm{SW}}+1)-0.20 \\
& +\frac{\mathrm{G}}{0.40+\frac{1094}{(\overline{\mathrm{SN}}+1)^{5.19}}}+0.37756(\mathrm{SSV}-3.0)
\end{aligned}
$$

To develop the entire MASHO Flexible model, weighted structural number and resional factor parameter are incorporated into the mathematical representation of the desion nomographs. The general relationship between structural number, weichted structural number and regional factor is written in the followine format:

$$
m f(R F)=n+f(S N)-f(\overline{S N})
$$

where

$$
\begin{aligned}
f(R F)= & \log (R F)=\text { losarithmic function of the } \\
& \text { recional factor scale. } \\
f(\overline{S N})= & \text { function of the structural number scale } \\
& \text { determined previously as the right-hand } \\
& \text { side of equation } A 2 .
\end{aligned}
$$




$$
\begin{aligned}
f(S N)= & f(\overline{S N})=\text { function of the weighted structural } \\
& \text { number scale which is the same as the } \\
& \text { structural number scale and }
\end{aligned}
$$

When the regional factor is 1.0 , the logarithm of the regional factor is zero, and the structural number function equals the welghted structural number function. Substituting these values into equation $A 8$ defines the constant $(n)$ as zero. The numerical value of the remaining constant is then determined by selecting corresponding values of structural number, reglonal factor and welghted structural number from the destgn nomograph. The solution for $(m)$ is 0.97 . A final expression. which contains all AAsHO Flexible design varlables, was obtained by writing the structural number function of equation A6 in terms of a restonal factor and welghted structural number.

$$
\begin{aligned}
\log (W)= & 9.36 \log (\mathrm{SN}+1)-0.20+\frac{G}{0.40+\frac{1094}{(\mathrm{SN}+1)^{5.19}}} \\
& +0.37756(\mathrm{SSV}-3.0)-0.97 \log (\mathrm{RF}) \quad[\mathrm{Ag}]
\end{aligned}
$$




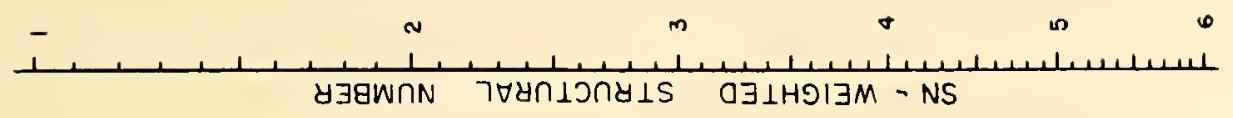

$$
\begin{aligned}
& \text { 웅을 옹 }
\end{aligned}
$$

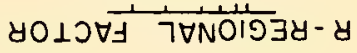
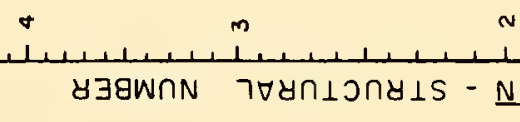

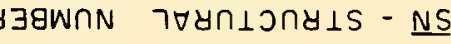

$\frac{\frac{d}{0}}{\frac{0}{x}}$

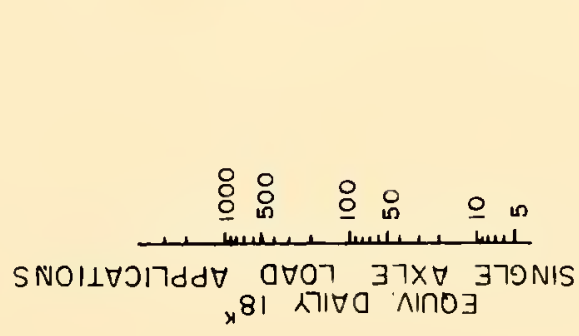

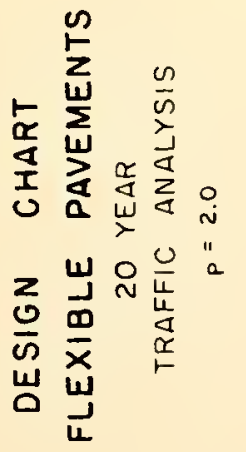

$\frac{0}{\frac{1}{4}}$

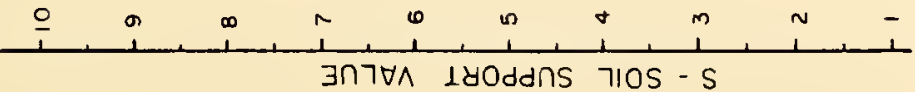




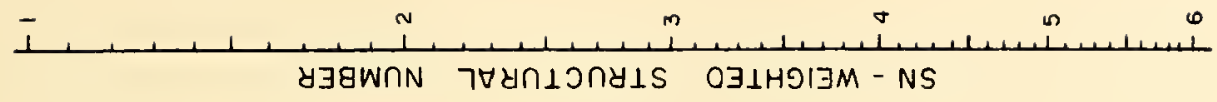

$$
\begin{aligned}
& \text { 응은 우 온 }
\end{aligned}
$$

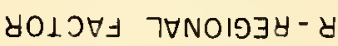

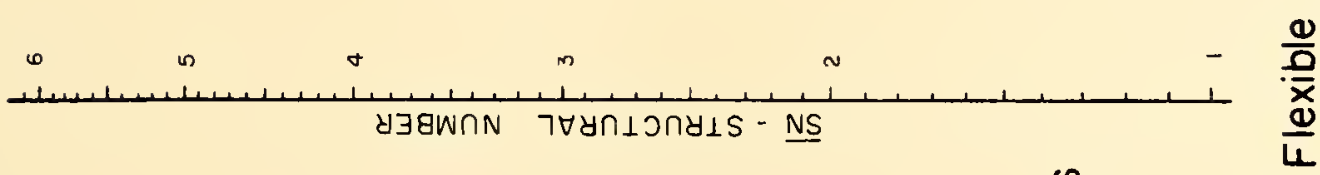

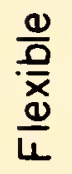
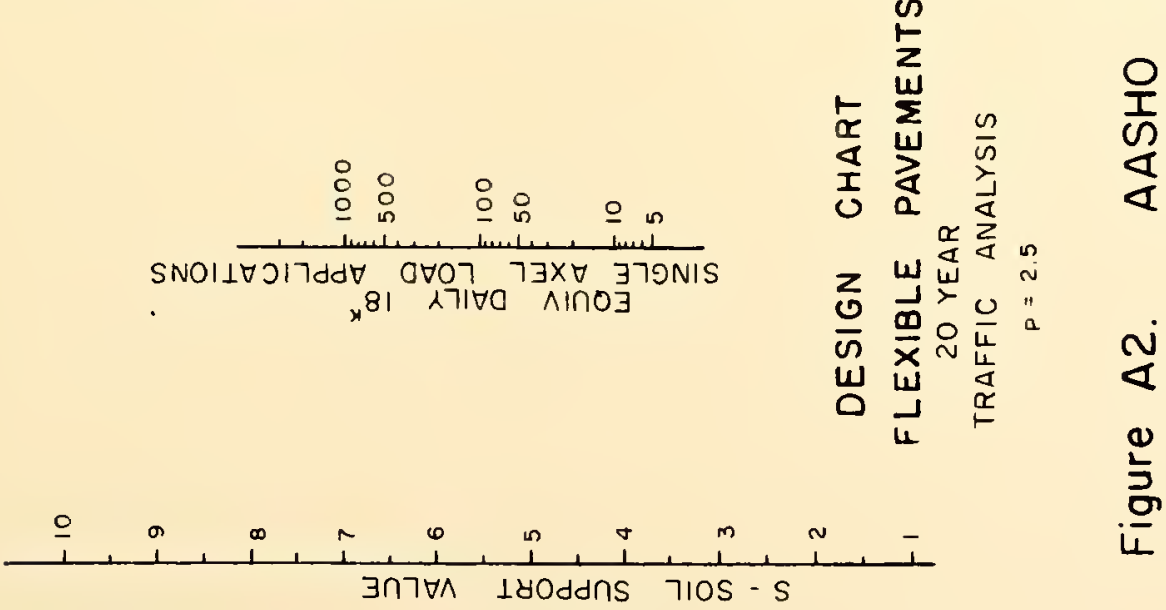
Table A1. First-order Fartial Derivatives of the AASHO Flexible Structural Humber with Respect to Design Parameters.

\begin{tabular}{|c|c|}
\hline Design Parameter & First-Order lartial Derivative \\
\hline Initial Serviccability Index & $\frac{\partial S N}{\partial c_{0}}=\left(\frac{0.4 .3429448}{0.40+\frac{1094}{(S N+1)^{5.19}}} \mid \frac{1}{c_{0}-p}-\frac{1}{c_{0}-1.5}\right\} \div \frac{\partial \pm}{\partial S N}$ \\
\hline Terminal Serviceability Index & $\frac{\partial S N}{\partial p}=\left\{\frac{-0.43429448}{0.40+\frac{1094}{(S N+1)^{5.19}}}\left\{\frac{1}{c_{0}-8}\right]\right\} \div \frac{\partial \phi}{\partial S N}$ \\
\hline Soil Support Value & $\frac{\partial S N}{\partial S S V}=\{0.37756\}: \frac{\partial \phi}{\partial S N}$ \\
\hline Regional Factor & $\frac{\partial S N}{\partial R F}=\left\{-\frac{0.4210505}{R H}\right\} \div \frac{\partial \Phi}{\partial S N}$ \\
\hline $\begin{array}{l}\text { Total Number of Equivalent } \\
18-h \text { ip Single Axle Loads } \\
\text { Applications }\end{array}$ & $\frac{\partial S N}{\partial W}=\left\{-\frac{0.4342944 S}{W,}\right\} \div \frac{\partial \phi}{\partial S N}$ \\
\hline
\end{tabular}

$\frac{\partial p}{\partial S N}=\frac{4.064996}{(S N+1)}+\log \left(\frac{c_{0}-p}{c_{0}-1.5}\right)\left[\frac{5077.80(S N+1)^{4.19}}{\left(0.40(5 N+1)^{5.10}+1094\right)^{2}}\right]$ 
APPENDIX B

Corps Flexible 
APPENDIX B

Corps Flexible

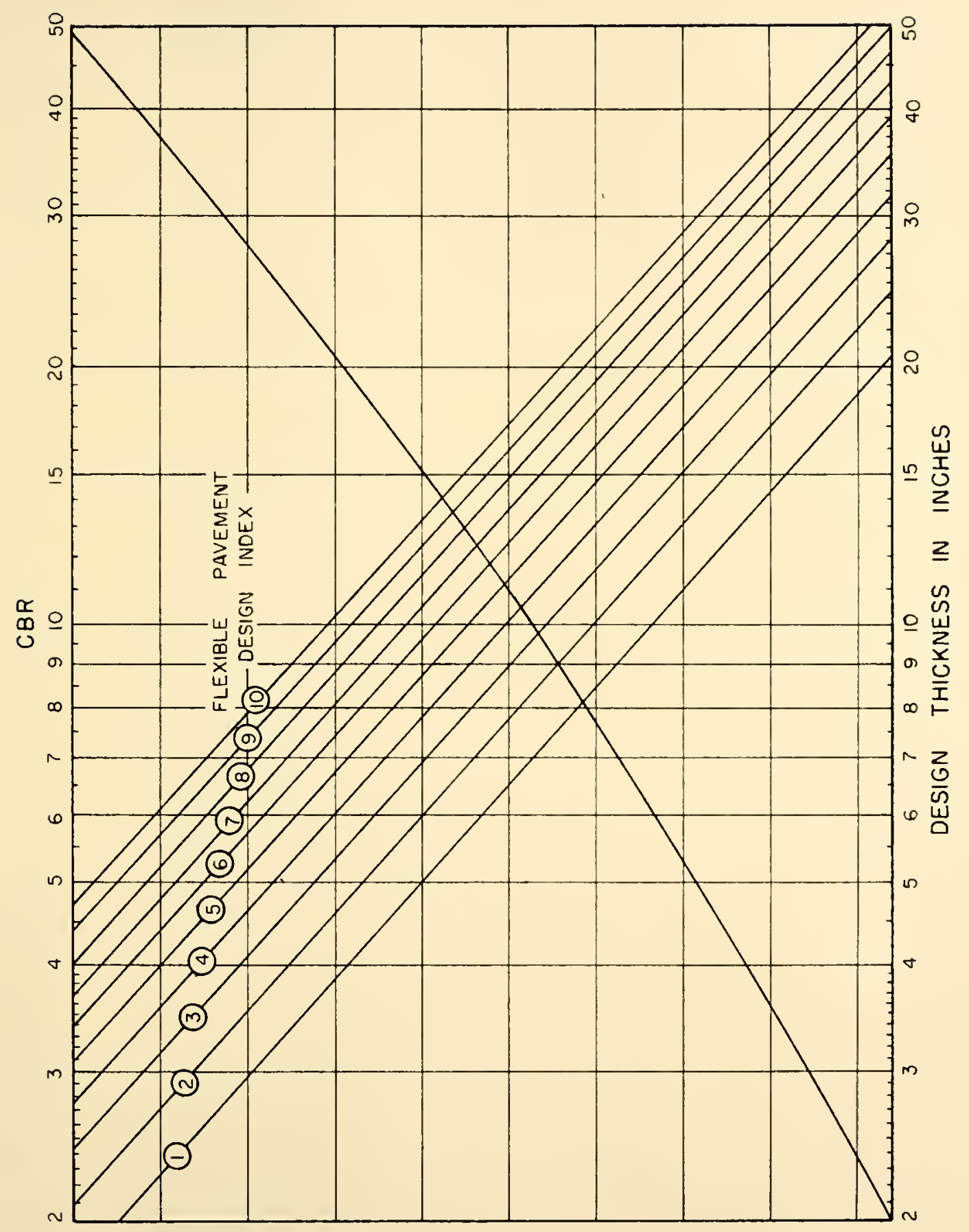

Figure BI. Corps Flexible Design Chart 


\begin{tabular}{|c|c|c|c|c|c|c|c|c|c|c|c|c|c|c|c|c|c|}
\hline 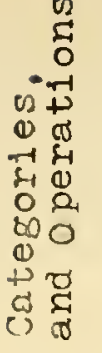 & 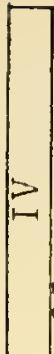 & 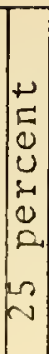 & $\mid \begin{array}{l}+ \\
5 \\
0 \\
u \\
-1 \\
0 \\
0 \\
0 \\
0 \\
-1\end{array}$ & $\begin{array}{l}+ \\
0 \\
0 \\
u \\
\vdots \\
0 \\
0 \\
0 \\
0 \\
=1\end{array}$ & $\begin{array}{l}-1 \\
0 \\
0 \\
0 \\
00 \\
0 \\
0 \\
0 \\
0 \\
0\end{array}$ & $\begin{array}{l}0 \\
0 \\
\sim \\
n \\
n \\
n \\
n\end{array}$ & $\begin{array}{c}m \\
m \\
\text { in } \\
\text { in }\end{array}$ & $\begin{array}{l}13 \\
\infty \\
0 \\
0 \\
0\end{array}$ & $\begin{array}{l}n \\
0 \\
0 \\
+ \\
-1\end{array}$ & $\begin{array}{l}0 \\
0 \\
\text { जn } \\
0 \\
0\end{array}$ & $\begin{array}{l}0 \\
\dot{\nabla} \\
\dot{\sigma} \\
\sim \\
\sim\end{array}$ & $\begin{array}{l}m \\
0 \\
m \\
m\end{array}$ & $\begin{array}{l}0 \\
0 \\
0 \\
0\end{array}$ & $\begin{array}{l}\sigma \\
0 \\
0 \\
0\end{array}$ & $\begin{array}{l}8 \\
\text { in } \\
\text { in } \\
a\end{array}$ & $\hat{n}$ & $\begin{array}{l}0 \\
\text { rn } \\
\text { ri }\end{array}$ \\
\hline $\begin{array}{cc}0 & 12 \\
-1 & 0 \\
4-1 & 60 \\
4-1 & 0 \\
0 & 4 \\
H & 0 \\
E-1 & p \\
0 \\
0 \\
-1 & 0 \\
-1 & 0 \\
0 & 0 \\
0 & -1\end{array}$ & 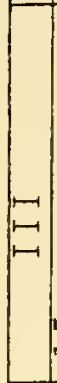 & $\begin{array}{l}+ \\
E \\
0 \\
U \\
2 \\
0 \\
0 . \\
1 \\
-1\end{array}$ & 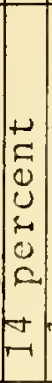 & 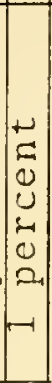 & $\begin{array}{l}a \\
a \\
0 \\
0 \\
00 \\
0 \\
0 \\
0 \\
0 \\
0\end{array}$ & $\begin{array}{c}0 \\
13 \\
0 \\
12 \\
13\end{array}$ & $\begin{array}{r}N \\
N \\
N\end{array}$ & $\begin{array}{l}\text { Ln } \\
\text { in } \\
n \\
n\end{array}$ & $\begin{array}{c}\infty \\
N \\
N \\
N \\
0\end{array}$ & $\begin{array}{l}\infty \\
\infty \\
\infty \\
0\end{array}$ & $\begin{array}{l}\text { in } \\
\text { in } \\
\text { in } \\
-1\end{array}$ & $\begin{array}{l}\infty \\
\text { in } \\
\text { in }\end{array}$ & $\stackrel{\infty}{0}$ & 뭉 & $\begin{array}{c}\infty \\
\underset{1}{0}\end{array}$ & in & $\begin{array}{l}0 \\
\text { in }\end{array}$ \\
\hline 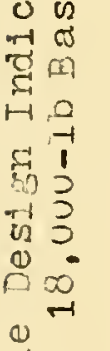 & 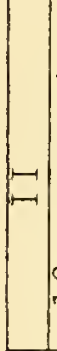 & $\begin{array}{l}\omega \\
\tilde{n} \\
0 \\
u \\
\Delta \\
0 \\
0 . \\
0 \\
-1\end{array}$ & $\begin{array}{l}w \\
\Xi \\
0 \\
u \\
0 \\
0 \\
0 \\
0 \\
0\end{array}$ & 0 & $\begin{array}{l}0 \\
0 \\
0 \\
0 \\
-1 \\
0 \\
0 \\
0\end{array}$ & $\begin{array}{l}\infty \\
\infty \\
\infty\end{array}$ & $\begin{array}{l}m \\
m \\
m\end{array}$ & in & 8 & $\begin{array}{l}\infty \\
\text { in } \\
0\end{array}$ & 0 & in & $\frac{\infty}{N}$ & M & 0 & -1 & -1 \\
\hline 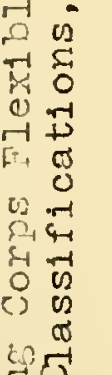 & $1-1$ & $\mid \begin{array}{l}\omega \\
\Xi \\
0 \\
0 \\
-1 \\
0 \\
0\end{array}$ & $\begin{array}{l}1 \\
5 \\
0 \\
u \\
-1 \\
0 \\
0 \\
-1\end{array}$ & 0 & $\begin{array}{l}E \\
\\
0 \\
0 \\
05 \\
0 \\
5 \\
0 \\
5 \\
0 \\
0\end{array}$ & $\begin{array}{l}\infty \\
\infty\end{array}$ & $m$ & $\begin{array}{l}0 \\
\text { in }\end{array}$ & $\widetilde{0}$ & $\stackrel{\circ}{\sim}$ & $\stackrel{0}{8}$ & in & $\begin{array}{l}\infty \\
\sim 1\end{array}$ & - & $\neg$ & -1 & -1 \\
\hline 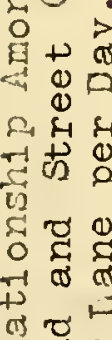 & & $\begin{array}{c}n \\
u \\
u \\
z \\
z\end{array}$ & & & {$\left[\begin{array}{cc}0 & \\
0 & 2 \\
0 & 0 \\
-1 & 0 \\
0 & - \\
0 & 0 \\
0 & 0 \\
0 & 0 \\
0 & 0 \\
0 & 0\end{array}\right.$} & $\stackrel{0}{0}$ & $\begin{array}{l}0 \\
0 \\
0 \\
0 \\
0\end{array}$ & $\stackrel{8}{8}$ & $\stackrel{8}{0}$ & $\begin{array}{l}0 \\
10 \\
0 \\
-1\end{array}$ & $\stackrel{0}{0}$ & $\stackrel{0}{0}$ & $\stackrel{0}{0}$ & $\begin{array}{l}\infty \\
0 \\
1\end{array}$ & L2 & in & $\stackrel{1}{0}$ \\
\hline 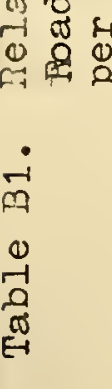 & $\begin{array}{c}5 \\
0 \\
0 \\
0 \\
0 \\
0 \\
\sigma \\
0 \\
0 \\
-1 \\
4 \\
\pi \\
\pi \\
-1 \\
-1\end{array}$ & 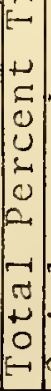 & 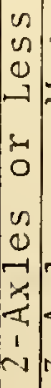 & $\begin{array}{l}0 \\
2-1 \\
0 \\
2 \\
3-1 \\
0 \\
0 \\
0 \\
2 \\
x \\
1 \\
m \\
m\end{array}$ & 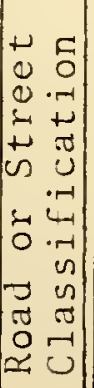 & $\begin{array}{l}0 \\
0 \\
0 \\
0 \\
\alpha \\
\infty \\
\omega \\
\infty \\
\sigma\end{array}$ & 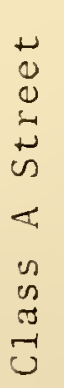 & $\begin{array}{l}0 \\
0 \\
0 \\
\simeq \\
\infty \\
\tilde{2} \\
\tilde{\omega} \\
-1\end{array}$ & $\begin{array}{l}\omega \\
0 \\
0 \\
i \\
\omega \\
\omega \\
\infty \\
\infty \\
0 \\
\infty \\
0\end{array}$ & 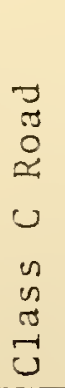 & $\begin{array}{l}+ \\
0 \\
0 \\
0 \\
\tilde{1} \\
\omega \\
0 \\
\omega \\
0 \\
\infty \\
0 \\
0\end{array}$ & $\begin{array}{l}0 \\
0 \\
0 \\
0 \\
0 \\
0 \\
0 \\
0 \\
0\end{array}$ & 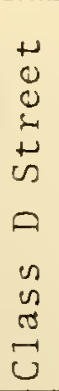 & 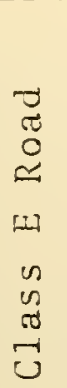 & $\begin{array}{l}H \\
u \\
n \\
\sim \\
u \\
u\end{array}$ & $\begin{array}{l}n \\
\text { un } \\
\text { w } \\
\tilde{U}\end{array}$ & $\begin{array}{l}+ \\
0 \\
0 \\
\infty \\
\infty \\
\infty\end{array}$ \\
\hline
\end{tabular}


APPENDIX C

California Stabilometer 


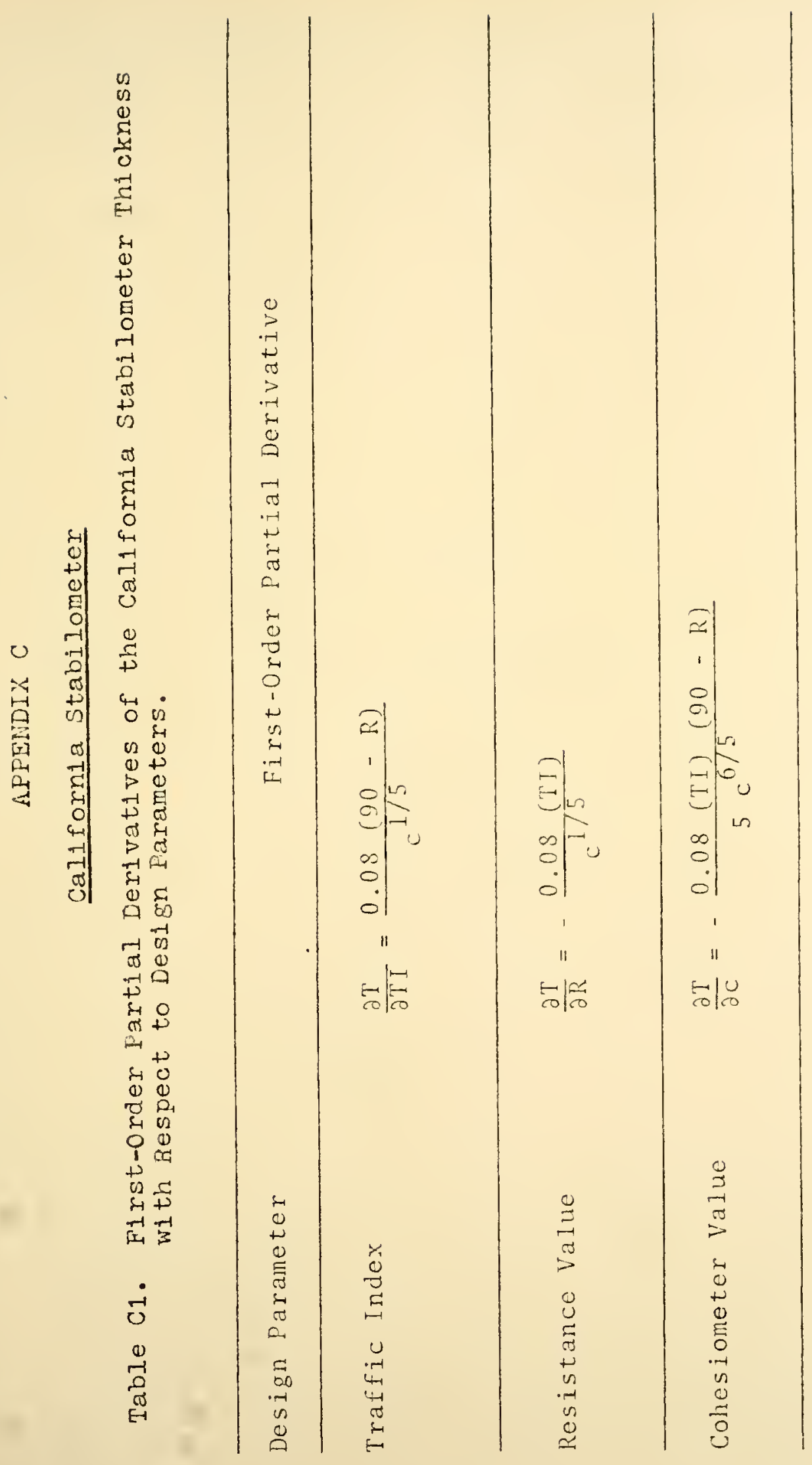


APPENDIX D

AASHO 2.1Sid 


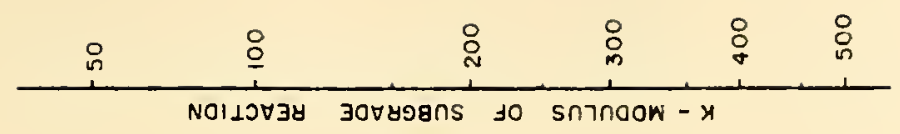

$\frac{5}{0}$

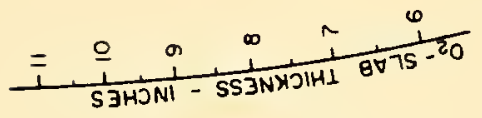

동
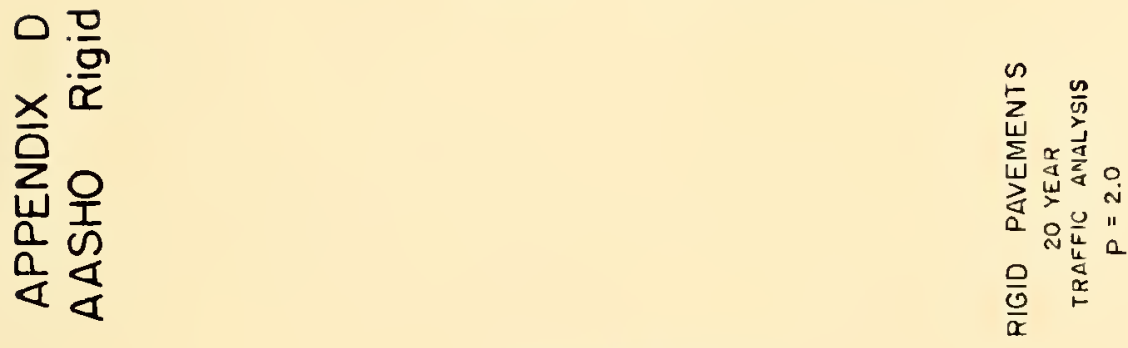

$\frac{7}{\frac{0}{x}}$

$\frac{0}{\frac{1}{4}}$

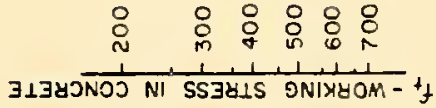

$\overline{0}$

논

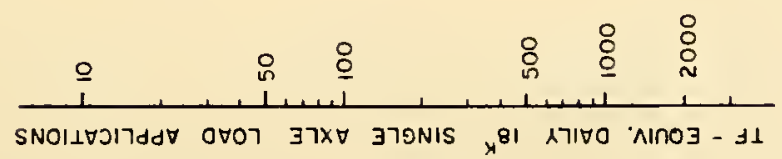



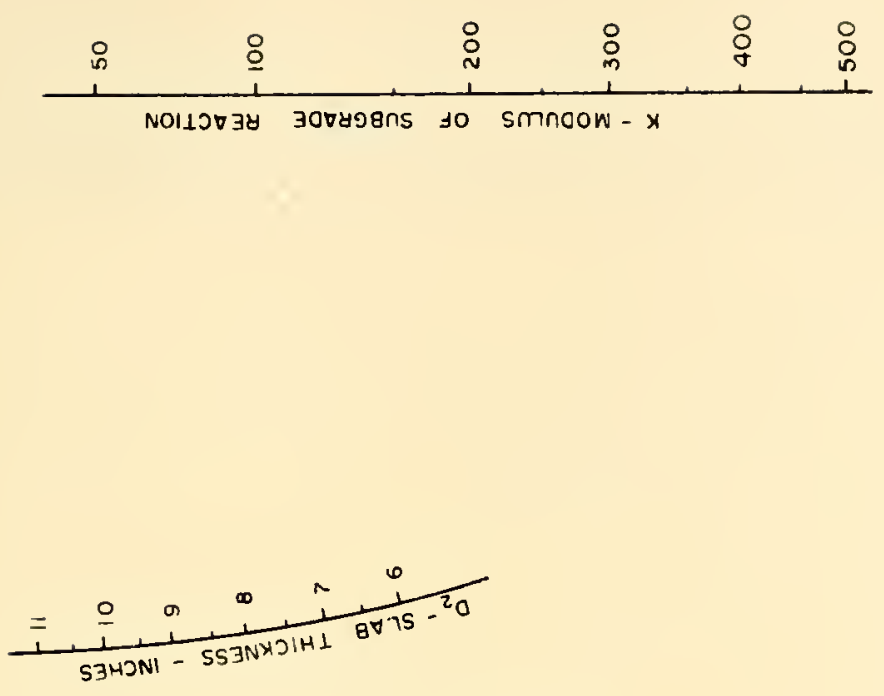

혼

$\frac{5}{\frac{5}{5}}$
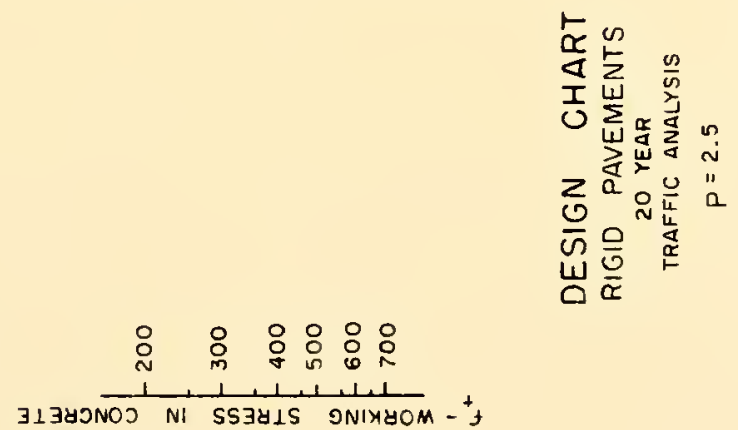

$\frac{}{ㅁ}$

옹

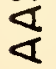

๑ั

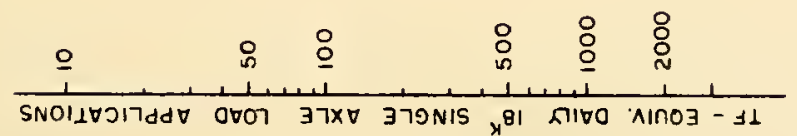


Table Di. First-Order Fartial Derivatives of the AASHO Rigid Thickness with Respect to Design Parameters.

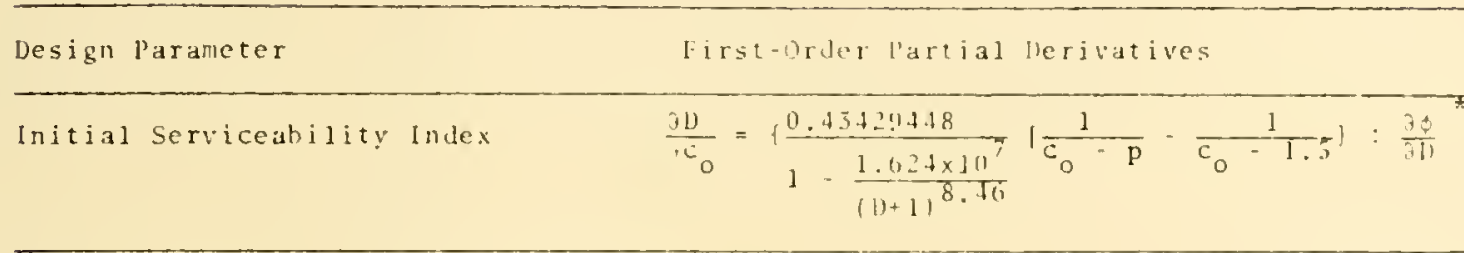

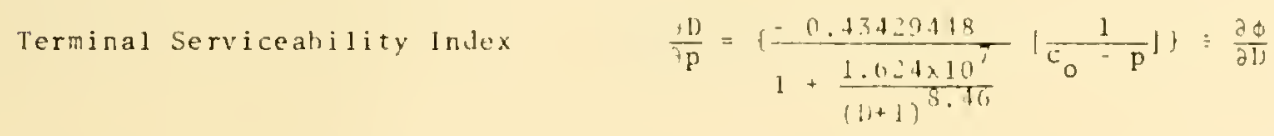

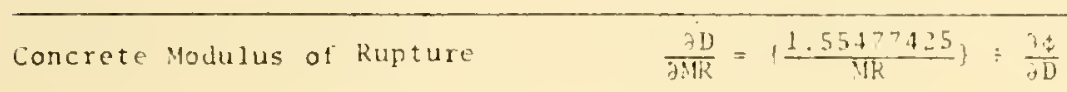

Modulus of Subgracle Reaction $\quad \frac{3 D}{+h}=\left(\frac{0.15819828}{\left.k^{.75} \cdot(1)^{-5}-40^{7} k^{-55}\right)}\right\} \div \frac{26}{31)}$

$\begin{aligned} & \text { Total Number of liquivalent } \\ & 18 \text { kips Single Axle Load }\end{aligned} \quad \frac{\pi D}{3 \pi}=\left\{-\frac{10.43429+48}{W}\right\}: \frac{\frac{\partial}{\partial I}}{\partial 1}$

* $\frac{\partial \phi}{\partial D}=\frac{3.19206444}{(D+1)}+\log \left(\frac{c_{0}-p}{c_{0}-1.5}\right)\left(\frac{1.024 \times 10^{7}(8.40)(11+1)^{7} .46}{\left.1(1)+1)^{8.10}+1.024 \times 10^{7}\right)^{3}}\right]$

$+[4.22-3.2(p)](0.43429448) \frac{0.75}{v^{.25}}\left[\frac{1}{\left(b^{.75}-1.132\right)}-\frac{1}{\left(b^{.75}-.407 k .25\right)}\right)$ 
APPENDIX E

Corns Rigid 
APPENDIX E

Corps Rigid

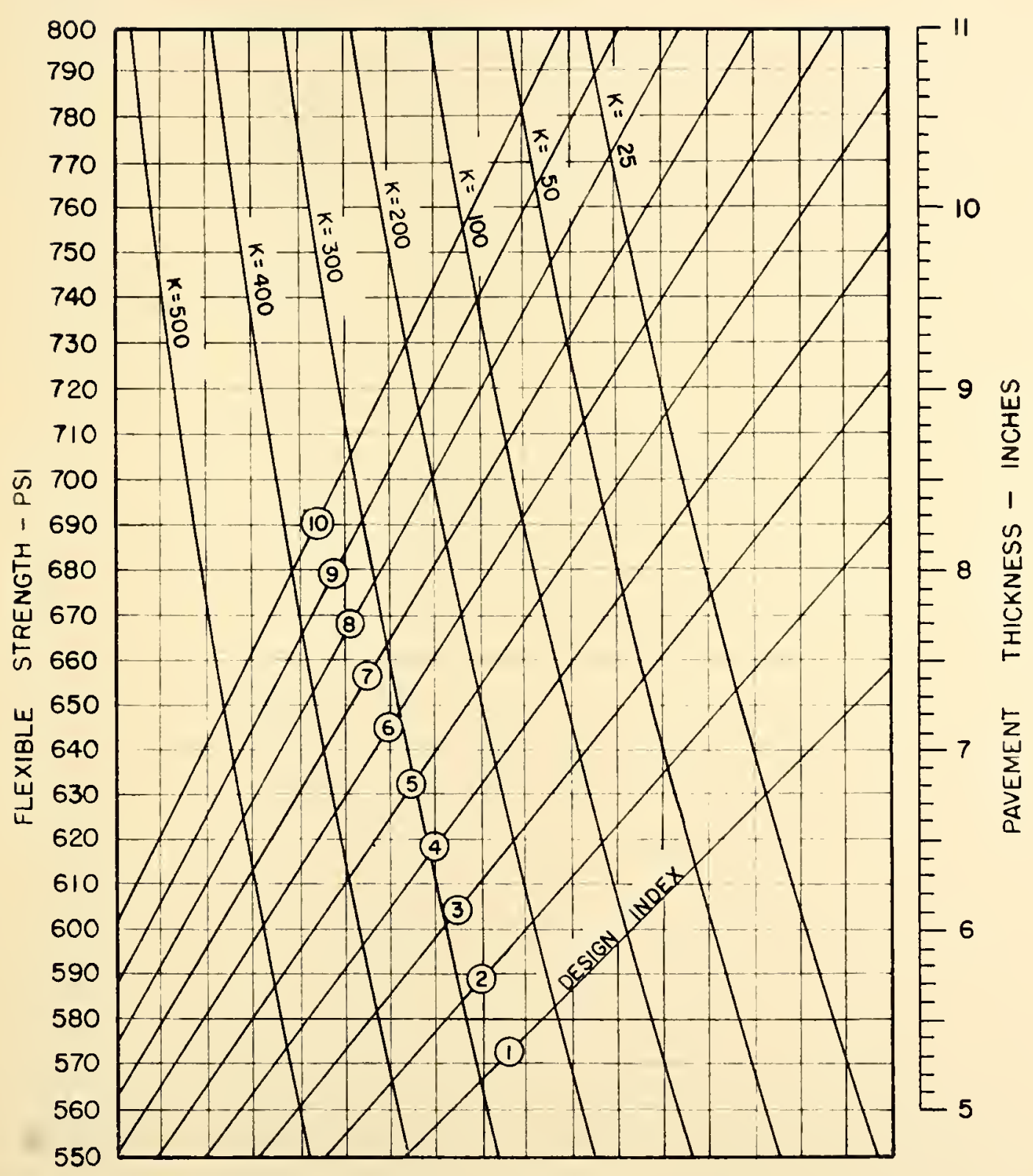

Figure El. Corps Rigid Design Chart 


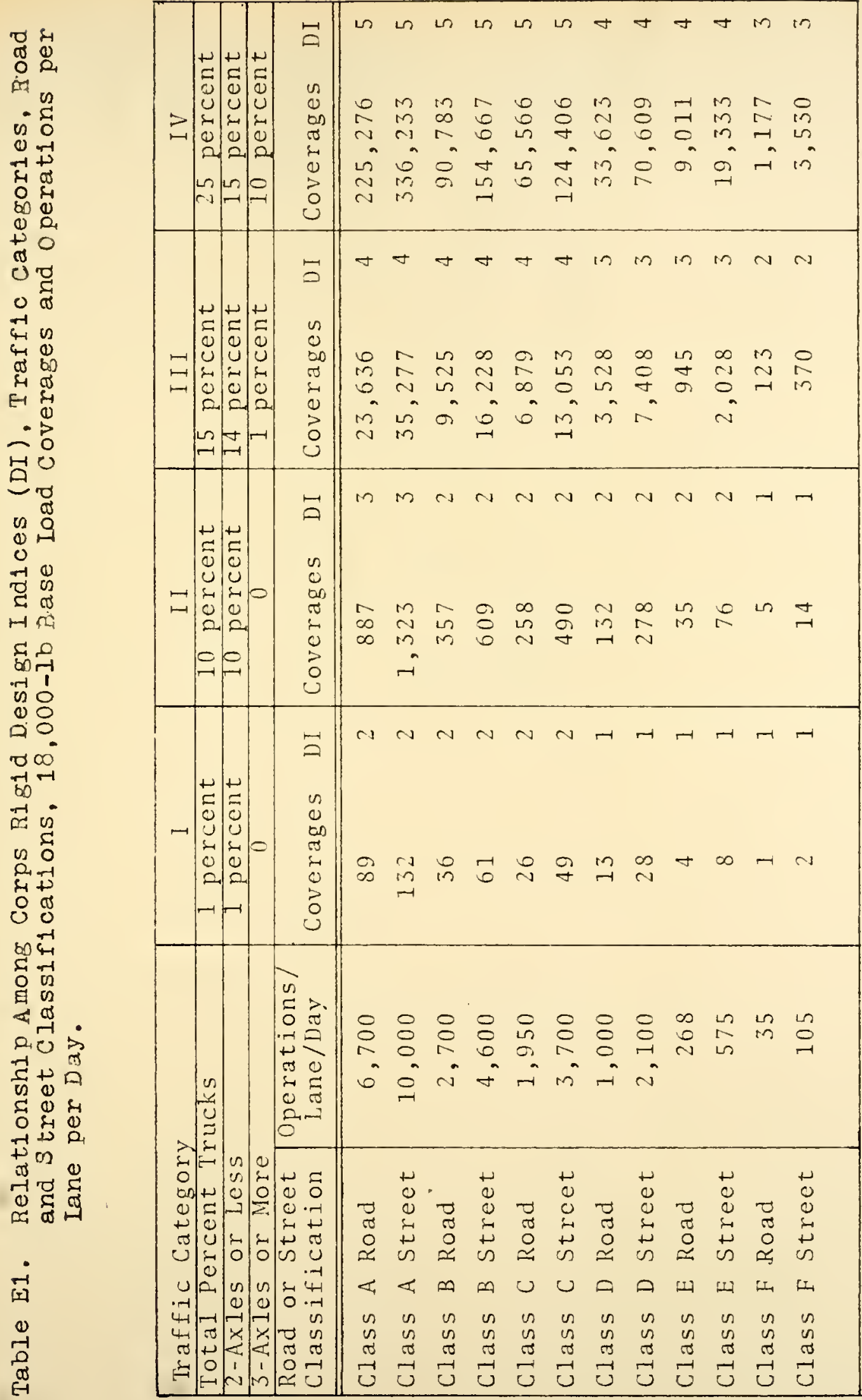


APPENDIX F

PCA R1Eid 


\section{AFPENDIX F}

\section{PCA Rigid}

Development of a PCA Rigid Iodel for the Sensitivity Analysis

The development of the PCA design model is an expansion of the design criterion that the consumed fatigue resistance can not be greater than 125 percent, into a single equation that incorporated the principal desion variables. The design criterion is symbolically written as:

$$
125=\sum_{i=1}^{n} 100 \frac{\mathrm{ERC}}{\mathrm{ARC}}
$$

where

$$
\begin{aligned}
& \mathrm{ERC}=\frac{1}{2}(\mathrm{ADT})(\mathrm{PTM} / 100)(\mathrm{PTRHL}) 365(\mathrm{DL})(\mathrm{AT} / \mathrm{1000})= \\
& A R C=\text { allowable axle load repetitions per axle } \\
& \text { load class ( } 1 \text { ). } \\
& A D T=\text { average daily traffic in both directions } \\
& \text { (vehicles per day). } \\
& \text { IT = percentage of total traffic which is trucks, } \\
& \text { PTRHL }=0.35=\text { fraction of the trucks traveling in } \\
& \text { the right-hand lane, } \\
& D L=20 \mathrm{yr}=\text { anticipated service life of the } \\
& \text { pavement (years) and } \\
& \Delta \mathrm{T}_{i}=\begin{array}{l}
\text { axles per } 1000 \text { trucks categorized in wei ght } \\
\text { class (i). }
\end{array}
\end{aligned}
$$


If the design life and percentage of trucks in the right-hand lane are assumed to be $20 \mathrm{yr}$ and 85 percent, respectively, then average dally traffic, percentage of trucks and the distribution of truck axles into various weight classes are sufficient to estimate the expected number of axle load repetitions. Allowable axle load repetitions are specified by the equation:

$$
S R=0.972-0.083 \log (A R C)
$$

where

$$
\begin{aligned}
\mathrm{SR}= & \sigma / \mathrm{MR}=\text { stress ratio. } \\
\sigma= & \text { stress induced in the pavenent by the weight } \\
& \text { characteristic of axle load class ( } 1 \text { ) (pounds } \\
& \text { per square inch) and } \\
\mathrm{MP}= & \text { modulus of rupture of concrete (pounds per } \\
& \text { square inch). }
\end{aligned}
$$

The above expression was determined from a plot, shown in Fleure $\mathrm{F} 1$, of stress ratios and corresponding allowable number of repetitions that are specified in the ECA design procedure. The load-induced stress is calculated from the formula:

$$
=\frac{1.68 \cdot P_{1}}{D^{2}}\left[1.0-\frac{\sqrt{a / 1}}{0.925+0.22 \mathrm{a} / 1}\right]
$$

Where $P_{1}=$ desien load equal to the midpoint of axle load class (1) (pounds).

$D=$ pavement thickness (inches).

$$
a_{1}=\begin{aligned}
& \text { radius of contact for axle loads of class ( } 1 \text { ) } \\
& \text { (inches). }
\end{aligned}
$$$$
I=\sqrt[4]{\frac{E D^{3}}{12\left(1-{ }^{2}\right) k}}=\text { radius of relative stiffness }
$$
(inches). 

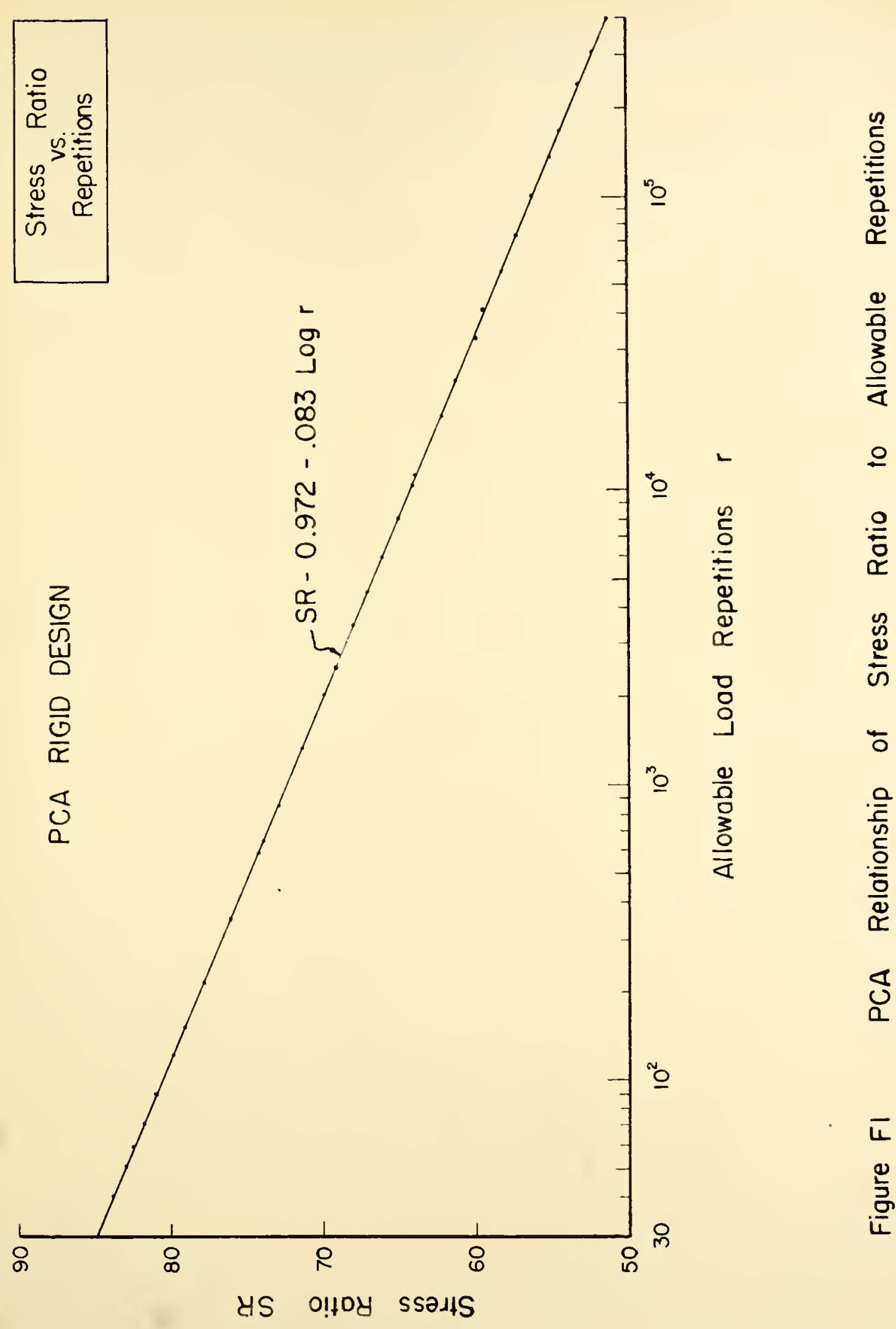

$\frac{0}{0}$
$\frac{3}{0}$
$\frac{0}{4}$
은
움

के

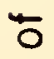

을

咨

$\bar{L}$

产 


$$
\begin{aligned}
E= & 4.0 \times 10^{6}=\text { modulus of elasticity of concrete } \\
& (\text { pounds per square } 1 \text { nch). } \\
\mu= & 0.15=\text { Poisson's ratio and } \\
k= & \text { modulus of subgrade reaction (pounds per cubic } \\
& \text { inch). }
\end{aligned}
$$

If the midpoint of axle class (i), the radius of contact. modulus of elasticity and Poisson's ratio are not regarded as design variables, the allowable number of axle load repetitions is a function of the modulus of rupture of concrete, the pavement thickness and the modulus of subsrade reaction. Substitution of the design variable into equation $F 1$ and simplifying and combining terms permits the PCA Rigid design method to be formulated into a single equation that is adequate for the sensitivity analysis.

$$
\begin{aligned}
\log \left[\mathrm{ADT}(\mathrm{PTT}) \mathrm{AT}_{1}\right]= & \frac{20.24 \mathrm{P}_{1}}{\operatorname{MK}(\mathrm{d})^{2}}\left[1.0-\frac{0.20342 \sqrt{\mathrm{a}_{1}}\left(\mathrm{k} / \mathrm{d}^{3}\right)^{\frac{1}{8}}}{0.925+.0091 \mathrm{a}_{1}\left(\mathrm{k} / \mathrm{d}^{3}\right)^{\frac{1}{4}}}\right] \\
& -12.0
\end{aligned}
$$


Table F1. First-order Partial Derivatives of the PCA R1 1 id Thiclness with Respect to Design Farameters.

Design larameter

\begin{tabular}{|c|c|c|}
\hline Percent Truch Traffic & $\frac{\partial \mathrm{D}}{\text { ताTT }}=\sum_{\mathrm{i}=1}^{n} \frac{(1.43429448}{1 \mathrm{TT} / 100}$ & $\left\{\frac{d 7}{\partial 1}\right.$ \\
\hline
\end{tabular}

Axles per 1000 Truchs $\quad \frac{\partial D}{\partial A T}=\sum_{i=1}^{n}\left(\frac{0,43429448}{N i \frac{1000}{i}}: \frac{\partial A D}{\partial D}\right)$

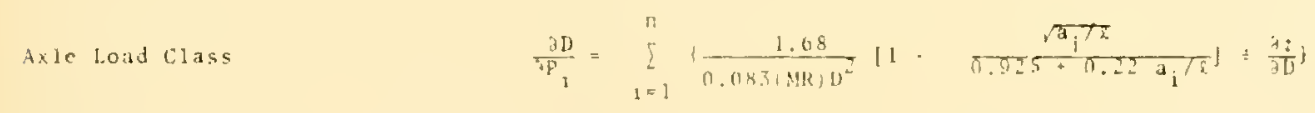

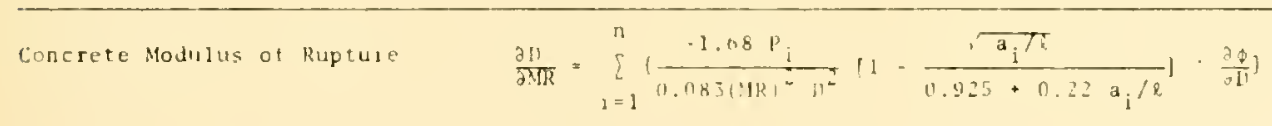

Modulus of Suhgrade keaction

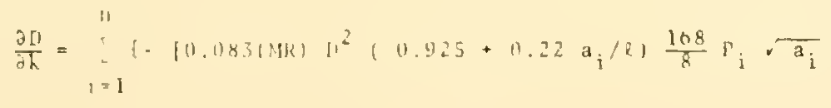

$$
\begin{aligned}
& \left.\frac{12\left(1 \cdot \mathrm{u}^{2}+1\right.}{10^{3^{2}-1}}\right)^{1,8}+7 / 8
\end{aligned}
$$

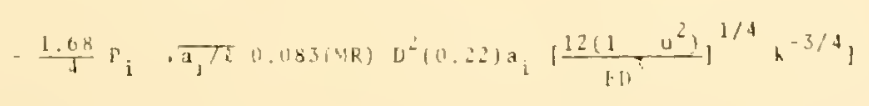

$$
\begin{aligned}
& \left.\left.\{0.093198) 11^{2}\left(0.925+0.22 a_{1} / 2\right)\right\}^{2} \div \frac{40}{a D}\right\}
\end{aligned}
$$

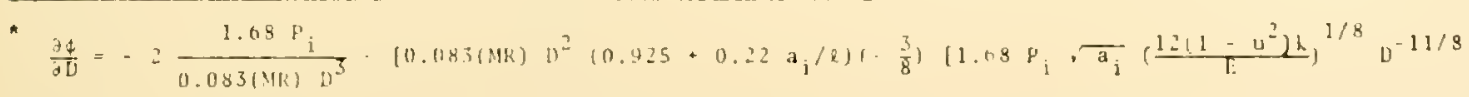

$$
\begin{aligned}
& -1.08 \mathrm{r}_{\mathrm{i}} \sqrt{\mathrm{a}_{1} / 2} 0.083(\mathrm{NR})\left[(2) 0.9250+\frac{5}{4}(0.22) \mathrm{a}_{\mathrm{i}}\left[\frac{12\left(1-\mathrm{u}^{2}\right) \mathrm{D}}{\mathrm{E}}\right]^{1 / 4}\right. \\
& =\left(0.083(\mathrm{MR}) \mathrm{D}^{2}\left(0.925+0.22 \mathrm{a}_{\mathrm{i}} / 2\right)\right]^{2}
\end{aligned}
$$

" Sumed over all axle load classes that contrithute to the fat igue resistance consumed. 
APPENDIX G 
APEDIDIX G

Table G1. Design Parameters and Their Variations.

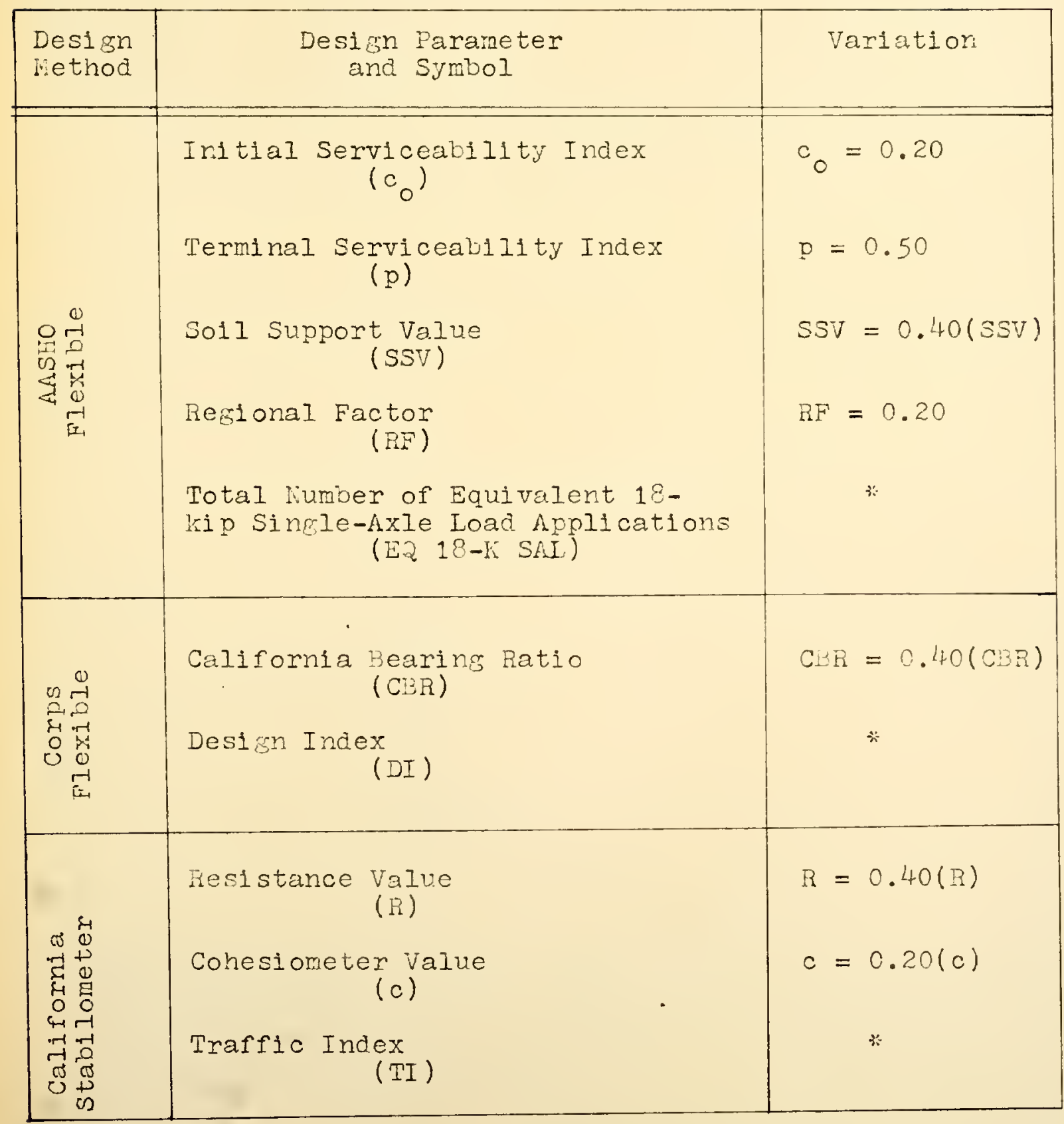


Table G1. (cont'd.)

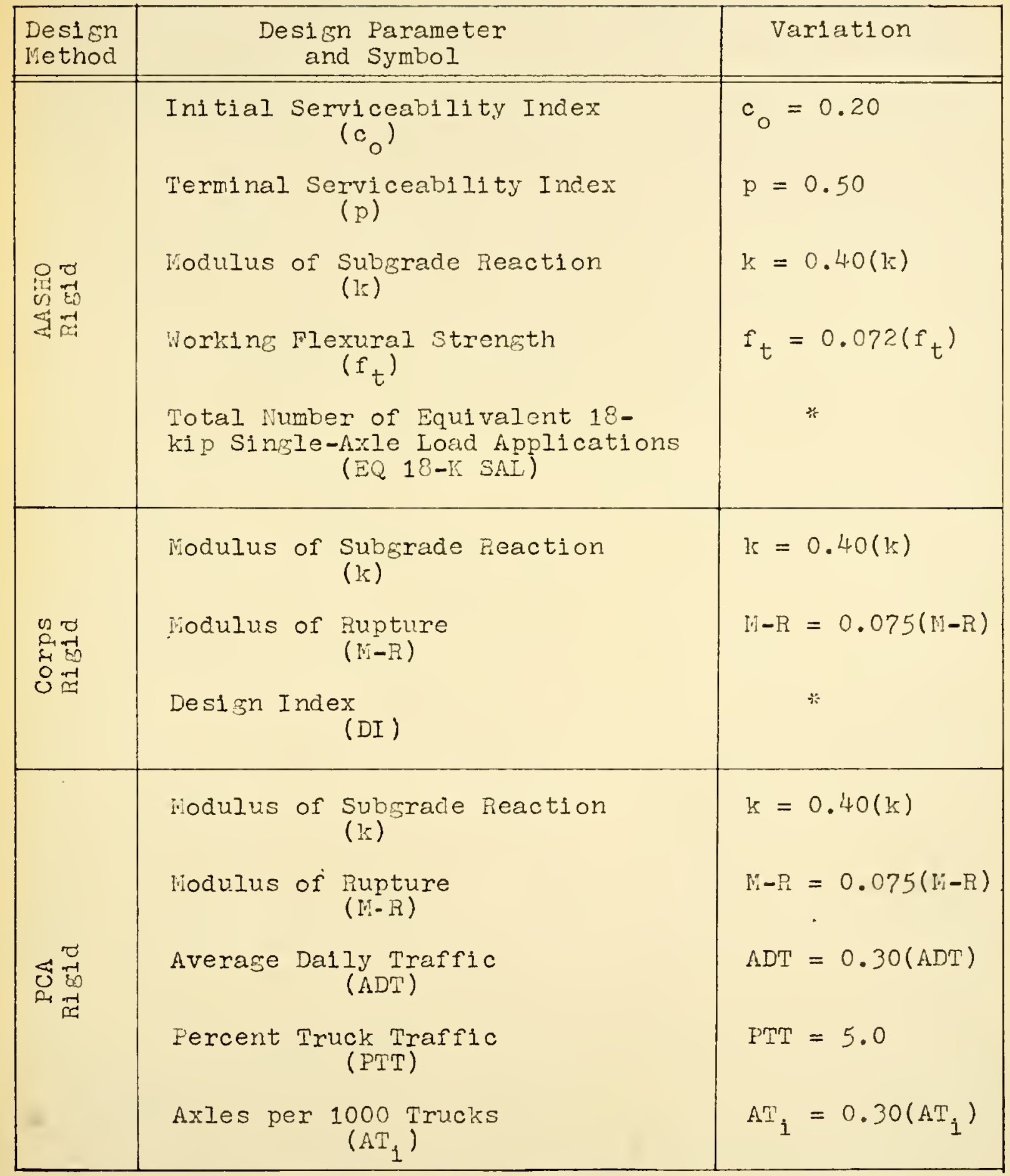

* The variation of the single traffic parameters of each technique, except PCA Rigid, is determined as the change produced by a 0.30 variation in the average daily traffic value, a net 5.0 percent truck traffic change and a 0.30 variation in axles per 1000 trucks value. 
te 
